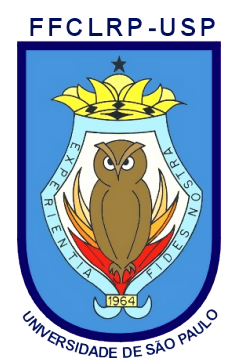

Universidade de São Paulo FFCLRP - Departamento de Física

EBENÉZER SILVA CAVALCANTI

Desenvolvimento de um Sistema para Medida Elastográfica Dinâmica por Ultrassom

Ribeirão Preto - SP

2012 


\title{
Desenvolvimento de um Sistema para Medida Elastográfica Dinâmica por Ultrassom
}

\author{
Tese apresentada à Faculdade de Filosofia, \\ Ciências e Letras de Ribeirão Preto da \\ Universidade de São Paulo, como parte das \\ exigências para a obtenção do título de Doutor \\ em Ciências.
}

Área de Concentração:

Física Aplicada à Medicina e Biologia.

Orientador:

Prof. ${ }^{\circ}$ Dr. Antonio Adilton Oliveira Carneiro.

\section{Versão corrigida}

Versão original disponível na FFCLRP-USP

Ribeirão Preto - SP

2012 
Autorizo a reprodução e divulgação total ou parcial deste trabalho, por qualquer meio convencional ou eletrônico, para fins de estudo e pesquisa, desde que citada a fonte.

\section{FICHA CATALOGRÁFICA}

Cavalcanti, Ebenézer Silva

Desenvolvimento de um Sistema para Medida Elastográfica Dinâmica por Ultrassom / Ebenézer Silva Cavalcanti; orientador Prof. ${ }^{\circ}$ Dr. Antonio Adilton Oliveira Carneiro. Ribeirão Preto SP, 2012.

191 f.:il.

Tese (Doutorado - Programa de Pós-Graduação em Física Aplicada à Medicina e Biologia) - Faculdade de Filosofia, Ciências e Letras de Ribeirão Preto da Universidade de São Paulo, 2012.

1. Medidas Elastográficas. 2. Ultrassom. 3. Sistema de Medidas. 4. Caracterização de Tecidos Moles. 
Nome: Cavalcanti, Ebenézer Silva

Título: Desenvolvimento de um Sistema para Medida Elastográfica Dinâmica por Ultrassom

Tese apresentada à Faculdade de Filosofia, Ciências e Letras de Ribeirão Preto da Universidade de São Paulo, como parte das exigências para a obtenção do título de Doutor em Ciências.

Aprovado em:

\section{Banca Examinadora}

Prof(a). Dr(a). :

Julgamento:

$\operatorname{Prof}(\mathrm{a}) . \operatorname{Dr}(\mathrm{a})$.

Julgamento:

Prof(a). Dr(a). :

Julgamento:

Prof(a). Dr(a). :

Julgamento:

Prof(a). Dr(a). :

Julgamento:
Instituição:

Assinatura:

Instituição:

Assinatura:

Instituição:

Assinatura:

Instituição:

Assinatura:

Instituição:

Assinatura: 
As

minhas amadas: Lindinha, Ruama e Aline, pelo carinho, paciência e compreensão, além

do tempo dispensados longe de meus braços.

Obrigado! 


\section{Agradecimentos}

Em primeiro lugar minha gratidão ao Ser Supremo, Maravilhoso Conselheiro e Doador da vida, fonte de toda energia, pela saúde e força para suplantar minha inércia psicológica e física.

A cada caminho trilhado, muitas vezes de modo solitário, não nos torna pretensioso sobre a natureza deste trabalho. O que seria injusto e irreal atribuir todo o mérito e resultados aqui alçados, apenas àquele que o fez. Muito pelo contrário, um trabalho comunitário, onde pessoas de inestimável valor e com uma visão multidisciplinar trouxeram valiosa colaboração, cada qual a seu modo e com diferenciada dedicação.

A todos aqueles (familiares, amigos, pesquisadores e colegas) que de algum modo contribuíram para concretização deste trabalho, no decorrer das diversas trajetórias percorridas, alternando sentimentos de motivação e desânimo, perseverança e desilusões, fazendo despertar em nós um 'modus' diferente de perceber nossas diversidades e riquezas. Em particular, meu pai, Misael Freire Cavalcanti pelo incentivo. Posso dizer também que "sou vencedor". Abraço!

A esposa e filhas que muitas vezes absorveram, sem saber, as decepções e frustrações de alguns caminhos errantes, meu pedido de perdão.

Aos colegas do IFBA que assumiram parte de meu trabalho para que pudesse estar disponível, a fim de partir nesta jornada e que manifestaram de maneira explicita, seu apoio e compreensão, obrigado!.

Ao Antonio Adilton Oliveira Carneiro, orientador, avalista e acima de tudo, um grande amigo por ter aceito meu pedido de orientação, acreditado em mim e dispensado seu tempo para ponderar minha formação. Pela atuação sincera, pela disponibilidade nos momentos de dúvida, pelo empenho na correção e formação dos conceitos deficitários e acima de tudo pelo respeito e profissionalismo no trato das questões acadêmicas e relacionais, eternamente grato.

Aos Prof ${ }^{\text {es }}$. do Programa FAMB aos quais tive oportunidade de beber 
do saber de suas especialidades, em especial, o Prof ${ }^{\circ}$. Dr. Marcelo Mulato; o Prof $^{\circ}$. Dr. Osvaldo Baffa Filho; o Prof ${ }^{\circ}$. Dr. Luiz Otávio Murta e o Prof ${ }^{\circ}$. Dr. Martin Eduardo Poletti, pelo algo mais acrescido na minha formação como pessoa e pesquisador, estabelecendo questões, corrigindo desvios conceituais e propondo caminhos e trabalhos para leitura e estudo do estado da arte de vários temas correlatos.

Aos Prof ${ }^{e s} \operatorname{Dr}(s)$. Carlos Ernesto Garrido Salmon e Antônio Carlos Shimano pela excelente contribuição, nos detalhes e correção de rota no período de minha qualificação, grato!

Aos técnicos do departamento de Física: José Luiz Aziani, Sérgio Oliveira Bueno da Silva (Serginho), Lourenço Rocha, Elcio Aparecido Navas, Carlos Alberto Brunello (Carlão), Agnelo dos Santos Bastos Neto e Carlos Renato da Silva, pela prontidão em ajudar a resolver os problemas advindos da confecção dos dispositivos e protótipos propostos. Levarei boas recordações das "curtições" vivenciadas.

Não é possível esquecer do profissionalismo e atenção dispensada pelas secretarias do Departamento de Física e da Pós-Graduação nas pessoas de Nilza Marina Leone Marino e Maria Inês Joaquim. Vocês são "dez mais”!

Agradeço aos colegas de laboratório Hermes Kamimura, Tenysson Will, Thiago Almeida, Theo Pavan, Silvio Leão, Alexandre Colello, Marden Fagundes, Rogério Bulha e André Baggio, pelas discussões técnicas, teóricas e auxílios nas configurações experimentais e manuseio de inúmeros instrumentos de medição, além da acolhida em seus respectivos lares quando me foi necessário.

Além disso, agradeço aos demais alunos de iniciação científica: Diego Ronaldo pelo apoio na programação, Cintia Maira, Larissa Gatto, Felipe Grillo, Geraldo S. Neto e Marcelo Luvizotto, cujas companhias foram importantes no convívio social e pessoal. E, a nossa estagiária em química, Michelle Ferreira.

Meu sincero agradecimento aos colegas do programa FAMB que quebraram a barreira "natural" entre os diferentes grupos de pesquisa e gastaram um tempinho para criar vínculos de amizades. Em especial: el peruano José Ramirez Vegas; Los panameños Raul Camargo y Felipe Chen; el Chileno Jorge Luna; os gaúchos Tobias Heimfarth e Marcelo Schwarcke; Luiz Virgílio, Isaías Soares; Leandro Gutierrez; Thiago Arruda; Matheus Rodrigo; Mairon Marques; Mirko Salomón; Lindomar Soares; David Marçal; Natália Destefano; André Peres; Diogo Porfírio; Denise de Arruda; Tatiana Marques; Gustavo Parra e da FMRP, 
Ailton Carneiro e o mineirinho Adelson de Castro.

O que seria deste pernambucano-baiano sem a cantina do Valter, principalmente nos domingos e feriados. Assim, meu público agradecimento ao João Valter Nogueira.

Nos momentos de cansaço encontrei energia extra para seguir em frente, através do apoio de grandes amigos que me acompanharam e torceram por mim. São eles: Raimundo Nonato Almeida Costa e Ana Verônica Serrano.

Não poderia deixar de citar meu público agradecimento ao Departamento de Física da FFCLRP (USP) por disponibilizar toda sua infraestrutura, em especial do Laboratório de pesquisa em Inovação e Instrumentação Médica e Ultrassom (GIIMUS). Bem como a agência de pesquisa CAPES pela bolsa de estudo (PIQDTEc) que propiciou minha estadia nesta localidade.

Enfim, àqueles que por um lapso de memória não foram citados explicitamente aqui, e que, de algum modo também responsáveis pelo traçado desta jornada, meu sincero muito obrigado! 
viii

"Muitos de nossos sonhos parecem impossíveis, depois improváveis, depois inevitáveis."

Christopher Reeve

Assim, "o valor das coisas não está no tempo que elas duram, mas na intensidade com que acontecem.

Por isso existem momentos inesquecíveis, coisas inexplicáveis e pessoas incomparáveis." 


\section{Resumo}

CAVAlCANTI, E. S. Desenvolvimento de um Sistema para Medida Elastográfica Dinâmica por Ultrassom. 2012. 191 f. Tese (Doutorado - Programa de Pós-Graduação em Física Aplicada à Medicina e Biologia) Faculdade de Filosofia, Ciências e Letras de Ribeirão Preto, Universidade de São Paulo, Ribeirão Preto - SP, 2012.

Este trabalho aborda o desenvolvimento de um aparato instrumental para efetuar medidas elastográficas por ultrassom. No qual foi considerado a elastografia tradicional que busca analisar as propriedades mecânicas de viscosidade e elasticidade de um meio, através da compressão e descompressão, de modo a simular o processo de palpação utilizado pelos médicos para avaliar a rigidez de um tecido, pois é sabido que estas mudanças estão relacionados a alguma forma de lesão do tecido biológico. Para alcançar tal propósito, foi construído simuladores de tecidos moles com características mecânicas próximas ao tecido biológico, nos quais foram utilizados materiais a base de parafinas (hidrocarbonetos) e gelatinas (proteínas extraída da hidrólise do colágeno de tecidos bovinos/suínos). Além do mais, foram introduzidos, na mistura, fluidos magnetoreológicos (FMR), que permitiram alterar estas propriedades mecânicas através da aplicação de um campo magnético externo. Os resultados apontam a viabilidade do protótipo em levantar o módulo de elasticidade destes simuladores, além de torná-lo um elemento diferencial para treinamento de profissionais da área de saúde e possível criação de protocolo para calibração de diferentes tumores e análise de medidas elastográficas, a partir da alteração de rigidez de um meio através da aplicação de campos magnéticos externos.

Palavras-chave: 1. Medidas Elastográficas. 2. Ultrassom. 3. Sistema de Medidas. 4. Caracterização de Tecidos Moles. 


\section{Abstract}

\section{CAVALCANTI, E. S. Development of a System for Measuring Dynamic}

Elastography by Ultrasound. 2012. 191 f. Thesis (Ph.D. Postgraduate program in Physics Applied to Medicine and Biology) - Faculty of Philosophy, Sciences and Literature, University of São Paulo, Ribeirão Preto SP, 2012.

This work approaches the development of an apparatus to perform instrumental measures elastográficas ultrasound. In elastography which was traditionally considered that seeks to analyze the mechanical properties of viscosity and elasticity of a medium, through compression and decompression in order to simulate the palpation process used by physicians to evaluate stiffness of a fabric, it is known that these changes are related to some form of injury of biological tissue. To achieve this goal, was constructed simulators soft tissues mechanical characteristics close to biological tissue in which the materials were used based on paraffin (oil) and gelatin (protein hydrolysis of collagen extracted from bovine tissue / pigs). Besides, were introduced into the mixture, magnetorheological fluids (FMR) which allowed to change these mechanical properties by applying an external magnetic field. The results indicate the viability of the prototype in raising the modulus of elasticity of these simulators, and make it a differential element of training for health professionals and possible creation of protocol for calibration of different tumors and analysis of measures elastográficas from changing the stiffness of a medium by applying external magnetic fields.

Key-words: 1. Measures elastography. 2. Ultrasound. 3. System of measures. 4. Characterization of soft tissue. 


\section{Lista de Figuras}

1.1 Esquema de propagação da onda sonora. . . . . . . . . . . 5

1.2 Espectro Sonoro . . . . . . . . . . . . . . . . . 6

1.3 Esquema de espalhamento da onda sonora - Difusa e Especular. . 7

1.4 Esquema de um transdutor de Ultrassom (a) e Fotografia microscópica de uma matrix de cerâmica PZT (b). . . . . . . . . . 8

1.5 Esquema de três molas conectadas antes e após a aplicação de uma força sobre elas. . . . . . . . . . . . . . . . . 13

1.6 Esquema de deformação em meios com diferentes propriedades mecânicas. . . . . . . . . . . . . . . . . . . . 13

1.7 Segmento de um eco antes e após a deformação apresenta uma defasagem temporal. . . . . . . . . . . . . . . . 14

1.8 Gráfico mostrando pico de correlação entre ecos. . . . . . . . . . . 15

2.1 Esquema apresentando esforços de tração (a) e Compressão (b). . 21

2.2 Esquema mostrando tensão cisalhante $\gamma \ldots \ldots$. . . . . . . . . . 22

2.3 Esquema mostrando tensão volumétrica. . . . . . . . . . . . . . 23

2.4 Sistema referencial apresentando deslocamento transversal em " $x$ "

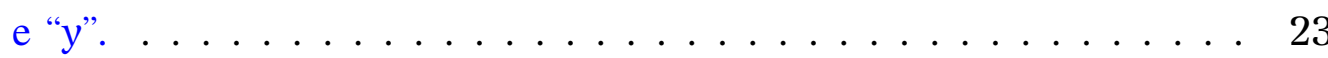

2.5 Esquema mostrando corpo cilindrico sobre tensão que produzem deformações. . . . . . . . . . . . . . . . 26

2.6 Curva tensão versus deformação no regime elástico linear. . . . . 26

2.7 Curva tensão versus deformação no regime não linear. . . . . . . . 27

2.8 Três modelos padrão de viscoelasticidade e suas respectivas respostas (Histerese[H] x $\log ($ frequência)): a) Maxwell, b) Voigt e c) Kelvin. [49] . . . . . . . . . . . . . . . . . . . . . 28

2.9 Diagrama esquemático do estudo reológico. (adaptado: Bird et al., 1987 [59]) . . . . . . . . . . . . . . . . . 29

2.10 Curvas de fluxo para diferentes tipos de comportamento reológico 30

2.11 Esquema de deformação infinitesimal num elemento de volume. . 30 
2.12 Diagrama esquemático de um modelo de oscilador harmônico amortecido (Voigt). . . . . . . . . . . . . . . . . . 34

2.13 Gráficos de um Sistema massa-mola com fator de amortecimento. 35

2.14 Gráfico de um Sistema Oscilante amortecido quando excitado por um impulso. . . . . . . . . . . . . . . . . . .

2.15 Gráfico esquemático do método da largura de banda para determinação do amortecimento.

2.16 Gráfico esquemático do método de histerese para determinação do amortecimento. . . . . . . . . . . . . . . .

2.17 Imagem de partículas magnéticas na matriz polimérica de um elastômero . . . . . . . . . . . . . . . . . . .

$2.18 \mathrm{Em}$ (a) decaimento exponencial $\left(e^{-\alpha z}\right)$ da onda de pressão com fator de atenuação $\alpha$; em (b) decaimento exponencial $\left(e^{-2 \alpha z}\right)$ da densidade de potência $\left(I=\mathrm{P}^{2} / \mathrm{Z}\right)$ numa taxa duas vezes maior. . .

2.19 Curva tensão $\mathrm{x}$ deformação para oito diferentes conjuntos de tecido mamário (adaptado: wellman et al., 1999 [76]). . . . . . . . .

2.20 Diagrama de um meio piezoelétrico com as curvas de resposta de tensão no tempo e frequência. (adaptado Szabo, 2004 [75]). . . . .

2.21 Diagrama de algumas geometrias de cerâmicas transdutoras para modos de vibração ao longo da direção "z". (adaptado Szabo, 2004 [75]). . . . . . . . . . . . . . . . . . .

2.22 Diagrama apresentando transdutor de geometria circular com campo de pressão próximo e distante. . . . . . . . . . . .

2.23 Variação do campo próximo e distante, de uma onda de pressão, num transdutor com geometria circular. (Adaptado: Christensen (1988) [74]) . . . . . . . . . . . . . . . . . . . . . . 48

2.24 Forma de onda de pressão quando excitada por pulso estreito. . . 49

2.25 Velocidade do som medido em diferentes meios biológicos. . . . . 50

2.26 Resumo de resultados experimentais publicados de atenuação $\mathrm{x}$ frequência para vários meios biológicos e água. (Adaptado: Cobbold, $2007[56,77,78]) \ldots \ldots \ldots \ldots \ldots$

3.1 Simuladores de tecidos com diferentes partículas espalhadoras e inclusões . . . . . . . . . . . . . . . . . .

3.2 Tabela apresentando características da parafina [fornecedor: Petrobrás S/A]. . . . . . . . . . . . . . . . . . . 
3.3 Simulador de tecido apresentando inclusões de partículas ferromagnéticas $\left(\mathrm{Fe}_{3} \mathrm{O}_{4}-\mathrm{FMR}\right) \ldots \ldots \ldots \ldots \ldots$

3.4 Imagem do "phantom" utilizado para testes no sistema oscilador de multifrequência (adaptado Vieira, 2009 [28]). . . . . . . . . . 58

3.5 Amostras com diferentes concentrações do FMR. . . . . . . . . 59

3.6 Imagem do porta amostra de acrílico utilizado para caracterização do FMR. . . . . . . . . . . . . . . . . . . . . 60

3.7 Montagem experimental para análise da velocidade e atenuação. . 61

3.8 Esquema de medição da velocidade e atenuação sonora no tanque acústico. . . . . . . . . . . . . . . . . . . . 61

3.9 Diagrama e foto do Oscilador multifrequência. . . . . . . . . . 62

3.10 Montagem experimental para medições de rigidez. . . . . . . . . . 64

3.11 Configuração para medições de rigidez, em modo quase estático. . 66

3.12 (a) Esquema das linhas de campo numa bobina, (b) foto da bobina excitadora e (c) esquema com fluxo de amplificação. . . . . . . . . .

3.13 Esquema e imagem da estrutura para medições dinâmicas com vibrador, mini-shaker 4810 e Ultrasonix $x^{\mathrm{R}}$, modelo "RP". . . . . . . .

3.14 Esquema para medições dinâmicas com mini-shaker 4810 acoplado ao Oscilóscopio de alta taxa de amostragem e ao Ultrasonix ${ }^{\mathrm{R}} \ldots \ldots \ldots \ldots \ldots \ldots \ldots$. . . . . . . . . . 72

4.1 Imagens com resultados do sistema oscilatório multifrequência . .

4.2 (a) Imagens obtidas em ultrassom modo-B e Doppler colorido durante vibração do "phantom" com inclusão rigida (Marini et al, 2008) [86]. . . . . . . . . . . . . . . . . . . . . .

4.3 Velocidade em função do campo magnético para Óleo STP com $20 \%$ e $50 \%$ de concentração de partículas magnéticas - Medições com transdutor de $1 \mathrm{MHz}$

4.4 Velocidade em função da frequência dos transdutores para quatro meios: $\mathrm{H}_{2} \mathrm{O}$, Óleo STP puro e com duas concentrações de partículas magnéticas $(20 \%$ e $50 \%)$. . . . . . . . . . . .

4.5 Sinal ultrassônico adquirido através do porta-amostra contendo água, com um par de transdutores de $1 \mathrm{MHz}$, através do método "pulser/receiver" (reflexão) e Transmissão. . . . . . . . . . . . . . 
4.6 Atenuação do porta amostra em função da frequência do transdutor US, em relação a água filtrada e desgaseificada do

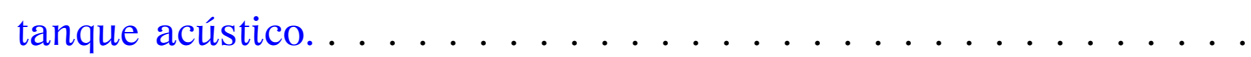

4.7 Atenuação em função do material com diferentes concentrações de partículas magnéticas obtidas pelo conjunto de transdutores de US

4.8 Atenuação em função do meio com e sem concentração de partículas magnéticas, para um transdutor de $1 \mathrm{MHz}$, sem aplicação do campo magnético. . . . . . . . . . . . . . .

4.9 Atenuação em função do campo magnético - Óleo STP com 20\% de partículas magnéticas. . . . . . . . . . . . . . . 86

4.10 Taxa de cisalhamento [1/s] em função da tensão de cisalhamento [Pa] para o gel de ultrassom com $10 \%$ de partículas ferromagnéticas. 87

4.11 Viscosidade em função da tensão de cisalhamento para o gel de US, a $25{ }^{\circ} \mathrm{C}$, sem partículas magnéticas, com e sem campo externo. 87

4.12 Taxa de cisalhamento em função da tensão de cisalhamento para óleo vegetal (Oliva) sob ação de um campo externo variável. . . .

4.13 Taxa de cisalhamento em função da tensão de cisalhamento para óleo de oliva com 10\% de partículas magnéticas sob ação de um campo externo variável. . . . . . . . . . . . . . .

4.14 Taxa de cisalhamento versus tensão de cisalhamento do óleo STP para diferentes concentrações partículas magnéticas, sem campo externo. . . . . . . . . . . . . . . . . . . 90

4.15 Taxa de cisalhamento versus tensão de cisalhamento do óleo STP para diferentes concentrações partículas magnéticas, com campo externo. . . . . . . . . . . . . . . . . . . . . 91

4.16 Taxa de cisalhamento versus Tensão de cisalhamento para óleo STP puro e com 50\% de partículas magnéticas, sob ação de um campo magnético externo variável. . . . . . . . . . . . . . . . . 92

4.17 Viscosidade do Óleo STP para diferentes concentrações de Partículas magnéticas sem campo e com campo magnético. . . . . 93

4.18 Modelo de uma mola helicoidal. . . . . . . . . . . . . . . . . . . . . 95

4.19 Velocidade do som na água a partir da diferença de deslocamento entre as medições: ultrassom versus micrômetro. . . . . . . . . . 
4.20 Tensão versus deformação para um "phantom" de parafina cristal, sem partículas magnéticas, medidas numa balança de precisão. . .

4.21 Tensão versus deformação para um "phantom" de parafina gel com $2 \%$ de espalhador e $10 \%$ de PM, com e sem campo externo, obtidos por US. . . . . . . . . . . . . . . . . . . .

4.22 Tensão versus deformação para a parafina cristal sem partículas magnéticas.

4.23 Tensão versus deformação para a parafina gel sem partículas

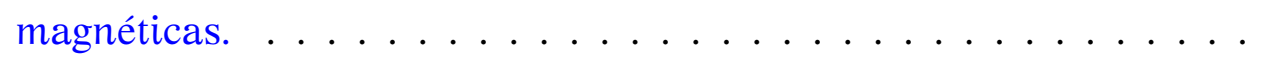

4.24 Tensão versus deformação para a gelatina (250Blomm) a 8\% sem partículas magnéticas. . . . . . . . . . . . . . . . . . 103

4.25 Tensão versus deformação para a gelatina 250 blomm em 4 concentrações, sem partículas magnéticas. . . . . . . . . . . 103

4.26 Deslocamento versus profundidade - "Phantom" de parafina com espalhador sem partículas magnéticas [referência]. . . . . . . . . . 104

4.27 Mapa de Deformação em função da profundidade - "Phantom" de parafina com espalhador sem partículas magnéticas [referência]. . 105

4.28 Deformação em função da profundidade e deslocamentos "Phantom" de parafina com espalhador sem partículas magnéticas [referência]. . . . . . . . . . . . . . . . . 105

4.29 Deformação em função da profundidade e deslocamentos "Phantom" de parafina com espalhador com inclusão de $10 \%$ de partículas magnéticas. . . . . . . . . . . . . . . 106

4.30 Deformação versus deslocamentos - "Phantom" de parafina com espalhador com e sem partículas magnéticas, com e sem campo externo. . . . . . . . . . . . . . . . . . 106

4.31 Sinal Amplificado de " $R F$ ", numa região da amostra contendo partículas magnéticas, com e sem ação do campo magnético externo.108

4.32 Mapa de deslocamento no tempo para frequência de $40 \mathrm{~Hz}$ "Phantom" de parafina com partículas magnéticas, com e sem campo magnético externo. . . . . . . . . . . . . . . . . . 109

4.33 Amplitude de deslocamento versus frequência de excitação "Phantom" de parafina com espalhador e partículas magnéticas - Medições no Osciloscópio. . . . . . . . . . . . . . . . . . 110 
4.34 Mapa de deslocamento no tempo para frequência de $140 \mathrm{~Hz}$ "Phantom" de parafina com partículas magnéticas, com e sem campo magnético externo. . . . . . . . . . . . . . . 111

4.35 Mapa de deslocamento no tempo para frequência de $40 \mathrm{~Hz}$ "Phantom" de parafina com partículas magnéticas, sem e com campo magnético externo. . . . . . . . . . . . . . . . . 112

4.36 Deslocamento no tempo para frequência de $80 \mathrm{~Hz}$ - "Phantom" de parafina com partículas magnéticas, com e sem campo magnético externo. . . . . . . . . . . . . . . . . . . . . . . . 114

4.37 Amplitude de deslocamento em função da frequência - "Phantom" de parafina com espalhador e partículas magnéticas - Medições no Ultrasonix ${ }^{\mathrm{R}} \ldots \ldots \ldots \ldots \ldots \ldots \ldots$

4.38 Mapa de deslocamento no tempo para frequência de $40 \mathrm{~Hz}$ "Phantom" de parafina com partículas magnéticas, sem e com campo magnético externo. . . . . . . . . . . . . . . . . . 117

4.39 Mapa de deslocamento no tempo para frequência de $80 \mathrm{~Hz}$ "Phantom" de parafina com partículas magnéticas, sem campo magnético externo. . . . . . . . . . . . . . . . . . . . 118

4.40 Imagem ultrasonix de "phantom "com inclusão líquida contendo 10\% de partículas magnéticas. Em cada quadro [(a) e (b)] há uma imagem elastográfica (direita) e uma imagem em modo-B (esquerda). (a) Sem campo externo, (b) com campo externo. . . . . 120

4.41 Imagem ultrasonix de "phantom "com inclusão líquida contendo $15 \%$ de partículas magnéticas. Em cada quadro [(a) e (b)] há uma imagem elastográfica (direita) e uma imagem em modo-B (esquerda). (a) Sem campo externo, (b) com campo externo. . . . . 121

4.42 Imagem ultrasonix de "phantom "com inclusão sólida contendo $15 \%$ de partículas magnéticas. Em cada quadro [(a) e (b)] há uma imagem elastográfica (direita) e uma imagem em modo-B (esquerda). (a) Sem campo externo, (b) com campo externo. . . . . 121

4.43 Imagem ultrasonix de "phantom "com inclusão sólida contendo 20\% de partículas magnéticas. Em cada quadro [(a) e (b)] há uma imagem elastográfica (direita) e uma imagem em modo-B (esquerda). (a) Sem campo externo, (b) com campo externo. . . . . 
4.44 Imagem ultrasonix de "phantom "com inclusão sólida contendo $25 \%$ de partículas magnéticas. Em cada quadro [(a) e (b)] há uma imagem elastográfica (direita) e uma imagem em modo-B (esquerda). (a) Sem campo externo, (b) com campo externo. . . . . 123

A.1 Imagem do viscosímetro Rheolab QC com refrigerador - aquecedor JULABO . . . . . . . . . . . . . . . . . . . . . . 140

A.2 Modelo da geometria do viscosímetro: Cone-cilíndrico. . . . . . . 141

B.3 Curva de caracterização da célula de carga $[5,0 \mathrm{~g}-50,0 \mathrm{~g}] . \ldots 145$

B.4 Curva de caracterização da célula de carga $[50,0 \mathrm{~g}-300,0 \mathrm{~g}] . .146$

C.5 Curvas de caracterização dos Imãs. . . . . . . . . . . . . . . . 148

D.6 Curva de caracterização do amplificador Ciclotron 4000-AB [Volts].149

D.7 Curva de caracterização do amplificador Ciclotron 4000-AB [dB]. 150

E.8 Curva de caracterização da bobina de excitação [0 Hz-700 Hz]. . 151

E.9 Curva de caracterização da bobina de excitação [0 Hz-100 Hz]. ${ }_{152}$

E.10 Curva de caracterização da bobina de excitação $[0 \mathrm{~Hz}-30 \mathrm{~Hz}]$. . 152

F.11 Curva de caracterização do mini-shaker 4810. . . . . . . . . 153

H.12 Limiar de dano em tecidos biológicos por exposição a US contínuo. (adaptado: Ulrich, 1974 [37]). . . . . . . . . . . . . 164

I.13 Limiar de dano em tecidos biológicos por exposição a US pulsado. (adaptado: Ulrich, 1974 [37]). . . . . . . . . . . . . . . . . . 165 


\section{Lista de Tabelas}

2.1 Nomes e unidades dos parâmetros $\lambda$ e $\mu[15,64] . \ldots \ldots . . .33$

3.1 Composição química usada na preparação da gelatina bovina 250 Blomm com 10\% FMR (adaptado: Fong et al., 2001 [84]). . . . . . 57

4.1 Velocidade média da $\mathrm{H}_{2} \mathrm{O}$ (tanque acústico) a $(24 \pm 1){ }^{\circ} \mathrm{C}[\mathrm{T} / \mathrm{R}]-$ Diferentes frequências US. . . . . . . . . . . . . . 77

4.2 Velocidade do Som pelo método da Reflexão (T/R) - Diferentes meios. . . . . . . . . . . . . . . . . . . . 78

4.3 Atenuação e impedância Acústica nos diferentes meios utilizados como base das inclusões, comparados com a $\mathrm{H}_{2} \mathrm{O} \ldots \ldots \ldots$. . . . 81

4.4 Atenuação Sonora obtida através do método de Transmissão Para diferentes meios e concentração de partículas magnéticas, tendo como referência a água filtrada e desgaseificada do tanque

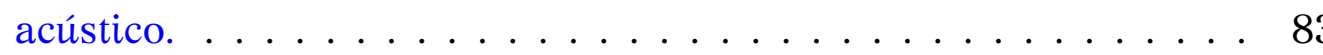

4.5 Viscosidade para os diferentes meios analisado, numa taxa de cisalhamento de $96 \mathrm{~s}^{-1} \ldots \ldots \ldots \ldots \ldots \ldots$. . . . . . . 94

4.6 Comparação das medições da Constante elástica da mola com US e micrômetro. . . . . . . . . . . . . . . . . . . . . . . 95

4.7 Valores das medições do deslocamento da mola de aço no micrômetro e US. . . . . . . . . . . . . . . . . . . 96

4.8 Valores do módulo de Young para um "phantom" contendo 10\% de FMR, com $2 \%$ de espalhador. . . . . . . . . . . . . . 98

4.9 Comparação do Módulo de Young - Parafina Cristal e Gel diferentes concentrações PM. . . . . . . . . . . . . . . . 100

4.10 Comparação do Módulo de Young - Gelatina 250 blomm diferentes concentrações. . . . . . . . . . . . . . . . . . . . . 102

4.11 Amplitude de deslocamento versus frequência - Medições com Osciloscópio. . . . . . . . . . . . . . . . . . . . . . 111 
4.12 Amplitude de deslocamento versus frequência - Medições com Ultrasonix. . . . . . . . . . . . . . . . . . . . . . . . . 115

4.13 Relação de rigidez nas imagens elastográficas obtidas com um equipamento de US da Sonix ${ }^{\mathrm{R}}$ - Diferentes meios e concentração. 119

A.1 Algumas propriedades da água pura. (Adaptado [56]). . . . . . . 155

B.2 Atenuação na água em função da frequência [90]. . . . . . . . . 157

C.3 Atenuação ultrassônica em alguns materiais em função da frequência [90]. . . . . . . . . . . . . . . . . . . 158

D.4 Contribuição do espalhamento no coeficiente de atenuação [56]. . 159

E.5 Algumas propriedades de tecidos humanos moles à $37^{\circ} \mathrm{C}$ [56]. . . 161

F.6 Comparação de modalidades de ultrassom médico para valores em água - (entre parêntesis, valores médios) [75]. . . . . . . . 162

G.7 Limites de Intensidade de saída acústica - FDA [75] . . . . . . . . 163 


\section{Lista de Abreviaturas}

AIUM Instituto americano de Ultrassom em Medicina (American Institute of Ultrasound in Medicine).

AOAC Associação Oficial de Químicos Agrícolas (Association of Official Agricutural Chemists).

ARF Força de Radiação Acústica (Acustic Radiation Force).

ARFI Imagens de Força de Radiação Acústica (Acustic Radiation Force Imaging).

ABNT Associação Brasileira de Normas Técnicas (Brazilian Association of Technical Standards).

ASME Sociedade Americana de Engenharia Mecânica (American Society of Mechanical Engineers).

ASTM Sociedade Americana de Teste e Materiais (American Society for Testing and Materials).

BI-RADS ${ }^{\mathrm{R}}$ Relatório de Imagens de Mamas e Sistema de Dados (Breast Imaging Reporting and Data System).

BSI Instituto de Normatização Britânico (British Standards Institution).

CPU Unidade central de Processamento (Central Processing Unit).

dB decibel (decibel).

DEC Companhia de equipamentos digitais (Digital Equipament Corporation).

DIN Instituto Alemão de Normatização (Deustsches Institut für Normung). 
DRAM Memória de acesso dinâmica aleatória (Digital Random Access Memory).

DSC Conversor de escaneamento digital (Digital Scanning Converter).

ECISS Comitê Europeu de Normatização para aços e ferro (European Comitte for Iron and Still Standartization).

FAMB Física Aplicada a Medicina e Biologia (Physics Applied to Medicine and Biology).

FDA Administração de Alimentos e Drogas (Food end Drug Administration - USA).

FigLabs FigLabs Pesquisa e Desenvolvimento Ltda. (FigLabs Research and development Inc.).

FPS Quadros por segundo (Frames per second).

FMR Fluído magnetoreológico (magnetorheological fluids).

$\mathrm{GE}^{\mathrm{R}} \quad$ General Electric (General Electric).

GIIMUS Grupo de Inovação em Instrumentação Médica e Ultrassom (Innovation Group in Medical Instrumentation and Ultrasound).

HIFU Ultrassom focado de alta intensidade (High intensity focused ultrasound).

LABVIEW ${ }^{\mathrm{TM}}$ Laboratory Virtual Instrument Engineering Workbench (Laboratory Virtual Instrument Engineering Workbench).

MAGIC $^{\mathrm{R}}$ Gelatina Iniciada por cobre, Metacrílico e ácido ascórbico (Methacrylic and Ascorbic acid in Gelatin Initiated by Copper).

MATLAB Matrix Laboratory (Matrix Laboratory).

MMR Materiais magnetoreológicos (magnetorheological materials).

MPEG Grupo de profissionais experientes em movimento de imagens (Moving Picture Experts Group). 
MRE Elastografia por Ressonância Magnética (Magnetic Resonance Elastography).

MRI Imagens por Ressonância Magnética (Magnetic Resonance Imaging).

ODS Padrão de Visualização de saída (Output Display Standard).

PDP Processador de dados programável (Programed Data Processor).

NCRP Conselho Nacional de Medidas e Proteção em Radiação (National Council on Radiation Protection and Measurements).

$\mathrm{NI}^{\mathrm{R}} \quad$ National Instruments (National Instruments).

ORIGIN"M OriginLaB - Data analysis and graphing software (OriginLaB - Data analysis and graphing software).

PPI Plano de indicação de posição (Indication Position Plane).

PVDF Fluoreto de Polivinilideno (Poly(vinylidene difluoride)).

PZT Titanato Zirconato de Chumbo (Plumbum Zirconate-Titanate).

RF Campo de Resposta (Response Field).

RMS Valor médio quadrático (Root Mean Square).

ROI Região de Interesse (Region-of-interest).

SMURF Força de Radiação ultrassônica modulada espacialmente (Spatially Modulated Ultrasound Radiation Force).

$\mathrm{SNR}_{e} \quad$ Relação Sinal-Ruído (Signal-to-Noise Ratio).

SONAR Navegação por Som e Distâncias (Sound Navigation and Ranging).

USA Estados Unidos da América (United States of America).

US Ultrassonografia (Ultrasonography).

VA Vibroacustografia (vibro-acoustography). 


\section{Lista de Símbolos}

$\omega \quad$ Frequência angular $[\mathrm{rad} / \mathrm{s}]$.

$\sigma \quad$ Tensão (“Stress”) [Pa].

$\varepsilon$ Deformação ("Strain") [adimensional].

v Razão de "Poisson" [adimensional].

$\rho \quad$ Densidade volumétrica $\left[\mathrm{Kg} / \mathrm{m}^{3}\right]$.

$\xi \quad$ Taxa de amortecimento (atenuação).

$\lambda$ Comprimento de Onda (Wavelength) [m].

Y Módulo de elasticidade (Young’s modulus) [Pa].

Z Impedância acústica $\left[\mathrm{kg} /\left(\mathrm{m}^{2} . \mathrm{s}\right), \quad \mathrm{N} . \mathrm{s} / \mathrm{m}^{3}, \mathrm{~Pa} . \mathrm{s} / \mathrm{m}\right.$, "rayl"].

I Intensidade radiação $\left[\mathrm{mW} / \mathrm{cm}^{2}, \mathrm{~W} / \mathrm{cm}^{2}\right]$. 


\section{Sumário}

Lista de Figuras $\quad$ xi

Lista de Tabelas $\quad$ xviii

Lista de Abreviaturas $\quad$ xx

Lista de Símbolos $\quad$ xxiii

1 Introdução 1

1.1 O ultrassom e sua evolução . . . . . . . . . . . . . . 1

1.2 O fenômeno sonoro ................... 5

1.3 O ultrassom e suas aplicações em sistemas biológicos . . . . . . 9

1.4 Justificativa . . . . . . . . . . . . . . . . . . . . 16

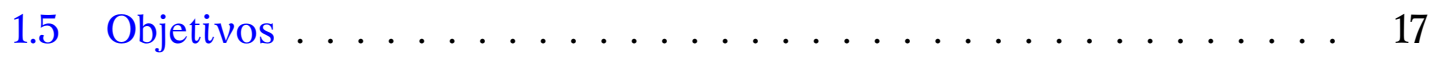

1.6 Estrutura dos Capítulos . . . . . . . . . . . . . . . 17

2 Estado da arte - Fundamentos Teóricos $\quad 19$

2.1 Teoria da Viscoelasticidade . . . . . . . . . . . . . 21

2.1.1 Elasticidade .................... 21

2.1.1.1 Caracterização da Elasticidade . . . . . . . . . 25

2.1 .2 Viscosidade . . . . . . . . . . . . . . . . 27

2.1.2.1 Caracterização da Viscoelasticidade. . . . . . . . 34

2.1.3 Métodos de determinação do amortecimento - atenuação . 36

2.2 Materiais magnético reológicos . . . . . . . . . . . . . . . . 40

2.3 Ultrassom e interações . . . . . . . . . . . . . . . . . 43

2.3.1 A fonte de ultrassom . . . . . . . . . . . . . . . 45

2.3.2 Velocidade e Atenuação Sonora . . . . . . . . . . . . 50

3 Materiais e Métodos $\quad \mathbf{5 4}$

3.1 Simuladores de Tecidos - "Phantom - Fantoma" . . . . . . . . . . . 54

3.1.1 Analisador de Velocidade e Atenuação . . . . . . . . . . . . 60 
3.2 Aparato Instrumental - "Protótipos" . . . . . . . . . . . . . . . . 62

3.2.1 Oscilador multifrequência a mão livre . . . . . . . . . . . . 62

3.2.2 Analisador de deslocamento por ultrassom - Estático . . . . 64

3.2.3 Analisador de deslocamento por ultrassom - Dinâmico . . 67

3.2.4 Imagens elastográficas - Ultrasonix ${ }^{\mathrm{R}} \ldots \ldots . \ldots 72$

4 Resultados e Discussões $\quad \mathbf{7 4}$

4.1 Oscilador Multifrequência a mão livre . . . . . . . . . . . . . . . 74

4.2 Analisador de velocidade e atenuação . . . . . . . . . . . . 76

4.3 Viscosidade e efeitos do campo magnético . . . . . . . . . . . 86

4.4 Atuador de carga estática . . . . . . . . . . . . . . . . . . . 94

4.5 Atuador de carga dinâmica . . . . . . . . . . . . . . . . . 107

4.5.1 Ultrassom Monocanal . . . . . . . . . . . . . . . . 109

4.5.2 Ultrassom Multicanal . . . . . . . . . . . . . . . 113

4.6 Imagem elastográfica - Ultrasonix . . . . . . . . . . . . . . . . 118

5 Conclusões e Perspectivas Futuras $\quad 124$

5.1 Conclusões . . . . . . . . . . . . . . . . . . . . . . . . . 124

5.2 Perspectivas futuras . . . . . . . . . . . . . . . . 127

$\begin{array}{lr}\text { Referências } & 129\end{array}$

Apêndice A - Protocolo para Medição de Viscosidade 140

Apêndice B - Curva de calibração da Célula de carga 145

Apêndice C - Curva de calibração do magneto 147

Apêndice D - Curva de calibração do amplificador de potência 149

Apêndice E - Curva de calibração da bobina excitadora para carga de 50 Ohms

Apêndice F - Curva de calibração do mini-shaker 4810153

Anexo A - Algumas Propriedades da água pura 154

Anexo B - Atenuação Sonora na Água em função da Frequência 156 
Anexo C - Atenuação Ultrassônica para alguns materiais em função da Frequência

Anexo D - Contribuição do espalhamento no coeficiente de atenuaçãd 59

Anexo E - Propriedades determinadas de tecidos humanos moles à $37^{\circ} \mathrm{C}$

Anexo F - Comparação de modalidades de ultrassom médico para valores em água

Anexo G - Limites de Intensidade de saída acústica - FDA (secção 3) 163

Anexo H - Limiar de danos no tecido biológico por US contínuo 164

Anexo I - Limiar de danos no tecido biológico por US pulsado 


\section{Capítulo}

\section{Introdução}

Ossos conhecimentos e inovação surgiram basicamente da observação do
nosso habitat, fauna e flora. Com o ultrassom, que é uma onda mecânica, não foi diferente. Pois, na natureza encontramos animais que utilizam o ultrassom para se localizar e caçar, como por exemplo, os morcegos, que, não tinham uma visão muito aguçada, contudo voavam sem colidir com objetos ao redor de si. Este fato foi observado primeiramente em 1793, por Lazzaro Spallanzani (Fisiologista italiano: 1729-1799) [1]. Ele constatou que os morcegos, mesmo impedidos de enxergar, desviavam-se de obstáculos e apanhavam as suas presas no ar. Ao contrário, quando eram impedidos de ouvir, através da aplicação de tampões de cera em seus ouvidos, porém com a visão mantida, perdiam completamente a capacidade de orientação em voo [2].

\subsection{O ultrassom e sua evolução}

Evoluindo de observações qualitativas, fisiológicas, o som teve seu estudo matemático registrado a partir do século XIX (1877) quando o cientista inglês John William Strutt, terceiro Barão de Rayleigh (Lord Rayleigh) [3], apresentou seu livro sobre "A Teoria do Som".

Este trabalho foi considerado um dos mais importantes sobre o assunto. O primeiro volume, em que aborda a mecânica do meio vibrante que produz o som, foi publicado em 1877 e o segundo volume, sobre a propagação do som, foi publicado no ano seguinte. Neles descreveu o som a partir de equações matemáticas; definiu o conceito de condutividade acústica de um orifício, a função de dissipação para um sistema sujeito a amortecimento, o teorema da reciprocidade acústica e sua representação complexa.

Paralelamente, em 1822, Daniel Colloden, mergulhava um sino num 
lago (Genebra - Suiça) na tentativa de calcular a velocidade do som debaixo d'água [4]. Entretanto, foi em 1906 que Lewis Nixon inventou o primeiro dispositivo de escuta (protótipo do SONAR - "Sound Navigation and Ranging") com objetivo de detectar icebergs. O interesse pelo dispositivo aumentou com o início da $1^{\text {a }}$ Guerra Mundial, cujo alvo principal era localizar submarinos. Todavia, somente em 1915, Paul Langévin inventou o primeiro dispositivo de escuta (tipo SONAR) para detectar submarinos usando as propriedades piezoelétricas do quartzo [5]. Porém, mesmo com o uso de geradores de sons de baixa frequência foi possível facilitar a navegação permitindo a detecção de "icebergs" distantes num raio de 5 quilômetros [6]. Deste modo, a Primeira Guerra Mundial impulsionou a teoria ultrassônica a se tornar uma realidade prática.

Contudo, a utilização dos ultrassons em medicina, somente teve início no final da década de 30, com foco primeiramente no âmbito terapêutico, tendo sido empregado empiricamente em várias áreas, desde o tratamento de artrite reumatoide até tentativas de cura da doença de Parkinson em neurocirurgia, sendo desestimulado na década seguinte por não mostrar dados conclusivos.

Em meados da década de 40, o ultrassom passa a ser utilizado pela primeira vez em medicina como análise diagnóstica. O neuropsiquiatra da Universidade de Viena, Karl Theodore Dussik e seu irmão Físico Friederich Dussik, tentavam localizar tumores e verificar o tamanho dos ventrículos cerebrais, através da mensuração da transmissão dos sons pelo crânio, técnica que denominaram de "Hiperfonografia" [7].

Durante a Segunda Guerra Mundial, o estudo da utilidade dos ultrassons para fins militares foi aprimorado com o desenvolvimento do SONAR (sigla em inglês para Sound Navigation and Ranging). Ainda neste período, o desenvolvimento do uso dos ultrassons para fins não-militares foi notável também na metalurgia, como por exemplo, para detecção de fissuras em metais.

A partir da década de 50, o ultrassom teve seu uso intensificado, com sucesso, em diferentes áreas para diagnóstico de várias estruturas. Com esta técnica, sob determinadas condições de frequência e direção de propagação da onda, é possível medir estruturas da ordem de micrômetros: deslocamentos, espessuras, áreas, volumes, descontinuidades, rugosidades (corrosão) de materiais, falhas na geometria, testes não destrutivos em materiais como polímeros, madeira etc. 
No final da década de 50, um resultado original foi apresentado pelo médico George D. Ludwig e colaboradores, do instituto de pesquisa médica naval, em Bethesda, Maryland. Eles verificaram que a velocidade de transmissão do som no tecido mole de animais estava entre $1490 \mathrm{~m} / \mathrm{s}$ a $1610 \mathrm{~m} / \mathrm{s}$, com um valor médio em torno de $1540 \mathrm{~m} / \mathrm{s}$. Este é um valor adotado ainda hoje nos equipamentos de ultrassom.

Além disso, se constatou que a frequência de varredura ideal do transdutor, para tecidos moles em animal, ficava entre $1 \mathrm{MHz}$ e $2,5 \mathrm{MHz}$. Sua equipe também mostrou que a velocidade do ultrassom e os valores de impedância acústica na interface água-tecidos, não diferem muito da água pura e que medições destas grandezas em diferentes direções não se alteram grandemente [2].

Nos anos de 1952-1953, a equipe formada pelo médico Douglass Howry, apoiado pelo nefrologista Joseph Homleso, junto aos engenheiros William Bliss Roderic e J Gerald Posakony, utilizaram o primeiro scanner linear composto que produziu imagens bi-dimensionais em modo-B (ou PPI, modo plano de indicação de posição), também conhecido como modo brilho. Assim, mostraram que imagens Bidimensionais transversais de estruturas de órgãos internos e suas alterações poderiam ser obtidas com ultrassom de modo convincente e interpretável. Demonstraram também que, com eco ultrassônico, as interfaces entre as estruturas individuais ou tecidos, como a existente entre gordura e músculo, poderiam ser delineadas. Assim, em maio de 1953 eles produziram imagens em tempo-real, usando um escaner de 15 megahertz, de tumores cancerosos de mamas. A partir daí tinham inventado a "ecografia" e seu método "echometry", sugerindo uma natureza quantitativa para investigação de tumores [2].

Em 1963, depois de dois longos anos de trabalho, uma equipe de pesquisadores formada por Joseph Holmes, Willian Wright e Ralph Eduard Meyerdirk, finalmente chegaram a um modelo de escaner inovador de múltiplos elementos composto com mecanismos de transdução de fios e potenciômetros eletrônicos. Deste modo, foi lançado comercialmente nos USA, o primeiro transdutor móvel, fixado a um braço articulado, que podia ser posicionado à mão e movido sobre a área de digitalização em várias direções pelo operador.

Deu-se inicio ao projeto mais popular na história dos transdutores de ultrassom: a do mecanismo de escaneamento por braço articulado, o que 
deu mobilidade ao transdutor e facilitou a compactação do equipamento, que era extremamente volumoso. Neste mesmo período foram desenvolvidos os "geis" que permitiram o casamento de impedância acústica e a consequente substituição dos tanques contendo água, na qual os pacientes eram submersos para realização dos exames.

No final dos anos 70, surgiram as placas de memória DRAM "Dynamic Random Access Memory" (principalmente da Intel ${ }^{\mathrm{R}}$ ) e conversores analógico-digital que aperfeiçoaram a eletrônica, mas ainda muito caros para aplicações comerciais.

Com o avanço da eletrônica computacional, o conversor de varredura analógica foi logo sendo substituído pelos conversores de varredura digital (DSC). Em 1976, Albert Waxman e outros especialista em ultrassom produziram um dos primeiros DSCs com capacidade de memória para imagens de 256 por 240 pixels. Os dados de posição e velocidade foram alimentados através de um PDP-11' ("programmed data processor" da Digital Equipment Corporation DEC), enquanto circuitos lógicos amostravam os dados do "front-end" analógico e os escreviam no lugar correto na DRAM, permitindo, ao mesmo tempo, ler os dados continuamente e exibi-los em um monitor de vídeo em tons de cinza. Daí, uma série de desenhos de equipamentos foram surgindo, entretanto, mesmo até os primeiros anos da década de 1980, ainda incorporavam todo o PDP-11 dentro do console [2].

No final da década de 80, a ultrassonografia (US) foi impulsionada pelo desenvolvimento tecnológico que a transformou num importante instrumento de pesquisa e investigação diagnóstica na área médica, oceanográfica, química, entre outras [8]. Dentre os métodos de diagnóstico por imagem, a US tem se mostrado extremamente versátil, de aplicação relativamente simples e com excelente relação custo-benefício. Suas principais peculiaridades são:

1. Um método não invasivo ou minimamente invasivo;

2. Gerar imagens seccionais em qualquer orientação espacial;

3. Não apresentar evidências de efeitos nocivos dentro do uso diagnóstico na medicina;

\footnotetext{
${ }^{1}$ PDP-11 foi uma série de minicomputadores de 16 bits fabricada pela empresa Digital Equipment Corp. nas décadas de 1970 e 1980. Foi pioneira na interconexão de todos os elementos do sistema - processador, memória RAM e periféricos - a um único barramento de comunicação, bidirecional, assíncrono. Este dispositivo, chamado Unibus permitia aos dispositivos enviar, receber ou trocar dados sem a necessidade de uma passagem intermediária pela memória. A série PDP-11 foi uma das séries de minicomputadores mais vendidas de sua época e uma das primeiras a executar o S.O Unix, desenvolvido nos Laboratórios Bell. http://ed-thelen.org/comp-hist/pdp-11.html
} 
4. Não utilizar radiação ionizante;

5. Possibilitar o estudo não invasivo da hemodinâmica corporal através do efeito Doppler;

6. Adquirir imagens em tempo-real, permitindo o estudo do movimento de estruturas corporais.

Com o avanço dos estudos, cada vez mais caracterizado pela interconexão de diferentes áreas do saber, este conhecimento tem se desenvolvido rapidamente pelo esforço de grupos de pesquisas multidisciplinares. Especificamente, a engenharia biomédica [9], que está muito ligada ao desenvolvimento da instrumentação e, em particular, à instrumentação médica, cujo progresso é necessário à interação de médicos e engenheiros, físicos, químicos, matemáticos, cientistas da computação, bioinformáticos, entre outros.

\subsection{O fenômeno sonoro}

As características do fenômeno sonoro são relacionadas à sua fonte e ao meio de propagação. Variáveis como pressão, densidade do meio, temperatura e mobilidade das partículas definem o comportamento da onda sonora ao longo da sua propagação.

Assim, o som provoca perturbações no meio material, produzindo defor-

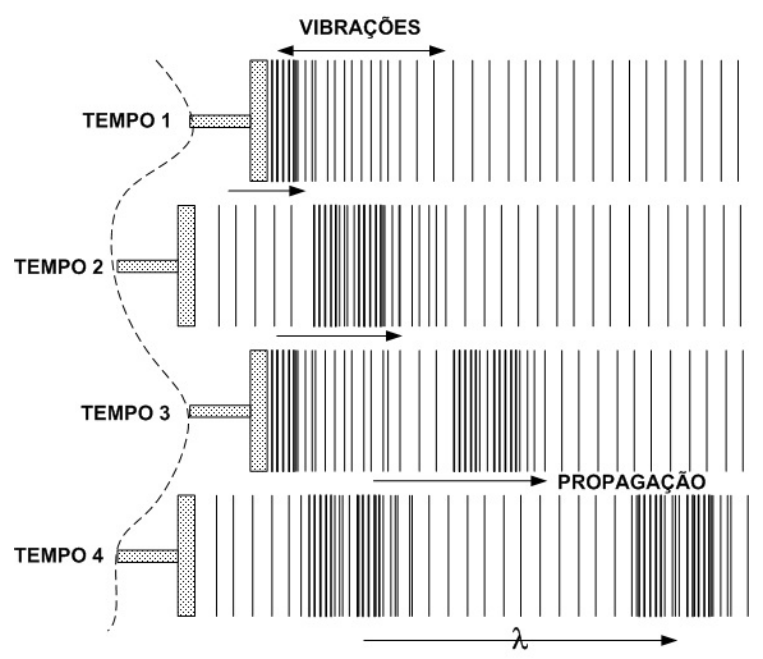

Figura 1.1: Esquema de propagação da onda sonora.

mações em relação à sua direção de propagação, com áreas de compressão 
e rarefação, conforme esquema apresentado na figura 1.1. Estas perturbações podem ser no eixo transversal ou longitudinal.

Os métodos ultrassonográficos até bem recentemente, aplicados em medicina, utilizavam apenas as ondas longitudinais - que vibram e se propagam na mesma direção.

Atualmente os transmissores e receptores de ultrassons comerciais, típicos de aplicações médicas, estão na faixa de $1 \mathrm{MHz}$ a $12 \mathrm{MHz}$ e obtém-se medições por métodos longitudinais e transversais. Nos quais, os pulsos de ultrassons, refletidos no interior do corpo, são captados e processados, podendo obter informações quanto à distância, à velocidade e à densidade do objeto refletor.

O espectro de sinais ultrassônicos está além do limite da audição humana, pois compreende as frequências acima de $20 \mathrm{kHz}$ (conforme mostra o esquema da figura 1.2).

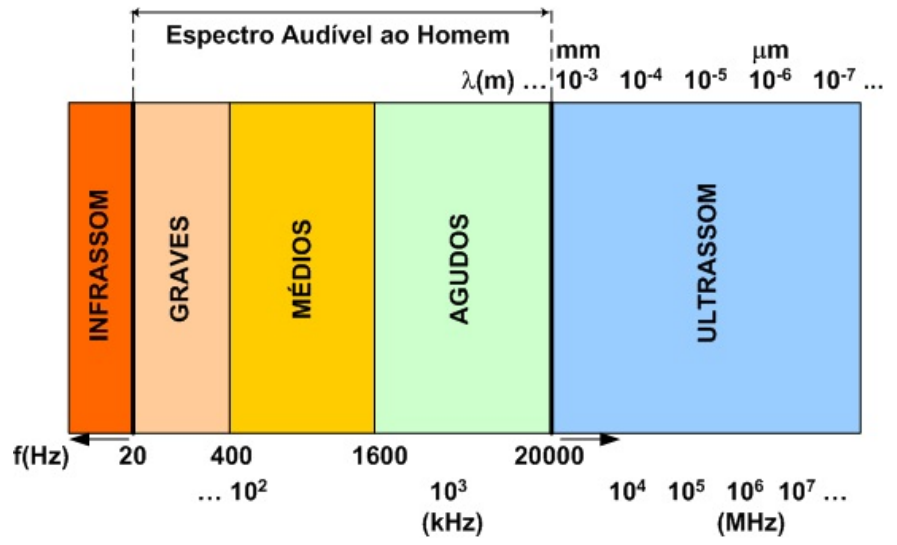

Figura 1.2: Espectro Sonoro - Faixa ultrassônica. (adaptado: http:// humanifestation. blogspot. com. br/2010/12/documentacaodiarioparte03. html). Último acesso: 08/12/2011.

O princípio que rege a utilização de ultrassons baseia-se na emissão de um pulso ultrassônico que, chegando a um objeto, retorna como um eco, cujas características possibilitam determinar a localização, tamanho, velocidade e textura deste objeto. O princípio pulso-eco refere-se à emissão de um pulso curto de ultrassom pelo dispositivo que transmite e recebe o sinal sonoro. Na medida em que este pulso atravessa os tecidos, ele é parcialmente refletido pelas interfaces e volta à fonte do sinal.

Este espalhamento pode ser simples, múltiplo ou difuso, conforme mostra a figura 1.3 . 


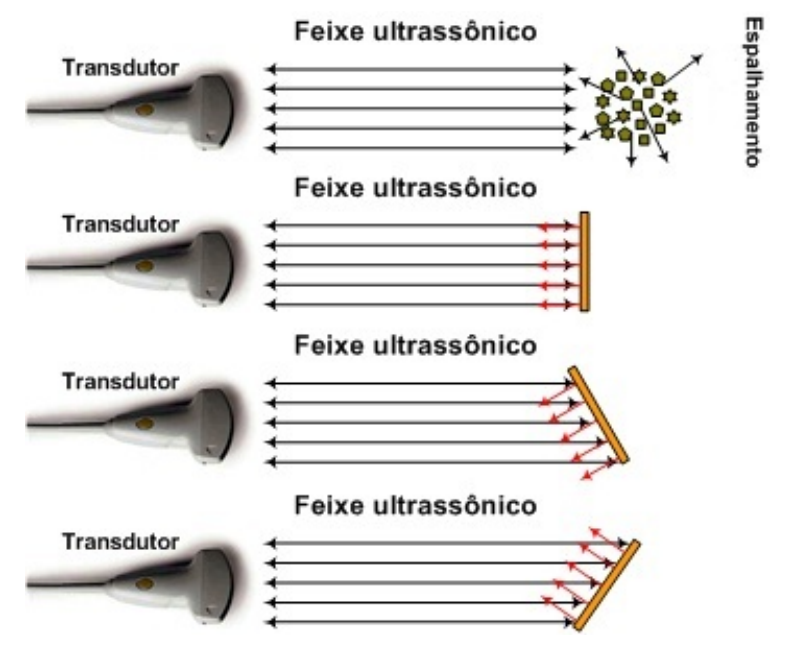

Figura 1.3: Esquema de espalhamento da onda sonora - Difusa e Especular.

Quando a reflexão é irregular, o feixe refletido se espalha por todas as direções. Isso ocorre quando o objeto é pequeno, ou a superfície é irregular. A reflexão é o elemento básico para produzir a imagem do objeto estudado. $\mathrm{O}$ ideal seria ter a onda ultrassônica retornando completamente na direção do receptor.

Assim, uma grande reflexão de energia pode ser observada nas múltiplas interfaces, como por exemplo, tecido mole-gás e tecido mole-osso devido à diferença de impedância acústica entre esses meios. Como o gás, além de sua fluidez, é muito menos denso que os tecidos moles, conduz o ultrassom com velocidade muito menor do que os tecidos moles.

Já o osso, ao contrário, possui estruturas bem localizadas e é mais denso conduzindo o som com velocidade muito maior do que as partes moles do corpo. Portanto, quando houver diferença de impedância entre os meios haverá uma interface acústica, o que propiciará espalhamentos, como ocorre por exemplo entre os meios: gordura-músculo, músculo-fáscia, tendão-periósteo, ligamento-periósteo etc.

Em geral somente uma pequena fração da energia sonora incidente é refletida na direção do receptor (menor do que $1 \%$ para a maioria das interfaces dos tecidos biológicos), o restante se espalha e continua sua trajetória através dos tecidos. Mesmo assim, esta energia que retorna ao receptor é mais do que suficiente para gerar contraste e construir uma imagem das estruturas observadas.

Os equipamentos de ultrassonografia, tanto diagnóstica quanto 


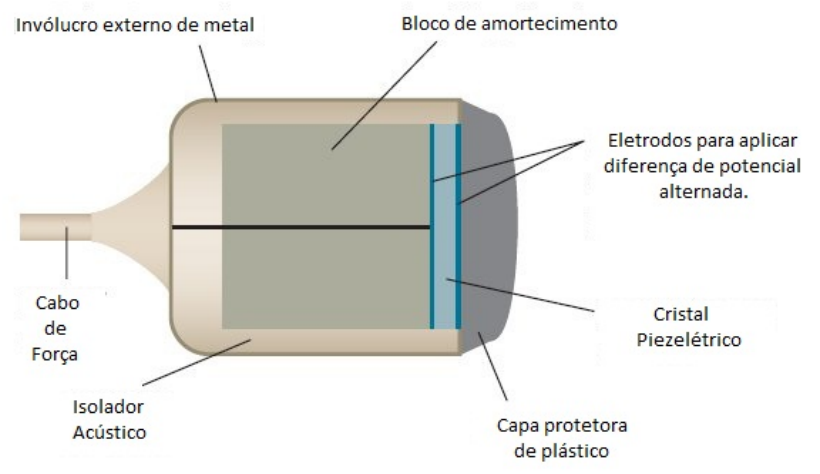

(a) Esquema de um transdutor (adaptado). [10]

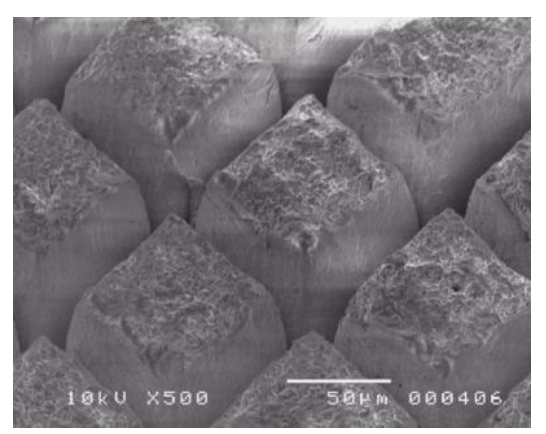

(b) Imagem "array" cerâmica. [11]

Figura 1.4: Esquema de um transdutor de Ultrassom (a) e Fotografia microscópica de uma matrix de cerâmica PZT (b).

terapêutica, possuem uma unidade básica denominada transdutor (ou sonda). Nos equipamentos de diagnóstico por imagens, esses transdutores são compostos de múltiplos sensores piezoelétricos arranjados numa matriz. A figura 1.4(a) mostra um modelo de transdutor.

Este elemento básico converte uma forma de energia em outra (elétrica-mecânica $\Leftrightarrow$ mecânica-elétrica). Os transdutores são montados de maneira a produzir e receber os ecos gerados pelas diversas interfaces. São compostos por materiais piezoelétricos (inicialmente cristais, como o quartzo, polímeros semicristalinos ou atualmente cerâmicas, como o titanato de bário - $\mathrm{BaTiO}_{3}$, titanato-zirconato de chumbo [PZT] - $\mathrm{PbTiO}_{3}$ ou fluoreto de polivinilideno [PVDF] - - $\left(\mathrm{C}_{2} \mathrm{H}_{2} \mathrm{~F}_{2}\right) n-$, figura 1.4 (b)), um aparato eletrônico (para a excitação das cerâmicas e captação dos ecos), uma lente acústica com material acoplador na parte frontal da cerâmica e por um material de amortecimento posterior (que absorve as frequências de ordens diferentes da frequência central produzida, que são inevitáveis pelo próprio processo de excitação).

Os elementos piezoelétricos que compõem os transdutores têm a capacidade de emitir pulsos elétricos quando pressionados e os mesmo transformam energia elétrica em mecânica (onda sonora), que é chamado efeito piezoelétrico inverso. São, portanto transmissores e receptores. No segundo capítulo, descreveremos com mais detalhes a forma da onda ultrassônica numa geometria específica. 


\subsection{O ultrassom e suas aplicações em sistemas biológicos}

De acordo com Lerner et al., 1990 [12], a ideia de caracterizar tecidos biológicos pelo movimento ou resposta mecânica não é nova, mas teve, inicialmente, uma avaliação limitada àqueles tumores acessíveis por apalpação. Num primeiro momento, um substancial crescimento de técnicas e estratégias de otimização, num segundo momento uma expansão de plataformas dedicadas para implementação de aplicações clínicas [13].

Segundo Ophir et al., 2002 [14], nos últimos 20 anos, inúmeros trabalhos têm focado sua investigação na caracterização das propriedades mecânicas dos tecidos biológicos, os quais são idealizados como materiais elásticos, homogêneos e isotrópicos. Estas propriedades elásticas dos tecidos moles, segundo Fung, 1993 [15], dependem de seus blocos de construções moleculares e da forma organizacional de suas estruturas, tanto microscópica quanto macroscópicas. E, estes parâmetros constitutivos do meio material não são resultados de uma medição direta.

Atualmente é sabido, conforme trabalhos apresentados por diversos pesquisadores, como, Parker 1990 [16], Fung 1993 [15], Ophir 1999 [17], Mcknight 2002 [18], Samani 2003 [19], Mofid 2003 [20], Hall 2003 [21], Gennisson 2004 [22], Miller 2005 [23], Sinkus 2006 [24], Sridhar 2007 [25], Boyer 2007 [26], Zheng 2008 [27], Vieira 2009 [28], Pavan 2010 [29] dentre outros, que a mudança na elasticidade e viscosidade de tecidos moles está sempre relacionada a alguma neoplasia ${ }^{2}$ benigna ou maligna.

Usualmente os médicos e pesquisadores apalpam esses tecidos para obter informações sobre suas propriedades mecânicas. Por exemplo, alguns tumores mamários, de fígado e próstata são detectados pela apalpação direta sobre o tecido. Todavia, em muitos casos ocorrem dúvidas sobre a malignidade destes tumores ${ }^{3}$, sendo necessário submeter os pacientes a uma biopsia ${ }^{4}$.

Os métodos de imagens comumente usados para um diagnóstico prévio da morfologia e, em alguns casos do tipo de lesão, são raios-X, tomografia

\footnotetext{
2"Neoplasia é uma proliferação anormal do tecido, que foge parcial ou totalmente ao controle do organismo e tende à autonomia e à perpetuação, com efeitos agressivos sobre o hospedeiro" (Pérez-Tamayo, 1987; Robbins, 1984).

${ }^{3}$ [São classificados segundo as categorias BI-RADS ${ }^{\mathrm{R}}$ (breast imaging reporting and data system) 3, 4 (A, B ou C)]. [30]

${ }^{4}$ Obtenção de uma amostra de tecido de um organismo vivo para fins diagnósticos. Remoção e exame de tecido de um organismo vivo para diagnosticar anomalias estruturais e funcionais. [dicionário médico: http: //www.xn-dicionriomdico-Ogb6k.com/display ·php?action=search\&word=biopsia].(último acesso: 18/02/2010).
} 
computadorizada, ressonância magnética e ultrassom. Assim, as técnicas atuais que geram imagens dos tecidos, como relaxometria por ressonância magnética, vibro-acustografia, elastografia etc, tem ainda oferecido pouca informação quantitativa sobre a mudança das propriedades mecânicas (rigidez) dos mesmos em função de suas origens patológicas ${ }^{5}$, embora, tenha tido um progresso ascendente à medida que ocorre o avanço tecnológico dos equipamentos de ensaios e processamento de sinais. Entretanto, as imagens das propriedades elásticas dos tecidos moles têm se tornado um importante e crescente foco de pesquisas visando obter uma avaliação mais precisa neste tipo de exame, sem a necessidade de submeter os pacientes ao processo invasivo da biópsia.

No caso do ultrassom, como dito anteriormente, busca-se, através da interação do som com os tecidos, observar suas propriedades mecânicas, a partir de diferentes abordagens. Por exemplo, enquanto os "sonogramas" transmitem informações relacionadas a energia de espalhamento acústico, os "elastogramas" buscam descrever deformações locais, módulo de elasticidade ou razão de Poisson [14]). Assim, diferentes métodos ultrassônicos têm sido propostos.

Na sonoelastografia de amplitude vibracional ou sonoelasticidade segundo Lerner et al., 1990 [12], uma vibração de baixa frequência, entre $20 \mathrm{~Hz}$ e 1000 $\mathrm{Hz}$, é aplicada externamente para produzir vibrações internas no tecido em estudo.

Deste modo, uma região com uma dureza não homogênea, circundada por um tecido mais mole produzirá distorções nos padrões dos modos normais de vibração. E, utilizando um algoritmo de deteção Doppler é possível visualizar, em tempo-real, imagens de vibração que podem trazer informações sobre a velocidade das ondas transversais do som no tecido. No final dos anos 90, usando técnicas de análise de elementos finitos e imagens experimentais, Lerner R. M e Parker K. J., mostraram que regiões com alto valor de dureza poderiam ser detetadas usando um transdutor Doppler convencional.

Uma outra variação da sonoelastografia é a de gradiente de vibração de fase, que segundo Yamakoshi e colaboradores, 1990 [31] é uma técnica que

\footnotetext{
${ }^{5}$ Patologia vem do grego páthos, doença, e lógos, estudo, tratado. Etimologicamente, portanto, significa estudo das doenças através de exame de órgãos, tecidos, fluidos corporais, e corpos inteiros (autópsias). A Patologia também abrange o estudo científico dos processos relacionados com a doença, chamada de patologia geral, na tentativa de explicar as razões e a localização dos sinais e sintomas manifestos pelos pacientes, fornecendo uma base para os cuidados clínicos e terapêuticos. Não deve, entretanto, ser usado como sinônimo de doença, apesar do desvio semântico (BECKER, Idel - Nomenclatura biomédica no idioma português do Brasil. São Paulo, Liv. Nobel, 1968.). News Medical - http://www.news-medical.net/health/Pathology-What-is-Pathology-\%28Portuguese\%29.aspx, e Portal Educação - http://www.portaleducacao.com.br/veterinaria/artigos/4054/o-que-e-patologia. (último acesso 07/08/2011).
} 
mapeia a fase e a amplitude, em baixas frequências, da propagação da onda dentro do tecido. E a partir deste mapa, é possível derivar as propriedades de dispersão e velocidade de propagação da onda. Com estes parâmetros calcula-se as características viscoelásticas do tecido.

Em 1990, Sugimoto et al. [32] explorando os efeitos de segunda ordem produzido pela absorção de energia, de uma força de intensidade localizada (o qual denominou força de radiação), quando da propagação do feixe de ultrassom num meio, desenvolveu um sistema que aplica esta força e mede o resultado do deslocamento com uma sonda ultrassônica.

Através da curva de deslocamento em função do tempo de relaxação e ajustes exponenciais, foi possível estabelecer um modelo das propriedades mecânicas do meio em estudo. Este método foi denominado de vibroacustografia por força de radiação. Em 1998, Fatemi e Greenleaf [33] aperfeiçoaram a técnica usando a estratégia de duas frequências com foco coincidentes e criaram imagens da resposta do tecido.

O uso de "força de radiação acústica - $A R F$ " para excitação mecânica de materiais "moles" tem sido largamente explorado para estudos das propriedades mecânicas dos materiais de forma não invasiva, conforme estudos apresentados por diversos autores, como Fatemi and Greenleaf, 1998 [33]; Nightingale et al., 2001 [34]; Chen et al., 2002 [35] e Baggio, 2011 [36]. Todavia, este método tem tido uma aplicação limitada e vem sendo dedicado à avaliação de micro-calcificação em mama.

As "imagens por força de radiação acústica - ARFI", bem como outras técnicas baseadas em ARF (como a SMURF - spatially modulated ultrasound radiation force), têm a vantagem de poder focar o sistema em qualquer órgão e seus pulsos curtos não produzem efeitos biológicos prejudiciais e duradouros (produz aquecimento), contudo, possui a desvantagem de seu efeito ser relativamente fraco, ou seja, necessita de uma alta intensidade do sinal para que se observe o deslocamento do tecido.

Esta energia média temporal é superior ao recomendado para tecidos biológicos $\left(720 \mathrm{~mW} / \mathrm{cm}^{2}\right.$, para US diagnóstico), conforme estudos apresentados por Ulrich, 1974 [37]; gráficos H.12, I.13 e "FDA - Food and Drug Administration, USA - 1998", vide tabelas F.6 e G.7, em anexo.

A elastografia por compressão, segundo Ophir et al., 1991, 2001 [38, 39], é um método de aquisição de imagens através da emissão e recepção de ondas 
curtas de som (ultrassonografia - US), usando uma pequena compressão e descompressão (força ou carga) quase-estática (ou dinâmica) sobre o tecido. Representa a medida da taxa de deformação interna dos tecidos, quando estes são submetidos a uma tensão mecânica. Se algum tecido tiver rigidez diferente dos demais, então a sua deformação pode ser maior ou menor que o restante do meio avaliado. Se for mais rígido, a deformação será menor.

As Imagens elastográficas convencionais são geradas usando análises paramétricas de similaridades entre dois mapas de ecos dos campos de resposta ultrassônica (Response Field - $R F$ ) adquiridos antes e após a compressão dos tecidos. A imagem elastográfica corresponde então à derivada da medida dos deslocamentos obtidos a partir da medida do atraso temporal entre os ecos ultrassônicos. Este atraso temporal é devido à perturbação mecânica aplicada na região de interesse (region-of-interest - ROI) [40, 41].

O método convencional para gerar imagens elastográficas "in vivo" é pressionando o transdutor manualmente, conforme apresentado por Ophir, Hall e colaboradores 1999, 2003 [17, 21]. Este método manual proporciona o aumento do ruído (signal-to-noise ratio - $\mathrm{SNR}_{e}$ ) devido à instabilidade do transdutor durante a aquisição dos mapas de ecos.

A elastografia, segundo Parker, 2011 [13], também pode ser realizada usando imagens de ressonância magnética (MRI), apesar de ter um tempo de aquisição maior, algo em torno de 15 min por direção, tem se mostrado eficiente para deteç̧ão e diagnóstico diferencial no câncer de mama, monitoramento de técnicas terapêuticas minimamente invasivas e caracterização de propriedades mecânicas do cérebro, dentre outras vantagens, como mostram os trabalhos de Manduca, 1996 [42]; Oliphant, 2001 [43]; Oliphant et al., 2002 [44] e Vieira, 2009 [28]. Entretanto, a MRI é muito mais cara do que ultrassom e ainda não traz um boa relação custo-benefício.

Assim, teoricamente, qualquer sistema que produza imagens em fatias (tomográficas) e permita traçar o movimento do meio, pode levantar alguma propriedade biomecânica do tecido. Contudo, Parker, 2011 [13] ressalta que todos os métodos, seja de compressão ou vibração, quando aplicados em testes clínicos de lesões em próstata e mamas, estão sujeitos a apresentar falsos-positivos numa taxa em torno de $20 \%$.

Um modo de compreender qualitativamente o princípio da elastografia convencional, parte por considerar um pequeno sistema mecânico de três molas 


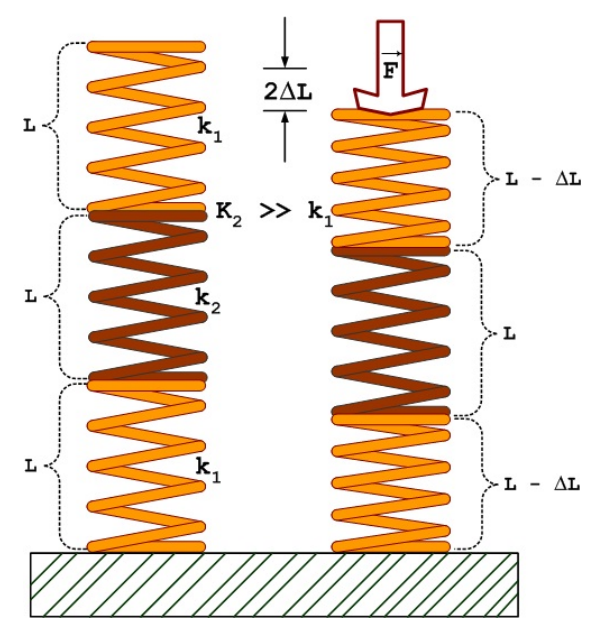

Figura 1.5: Esquema de três molas conectadas antes e após a aplicação de uma força sobre elas. A mola central de constante elástica muito maior que as demais, representa um tecido mais rígido e praticamente não deforma com a aplicação da força (adaptado Ophir, 1991) [38].

acopladas, representando diferentes camadas do tecido humano, como mostra a Figura 1.5.

Estas três molas são presas em sequência, sendo o tecido mais rígido representado pela mola central, que possui uma constante elástica maior que as outras duas molas das extremidades. Pode-se imaginar que esta mola representa a lesão no interior do tecido, sendo o tecido circundante normal representado pelas outras duas molas, menos rígidas.

Quando uma força externa é aplicada neste conjunto de molas, como acontece no exame de elastografia, as molas laterais sofrem uma deformação maior do que a mola central.

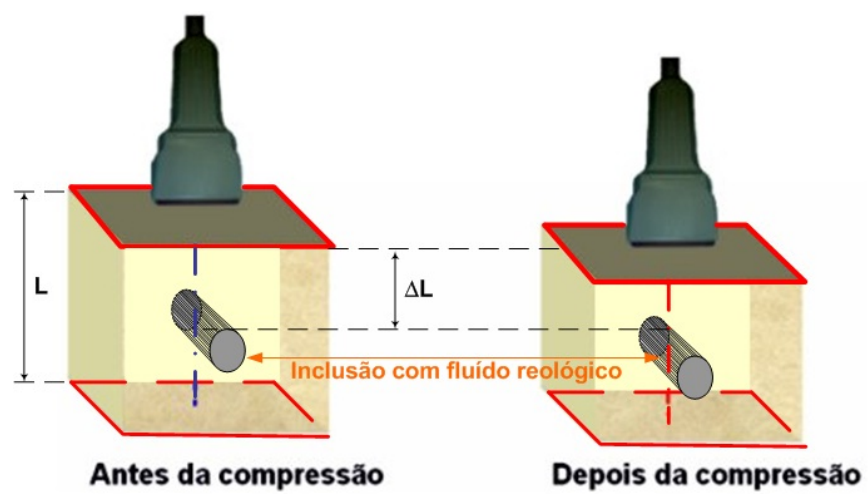

Figura 1.6: Esquema de deformação em meios com diferentes propriedades mecânicas.

De modo paralelo e análogo tomemos um bloco representando um 
material que simula o tecido humano, em cujo interior está um cilindro que simula um tumor, que é mais rígido que o tecido não tumoral no seu centro, conforme está representado na figura 1.6.

Analogamente às molas mostradas na figura 1.5, essa lesão apresenta menor deformação que o restante da estrutura, após a compressão. Nesse caso, o material mais rígido, da figura 1.6, representa a mola mais rígida da figura 1.5, e desta forma, após a compressão, o cilindro está mais próximo ao transdutor de ultrassom. Fazendo com que o eco no caso pós-compressão chegue mais rápido em relação ao pré-compressão, conforme mostra o esquema da figura 1.7.

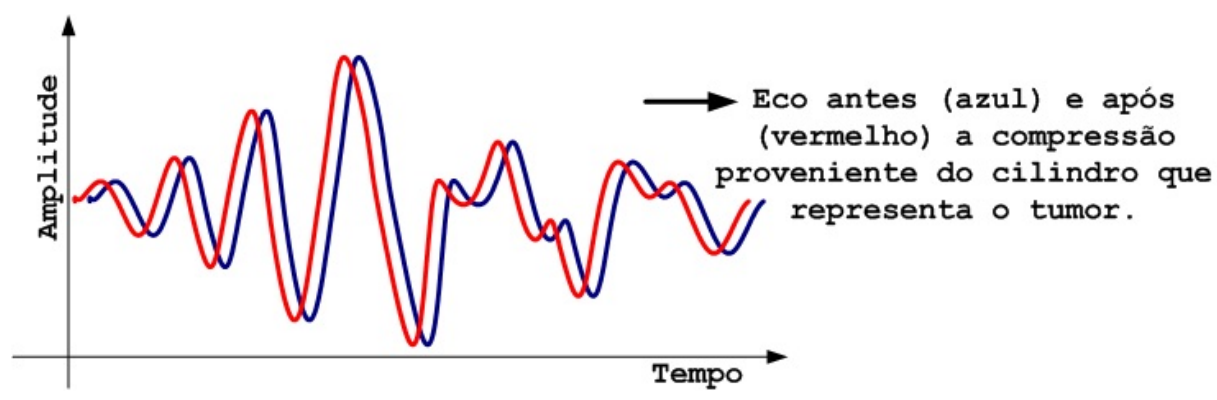

Figura 1.7: Segmento de um eco antes e após a deformação apresenta uma defasagem temporal.

Deste modo, ao se aplicar uma pequena tensão ("stress") sobre o meio material suficiente para deformá-lo ("strain"), pode-se medir o quanto a estrutura deslocou-se. Basta apenas verificar a diferença temporal na resposta entre a onda emitida e a recebida (eco).

Sabendo-se a velocidade de propagação da onda no meio, é possível estabelecer o deslocamento medindo a diferença de fase entre os ecos do meio antes e após aplicação da deformação. E, ao analisar os parâmetros, velocidade e a atenuação da amplitude do eco pode-se extrair as propriedades mecânicas (como elasticidade e viscosidade) do meio material em estudo.

Quando o meio é deformado, os intervalos de tempo ( $\delta \mathrm{t})$ entre os picos de ecos que retornam do tecido também são deslocados. Assim, através de algoritmos matemáticos dedicados que processam os sinais, estimam-se essas variações temporais entre os seguimentos axiais de dois ou mais ecos adquiridos antes e após a deformação.

Este intervalo de tempo é estimado deslocando um dos ecos em passos pré-definidos e comparando um com o outro. Quando este deslocamento coincidir com o sofrido pelas estruturas internas do tecido, tem-se a máxima 
correlação entre os dois sinais e, consequentemente, a medida deste intervalo.

Assim, o deslocamento interno corresponde ao produto da velocidade da onda ultrassônica no tecido biológico com o intervalo de tempo medido. A Figura 1.8 representa detalhes deste procedimento matemático.

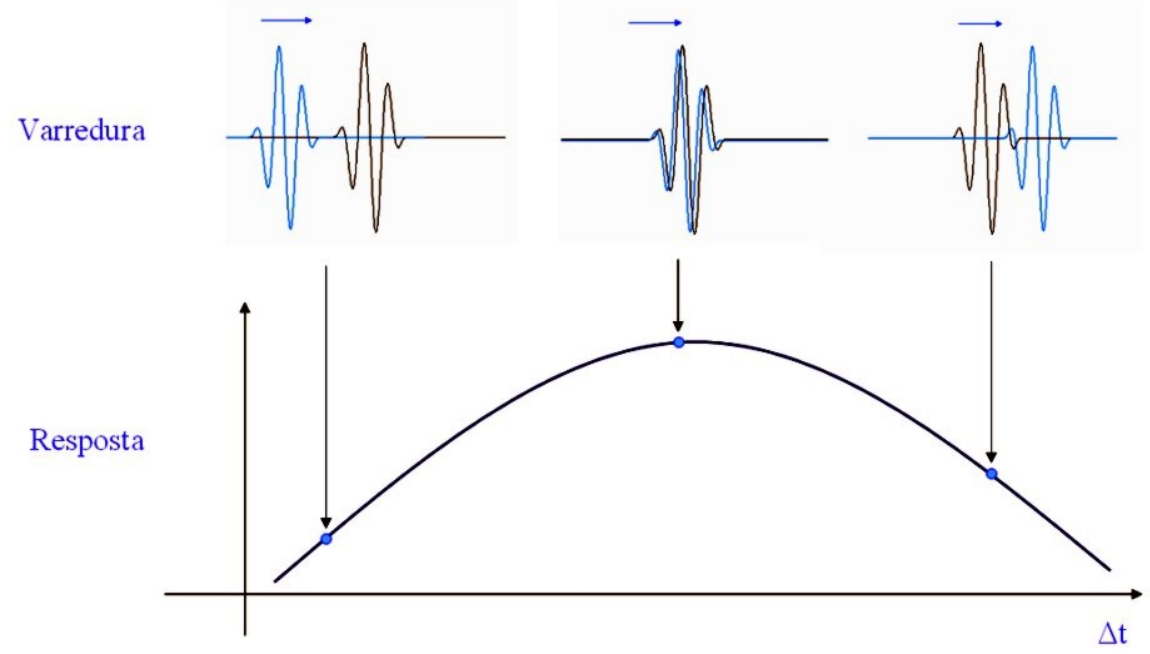

Figura 1.8: Gráfico mostrando pico de correlação entre ecos.

Um algoritmo matemático comumente utilizado para medir as variações temporais $(\delta t)$ entre dois mapas de ecos é denominado de "correlação cruzada" [45]. Enquanto outro algoritmo para detetar movimento, utilizado em elastografia, é conhecido como "Block Matching"6, que é uma ferramenta muito utilizada em computação para detecção de movimentos em imagem, como pode ser visto no trabalho de Neves, 2007 [46]. Esse procedimento é mais conhecido por ser aplicado em técnicas de compressão de vídeo como o formato MPEG ("Moving Picture Experts Group").

Para testar e validar os pressupostos teóricos faz-se necessário a construção de um objeto simulador de tecido, comumente chamado na literatura de "phantom ou fantoma". Assim, neste trabalho, foi construído um "phantom" de treinamento e controle elastográfico por ultrassom composto de um material sintético, com propriedades mecânicas e acústicas equivalente ao tecido biológico. Além disso, inserimos uma inclusão preenchida com fluído magnético reológico $(\mathrm{FMR})^{7}$. A presença deste fluído é uma característica diferencial deste

\footnotetext{
${ }^{6}$ O algoritmo de "Block Matching" consiste em comparar regiões dos mapas de eco obtidos antes da deformação com regiões de mesmo tamanho do mapa depois da deformação.

${ }^{7}$ Material que sob ação de um campo magnético tem suas propriedades viscoelásticas alteradas de forma rápida e reversível.
} 
produto com relação ao recentemente lançado no mercado internacional por uma empresa americana $\mathrm{CIRS}^{\mathrm{R} 8}$.

Com o uso de fluído magnético, poder-se-á modificar a rigidez da inclusão aplicando-se um campo magnético externo. Desta forma, poderá gerar diferentes níveis de rigidez em uma mesma inclusão. Além de proporcionar a calibração de um protocolo de imagem em um equipamento de ultrassom, o diagnóstico também proporcionará a habilidade de observar diferentes contrastes na imagem elastográfica sem a necessidade de deslocar o transdutor.

Neste contexto, este trabalho focará na técnica de elastografia por ultrassom, que consiste essencialmente em medir a taxa de deformação interna dos tecidos quando estes são submetidos a uma tensão mecânica, além de buscar a caracterização de um aparato instrumental, composto de agentes mecânicos, eletrônicos, computacional e de software, aplicando um sistema de ultrassom acoplado a um dispositivo convencional de medidas, para avaliar o comportamento viscoelástico de alguns materiais que tem propriedades próximas dos tecidos moles, que poderão ser utilizados para comparação e análise de tecidos moles "in vivo".

\subsection{Justificativa}

O Grupo de Inovação em Instrumentação Médica e Ultrassom (GIIMUS) desta instituição desenvolve pesquisas sobre os métodos elastográficos envolvendo técnicas ultrassônicas e magnéticas. Estes estudos estão sendo feitos em colaboração com o grupo de ultrassom da Mayo Clinic, Rochester, USA; com o grupo de ultrassom da University of Wisconsin, Madison, USA e com o grupo de Biomagnetismo da Universidade de São Paulo, campus de Ribeirão Preto.

Do histórico apresentado, nos motiva buscar o desenvolvimento e caracterização de um produto nacional com inovação tecnológica que possibilite a identificação de variações mecânicas nos tecidos biológicos provenientes de uma lesão, de modo não invasivo. Isto, além de trazer consigo inúmeras vantagens, tornar-se um passo importante para a criação de um novo módulo a ser acoplado aos sistemas de ultrassom convencionais. Possibilitando o desenvolvimento de um produto tecnológico de interesse comercial.

\footnotetext{
${ }^{8}$ Computer Imaging Reference Systems, Inc. Tissue Simulation \& Phantom Technology. (http://www.cirsinc. com/products? show=all\&id=44. último acesso: 08/08/2011).
} 


\subsection{Objetivos}

Este trabalho teve como objetivo geral desenvolver e caracterizar um sistema que permita avaliar e classificar as variações biomecânicas de simuladores de tecidos moles, especificamente a rigidez (módulo de Young). Para tal, foram aplicados deslocamentos mecânicos de forma estática e dinâmica e efetuadas medições da deformação das estruturas internas das amostras por ultrassom pulso-eco.

Como objetivos específicos para mostrar a viabilidade técnica se destaca:

1. Montar e caracterizar um sistema de avaliação de rigidez em estruturas internas de amostras semi-fluidas (simuladores de tecidos biológicos moles) usando força estática e/ou dinâmica, e, medições do deslocamento das estruturas internas da amostra usando um Ultrassom monocanal (pulse-receiver);

2. Acoplar um transdutor linear de ultrassom de diagnóstico por imagem, a um vibrador mecânico de baixa frequência para que a deformação aplicada aos tecidos sejam regulares e independente do movimento da mão do operador;

3. Construir e analisar de simuladores de tecido biológicos moles com inclusões marcadas com fluido magnético reológico;

4. Avaliar a mudança de rigidez, nas inclusões com material reológico, quando na presença de campo magnéticos estáticos.

\subsection{Estrutura dos Capítulos}

No primeiro capítulo apresentamos um breve histórico da evolução do ultrassom e suas diversas aplicações, bem como alguns conceitos básicos envolvidos na técnica.

No segundo capítulo apresentaremos um estudos dos conceitos aplicados na construção teórica dos temas correlatos, tais como elasticidade, viscosidade, tensão, deformação, atenuação, modelo de tecidos, onda acústica etc. Assim, os leitores mais experientes poderão avançar sem prejuízo na compreensão dos métodos e resultados apresentados nos demais capítulos.

No terceiro capítulo descreveremos a parte instrumental dos equipamentos, métodos e resultados experimentais da construção dos protótipos envolvidos na caracterização dos meios analisados. 
No quarto capítulo faremos uma discussão dos resultados e seus desdobramentos.

No quinto capítulo finalizamos com as conclusões e sugestões para trabalhos futuros. 


\section{Capítulo}

\section{Estado da arte - Fundamentos Teóricos}

Quase totalidade dos materiais usados na confecção de produtos de
utilidade humana, em diferentes áreas, são submetidos a forças ou cargas, estáticas e/ou dinâmicas, sendo necessário conhecer suas características mecânicas. Dentre estas, os módulos elásticos, para se ter noção da deformação resultante a fim de prever o ponto de ocorrência das deformações plásticas, fadiga acelerada ou mesmo uma ruptura. E, os módulos viscosos para compreender de que maneira o meio resiste ao escoamento (fluidez).

O comportamento mecânico de um material depende em grande medida de sua resposta (ou deformação) à carga ou força à que é submetido. A propriedade que correlaciona a deformação elástica com a tensão é o módulo elástico, que terá diferentes definições dependendo do tipo de esforço aplicado.

A medição das propriedades mecânicas é realizada através de experimentos de laboratório cuidadosamente programados, de acordo com condições regidas por normas. No caso específico dos módulos elásticos, os métodos empregados podem ser dinâmicos, através de vibrações com diminutas amplitudes de deformação, ou estáticos, que submetem o corpo de prova a uma tensão conhecida e simultaneamente mensuram a deformação induzida. Estes ensaios podem ser conduzidos tanto em temperatura ambiente, ou outras, com ou sem atmosfera controlada [47].

O conhecimento dos módulos elásticos é objeto da atenção de diversos profissionais, com necessidades e aplicações diferenciadas. Deste modo, é necessário que haja uma padronização na maneira segundo a qual os ensaios são conduzidos e na interpretação de seus resultados. Esse procedimento é obtido com uso de técnicas de ensaio padronizadas. O estabelecimento e a publicação dessas normas padrão são frequentemente coordenados por sociedades profissionais.

No Brasil a ABNT (Associação Brasileira de Normas Técnicas), nos 
Estados Unidos a ASTM (“American Society for Testing and Materials”), na Alemanha temos a DIN ("Deustsches Institut für Normung"), BSI ("British Standards Institution") na Inglaterra, ECSIS ("European Comitte for Iron and Still Standartization") recente comunidade Europeia, entre outras, são responsáveis pela padronização dos ensaios de materiais.

Segundo Fung, 1993 [15], a fonte de elasticidade dos tecidos está associada a mudanças na energia interna e na entropia. Assim, aqueles meios elásticos constituídos por moléculas longas, flexíveis e interligadas, como os tecidos biológicos, formando extensas malhas tridimensionais, trocam contínua energia térmica que as mantém em movimento constante.

Os tecidos moles como pele, fígado, rins, mama, próstata, pulmão etc. são compostos por muitas estruturas interconectadas que desempenham uma função específica dentro de um organismo, deste modo, quando submetido a uma tensão ("stress"), segundo Vacalebri et al., 2003 [48], pode ter uma resposta mecânica indesejável que não descreve corretamente o comportamento de seus constituintes, pois suas estruturas podem apresentar não linearidade para as medidas viscoelásticas, histereses e pré-condicionamentos. Assim, do ponto de vista da biomecânica, os experimentos para determinar as propriedades mecânicas dos tecidos devem estar fundamentadas em equações que representem a constitutividade do meio.

As medidas de rigidez ou tensão de tecidos moles são usadas para detectar e ou classificar tumores [49], micro-calcificações [50] apresentando resultados bem sucedidos em músculo, próstata e mama. Baseada no princípio da apalpação a elastografia foi inicialmente proposta para detecção de tumores dentro de tecido normal, que neste caso, apresentam rigidez entre 5 a 28 vezes maior que em um tecido sadio.

Há diferentes métodos para produzir deformações nas estruturas mecânicas dos tecidos moles. Uma maneira seria provocar variações de tensão em volumes reduzidos e bem localizados, oferecendo assim informações viscoelásticas em cada ponto (voxel) da amostra. Outra mais simples e aplicada desde os primeiros ensaios elastográficos é usar uma fonte externa de força para produzir uma distribuição de força estática ou dinâmica ao longo de toda a superfície da amostra. Este segundo procedimento foi adotado neste trabalho e apresentaremos com mais detalhes no decorrer dos capítulos. 


\subsection{Teoria da Viscoelasticidade}

Como introduzido anteriormente, os módulos elásticos e viscosos de um meio são parâmetros fundamentais para a engenharia e aplicação de materiais, uma vez que estão ligados à descrição de várias outras propriedades mecânicas, como, a tensão de ruptura, a tensão de escoamento, fator de amortecimento (dissipação energia - atenuação), a variação de temperatura crítica para a propagação de fissuras sob a ação de choque térmico, etc. Estas são propriedades intrínsecas dos materiais que descrevem a relação entre tensão e deformação no regime elástico e/ou viscoso, e que dependem da sua composição química, microestrutura e energia [51].

\subsubsection{Elasticidade}

No caso de materiais isotrópicos, em que as propriedades não dependem da direção em que são medidas, os módulos fundamentais são:

1. Módulo de elasticidade ou módulo de Young (uniaxial - Y): é uma grandeza que é proporcional à rigidez de um material quando este é submetido a uma tensão externa de tração ou compressão, conforme esquema da figura 2.1 .

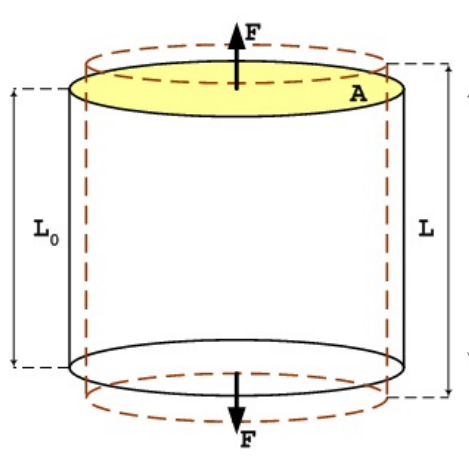

(a) Tração.

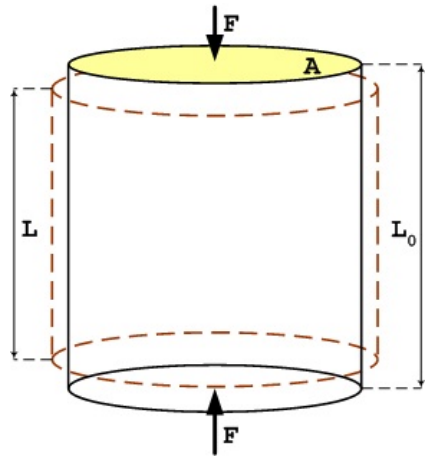

(b) Compressão.

Figura 2.1: Esquema apresentando esforços de tração (a) e Compressão (b).

Basicamente, é a razão entre a tensão ( $\sigma$ - "stress") aplicada e a deformação ( $\varepsilon$ - "strain") sofrida pelo corpo, isto quando o comportamento é linear, como mostra a equação 2.1:

$$
\mathrm{Y}=\frac{\sigma}{\varepsilon}
$$


em que:

Y = Módulo de elasticidade ou módulo de Young [Pa],

$\sigma=$ Tensão aplicada [Pa],

$\varepsilon=$ Deformação elástica longitudinal [adimensional].

2. Módulo de cisalhamento G: a tensão de cisalhamento relaciona-se com um sistema de forças aplicadas paralelamente a uma superfície, com o objetivo de causar o deslizamento de planos paralelos uns em relação aos outros, conforme mostra a figura 2.2.

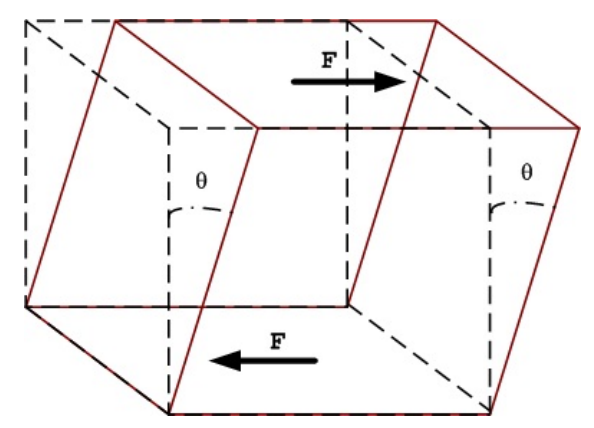

Figura 2.2: Esquema mostrando tensão cisalhante $\gamma$.

No caso, a deformação de cisalhamento, $\gamma$, pode ser calculada pela tangente do ângulo $\theta$. Então, o módulo de cisalhamento pode ser definido pela equação 2.2:

em que:

$$
\mathrm{G}=\frac{\tau}{\gamma}
$$

$\mathrm{G}=$ Módulo de cisalhamento $[\mathrm{Pa}]$,

$\tau=$ Tensão cisalhante $[\mathrm{Pa}]$,

$\gamma=$ Deformação elástica de cisalhamento [adimensional].

3. O módulo volumétrico, $\mathbf{K}$, descreve a elasticidade volumétrica, ou a tendência de um objeto se deformar em todas as direções quando submetido uniformemente a um carregamento multidirecional, conforme mostra a figura 2.3.

Esse módulo é definido como a tensão volumétrica $(\Delta P)$ sobre a deformação volumétrica $\left(\Delta \mathrm{V} / \mathrm{V}_{0}\right)$, como expresso pela equação 2.3 , e 


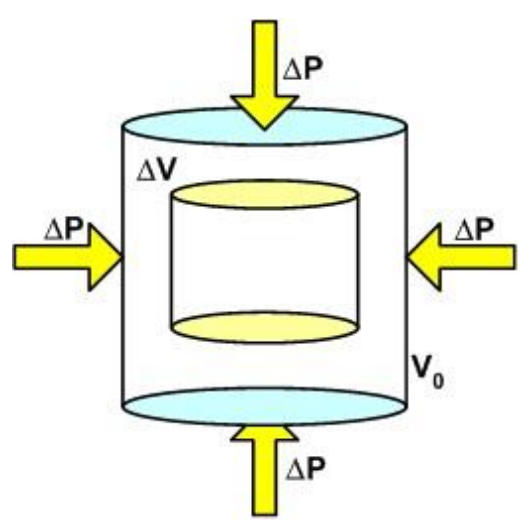

Figura 2.3: Esquema mostrando tensão volumétrica.

representa o inverso da compressibilidade.

em que:

$$
\mathrm{K}=-\frac{\Delta \mathrm{P}}{\Delta \mathrm{V} / \mathrm{V}_{0}}
$$

$\mathrm{K}=$ Módulo Volumétrico [Pa],

$\Delta \mathrm{P}=$ Diferença de Pressão [Pa],

$\Delta \mathrm{V} / \mathrm{V}_{0}=$ Deformação volumétrica [adimensional]

4. A Razão de Poisson, v, mede a deformação transversal, em relação à direção longitudinal de aplicação da carga, de um material homogêneo e isotrópico, conforme mostra o esquema da figura 2.4 .

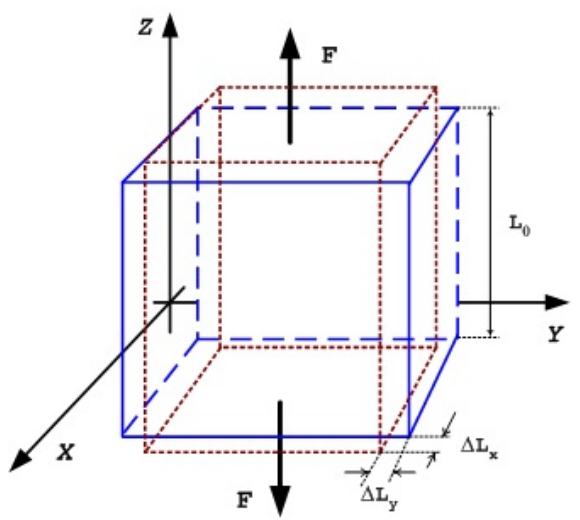

Figura 2.4: Sistema referencial apresentando deslocamento transversal em " $x$ " e " $y$ ".

No caso da razão de Poisson, a relação estabelecida não é entre tensão e deformação, mas sim entre deformações ortogonais, como mostra a equação 2.4 .

$$
v=-\frac{\varepsilon_{x}}{\varepsilon_{z}}=-\frac{\varepsilon_{y}}{\varepsilon_{z}},
$$


em que:

$v=$ Razão de Poisson (adimensional),

$\varepsilon_{x}=$ Deformação na direção $x$, que é transversal a carga aplicada,

$\varepsilon_{y}=$ Deformação na direção $y$, que é transversal a carga aplicada,

$\varepsilon_{z}=$ Deformação na direção $\mathrm{z}$, que é a longitudinal a carga aplicada,

$\varepsilon_{x}, \varepsilon_{y}$ e $\varepsilon_{z}$ são também grandezas adimensionais.

O sinal negativo na equação 2.4 é adotado porque as deformações transversais e longitudinais possuem sinais contrários. Os materiais convencionais se contraem transversalmente quando esticados na direção longitudinal e se alongam transversalmente quando comprimidos longitudinalmente.

Segundo Lakes, 2004 [52], os biomateriais típicos e materiais que imitam tecidos ('fantomas'), tem a velocidade das ondas de pressão muitas vezes maior que a velocidade das ondas elásticas transversais. Isto é, a velocidade longitudinal, para alguns tecidos mole é da ordem de $1500 \mathrm{~m} / \mathrm{s}-1580 \mathrm{~m} / \mathrm{s}$, enquanto, a velocidade transversal é da ordem de $0,5 \mathrm{~m} / \mathrm{s}-20 \mathrm{~m} / \mathrm{s}$. [53] e [54].

Assim, a grande maioria dos tecidos biológicos são aproximadamente incompressíveis com um coeficiente de Poisson que varia entre $0,49<$ $v<0,5$. [55]. Todavia, devido a complexidade em descrever e analisar a propagação das ondas em meios materiais, busca-se aproximações em modelos de líquidos ideais e sólidos isotrópicos e homogêneos. Segundo Cobbold, 2007 [56]; a análise da propagação infinita de ondas através dos meios materiais é conduzida com a introdução e duas constantes elásticas denominadas de coeficientes de Lamé (G. Lamé, 1852)1. Que, segundo Fung, 1993 [15], possuem valores distintos a depender do tecido biológico.

Se considerarmos materiais isotrópicos e o fato de que o coeficiente de Poisson para tecidos moles é muito próximo de $v=1 / 2$, além de condições de incompressibilidade constante ou divergência nula, vide trabalho de Vieira, 2009 [28], pode-se mostrar que o módulo de Young está associado ao módulo de cisalhamento e a razão de Poisson pela expressão:

$$
Y=2 \cdot G(1+v) \text {, }
$$

\footnotetext{
${ }^{1}$ Gabriel Léon Jean Baptiste Lamé, matemático francês [1795 - 1870].
} 
Enquanto o módulo de Young, o módulo volumétrico e a razão de Poisson, pela expressão:

$$
\mathrm{Y}=3 . \mathrm{K}(1-2 . v),
$$

Contudo, alguns materiais são elasticamente anisotrópicos, como os tecidos biológicos, que são assumidos também como hiperelásticos, ou seja, materiais elásticos altamente deformáveis. Isto possibilita a criação de novas relações constitutivas a fim de modelar o comportamento não-linear destes tipo de materiais. Ou seja, o comportamento elástico [magnitude do módulo de Young (Y)] varia de acordo com a direção cristalográfica.

Para esses materiais, as propriedades elásticas são completamente caracterizadas, se somente se, especificar valores diversos de constantes elásticas. E o número destas depende das características estruturais. Normalmente estes modelos são descritos com base na energia potencial armazenada no material devido a uma deformação aplicada. E, dentre as várias representações semi-empíricos, para descrever seu comportamento, o modelo Veronda-Westman, 1970 [57], para a deformação hiperelásticos é um exemplo de modelagem que utiliza uma expansão exponencial para obter o parâmetro de não linearidade de um meio material.

Este modelo traz uma boa relação entre precisão e complexidade e também tem a vantagem de ter apenas dois parâmetros independentes a ser determinado. [58]. Mesmo para os materiais isotrópicos, pelo menos duas constantes devem ser dadas para que se tenha a caracterização completa das propriedades elásticas.

\subsubsection{Caracterização da Elasticidade}

Os módulos elásticos podem ser caracterizados por métodos quase-estáticos e/ou dinâmicos. Nos métodos quase-estáticos aplica-se uma carga lentamente e simultaneamente monitora-se a deformação induzida. A carga, que pode ser estática ou se alterar de maneira relativamente lenta ao longo do tempo, é aplicada uniformemente sobre uma secção reta (A) ou superfície de um corpo, e a deformação ( $\varepsilon$ - "strain") é medida e relacionada ao módulo elástico que pode ser o módulo de Young ou cisalhamento dependendo do tipo de ensaio. Para a figura 2.5 temos o módulo de Young de compressão.

A deformação ( $\varepsilon$ - "strain") de um corpo depende da magnitude da tensão $(\sigma$ - "stress") a qual ele é submetido. Para, a maioria dos materiais, 


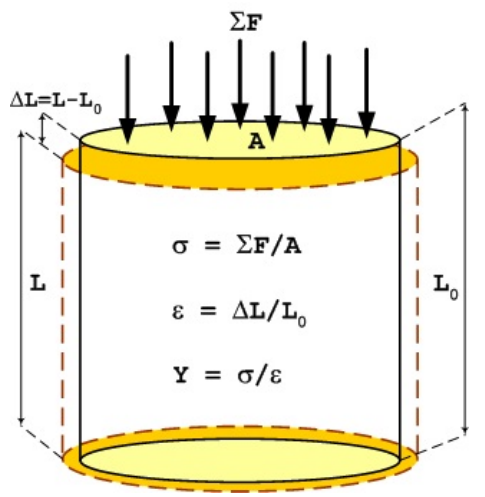

Figura 2.5: Esquema mostrando corpo cilindrico sobre tensão que produzem deformações.

quando são aplicados níveis de tensão relativamente baixos, a tensão ( $\sigma$ "stress") e a deformação ( $\varepsilon$ - "strain") são proporcionais entre si, sendo que essa proporcionalidade é representada pela lei de Hooke e está descrita pela equação 2.8 apresentada na próxima seção.

A lei de Hooke é válida para o regime elástico linear. Nessa região, o módulo de Young pode ser obtido pelo coeficiente angular do gráfico "tensão $\mathrm{x}$ deformação", como mostrado na figura 2.6.

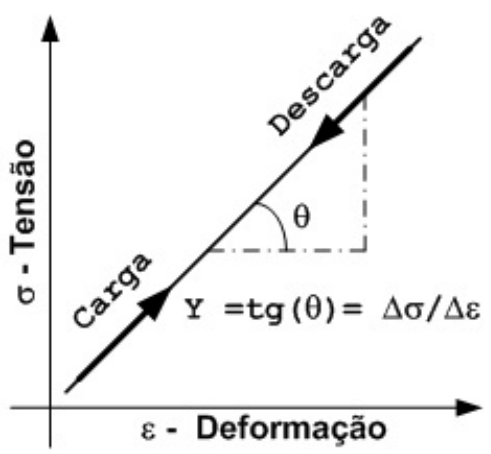

Figura 2.6: Curva tensão versus deformação no regime elástico linear.

Entretanto, existem alguns materiais para os quais esta porção inicial elástica da curva "tensão x deformação" não é linear e, portanto, não é possível determinar o módulo de "Young" como descrito anteriormente. Para este comportamento não-linear, tanto o módulo tangente quanto o módulo secante podem ser normalmente usados.

$O$ módulo tangente é tomado como sendo a inclinação da curva "tensão $x$ deformação" em um nível de tensão específico, enquanto que o módulo secante representa a inclinação de uma secante traçada a partir da origem até um 
dado ponto da curva $\left[\begin{array}{lll}\sigma & \chi & \varepsilon\end{array}\right]$. A determinação destes módulos é ilustrada na Figura 2.7.

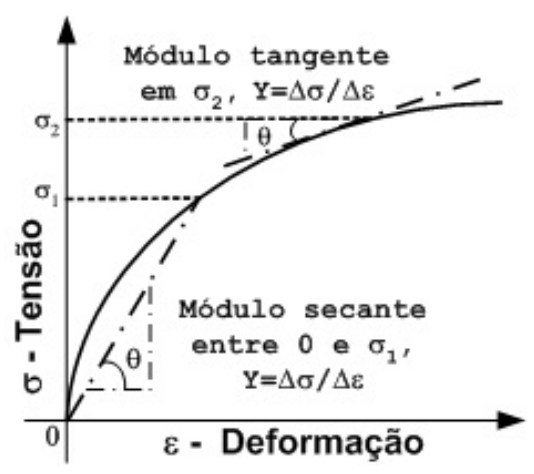

Figura 2.7: Curva tensão versus deformação no regime não linear.

Os fundamentos matemáticos para os cálculos dos módulos elásticos dinâmicos, com precisão, foram desenvolvidos entre a década 40 e 60, levando em consideração os modos de vibração fundamentais.

Sob determinadas condições de contorno mecânicas, o corpo de prova é excitado em um determinado modo de vibração por um atuador, que pode ser de origem mecânica (como o ultrassom) ou eletromagnética. Um aparato eletrônico capta esta vibração com um sensor piezoelétrico e informa ao usuário a respectiva frequência de ressonância, a partir da qual são calculados os módulos elásticos através das frequências naturais de vibração do corpo de prova e de seus parâmetros geométricos.

\subsubsection{Viscosidade}

Há vários modelos usados para simular o comportamento elástico e/ou viscoelástico de um meio, como o de Maxwell, Voigt ou Kelvin. E estes são geralmente combinações de molas lineares com constante elásticas ' $k$ ' e elementos amortecedores com parâmetros de viscosidade ' $b$ ', conforme apresentado na figura 2.8 .

A viscosidade pode ser entendida como a resistência que um meio oferece a fluidez (ou escoamento). Assim, não tem o mesmo significado de densidade volumétrica (relação massa/volume), apesar de estarem relacionadas, por exemplo: um óleo vegetal, como o de oliva é menos denso que a água, no entanto, é mais viscoso que a mesma.

Deste modo, a viscosidade é uma das variáveis que caracteriza 


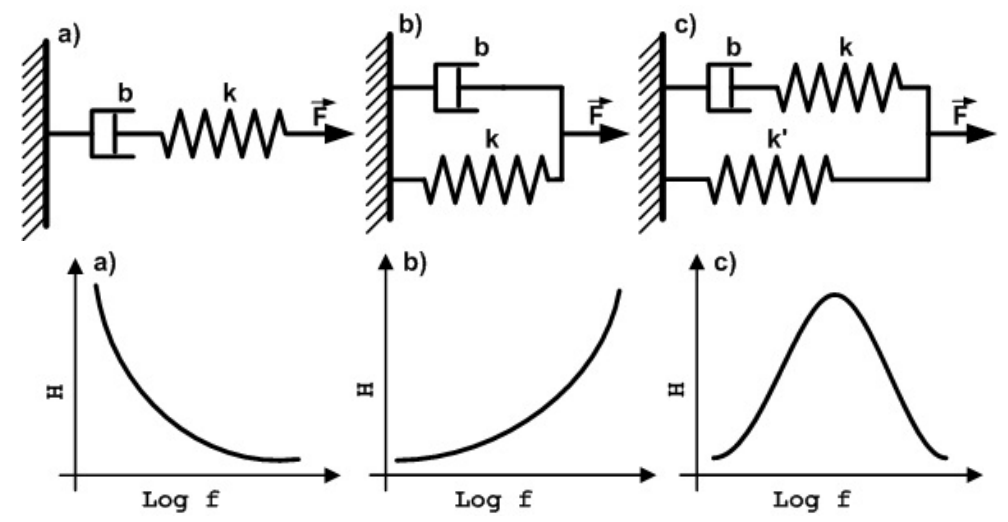

Figura 2.8: Três modelos padrão de viscoelasticidade e suas respectivas respostas (Histerese[H] x Log(frequência)): a) Maxwell, b) Voigt e c) Kelvin. [49]

reologicamente uma substância. A reologia ${ }^{2}$ estuda as propriedades físicas que afetam o escoamento de um fluido: o fluxo nos materiais líquidos e a deformação no caso dos sólidos. A depender do comportamento reológico do meio pode-se classificá-la em puramente viscosa ou elástica.

O tecido biológico apresenta ambas as propriedades [15]. Quando submetido a pequenas deformações (módulo de Young $\leq 0,5$ ) e baixas frequências $(\leq 10 \mathrm{~Hz})$, pode ser considerado como puramente elástico. Para altas deformações e frequências, as propriedades viscosas se manifestam. Esta consideração baseia-se em modelos lineares que relacionam a deformação $(\varepsilon$ "strain") à tensão ( $\sigma$ - "stress") aplicada no material.

O modelo para líquidos deve-se a Isaac Newton (1642-1727), equação 2.7, e o modelo para sólidos a Robert Hooke (1635-1703), equação 2.8:

$$
\begin{gathered}
\sigma=\mu \cdot \frac{\mathrm{d} \varepsilon}{\mathrm{dt}} \Rightarrow \frac{\mathrm{d} \varepsilon}{\mathrm{dt}}=\frac{\mathrm{d}}{\mathrm{dt}}\left(\frac{\Delta \mathrm{l}}{\mathrm{l}_{0}}\right), \quad \text { [Fluido Newtoniano] } \\
\sigma=\mathrm{G} \cdot \varepsilon \Rightarrow \varepsilon=\frac{\Delta \mathrm{l}}{l_{0}} \Rightarrow \Delta \mathrm{l}=\mathrm{l}-\mathrm{l}_{0}, \quad \text { [Sólido Hookeano] }
\end{gathered}
$$

Na equação 2.7, a constante de proporcionalidade $\mu$ é denominada de viscosidade dinâmica, cuja unidade é [Pa.s] ou $[\mathrm{kg} / \mathrm{s} / \mathrm{m}]$. Na equação $2.8,{ }^{\prime} \mathrm{G}^{\prime}$ é a constante de Lamé, cuja unidade é [Pa]. Estes dois modelos expressam uma importante diferença existente entre um fluido e um sólido. Entretanto, há fluidos e sólidos que têm comportamento não linear de tensão versus deformação.

\footnotetext{
${ }^{2}[$ do grego $($ rheo $=$ fluxo $+\operatorname{logos}=$ estudo $)]$
} 
As forças aplicadas em fluidos causam escoamento, daí a tensão ser proporcional a taxa temporal de deformação; enquanto, forças aplicadas em sólidos causam deformações, daí a tensão ser proporcional à deformação.

Além disso, existem materiais que apresentam, simultaneamente, características viscosas e elásticas, como os tecidos moles. As características destes materiais ampliam a definição de sólidos e fluidos, constituindo uma área de pesquisa conhecida como Reologia [59], esquematizada na figura 2.9.

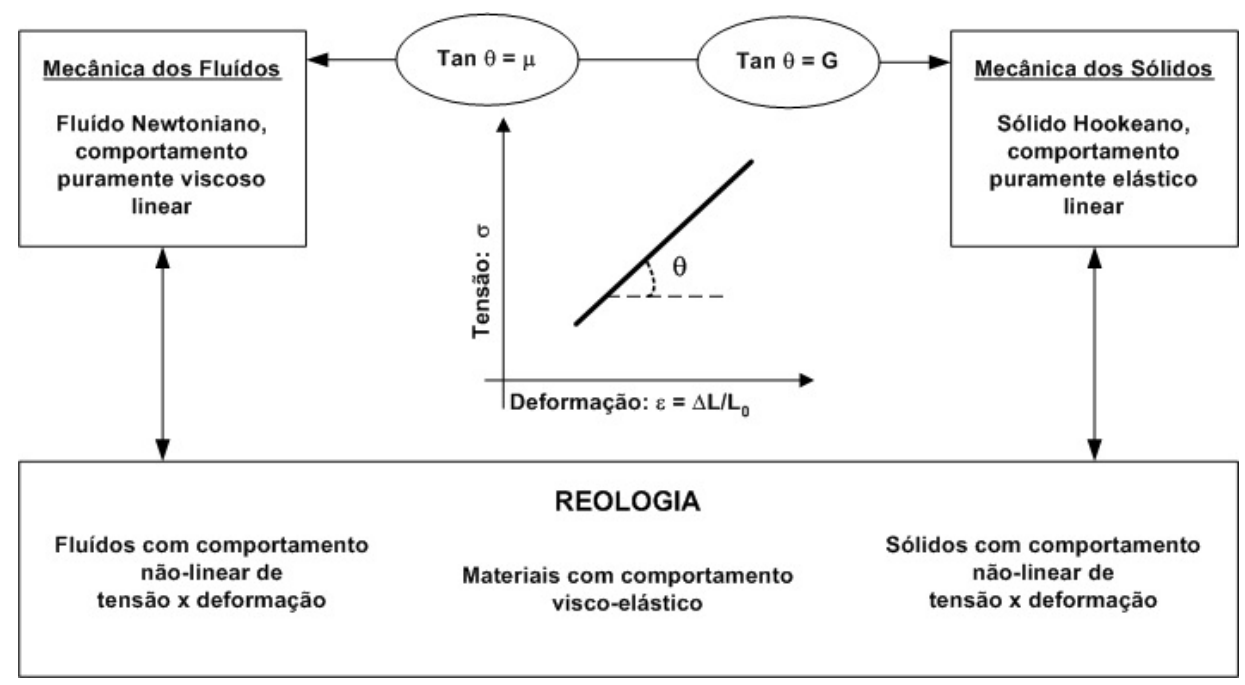

Figura 2.9: Diagrama esquemático do estudo reológico. (adaptado: Bird et al., 1987 [59])

O comportamento reológico de um líquido é frequentemente representado por uma curva de fluxo, isto é, tensão de cisalhamento versus a taxa de cisalhamento. Quando este gráfico, à temperatura e pressão constantes, for linear, a viscosidade será constante e igual ao coeficiente angular da reta.

A maioria dos líquidos puros e muitas soluções e dispersões apresentam este tipo de comportamento e são denominados líquidos newtonianos. Entretanto, muitas soluções concentradas e dispersões apresentam desvio deste comportamento e são denominadas de fluidos não-newtonianos.

Os sistemas com escoamento não-newtonianos podem apresentar comportamentos dependentes (denominados tixotropia $^{3}$ e reopexia ${ }^{4}$ ) ou independentes do tempo (também denominado de estacionário), que podem

\footnotetext{
${ }^{3}$ A tixotropia é o fenômeno da diminuição da viscosidade aparente com o tempo de cisalhamento, à uma taxa de cisalhamento constante.

${ }^{4} \mathrm{~A}$ reopexia é o fenômeno do aumento da viscosidade aparente com o tempo de cisalhamento, à uma taxa de cisalhamento constante.
} 
apresentar comportamentos pseudoplásticos ${ }^{5}$, plásticos $^{6}$ e dilatantes ${ }^{7}$. Conforme resumo apresentado na figura 2.10 .
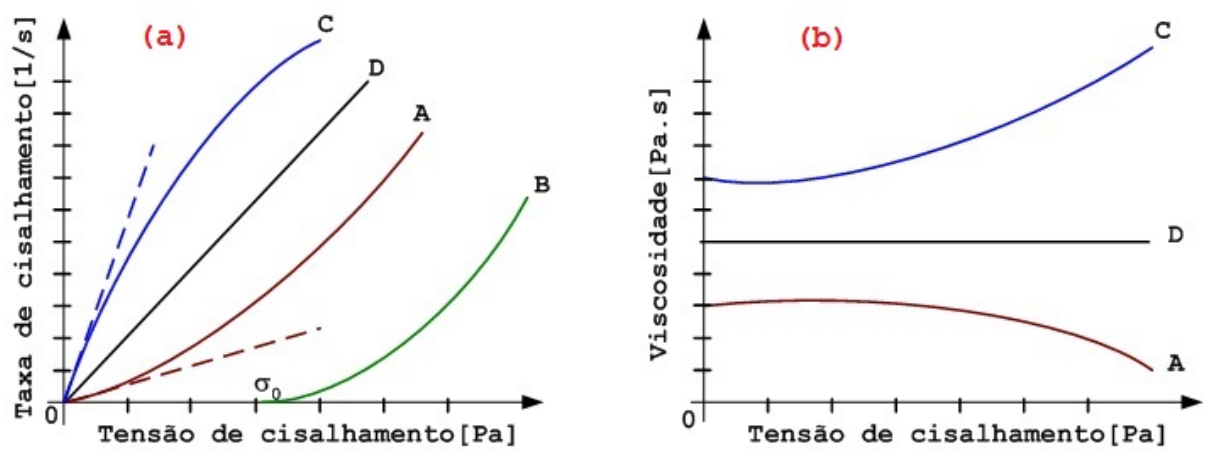

Figura 2.10: (a) Curvas de fluxo para diferentes tipos de comportamento reológico:[A] Plástico, [B] Pseudoplástico, [C] Dilatante, [D] Newtoniano, [- - -] Newtoniano extrapolado. (b) Curvas de viscosidade correspondentes às curvas de fluxo. (adaptado: Vieira, 1971 [60]).

Se considerarmos o sólido da figura $2.11 \mathrm{e}$, tomando a face ABCD infinitesimal de lados $\mathrm{L}_{x}$ e $\mathrm{L}_{y}\left(\Delta x=\mathrm{L}_{x}, \quad \Delta y=\mathrm{L}_{y}\right)$, quando aplicamos uma

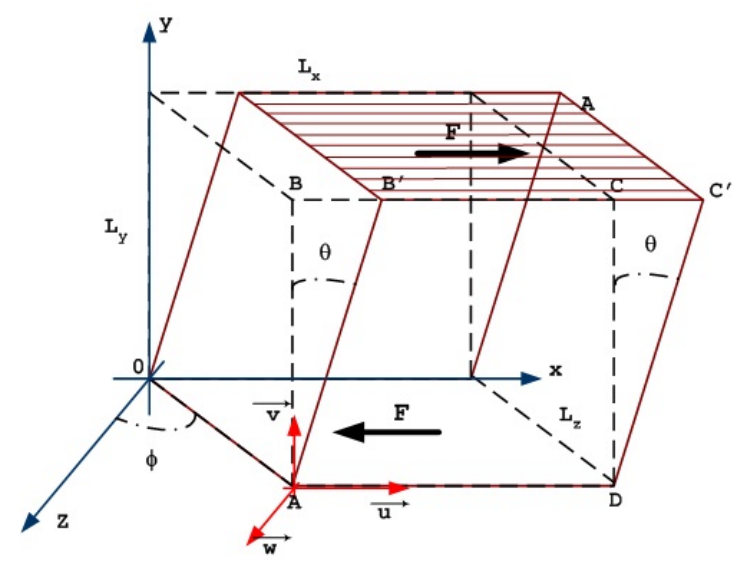

Figura 2.11: Esquema de deformação infinitesimal num elemento de volume.

tensão na face $\mathbf{B C}$, os pontos $\mathbf{B}$ e $\mathbf{C}$ deslocam-se respectivamente para $\mathbf{B}$ ' e $\mathbf{C}$ '. Assim, a deformação dada pelo ângulo $\theta$, ou seja,

$$
\operatorname{tg} \theta \cong \theta=\frac{\mathrm{BB}^{\prime}}{\mathrm{AB}}=\frac{\mathrm{BB}^{\prime}}{\mathrm{L}_{\mathrm{y}}}
$$

\footnotetext{
${ }^{5}$ Quando ocorre diminuição da viscosidade aparente com o aumento da tensão de cisalhamento.

${ }^{6}$ Quando há existência de uma tensão de cisalhamento mínima para iniciar o escoamento.

${ }^{7}$ Quando ocorre aumento da viscosidade aparente com o aumento da tensão de cisalhamento.
} 
produz movimento relativo de $\mathbf{B}$ para $\mathbf{B}$ ', em relação ao ponto $\mathbf{A}$, tomado aqui como referência. Deste modo,

* Se o segmento BB' deforma continuamente (fluido), então, $\vec{u}$ será o vetor velocidade do fluido em relação ao ponto $\mathbf{A}$, num intervalo de tempo $\Delta$ t. Assim,

$$
\mathrm{BB}^{\prime}=\left(\frac{\mathrm{du}}{\mathrm{dy}} \cdot \mathrm{L}_{\mathrm{y}}\right) \cdot \Delta \mathrm{t},
$$

substituindo a equação 2.10 na equação 2.9 , temos:

$$
\begin{array}{r}
\theta=\frac{\left(\frac{d u}{d y} \cdot L_{y}\right) \cdot \Delta t}{L_{y}}, \\
\frac{\theta \cdot L_{y}}{L_{y} \cdot \Delta t}=\frac{d u}{d y}, \\
\frac{\theta}{\Delta t}=\frac{d u}{d y} \Rightarrow \lim _{\Delta t \rightarrow 0} \frac{\theta}{\Delta t}=\frac{d \theta}{d t}=\frac{d u}{d y} ;
\end{array}
$$

* Se o segmento BB' não se deforma continuamente (sólido), então $\vec{u}$ será o vetor deslocamento de $\mathbf{B}$ em relação ao ponto A. Assim,

$$
\mathrm{BB}^{\prime}=\left(\frac{\mathrm{d} u}{\mathrm{dy}} \cdot \mathrm{L}_{\mathrm{y}}\right),
$$

substituindo a equação 2.12 na equação 2.9 , temos:

$$
\theta=\frac{\left(\frac{d u}{d y} \cdot L_{y}\right)}{L_{y}}, \Rightarrow \theta=\frac{d u}{d y} ;
$$

De modo geral, os efeitos físicos gerados por forças externas aplicadas num meio material sólido, com características viscoelásticas, são descritos por um conjunto de equações denominadas, equações constitutivas. Segundo Timonshenko, 1970 [61], estas equações descrevem as propriedades mecânicas do meio quando sujeitos a ação de forças externas. Numa primeira análise, somos levados a esperar, pelos princípios de conservação, que as relações entre tensão versus deformação obedeça uma certa linearidade. Entretanto, esta expectativa só se concretiza quando impomos determinadas condições de contorno, tais 
como: obedecer limites de elasticidade (linearidade), ter algumas simetrias, homogeneidades e isotropias (mesma relação constitutiva sob qualquer rotação).

Assim, considerando como pressuposto que obedecemos as condições de linearidade entre tensão versus deformação e que certas condições de simetria devam permanecer invariantes sob um conjunto de transformações. As equações constitutivas ficam condicionadas apenas a dois parâmetros linearmente independentes. Simplificando assim, a análise das suas propriedades mecânicas.

De modo generalizado, a expressão matemática que descreve as características de um meio, podem ser escritas tensorialmente, segundo Butkov, 1998 [62], como:

$$
\sigma_{\mathrm{kl}}=\mathrm{D}_{\mathrm{klmn}} \cdot e_{\mathrm{mn}}
$$

onde as componentes da matriz $\mathbf{D}$ representam as propriedades intrínsecas do material.

Estas componentes totalizando $81\left(=3^{4}\right)$ termos, correspondem aos índices $\mathrm{k}, \mathrm{l}, \mathrm{m}, \mathrm{n}$ assumindo valores 1,2 e 3 . Se considerarmos que ambos os tensores, Tensão $\left(\sigma_{\mathrm{kl}}\right)$ e elasticidade $\left(\mathrm{D}_{\mathrm{klmn}}\right)$, possuem simetria, tal que $\mathrm{D}_{(\mathrm{kl})(\mathrm{mn})}=$ $\mathrm{D}_{(\mathrm{mn})(\mathrm{kl})}$, então, o número de termos se reduz a 21, que caracteriza um material elástico, linear e anisotrópico. Além disso, se as propriedades elásticas do material são isotrópicas, ou seja, independam da orientação espacial, então, o número de componentes se reduz a três. Assim, podemos expressar a equação constitutiva do meio material em função de apenas dois parâmetros independentes, conhecidos como constantes de Lamé $(\lambda$ e $\mu)$, e, apresentada a seguir, como:

$$
\sigma_{\mathrm{kl}}=\lambda \cdot \mathrm{D}_{\mathrm{kl}} \cdot \delta_{\mathrm{kl}}+2 \cdot \mu \cdot \mathrm{D}_{\mathrm{kl}} ;
$$

Sendo $\delta_{\mathrm{kl}}$, o delta de Kronecker.

$$
D_{k l}=\left[\begin{array}{ccc}
D_{x x} & D_{y x} & D_{z x} \\
D_{x y} & D_{y y} & D_{z y} \\
D_{x z} & D_{y z} & D_{z z}
\end{array}\right]=\frac{1}{2}\left[\begin{array}{ccc}
\left(\frac{\partial u}{\partial x}\right) & \left(\frac{\partial u}{\partial y}+\frac{\partial v}{\partial x}\right) & \left(\frac{\partial u}{\partial z}+\frac{\partial w}{\partial x}\right) \\
\left(\frac{\partial u}{\partial y}+\frac{\partial v}{\partial x}\right) & \left(\frac{\partial v}{\partial y}\right) & \left(\frac{\partial v}{\partial z}+\frac{\partial w}{\partial y}\right) \\
\left(\frac{\partial u}{\partial z}+\frac{\partial w}{\partial x}\right) & \left(\frac{\partial v}{\partial z}+\frac{\partial w}{\partial y}\right) & \left(\frac{\partial w}{\partial z}\right)
\end{array}\right]
$$

$D_{k l}$ é o tensor das deformações definido na equação 2.16. Os vetores $\vec{u}, \vec{v}$ e $\vec{w}$ são paralelos às direções $\mathbf{x}, \mathbf{y}, \mathbf{z}$, conforme mostra a figura 2.11, e representam velocidades (se fluidos) ou deformações (se sólidos). Os parâmetros 
$\lambda$ e $\mu$ dependem da temperatura e expressam, tanto para fluidos ou sólidos, uma relação linear entre o tensor de deformações e o campo de tensões [63]. Estes parâmetros são conhecidos por diferentes nomenclaturas, conforme mostra a tabela 2.1.

Tabela 2.1: Nomes e unidades dos parâmetros $\lambda$ e $\mu$ [15, 64].

\begin{tabular}{|c|c|c|c|c|c|}
\hline 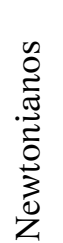 & $\mu$ & $\begin{array}{l}\text { Primeiro } \\
\text { coeficiente de } \\
\text { viscosidade ou } \\
\text { viscosidade } \\
\text { dinâmica }\end{array}$ & $\mu=\frac{F}{S} \cdot \frac{d u}{d y} \rightarrow \mu=\sigma \cdot \frac{d u}{d y}$ & $\begin{array}{l}{[\text { Pa.s }] \text { ou }} \\
{\left[\text { N.s } / \mathrm{m}^{2}\right]}\end{array}$ & (Experimental) \\
\hline $\begin{array}{l}0 \\
0 \\
: 3 \\
\overrightarrow{3} \\
0\end{array}$ & $\lambda$ & $\begin{array}{l}\text { Segundo } \\
\text { coeficiente de } \\
\text { viscosidade ou } \\
\text { viscosidade } \\
\text { cinemática }\end{array}$ & $\begin{array}{c}\lambda=\frac{\mu}{\rho} \\
\mu=\text { viscosidade dinâmica }, \\
\rho=\text { densidade } \\
\text { volumétrica }\end{array}$ & $\begin{array}{l}{[\text { Pa.s }] \text { ou }} \\
{\left[\text { N.s } / \mathrm{m}^{2}\right]}\end{array}$ & $\begin{array}{l}\lambda=(2 / 3) \cdot \mu \\
\text { (Modelo) }\end{array}$ \\
\hline 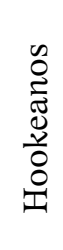 & $\mu$ & $\begin{array}{l}\text { Coeficiente de } \\
\text { Lamé, conhecido } \\
\text { por G } \\
\text { (viscosidade } \\
\text { dinâmica) }\end{array}$ & $\begin{array}{c}\mathrm{G}=\frac{\mathrm{Y}}{2 \cdot(1+v)} \\
\mathrm{Y}=\text { módulo de Young, } \\
v=\text { coeficiente de Poisson }\end{array}$ & $\begin{array}{l}{[\mathrm{Pa}] \mathrm{ou}} \\
{\left[\mathrm{N} / \mathrm{m}^{2}\right]}\end{array}$ & $\begin{array}{l}v \cong(1 / 2) \text { e } \mathrm{Y}= \\
\text { 3.G, } \\
\text { (Experimental) }\end{array}$ \\
\hline $\begin{array}{l}0 \\
: 0 \\
: 0 \\
0 \\
0\end{array}$ & $\lambda$ & $\begin{array}{c}\text { Coeficiente de } \\
\text { Lamé, conhecido } \\
\text { por } \mathbf{G} \\
\text { (viscosidade } \\
\text { cinemática) }\end{array}$ & $\begin{array}{c}\mathrm{G}=\frac{\mathrm{Y} . \mathrm{v}}{(1+v) \cdot(1-2 . v)} \\
\mathrm{Y}=\text { módulo de Young, } \\
v=\text { coeficiente de Poisson }\end{array}$ & $\begin{array}{l}{[\mathrm{Pa}] \text { ou }} \\
{\left[\mathrm{N} / \mathrm{m}^{2}\right]}\end{array}$ & $\begin{array}{l}\nu \cong(1 / 4) \text { e } \lambda= \\
G, \\
\text { (Experimental) }\end{array}$ \\
\hline
\end{tabular}

Contudo, segundo Ophir et al., 2002 [14], os tecidos biológicos moles são, em geral, anisotrópicos, não lineares e viscoelásticos. Mesmo assim, em alguns estudos, estes são usualmente assumidos que seu comportamento é linear, elástico e isotrópico a fim de simplificar sua análise. Para que isto seja razoável, deve-se considerar pequenas deformações, aplicações de carga rápidas e uma escala espacial ampla comparada a largura relativa de correlação da variabilidade elástica da amostra do tecido. 


\subsubsection{Caracterização da Viscoelasticidade}

O modelo básico de vibração de um sistema oscilatório simples consiste em um corpo com uma determinada massa, uma mola com massa desprezível comparada à massa do corpo e um amortecedor, conforme é mostrado na Figura 2.8.

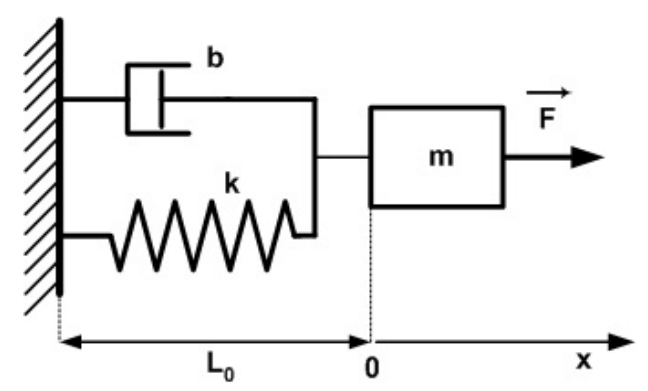

Figura 2.12: Diagrama esquemático de um modelo de oscilador harmônico amortecido (Voigt).

Considerando o modelo de Voigt, figura 2.12, a relação força-alongamento (ou contração) sofrida pelo conjunto "massa-mola" é considerada linear e pode ser descrita pela Lei de Hooke, conforme apresentado na equação 2.8: ou de forma simplificada (para uma dimensão) $\overrightarrow{f_{e l}}=-k \cdot \vec{x}$, em que ' $k$ ' é a rigidez da mola e 'x' é o deslocamento da posição de equilíbrio estático sofrido pela massa. $\mathrm{O}$ amortecimento viscoso é descrito por uma força proporcional à velocidade, ou seja, $\overrightarrow{f_{v i s c}}=-b . \vec{u}$, em que 'u' é a velocidade de deslocamento e 'b' é o coeficiente de amortecimento. Este modelo, ilustrado pela Figura 2.12, pode ser descrito pela seguinte equação diferencial:

$$
\begin{array}{r}
\mathrm{m} \cdot \frac{\mathrm{d}^{2} \mathrm{x}}{\mathrm{dt^{2 }}}+\mathrm{b} \cdot \frac{\mathrm{d} x}{\mathrm{dt}}+\mathrm{k} \cdot \mathrm{x}=0, \quad \Rightarrow \quad \gamma=\frac{\mathrm{b}}{\mathrm{m}} \quad \text { e } \frac{\mathrm{k}}{\mathrm{m}}=\omega_{0}^{2}, \\
\text { assumindo que, } \quad \mathrm{b}=2 . \xi \cdot m \cdot \omega_{0} \quad \text { e } \quad \xi=\frac{\mathrm{b}}{2 \sqrt[2]{\mathrm{k} \cdot \mathrm{m}}}
\end{array}
$$

a equação pode ser apresentada como: $\frac{\mathrm{d}^{2} x}{\mathrm{dt}^{2}}+\left(2 . \xi . \omega_{0}\right) \cdot \frac{\mathrm{d} x}{\mathrm{dt}}+\omega_{0}^{2} \cdot x=0$,

em que ' $\omega_{0}$ ' é chamado de frequência natural de vibração (ou frequência de ressonância) e ' ' ' é a taxa de amortecimento.

Tomando $x(t)=$ A.e $e^{\alpha . t}$ como solução do modelo, derivando $\mathrm{e}$ substituindo na equação 2.17 , temos: 


$$
\begin{aligned}
& \alpha^{2} \cdot x(t)+\alpha \cdot \gamma \cdot x(t)+\omega_{0}^{2} \cdot x(t)=0 \Rightarrow\left(\alpha^{2}+\alpha \cdot \gamma+\omega_{0}^{2}\right) \cdot x(t)=0 \\
& \alpha_{ \pm}=\left(\frac{-\gamma \pm \sqrt[2]{\gamma^{2}-4 \cdot \omega_{0}^{2}}}{2}\right)
\end{aligned}
$$

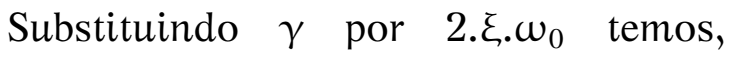

$$
\begin{aligned}
& \alpha=\omega_{0}\left(-\xi \pm \sqrt[2]{\xi^{2}-1}\right)
\end{aligned}
$$

Então o comportamento da equação 2.17 depende da solução da equação 2.18, especificamente da taxa de amortecimento $\xi$. Assim, para:

$\star \xi>1$ : há duas soluções reais e o sistema é superamortecido;

$\star \xi=1$ : há uma solução real e o sistema é criticamente amortecido;

$\star 0<\xi<1$ : há duas soluções complexas e o sistema é sub-amortecido.

Os casos superamortecido e criticamente amortecido são não-oscilatórios, conforme mostra o gráfico da figura 2.13 e, portanto, não representam os resul-

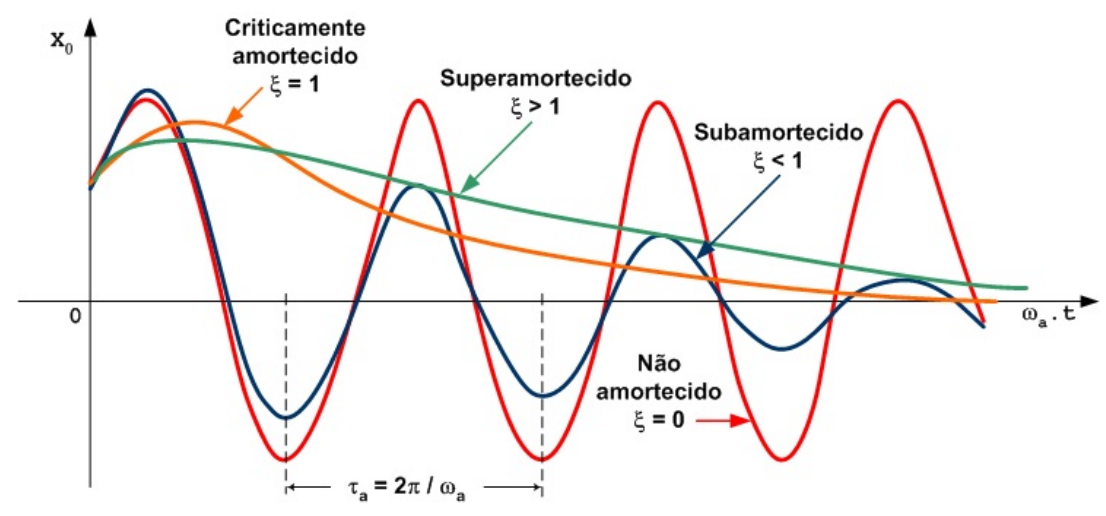

Figura 2.13: Gráficos de um Sistema massa-mola com fator de amortecimento.

tados experimentais com os tecidos moles que absorvem energia da onda sonora e sofre atenuação. O que nos leva a considerar os tecidos moles como um sistema sub-amortecido, onde a taxa de amortecimento $(\xi)$ varia entre os limites de 0 a 1.

Assim, para este caso, a solução geral será dada pela equação:

$$
x(t)=A_{0} \cdot e^{-\xi \cdot \omega_{0} \cdot t} \cdot \cos \left(\omega_{a} \cdot t+\phi\right),
$$


em que $A_{0}$ é a amplitude inicial de vibração, $\phi$ é a fase inicial da vibração e $\omega_{a}$ é chamada de frequência natural amortecida, sendo expressa por:

$$
\omega_{\mathrm{a}}=\omega_{0} \cdot \sqrt[2]{1-\xi^{2}}
$$

Assim, temos um sistema linear amortecido com um grau de liberdade. Se considerarmos que a ressonância dos materiais pode ser vista como uma associação de vários sistemas de um grau de liberdade, o modelo para vibração pode ser dado por:

$$
x(t)=\left[\sum_{i=1}^{N} A_{i} e^{-\xi_{i} \omega_{n i t} t} \cos \left(\omega_{a i} t+\phi_{i}\right)\right]+R_{w n},
$$

em que $A_{i}, \xi_{i}, \omega_{n i}, \omega_{a i}$ e $\phi_{i}$ são, respectivamente, a amplitude inicial, a taxa de amortecimento, a frequência natural de vibração, a frequência natural amortecida e fase inicial do i-ésimo modo de vibração. E o termo $R_{w n}$ é chamado de ruído branco que está descorrelacionado do sinal.

\subsubsection{Métodos de determinação do amortecimento - atenuação}

Segundo Cossolino, 2010 [65], os métodos de determinação do amortecimento são diversos e a escolha depende principalmente da faixa de amortecimento e da frequência de vibração. Os mais utilizados são o do decremento logarítmico e o da largura a meia banda.

1. O termo decremento logarítmico refere-se à taxa de redução logarítmica, relacionada com a redução do movimento após o impulso (F. $\Delta t$ ), pois a energia é transferida para outras partes do sistema ou é absorvida pelo próprio elemento.

Assim, quando excitamos um sistema oscilatório com amortecimento viscoso por um impulso (F. $\Delta \mathrm{t}$ ), sua resposta vem na forma de decaimento no tempo, sendo obtido através da razão entre duas amplitudes sucessivas do sinal, conforme mostrado na figura 2.14. Que é representada pela equação 2.22 .

Esta equação 2.22 é análoga a equação 2.19 , cuja frequência natural amortecida foi apresentada na equação 2.20.

$$
y(t)=y_{0} e^{-\xi \omega_{0} t} \operatorname{sen}\left(\omega_{a} t\right)
$$




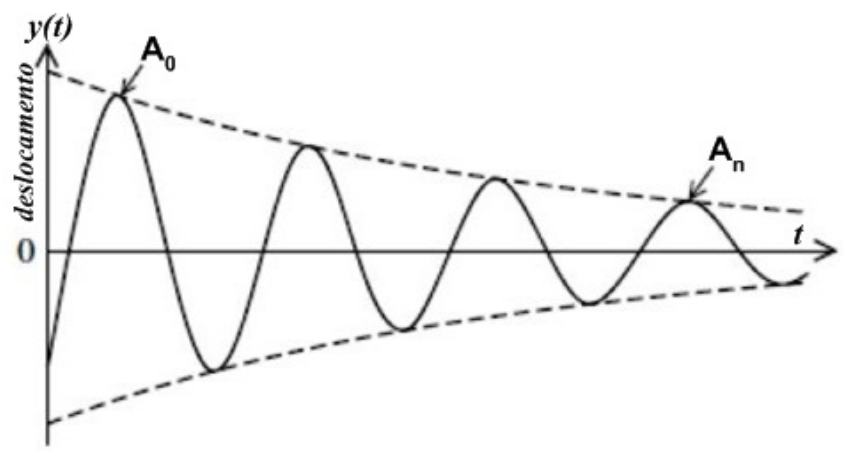

Figura 2.14: Gráfico de um Sistema Oscilante amortecido quando excitado por um impulso.

Se a resposta no tempo $t=t_{0}$ é dada por $y_{0}$, e a resposta no tempo $\mathrm{t}=\mathrm{t}_{0}+\frac{2 \pi \mathrm{n}}{\omega_{\mathrm{a}}}$ é denotada por $\mathrm{y}_{\mathrm{n}}$, então, da equação 2.22 , temos que:

$$
\frac{y_{n}}{y_{0}}=\exp \left[-\xi\left(\frac{\omega_{0}}{\omega_{a}}\right) 2 \pi n\right], \quad n=1,2,3 \ldots,
$$

Supondo que $y_{0}$ corresponde a um ponto no decaimento da função com magnitude igual a $A_{0}$, e que $y_{n}$ corresponde ao pico, $n$ ciclos mais tarde, com magnitude $A_{n}$. Assim, temos que:

$$
\frac{A_{n}}{A_{0}}=\exp \left[-\xi\left(\frac{\omega_{0}}{\omega_{a}}\right) 2 \pi n\right], \Rightarrow \frac{A_{n}}{A_{0}}=\exp \left[-\frac{\xi}{\sqrt[2]{1-\xi^{2}}} 2 \pi n\right]
$$

Desta forma, o decremento logarítmico ( $\delta)$ é obtido por:

$$
\delta=\frac{1}{n} \ln \left(\frac{A_{n}}{A_{0}}\right)=\frac{2 \pi \xi}{\sqrt[2]{1-\xi^{2}}}
$$

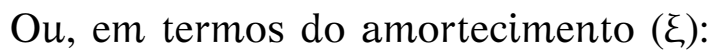

$$
\xi=\frac{1}{\sqrt[2]{1+\left(\frac{2 \pi}{\delta}\right)^{2}}},
$$

2. No método de largura de banda, a medida do amortecimento é baseada na resposta da frequência. Esta largura a meia potência é definida como a largura da curva da resposta de frequência quando a magnitude (Q) é $\left(\frac{1}{\sqrt{2}}\right)$ vezes o valor do pico. Este valor é denotado por $\Delta \omega$, como visto na Figura 2.15. 


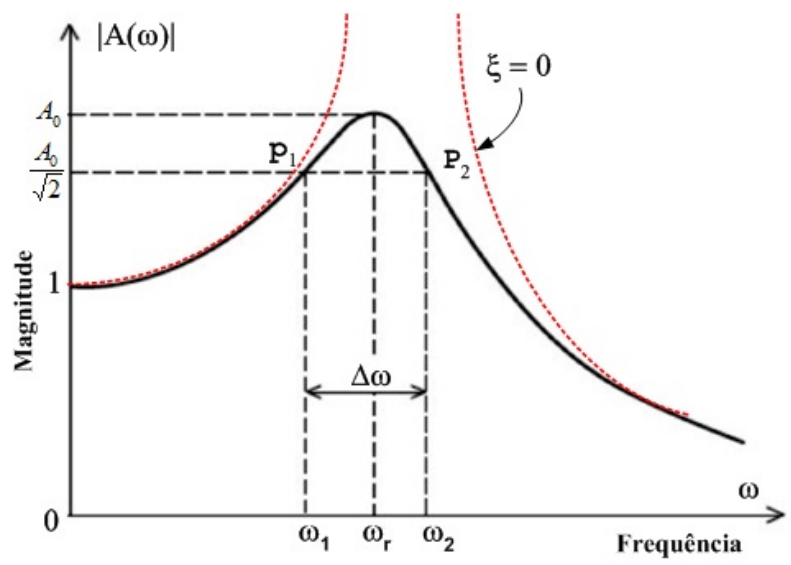

Figura 2.15: Gráfico esquemático do método da largura de banda para determinação do amortecimento.

Segundo Meirovitch, 1967 [66], o valor máximo da magnitude $|A(\omega)|$ é obtido quando satisfaz a equação 2.20. Portanto, em um valor menor do que a frequência natural de vibração (ressonância). É fácil ver que quando este amortecimento é muito pequeno $(\xi<0,05)$, o máximo ocorre aproximadamente na frequência natural de ressonância. Então, podemos dizer que $|A(\omega)|=Q$, e o amortecimento será, aproximadamente:

$$
\mathrm{Q} \cong \frac{1}{2 . \xi}
$$

e a curva $|A(\omega)|$ versus $\omega$ será proximamente simétrica em relação ao eixo vertical. Assim $\omega_{\mathrm{a}}=\omega_{0}=\omega_{\mathrm{r}}$. Logo, nos pontos $\mathrm{P}_{1}$ e $\mathrm{P}_{2}$ onde a amplitude $|A(\omega)|$ cai para $\left(\frac{1}{\sqrt{2}}\right) \cdot Q$ temos os "pontos a meia potência (energia)", pois, a energia absorvida pelo amortecimento, num movimento oscilatório harmônico, numa dada frequência, é proporcional ao quadrado da amplitude.

Deste modo, a diferença de frequência entre os pontos $\mathrm{P}_{1}$ e $\mathrm{P}_{2}$ a "meia potência" é geralmente chamada de "largura de banda" do sistema. E, para pequenos amortecimentos este valor pode ser dado por:

$$
\Delta \omega=\omega_{2}-\omega_{1}=2 . \xi \cdot \omega_{r},
$$

E, portanto, o amortecimento pode ser estimado através da "largura de 
banda" pela expressão:

$$
\xi=\frac{1}{2} \cdot \frac{\Delta \omega}{\omega_{r}}
$$

Uma outra forma de analisar os efeitos do amortecimento (atenuação) é através do levantamento da curva de histerese do material, a partir do gráfico de tensão ("stress") versus deformação ("strain”), visto que está associado a área entre as curvas, como mostra o gráfico da figura 2.16.

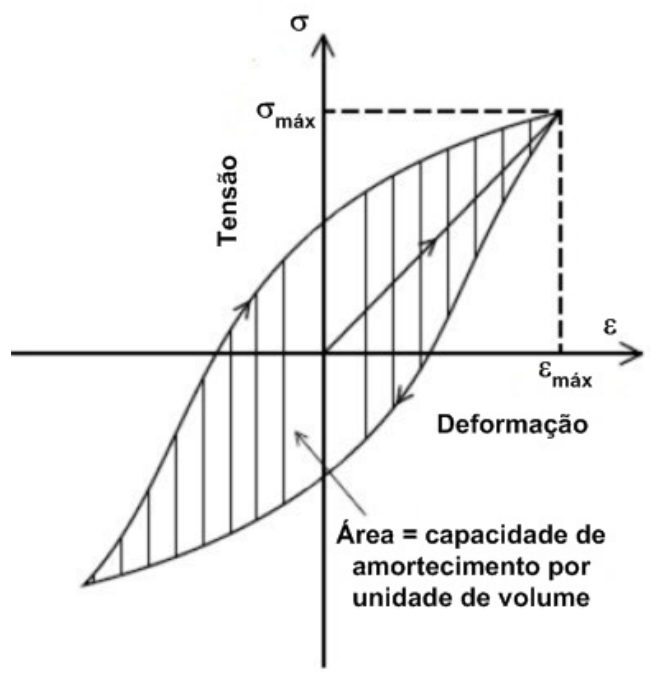

Figura 2.16: Gráfico esquemático do método de histerese para determinação do amortecimento.

Denominando a capacidade de amortecimento por unidade volume por " $\mathrm{C}_{\mathrm{am}}$ " e calculando a integral cíclica 2.30 a seguir:

$$
\mathrm{C}_{\mathrm{am}}=\oint \sigma \cdot \mathrm{d} \varepsilon
$$

teremos o trabalho realizado pela força "resistente" (de amortecimento), ou seja, esta integral determina a energia dissipada, atenuada (absorvida) nos ciclos do movimento. Ao dividirmos pelo volume do material determinamos a capacidade (por unidade de volume) que o material possui ao amortecimento (" $C_{a m}$ "), que por sua vez, nos leva ao módulo volumétrico, "Young's", "Poisson" etc, através das relações 2.5 e 2.6 já descritas anteriormente. 


\subsection{Materiais magnético reológicos}

Os fluidos magnetoreológicos (FMR) surgiram a partir de um programa de pesquisas para o exército dos Estados Unidos da América (EUA). Foi desenvolvido por Jacob Rabinow após meados da década de 40, com aplicação específica em atuadores hidráulicos, amortecedores e embreagens. [67]. Sua resposta magnetoreológica é decorrente da polarização induzida de partículas magnéticas em suspensão num meio não magnético, quando da aplicação de um campo magnético externo.

Os materiais magnetoreológicos (MMR) são uma classe de materiais inteligentes, em que as propriedades reológicas podem variar rapidamente quando submetidos a ação de um campo magnético. São compostos de micro partículas magnéticas, da ordem de $3 \mu \mathrm{m}$ a $5 \mu \mathrm{m}$, com permeabilidade magnética e suspensas em um meio não magnético, usualmente óleos (hidrocarbonetos) ou polímeros.

A figura 2.17 apresenta uma imagem microscópica da estrutura de um FMR, quando está sem (2.17.(a)) e com (2.17.(b)) atuação de um campo magnético externo.

a)

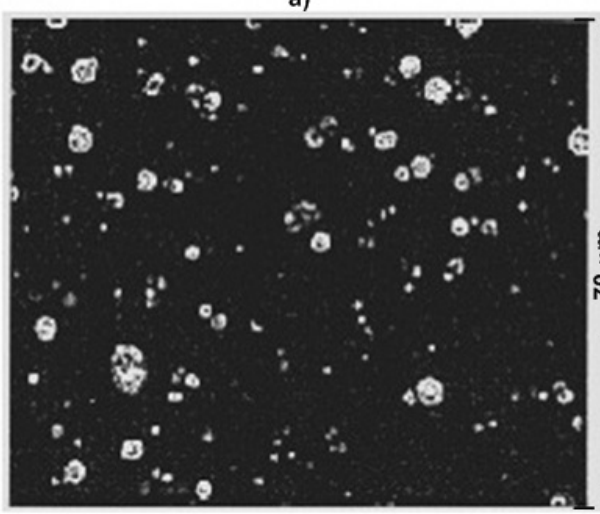

b)

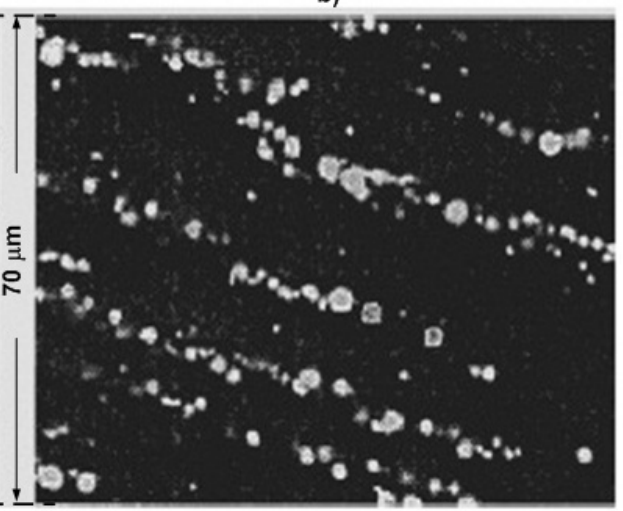

Figura 2.17: Imagem de partículas magnéticas na matriz polimérica de um elastômero. Em (a) com partículas dispersas randomicamente e, em (b) com partículas alinhadas pela aplicação do campo magnético. (Adaptado: Jolly et al, 1996 [68]).

Normalmente quando se aplica campos magnéticos nos elastômeros ${ }^{8}$ com suas ligações cruzadas, as partículas se agrupam em cadeias que ficam bloqueadas na estrutura alterando suas propriedades reológicas.

\footnotetext{
${ }^{8}$ Os elastômeros são um tipo de polímero (Poli = vários e Meros = unidades), com associação de várias cadeias carbônicas $\left(\mathrm{CH}_{n}\right)$, que podem apresentar ligações cruzadas em baixa e alta densidade cruzadas internamente. Os elastômeros degradam facilmente com o calor, não são reversíveis e não servem para reutilização.
} 
Entretanto, segundo Arkadiusz, 2003 [69], as mudanças na estrutura dos FMR não ocorrem imediatamente, nem de forma total, logo após a aplicação do campo magnético variável, mas seu estado de equilíbrio leva um certo tempo. A mudança para um novo estado de equilíbrio depende da taxa de varredura do campo e o processo de agregação das partículas magnéticas continua, mesmo após o campo atingir o valor final.

Segundo Bramantya et al., 2011 [70], o resultado da interação entre os dipolos induzidos produz estruturas em forma de colunas ou grupos de cadeias ("clusters"), que aumentam proporcional ao incremento da intensidade do campo magnético externo.

Este campo magnético, bem como sua memória armazenada, tem um importante efeito na velocidade de propagação da onda ultrassônica e sua atenuação. Pois, segundo Sawada et al., 2002 [71], os agrupamentos formados nos FMR, quando da aplicação do campo magnético, produz anisotropia na propagação da onda sonora.

Segundo Jolly et al., 1996 [68], quando estes materiais (MMR) são submetidos a um campo magnético, sofrem um efeito "bulk" (massa ou volume) devido a interação da indução magnética entre as partículas dentro da matriz estrutural. Se o material for um fluido magnetoreológico (FMR), a interação mútua entre as partículas causa a formação de cadeias, com estruturas aproximadamente alinhadas ao campo magnético aplicado.

Além disso, o mecanismo físico de magnetização macroscópica, segundo Gotoh e Chung, 1984 [72], está associado ao fato das partículas possuírem um grau de liberdade rotacional, e, quando sob ação do campo magnético, através da interação eletromagnética aparece um momento espacial no fluido que orienta os dipolos das partículas ao longo da direção do campo.

Este efeito rotacional é acompanhado de dissipação de energia devido ao trabalho contrário, ao deslocamento rotacional, das forças de resistência viscosa do fluido em torno das partículas. Este mecanismo de dissipação da viscosidade e condução térmica no fluido são responsáveis pela atenuação da onda sonora.

Um método, segundo Gotoh e Chung, 1984 [72], que permite verificar a anisotropia do FMR é medir a velocidade e a atenuação da onda sonora em função do ângulo do campo magnético. Visto que a propagação ultrassônica é bastante sensível ao estado físico e a memória magnética do fluido. Contudo, 
deve-se controlar a potência ultrassônica, pois, sob influência do campo magnético os resultados serão alterados.

A maioria dos modelos dos MMR tem seu comportamento simulado pela interação de dipolos magnéticos entre as partículas adjacentes no interior das cadeia de partículas. Levando em consideração as médias das interações sobre toda a amostra e fazendo analogias com modelos de fluidos eletroreológicos. Entretanto, estes modelos ainda não explicam claramente como a densidade do fluxo magnético se distribui dentro da rede de partículas, ou, como levar em consideração as não-linearidades magnéticas e os efeitos da saturação das partículas.

Apesar do modelo não explicitar todas as questões associadas a não linearidades magnéticas, segundo Jolly et al., 1996 [68], este modelo tem boa concordância com os dados experimentais e permite examinar o comportamento de MMR tanto referente as propriedades mecânicas quanto magnéticas, além de apresentar relativa concordância com outras publicações no campo de tensões sobre FMR.

Estas partículas magnéticas também podem ser revestidas com uma camada dispersante compatível tanto com o líquido transportador quanto com as partículas, e são, segundo Skumiel et al., 2003 [73], descritas usualmente como materiais magneticamente moles por causa do vetor magnetização acompanhar o campo magnético aplicado, sem histerese. De acordo com o autor, estes FMR seriam aplicados na medicina, in vivo, como drogas alvo ("target drugs") de absorção seletiva, que pode enriquecer um tecido específico do corpo pela aplicação de um campo magnético.

Estes materiais magnetoreológicos tiveram inicialmente suas aplicações mais voltadas para área industrial em controles de amortecimentos, suspensão veicular, freios, embreagens etc. Atualmente, tem-se incrementado pesquisas para aplicações nas áreas médicas e biológicas. Neste trabalho fazemos uso de um FMR da empresa "Lord Corporation, MR solution Division - model MRF-122EG (022908 3)", para aplicações na área médica, em "phantoms" que simulem variação de rigidez em tecidos moles, conforme apresentado no capítulo de materiais e métodos. 


\subsection{Ultrassom e interações}

Como apresentamos no primeiro capítulo, há várias vantagens na utilização do ultrassom. A de maior destaque é como instrumento de medição de comprimento (uma "trena" baseada na propagação do som), o que o torna um método muito utilizado devido à sua simplicidade.

Não obstante, existe uma incerteza grande nas medidas das propriedades mecânicas que estão relacionadas de forma indireta, como por exemplo, a razão de Poisson, uma vez que medimos apenas a velocidade longitudinal do som e seria necessário conhecer também a velocidade transversal.

Assim, quando se efetiva os cálculo para extrair os módulos elásticos e/ou viscosos, a razão de Poisson deve ser arbitrada, o que acarreta erros nas medidas, que são proporcionais à dispersão entre o valor real da razão de Poisson e aquele estimado.

Outro fator importante nesta interação som-meio é a necessidade de um "elemento que possibilite o acoplamento (geis)" entre a amostra e os transdutores permitindo a transferência de energia, e elimine a interface ar-amostra entre eles, evitando maiores perda de energia (atenuação).

Sempre quando as ondas ultrassônicas se propagam num meio real ocorrerá perdas pelas forças de fricção, que por sua vez produzem um leve aquecimento localizado. Estas perdas são chamadas de "atenuação", que são causadas por diversos fatores, tais como: divergências na frente de onda, reflexões elásticas nas interfaces planas, espalhamento elástico devido as irregularidades e/ou absorção desta energia no meio, sendo esta última, a de maior predominância.

De acordo com Christensen, 1988 [74], a causa exata da absorção dos meios biológicos, não é amplamente conhecida, mas está relacionada a uma variedade complexa de interações. E pode ser associada a um modelo simples de viscosidade de um fluido, a fim de fornecer a natureza matemática desta perda de energia. Todavia, um tecido real, não é um fluido ideal, logo, as equações do modelo não descrevem todos os efeitos experimentais observados nos tecidos moles.

Segundo Szabo, 2004 [75], num tecido biológico, a absorção obedece uma lei de potência que depende da frequência, isto resulta numa redução da amplitude de pressão da onda e mudança na sua forma. Enquanto a densidade de potência (I) decai numa taxa duas vezes maior. Como pode ser visto na 
figura 2.18.

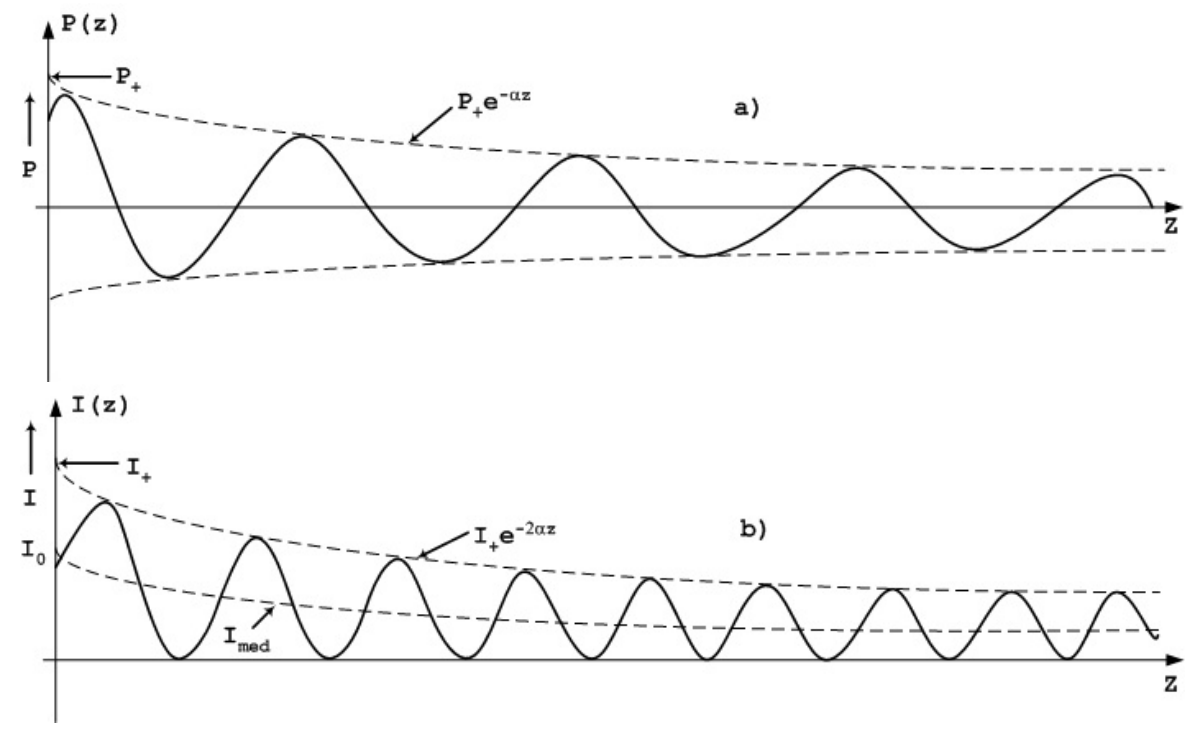

Figura 2.18: Em (a) decaimento exponencial $\left(e^{-\alpha z}\right)$ da onda de pressão com fator de atenuação $\alpha$; em (b) decaimento exponencial $\left(e^{-2 \alpha z}\right)$ da densidade de potência $\left(\mathrm{I}=\mathrm{P}^{2} / \mathrm{Z}\right)$ numa taxa duas vezes maior.

Se considerarmos uma onda plana se propagando numa direção 'z', para uma única frequência $\left(f_{c}\right)$, obedecendo a equação 2.31 :

$$
\mathrm{P}(z, \mathrm{t})=\mathrm{P}_{0} \cdot \mathrm{e}^{\mathrm{i}\left(\omega_{\mathrm{c}} \mathrm{t}-\mathrm{kz}\right)},
$$

o termo que expressa a diminuição da amplitude $\left(e^{-\alpha z}\right)$ pode ser adicionado à equação de propagação da onda, conforme equação 2.32 :

$$
\mathrm{P}(z, \mathrm{t})=\mathrm{P}_{0} \cdot \mathrm{e}^{\mathrm{i}\left(\omega_{\mathrm{c}} \mathrm{t}-\mathrm{kz}\right)} \cdot \mathrm{e}^{-\alpha z},
$$

em que, o fator de atenuação $\left[\alpha\left(f_{c}\right)\right]$ é dado na maioria das vezes em $[\mathrm{dB} / \mathrm{cm}]$, enquanto a amplitude de pressão é usualmente expressa em decibel (dB). Se tomarmos a razão entre duas amplitudes $\left(\mathrm{P}\right.$ e $\left.\mathrm{P}_{0}\right)$, numa escala logarítmica, temos:

$$
\begin{gathered}
\operatorname{Razao}(\mathrm{dB})=20 \cdot \log _{10}\left(\frac{\mathrm{P}}{\mathrm{P}_{0}}\right) \quad \text { Ou, considerando que } \mathrm{I}_{0} \propto \mathrm{P}_{0}^{2} \text { temos, } \\
\operatorname{Razao}(\mathrm{dB})=10 \cdot \log _{10}\left(\frac{\mathrm{I}}{\mathrm{I}_{0}}\right)=10 \cdot \log _{10}\left(\frac{\mathrm{P}}{\mathrm{P}_{0}}\right)^{2}
\end{gathered}
$$

Entretanto, medidas experimentais mostram que na faixa de frequência dos ultrassons médicos, a atenuação $(\alpha(f)$ - em função da frequência) é mais 
próxima de uma função linear para muitos tecidos moles, como gordura e tecido glandular.

Estes efeitos podem ser visto através do gráfico de tensão ("stress") versus deformação ("strain") 2.19 apresentado por Wellman et al., 1999 [76].

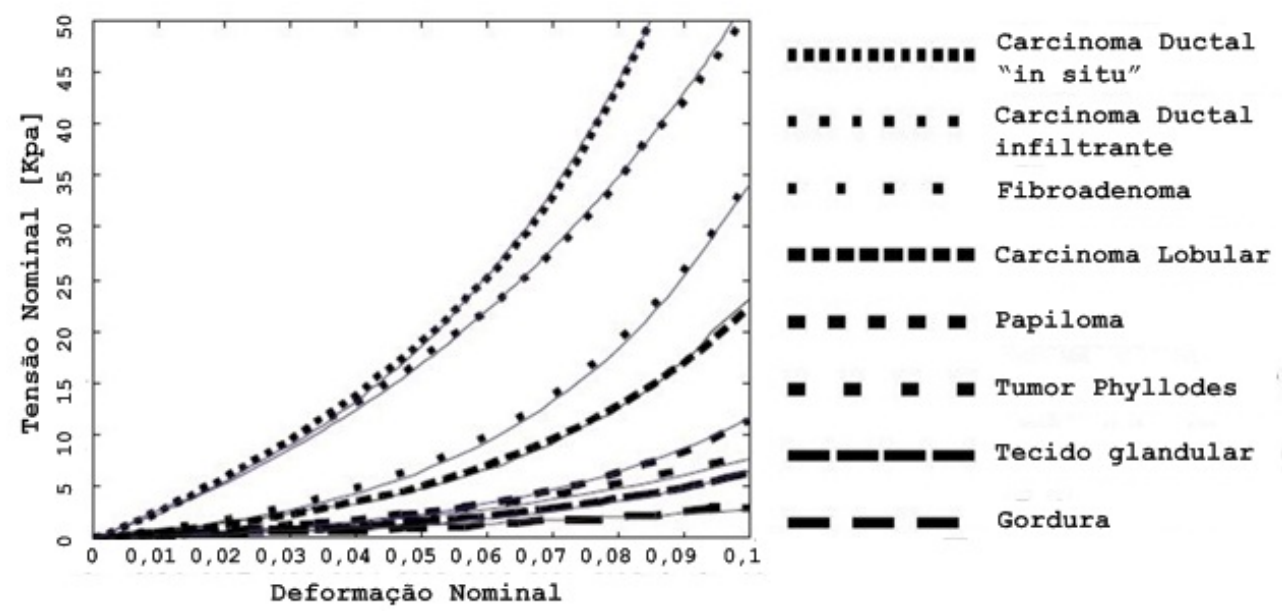

Figura 2.19: Curva tensão $x$ deformação para oito diferentes conjuntos de tecido mamário (adaptado: wellman et al., 1999 [76]).

Assim, o gráfico 2.19 nos mostra que os carcinomas tem um comportamento altamente não linear, enquanto a gordura é aproximadamente linear e extremamente mole.

\subsubsection{A fonte de ultrassom}

Um outro elemento indispensável no estudo da interação do som com o meio é entender como a fonte de ultrassom atua, quais suas características e de que forma ele interfere nos resultados observados.

Os fatores fundamentais que determinam os parâmetros de um transdutor são a sua geometria (forma: retangular, circular, prismático etc), o material piezoelétrico, a orientação cristalográfica do meio piezoelétrico com respeito a polarização elétrica e a fixação dos elétrodos. Ao considerar um elemento piezoelétrico prismático conforme o diagrama da figura 2.20 , em que aplica-se uma voltagem (V) em suas faces, gera-se uma onda que se propaga nesta mesma direção.

As faces opostas da cerâmica são banhadas com um filme de metal condutor. Um gerador de voltagem é acoplado aos elétrodos que produz um 


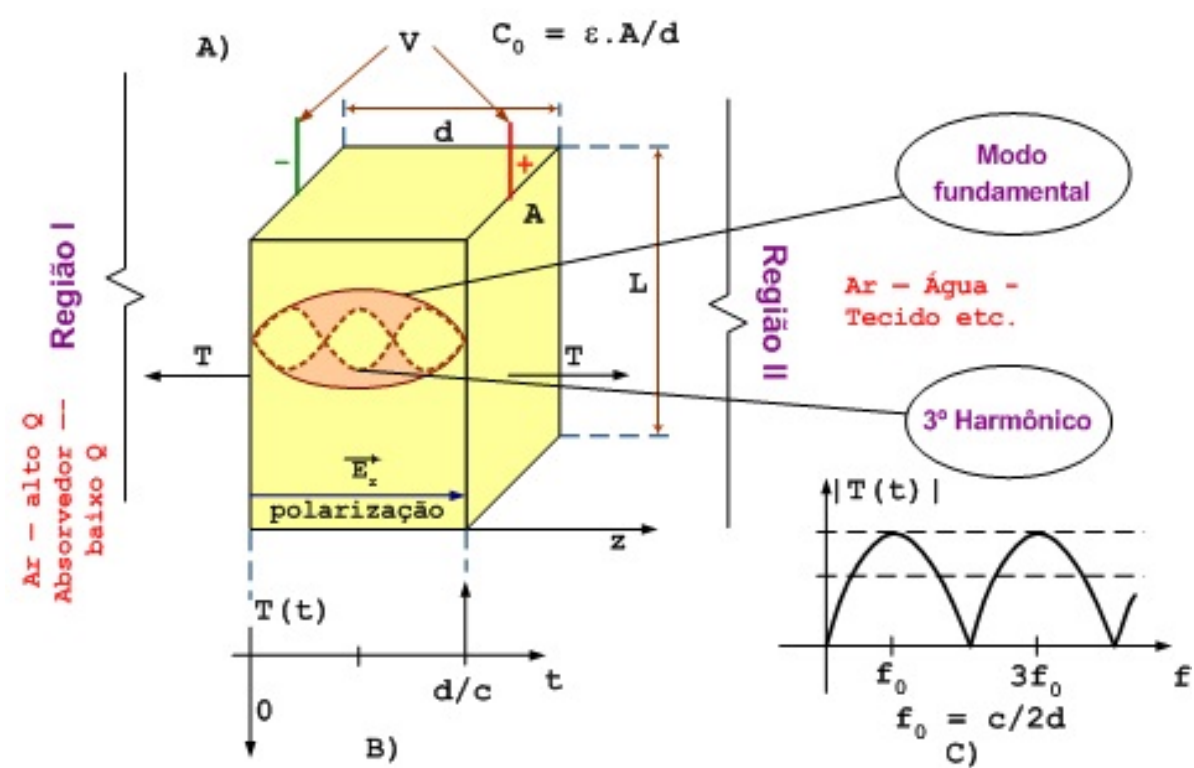

Figura 2.20: Diagrama de um meio piezoelétrico com as curvas de resposta de tensão no tempo e frequência. (adaptado Szabo, 2004 [75]).

campo elétrico $\left(E_{z}\right)$, cruzando a espessura 'd' $(d<<L)$, que se propaga no tempo " $d / c$ " com amplitude dada por:

$$
\mathrm{E}_{z}=\mathrm{V} / \mathrm{d}
$$

Isto resultará numa ação de compressão das ondas. Em uma das regiões (I) acopla-se um material que absorva a onda e na outra região (II) obtém-se a onda para excitação dos meios. A frequência de excitação, conforme citado no segundo parágrafo desta seção, é característica da construção de cada elemento piezoelétrico.

$\mathrm{Na}$ prática, a orientação do campo aproveita a direção de maior coeficiente piezoelétrico, que, na maioria dos materiais coincide também com a direção de tensão de compressão. Conhecendo a espessura e modos de vibração, a pressão nas faces terão direção, preferencialmente, longitudinais.

A fum de combinar a excitação com as condições de bordas, um número impar de meio comprimentos de onda $(\lambda / 2)$ deverão ser ajustados entre as interfaces do cristal.

Atualmente a maioria dos transdutores de ultrassom são agrupados em forma de matrizes ("arrays"). Os primeiros eram de disco circular concêntricos, hoje são mais comuns os de barras (prismáticos) de comprimento alongados, conforme exemplos apresentados na figura 2.21 (D, C), respectivamente. 


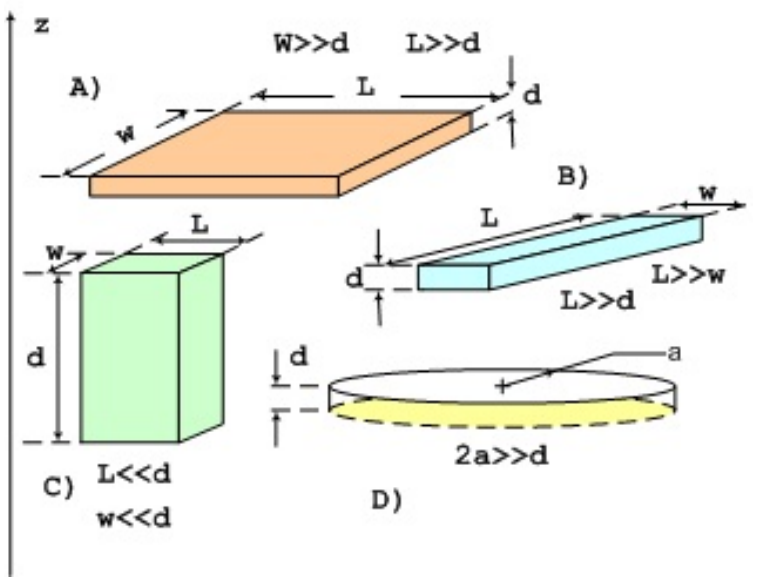

Figura 2.21: Diagrama de algumas geometrias de cerâmicas transdutoras para modos de vibração ao longo da direção "z". (adaptado Szabo, 2004 [75]).

Ao observarmos um transdutor com geometria circular, tipo o da figura 2.22 (A, B), de um ponto no eixo " $\mathrm{z}$ ",

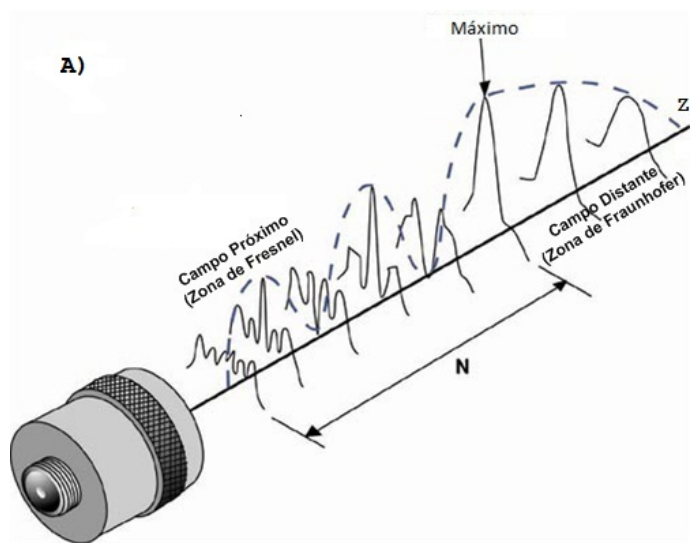

(a) Transdutor circular.

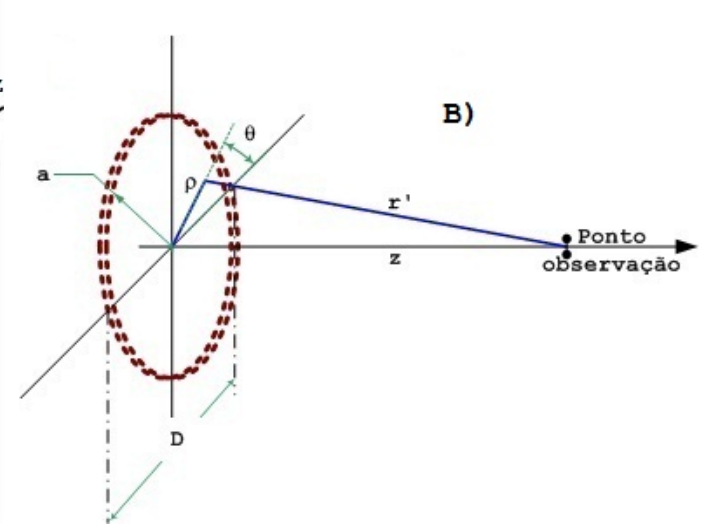

(b) Esquema transdutor circular.

Figura 2.22: Diagrama apresentando transdutor de geometria circular com campo de pressão próximo e distante.

veremos uma variação muito rápida da onda de pressão assumindo valores nulos, num campo muito próximo ("near field" - região de Fresnel) a superfície do transdutor, conforme figura 2.23, caracterizando uma interferência completamente destrutiva.

A medida que ocorre o distanciamento da superfície do transdutor o padrão de deslocamento espacial da onda de pressão sofre um decaimento suave, do tipo $1 / Z$, conhecido como zona de campo distante ("far field" - região de Franhourf). 


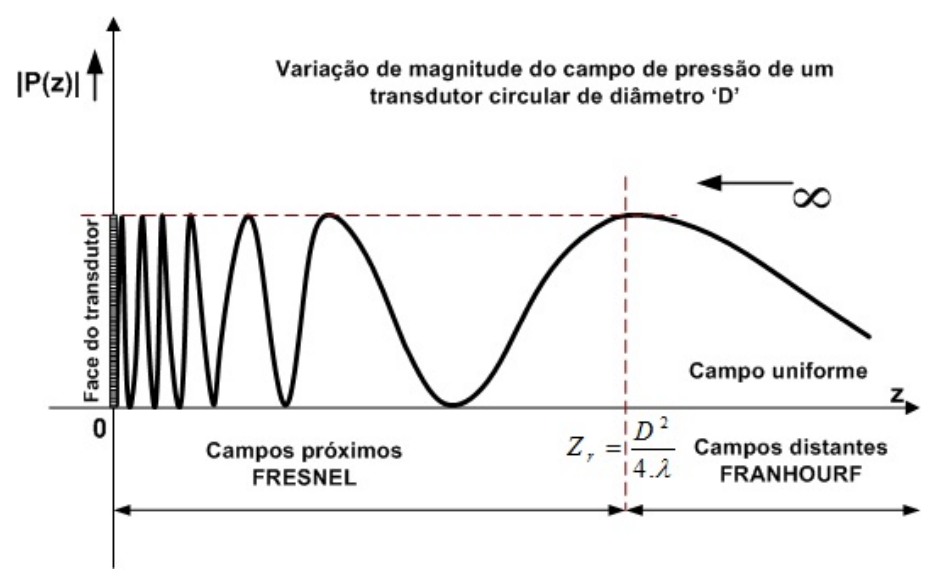

Figura 2.23: Variação do campo próximo e distante, de uma onda de pressão, num transdutor com geometria circular. (Adaptado: Christensen (1988) [74])

O resultado para a amplitude de pressão sonora na direção "z", com esta geometria circular, é expressa pela equação 2.35 [74].

$$
p(z, t)=Z \cdot u_{0}\left[\cos (\omega t-k z)-\cos \left(\omega t-k \sqrt{a^{2}+z^{2}}\right)\right]
$$

em que, ' $Z$ ' é a impedância acústica, $\mathfrak{u}_{0}$ é a velocidade de propagação da onda, $\omega$ é a frequência angular e ' $k$ ' é a constante de propagação da onda acústica.

Então, o ponto que marca a transição entre os campos próximos e distantes é obtido considerando o último máximo da função, para que se tenha a maior distância "z". Isto ocorre quando os dois cossenos da função se somam, ou seja, quando a diferença de fase do sinal for igual a $\pi$. Deste modo, as ondas terão componentes positivas e suas interferências serão construtivas. Este ponto denotado por $Z_{r}$, onde $Z_{r}>>$ a, é expresso pela equação 2.36 .

$$
\mathrm{Z}_{\mathrm{r}}=\frac{\mathrm{a}^{2}}{\lambda}=\frac{\mathrm{D}^{2}}{4 . \lambda}
$$

em que, 'a' é o raio da cerâmica circular, ' $D^{\prime}$ é o diâmetro e ' $\lambda$ ' é o comprimento de onda.

Assim, para um transdutor não focado usado em imagens médicas, a estrutura do corpo que está sendo imageado, não está totalmente na região de radiação dos campos distantes, onde seria desejável por ter campos uniformes. Portanto, se usássemos um transdutor circular de 2,0 cm de diâmetro, com frequência central de 2,25 $\mathrm{MHz}$, velocidade de 1500,00 m/s, a distância de transição $\left(Z_{r}\right)$ ocorreria em 15,0 cm, o que seria muito profundo se comparado a largura de uma pessoa mediana. 
Quando excitamos a cerâmica com um pulso estreito, esta ressoa senoidalmente na frequência fundamental. O envelope desta onda decai numa taxa proporcional as perdas (internas e de transmissão - conforme fator $\mathrm{Q}$, equação 2.27) do transdutor, visto no gráfico da figura 2.24 .

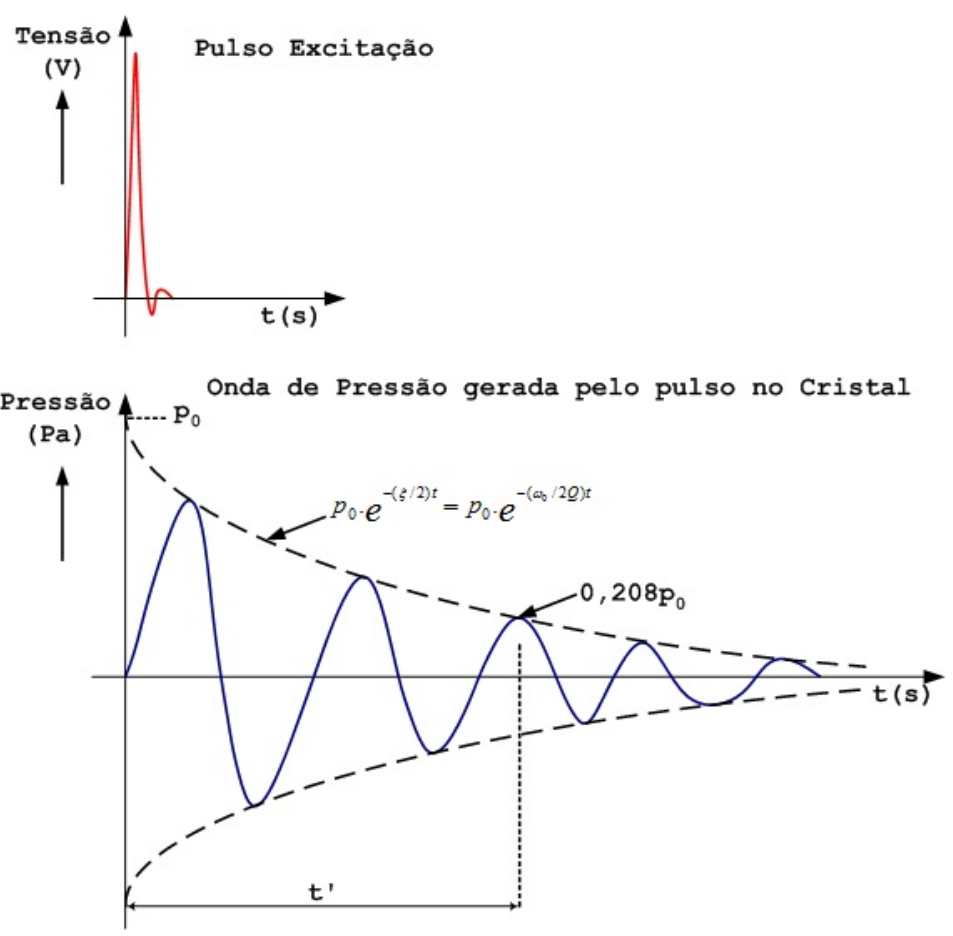

Figura 2.24: Forma de onda de pressão quando excitada por pulso estreito. A onda de pressão decai segundo fator $\mathrm{Q}$ [ $\mathrm{t}^{\prime} \approx \mathrm{Q}$ períodos de potência]. (adaptado: Christensen, 1988 [74])

Segundo Christensen, 1988 [74], os meios piezoelétricos atuam como um sino ou diapasão quando recebe um golpe de martelo. Com a diferença no tempo de vibração, pois, as perdas devido a radiação do transdutor ultrassônico serão maiores e não permanecerá ressoando por muito tempo.

Um fator importante e desejável em qualquer instrumento de medida é saber a sua capacidade ou habilidade de medição. Este fator, no transdutor de ultrassom, depende da largura da onda pulsada. Que é determinado pela medição do tempo de ida e volta dos ecos refletidos nas bordas das interfaces do objeto que está sendo investigado.

Definindo um pulso de duração $t^{\prime}$ e usando a relação direta de que distância é igual a velocidade vezes o tempo, temos que:

$$
\text { Resolução axial } \Rightarrow\left(R_{a} x\right) \approx \frac{t^{\prime} \cdot c}{2}
$$


Então a habilidade do instrumento em diferenciar duas interfaces consecutivamente espaçadas, na direção axial (ou longitudinal) é chamada de Resolução axial. A resolução axial se refere a resolução espacial na direção de propagação do feixe sonoro. E pode ser escrita também em função do comprimento de onda $(\lambda)$, como:

$$
\left(\mathrm{R}_{\mathrm{a}} \mathrm{x}\right) \approx \frac{\mathrm{Q} \cdot \mathrm{c}}{4 . \mathrm{f}_{0}} \Rightarrow\left(\mathrm{R}_{\mathrm{a}} \mathrm{x}\right) \approx \frac{\mathrm{Q} \cdot \lambda}{4}
$$

Do exposto, podemos perceber que o comportamento deste feixe ultrassônico é importante para determinar a sensibilidade espacial do nosso instrumento de medição.

\subsubsection{Velocidade e Atenuação Sonora}

Segundo Cobbold, 2007 [56], conhecer a velocidade e a atenuação da onda ultrassônica do meio biológico em estudo é importante, visto que, há um amplo limite de valores obtidos devido a variações na forma de preparação da amostra, configuração do experimento, temperatura, tempo de execução das medições, dentre outras. Isto pode ser visto no resumo apresentado na figura 2.25 .

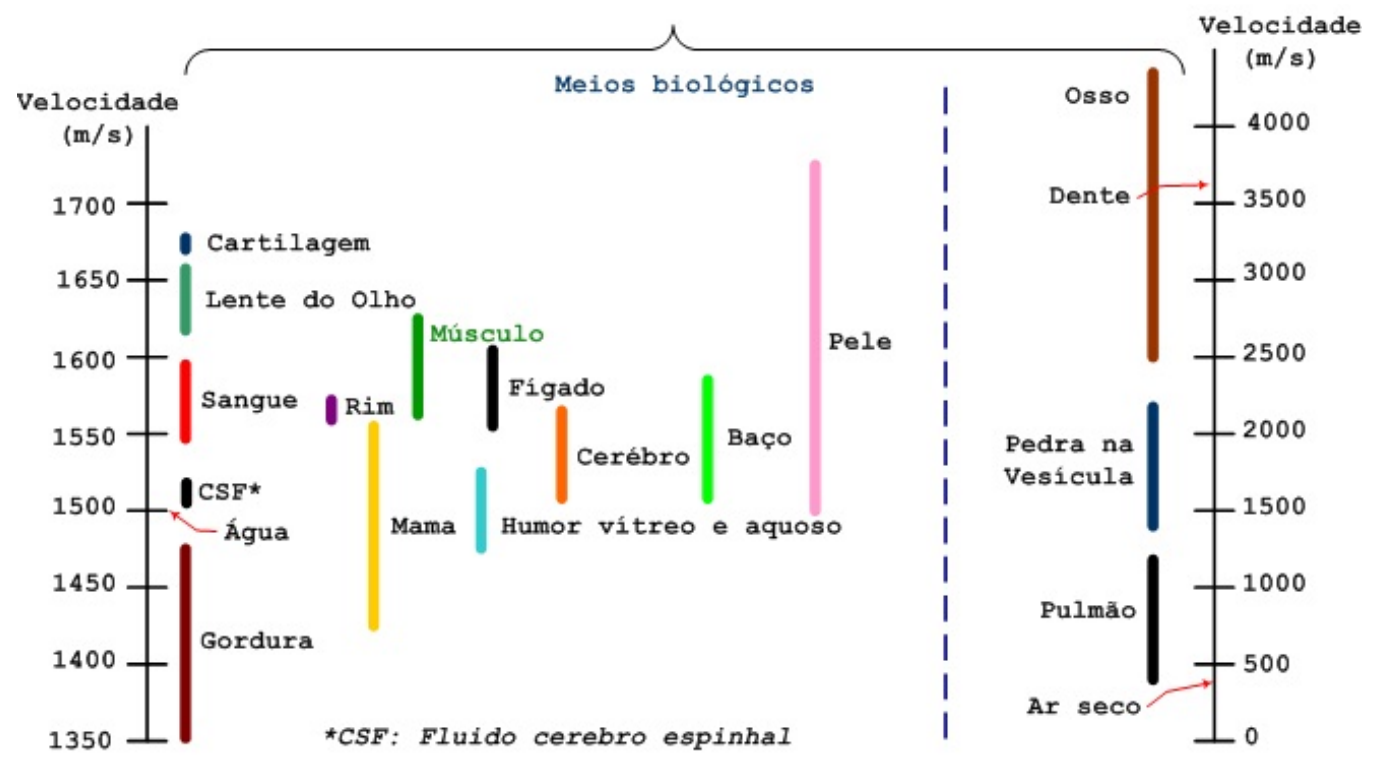

Figura 2.25: Velocidade do som medido em diferentes meios biológicos, numa temperatura entre $20^{\circ} \mathrm{C}-37^{\circ} \mathrm{C}$, para frequências entre $1 \mathrm{MHz}$ a $10 \mathrm{MHz}$. (Adaptado: Cobbold, 2007 [56]). 
Além da velocidade dos tecidos moles terem um espectro relativamente estreito, a medida da velocidade numa amostra extraída de um tecido ("ex-vivo") pode diferir significativamente da velocidade do tecido "in-vivo".

Quando uma onda plana ideal passa através de um meio, sofre perda de energia por absorção e espalhamento devido a mudanças de compressibilidade e densidade. A absorção é o processo de transformação da energia cinética da onda em calor, energia química ou luz, além dos efeitos da condução térmica. Por outro lado, o espalhamento representa uma mudança na direção de propagação da onda incidente noutras direções. Consequentemente, haverá novas absorções e múltiplos espalhamentos.

Desde modo, a atenuação da onda é dada pela contribuição dos efeitos de absorção e espalhamento (que incluem a reflexão e refração). Ou seja, a amplitude do coeficiente de atenuação $(\alpha)$, conforme visto no início desta seção, é a soma das amplitudes dos coeficientes de absorção e espalhamento: $\alpha=$ $\alpha_{s}+\alpha_{a}$. E dependem da frequência, temperatura e pressão.

Todavia, Cobbold, 2007 [56], nos mostra através de diversos trabalhos, como apresentado na tabela D.4 em anexo, que apesar de alguns meios o espalhamento contribuir mais para o valor da atenuação, a absorção também é a componente que mais contribui na perda de energia do espalhamento.

Uma vez que a atenuação é a combinação dos efeitos da absorção e espalhamento, é esperado que a dependência da frequência seja também para ambos os fenômenos. Para os fluidos puros não há espalhamento, então as características de absorção e atenuação são idênticas. E os efeitos da viscosidade governam a atenuação e as perda por relaxação. Contudo, ambos os termos levam a uma dependência da frequência, numa primeira aproximação, variando com o quadrado da frequência. Assim:

$$
\alpha=\alpha_{0} \cdot f^{2}
$$

onde $\alpha_{0}$ é um fator dependente da temperatura que pode ser expresso em $\mathrm{Np} /\left(\mathrm{cm} \cdot \mathrm{MHz} z^{2}\right)$ ou $\mathrm{dB} /\left(\mathrm{cm} \cdot \mathrm{MH} z^{2}\right)$, e f em MHz.

De modo geral, pode ser visto que uma boa aproximação para a dependência da frequência para a maioria dos tecidos moles pode ser expressa pela relação:

$$
\alpha=\alpha_{0} \cdot f^{n}
$$

em que 'n' é verdadeiro no limite entre 1 e 2. 
Um resumo dos resultados para diferentes fontes e uma variedade de condições experimentais é apresentado na figura 2.26 .

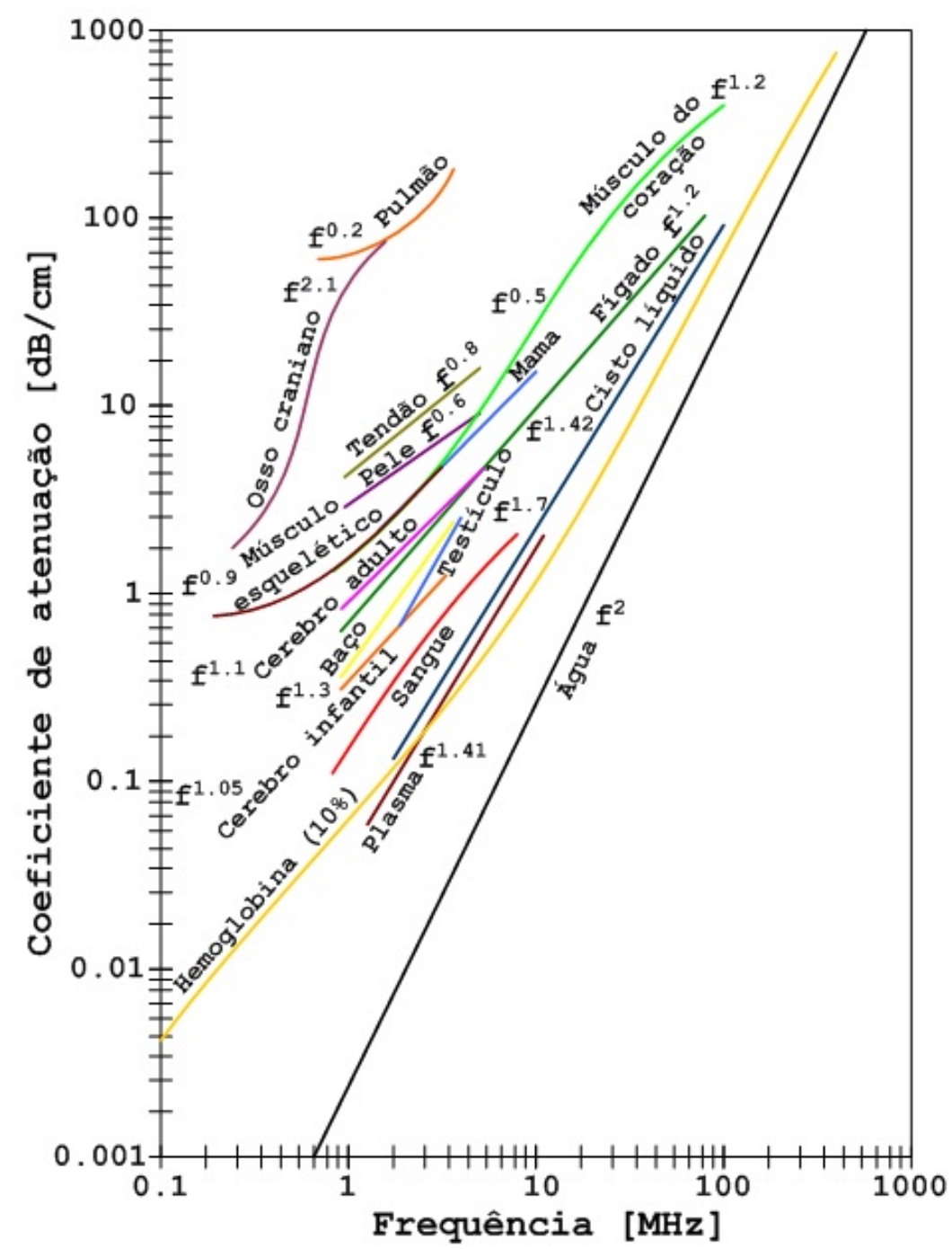

Figura 2.26: Resumo de resultados experimentais publicados de atenuação x frequência para vários meios biológicos e água. (Adaptado: Cobbold, 2007 [56, 77, 78]).

Entretanto, a maioria dos experimentos utilizam amostras extirpadas dos tecidos, "ex-vivo", o que leva os resultados das características (velocidade, atenuação e frequência), a valores com diferenças razoáveis entre a amostra extraída e a medida "in-vivo", que segundo Cobbold, 2007 [56], podem estar associadas a presença do fluxo sanguíneo ou também das condições na qual as amostras foram armazenadas.

Como a água pura é sempre utilizada como meio de referência para medidas de velocidade e atenuação, é importante que a mesma seja medida 
com bastante cuidado e precisão, a fim de minimizar os erros e possibilitar uma melhor discriminação dos meios.

Bamber, 2004 [77], tem buscado rever as características de atenuação versus frequência para diversas espécies biológicas. Além de também demonstrar que muitas medidas podem ser obtidas "in-vivo", através do processamento de dados dos sistemas de ultrassom diagnóstico. Almejando assim, desenvolver uma metodologia para identificar os tecidos anormais, todavia, ainda sem muito sucesso.

Em anexo (E.5), é apresentada uma tabela com valores medidos de velocidade do som, densidade, atenuação e parâmetros de não linearidade para diversos tecidos humanos moles, que, segundo Cobbold, 2007 [56], foram utilizados por Mast, 2000 [79] na investigação de correlação entre os vários parâmetros acústicos. Onde mostra, por exemplo, que a densidade e a velocidade do som, para uma ampla faixa de tecidos, tem um alto fator de correlação $(0,917)$. 


\section{Capítulo}

\section{Materiais e Métodos}

\subsection{Simuladores de Tecidos - "Phantom - Fantoma"}

$\mathrm{O}$

S simuladores de tecido biológicos também denominados "Phantoms ou fantomas", são uma alternativa inicial para substituir os tecidos "in-vivo" ou "ex-vivo" por serem mais acessíveis, apresentarem características físicas e morfológicas muito próximas do tecido humano, serem mais duradouros e fáceis de reproduzir, além de facilitar as relações que envolvem as questões éticas.

Os simuladores para estudos com ultrassom, geralmente são confeccionados com parafinas, ou gelatinas à base de tecido bovino ou suíno, misturadas com partículas espalhadoras de ultrassom, que permitem uma boa discriminação dos meios de propagação da onda, conforme o exemplo mostrado na figura 3.1.

A)

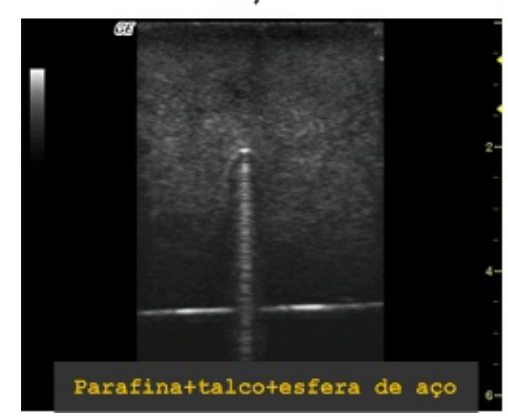

B)

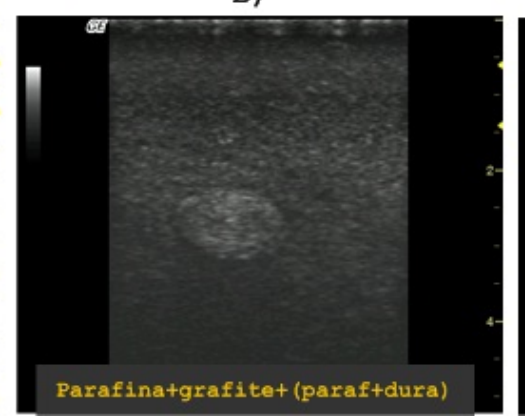

C)

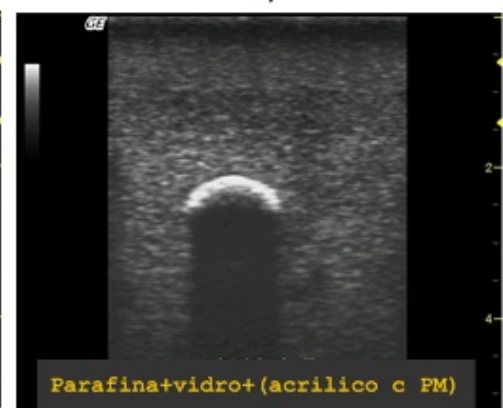

Figura 3.1: Simuladores de tecidos com diferentes partículas espalhadoras e inclusões: (A) Parafina com talco + inclusão de uma esfera de aço, (B) Parafina gel com grafite + inclusão de parafina cristal com maior concentração de espalhador, (C) Parafina com pó de vidro + parafina com inclusão de partículas magnéticas e pó de vidro - Imagens em modo $B$ (logic book, GE).

Entretanto, estes materiais (gelatina e parafina) [80] possuem uma estrutura complexa de cadeias entrelaçadas de monômeros que altera suas propriedades ópticas, magnéticas e mecânicas a medida que se incrementa o 
grau de polimerização ou agrupamento de suas cadeias. Segundo Crescenti et al., 2007 [81], estas mudanças são esperadas porque ocorre um alargamento das cadeias poliméricas e, muitas vezes a formação de ligações cruzadas na estrutura molecular.

Estes fatores, além das variações de temperatura, interferem diretamente na caracterização destes simuladores de tecidos. Segundo Yin et al., 2004 [82], a própria norma ASTM D4065-01 [83] especifica que, quando se caracteriza materiais viscoelásticos, é comum surgirem aparentes discrepâncias nos resultados obtidos sob diferentes condições experimentais.

Os simuladores de tecidos usados neste trabalho foram construídos à base de dois materiais: a parafina (gel e cristal) ${ }^{1}$, conforme especificações da figura 3.2, e a gelatina à base de água com tecido bovino (que é uma proteína pura, obtida pela hidrólise parcial e alcalina do colágeno de origem bovina ou suína.), 'Blomm 250'2.

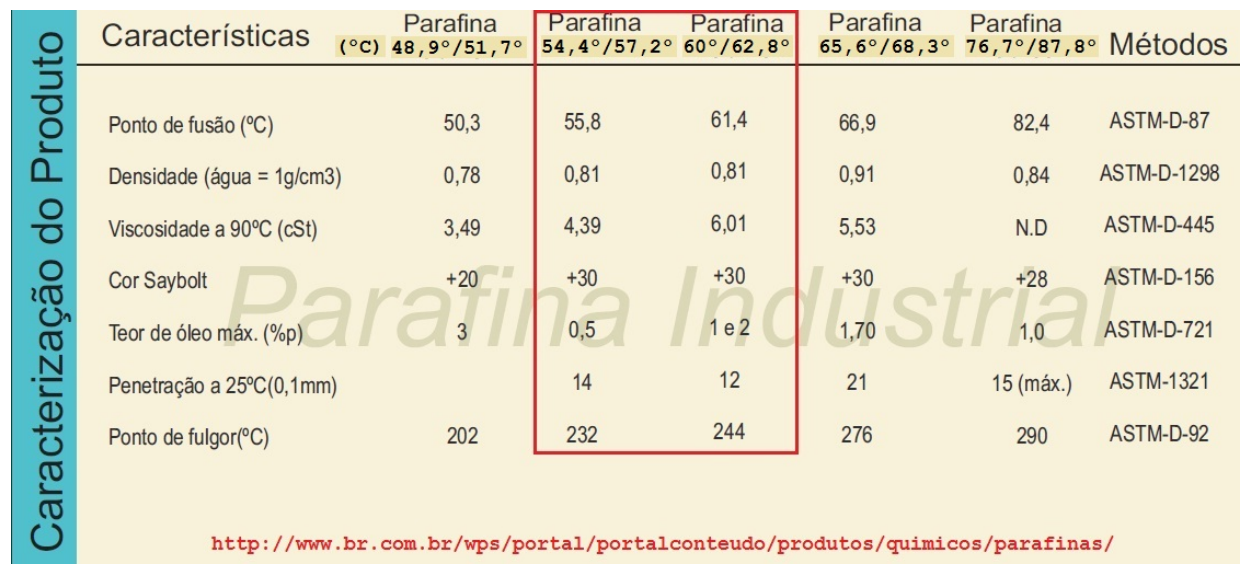

Figura 3.2: Tabela apresentando características da parafina [fornecedor: Petrobrás $S / A]$.

O preparo do "phantom" parafinoso é feito simplesmente aquecendo a parafina em um "Becker" até ficar em estado líquido, em torno de $70{ }^{\circ} \mathrm{C}$, a seguir

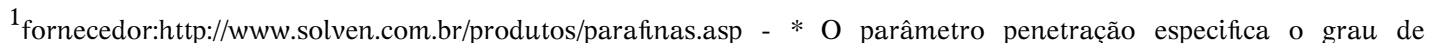
consistência da parafina. Quanto maior o valor, menos consistente é o meio. Este valor é obtido através do ensaio de agulha descrito na norma ASTM-1321.

${ }^{2} \mathrm{O}$ Blomm é a força, expressa em gramas, necessária para penetrar $4 \mathrm{~mm}$ na superfície de um gel de gelatina, segundo método oficial da AOAC. Está relacionado à elasticidade mecânica do gel e é usado para classificar os tipos de gelatina. Varia de 50 Blomm a 300 Bloom a às vezes nos referimos a baixo, médio ou alto Bloom, com os seguintes limites: Baixo Bloom = força do gel abaixo de $120 \mathrm{~g}$, Médio Bloom $=$ força do gel entre $120 \mathrm{~g}$ e $200 \mathrm{~g}$ e Alto Bloom = força do gel acima de $200 \mathrm{~g}$. Fontes: BRASIL ALIMENTOS - no 27 - Setembro/Outubro de 2004. www.signuseditora.com.br/BA/pdf/27/27\%20-\%20Gelatina. pdf; http://www.decorart.com.br/products/500-g-gelatina-bovina-150-bloom; http://www.rousselot.com/ pt/gelatina-rousselot/caracterisiticas/definicao-e-descricao/bloom-ou-forca-do-gel/. (último acesso: 03/12/2012).
} 
acrescenta-se o elemento espalhador de Ultrassom misturando-o bastante com uma espátula, porém com baixa velocidade para evitar a formação de bolhas; em seguida, derrama-o em um molde de acrílico, vidro, alumínio ou porcelana e o leva a um forno pré-aquecido a $60{ }^{\circ} \mathrm{C}$, deixando-o por um curto período (em torno de $10 \mathrm{~min}$ ), a fim de diminuir o gradiente de temperatura. Deve-se evitar choques térmicos, a fim de não criar bolhas de ar no seu interior.

Nos "phantoms" com inclusões, a depender da quantidade e tamanho das inclusões, prepara-se o molde com espaços internos para ser preenchido com outro material.

Neste trabalho, estas inclusões consistiram de um meio fluido ou gel marcado com partículas ferromagnéticas $\left(\mathrm{Fe}_{3} \mathrm{O}_{4}-\mathrm{FMR}\right)$. A figura 3.3 apresenta um modelo cilíndrico com uma inclusão esférica, de volume aproximadamente igual a $2 \mathrm{~mL}$, o qual foi utilizado para verificar mudanças de rigidez quando submetido a um campo magnético externo.

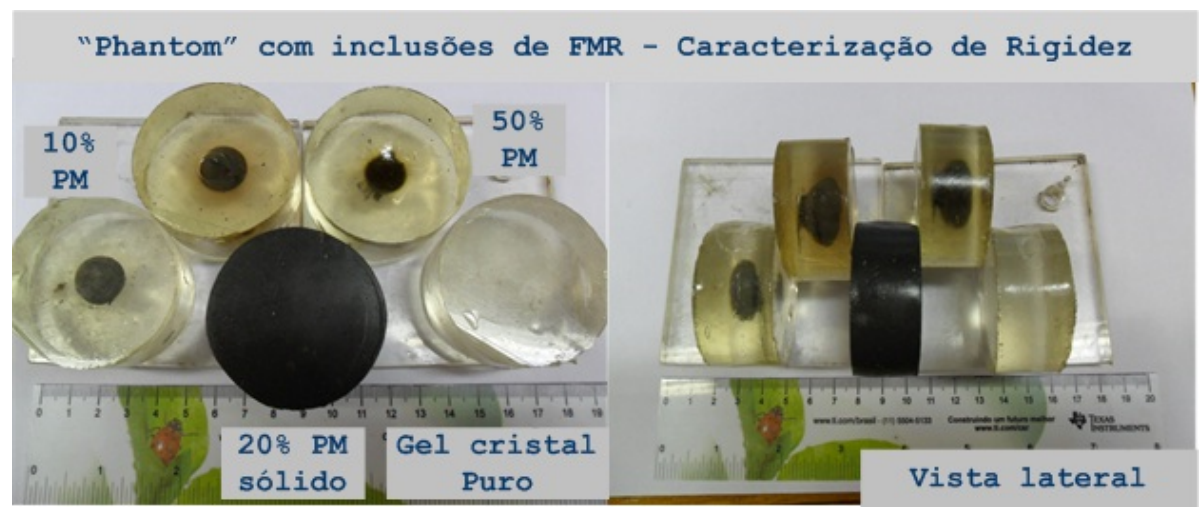

Figura 3.3: Simulador de tecido apresentando inclusões de partículas ferromagnéticas $\left(\mathrm{Fe}_{3} \mathrm{O}_{4}-\mathrm{FMR}\right)$.

Conforme descrito no trabalho de Fong et al., 2001 [84], a preparação da gelatina à base de tecido bovino $\backslash$ suíno é bem simplificada, porém, neste trabalho, a adição dos novos componentes espalhadores e marcadores magnéticos exigiram mais um mecanismo de preparo, além de recalcular as quantidades a fim de manter as proporções da mistura.

$\mathrm{Na}$ tabela 3.1 são apresentadas as proporções de componentes usados na preparação dos "phantoms" construídos a base de gelatina bovina 'blomm' 250. Além da inclusão dos novos componentes de contraste em ultrassom (absorvedor e espalhador), como pó de vidro, talco, grafite e pó de acrílico, mais o material marcado com partículas ferromagnéticas (reológico), contudo foram mantidas a 
proporcionalidade dos componentes.

Tabela 3.1: Composição química usada na preparação da gelatina bovina 250 Blomm com 10\% FMR (adaptado: Fong et al., 2001 [84]).

\begin{tabular}{|c|c|}
\hline Componentes & Massa (\%) \\
\hline Água Mili-Q (usado água comum) & 76,20 \\
\hline Gelatina Bovina \Suína & 8,08 \\
\hline Emulsionante (detergente líquido) & 2,00 \\
\hline Formaldeído & 3,22 \\
\hline Pó de vidro $(38 \mu \mathrm{m}-74 \mu \mathrm{m})$, talco, grafite ou acrílico & 0,50 \\
\hline Material reológico (Fluído magnetoreológico - FMR) & 10,00 \\
\hline Totalização & 100,00 \\
\hline
\end{tabular}

Os passos para o preparo do simulador de gel polimérico à base de tecido bovino \suíno, adaptados de Vieira, 2009 [28] foram: A pesagem dos componentes, segundo concentração requerida. Assim, para uma concentração de $8 \%$, que determinará a rigidez da amostra, deve-se ter 8\% (em massa) de pó de gelatina ${ }^{3}$, que foi introduzido num "becker" contendo $76,2 \%$ de água a temperatura ambiente, conforme apresentado na tabela 3.1, e neste exemplo, para uma concentração de $10 \%$ de partículas magnéticas.

Para outras concentrações, alterava-se a proporção de água e material fluido magnético. O percentual em massa, para os meios líquidos, foi obtido através da relação de densidade $(\rho=m / V)$.

Esta mistura foi então aquecida a $50{ }^{\circ} \mathrm{C}$ num aquecedor - agitador térmico da Fusatom, modelo 752A, $650 \mathrm{~W}-230 \mathrm{~V}$, com faixa de temperatura entre $(50 \pm 5){ }^{\circ} \mathrm{C}-(300 \pm 5){ }^{\circ} \mathrm{C}$, e mantida sob agitação até a obtenção de uma solução completamente homogênea. Na sequência, o aquecimento foi desligado e a solução foi mantida sob agitação até atingir a temperatura em torno de $35{ }^{\circ} \mathrm{C}$. Então, após 5 minutos de resfriamento, quando a temperatura ficou em torno de $28{ }^{\circ} \mathrm{C}$ a $30{ }^{\circ} \mathrm{C}$, foram adicionados 3,2\% de formaldeído $\left(\mathrm{Acros}^{\mathrm{R}}\right.$ ).

Após mais 5 minutos, acrescentou-se $0,5 \%$ de pó de vidro (talco, acrílico ou grafite), com tamanhos entre $38 \mu \mathrm{m}$ e $74 \mu \mathrm{m}$, à solução, que foi mantida sob agitação mecânica por mais 10 minutos para garantir uma boa homogeneização. Por último, foram acrescidos o emulsionante (detergente líquido) e o fluido

\footnotetext{
${ }^{3}$ (Gelita ${ }^{\mathrm{R}}$ América do Sul, Brasil).
} 
magnético reológico. Esta composição foi transferida aos recipientes e colocados dentro da geladeira para aguardar sua completa solidificação.

Os simuladores de gelatina foram utilizados para caracterização da rigidez mecânica, numa excitação quase-estática. Além disso, foi utilizado um "phantom" de gelatina, com regiões de rigidez distintas, obtido através de uma exposição a irradiação para teste do sistema de vibração multifrequência. Pois, já é conhecido na literatura, que estes "geis" poliméricos são sensíveis a radiação e têm suas propriedades alteradas [85].

Deste modo, o "phantom" de gelatina (MAGIC gel) apresentado na figura 3.4 e confecionado, conforme características apresentadas por Vieira, 2009 [28], foi irradiado a partir de um campo quadrado de $1,0 \mathrm{~cm} \times 1,0 \mathrm{~cm}$, onde foram depositados $50 \mathrm{~Gy}$ de dose absorvida, utilizando-se uma unidade radioterápica convencional de raios- $\mathrm{X}$ de $10 \mathrm{MeV}$ de energia ${ }^{4}$, do serviço de Radioterapia do Hospital das Clínicas da Faculdade de Medicina de Ribeirão Preto, da Universidade de São Paulo (HC-FMRP-USP).

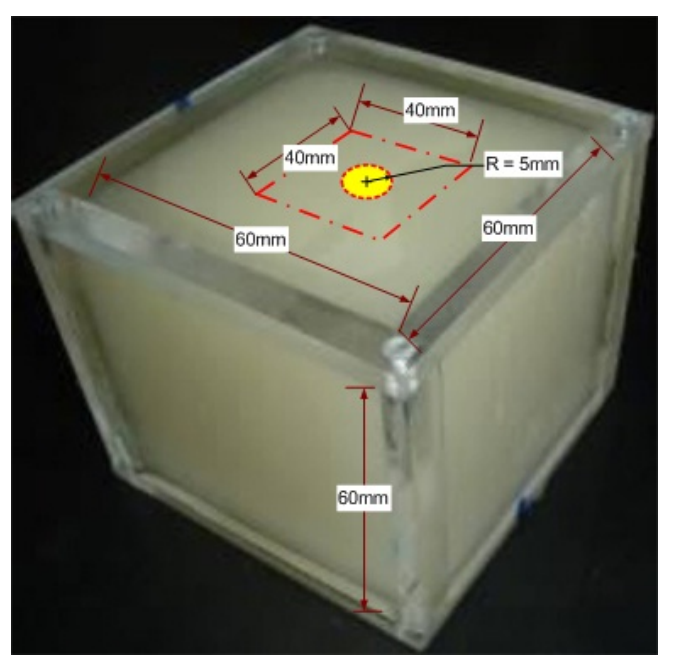

Figura 3.4: Imagem do "phantom" utilizado para testes no sistema oscilador de multifrequência (adaptado Vieira, 2009 [28]).

Este processo alterou a rigidez da área irradiada, região circular de raio $5 \mathrm{~mm}$, dentro do contorno quadrado, mostrada na figura 3.4. Isto permitiu utilizá-lo para testes no protótipo de um oscilador multifrequência construído no inicio desta pesquisa, para mostrar imagens através de processamento Doppler.

Entretanto, após verificar as limitações técnicas para manipular os materiais gelatinosos à base de água, foram priorizados os simuladores

\footnotetext{
${ }^{4}$ modelo Clinac $2300 \mathrm{C} \backslash \mathrm{D}$ (Varian Medical Systems, Inc., Mountain View, CA, EUA)
} 
confecionados em parafina por permitirem melhor emulsão do fluido magnetoreológico, visto que este são embevecidos em óleo.

O fluido magnetoreológico (FMR) utilizado para composição dos simuladores de tecido foi da empresa "Lord Corporation, MR solution Division model MRF-122EG (022908 3)", cujas características, descritas por Bramantya et al, 2011 [70], são: partículas de ferro $\left(\mathrm{Fe}_{3} \mathrm{O}_{4}\right)$ de tamanho médio de $3 \mu \mathrm{m}$ a $10 \mu \mathrm{m}$, fração de volume de $22 \%$, com líquido transportador composto de um óleo de hidrocarbonetos com viscosidade de $(0,042 \pm 0,02)$ Pa.s, a temperatura de $40{ }^{\circ} \mathrm{C}$, e densidade variando de $(2,28-2,48) \times 10^{3} \mathrm{~kg} / \mathrm{m}^{3}$.

Este FMR foi modificado, em relação ao fluido transportador, por outro óleo de hidrocarbonetos, disponível no comércio com a marca STP, cuja densidade é de $(0,87 \pm 0,05) \times 10^{3} \mathrm{~kg} / \mathrm{m}^{3}$, tendo viscosidade média de $(6,26 \pm 0,37) \mathrm{Pa} . s$, a $25{ }^{0} \mathrm{C}$, para uma taxa de cisalhamento de $1 / \mathrm{s}$ e velocidade $1 / \mathrm{min}$.

Este novo óleo utilizado, além de proporcionar uma menor atenuação (em relação a água) da onda ultrassônica, também possibilitou o retardamento no processo de decantação das partículas magnéticas.

Foram preparadas sete amostras para compor as inclusões dos simuladores de tecidos, sendo: uma contendo água filtrada e desgaseificada, outra com apenas óleo transportador e outras cinco misturas de óleo STP com concentrações de partículas magnéticas variando de 10 a 50\%, como mostra a figura 3.5.

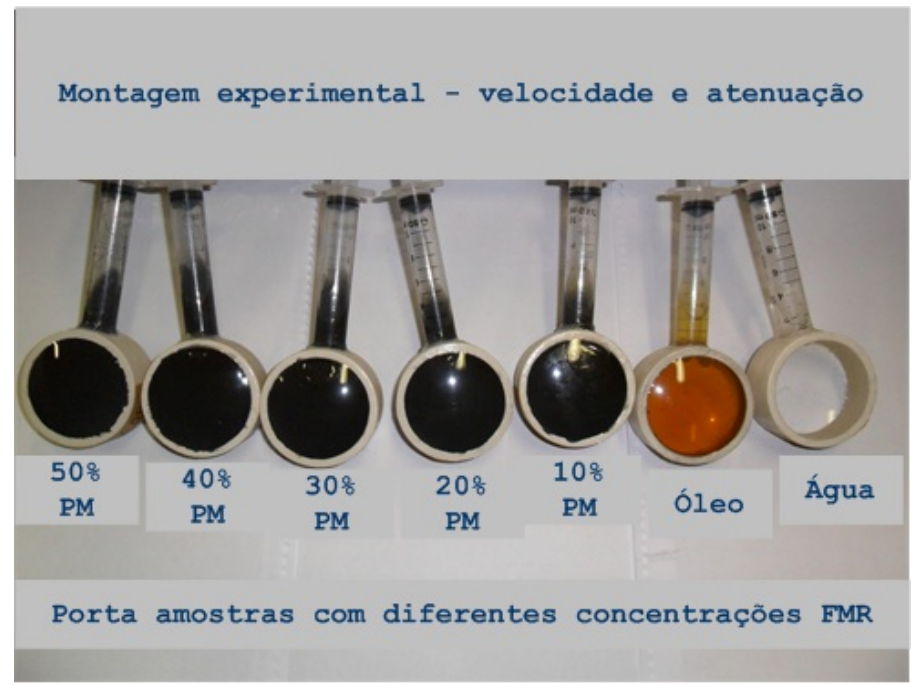

Figura 3.5: Amostras com diferentes concentrações do FMR. 
Todas as amostras fluidas, com partículas magnéticas, tiveram sua viscosidade analisada em um viscosímetro da Anton Paar - Germany, modelo Rheolab QC acoplado a um aquecedor/refrigerador JULABO, modelo F25-MC, da Labortechnik GMbH. O procedimento experimental está descrito no apêndice A.1.

\subsubsection{Analisador de Velocidade e Atenuação}

Um porta-amostra de acrílico, cujas dimensões internas são diâmetro $4,4 \mathrm{~cm}$ e espessura de $2,0 \mathrm{~cm}$; foi construído para analisar a velocidade e a atenuação da onda sonora, na região de campo próximo, com e sem a aplicação de campo magnético, conforme mostra a figura 3.6.

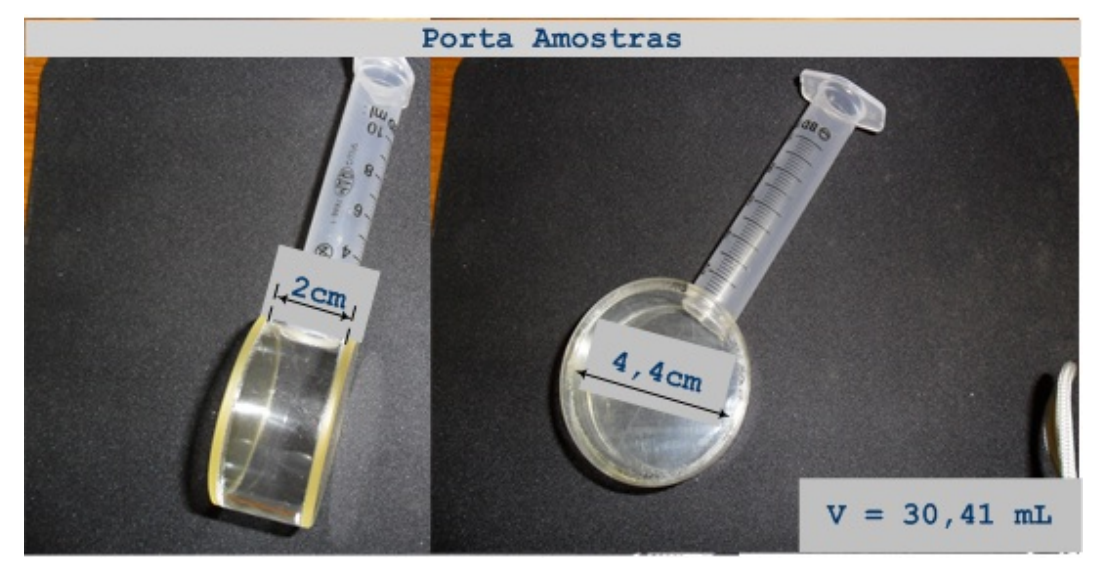

Figura 3.6: Imagem do porta amostra de acrílico utilizado para caracterização do FMR.

As laterais do porta-amostra são rígidas (espessura de 2,0 $\mathrm{mm}$ ) e foram confecionadas com material ${ }^{5}$, cuja impedância acústica é próxima a da água, evitando assim uma alta reflexão do ultrassom na interface.

A configuração para análise da velocidade e atenuação da onda sonora do FMR com diferentes concentrações foi montada conforme ilustrado na figura 3.7 .

Num suporte em aço inoxidável foram fixados pares de transdutores de ultrassom, faces planas, cerâmica circular, de mesma frequência central, que variaram entre $1 \mathrm{MHz}$ a $10 \mathrm{MHz}$; distante cerca de $(100,0 \pm 0,1) \mathrm{mm}$ entre suas interfaces. Entre os transdutores foi fixado o porta-amostra, como ilustra a figura 3.7 (a).

\footnotetext{
${ }^{5}$ Westlake Chemical - http://www.westlake.com/
} 


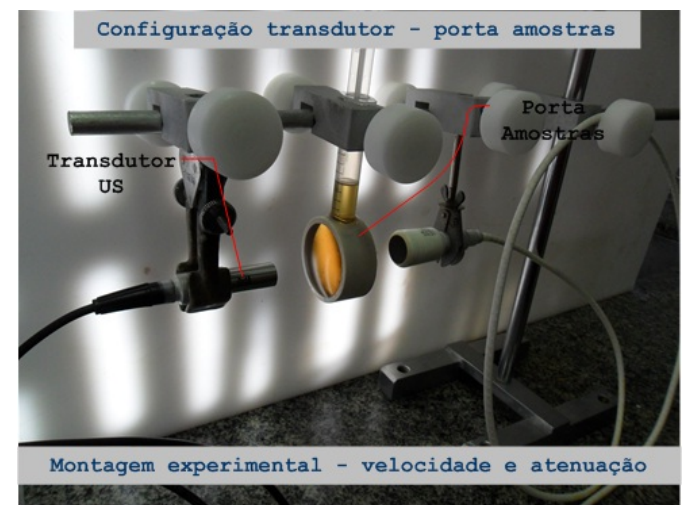

(a) Montagem US - amostra

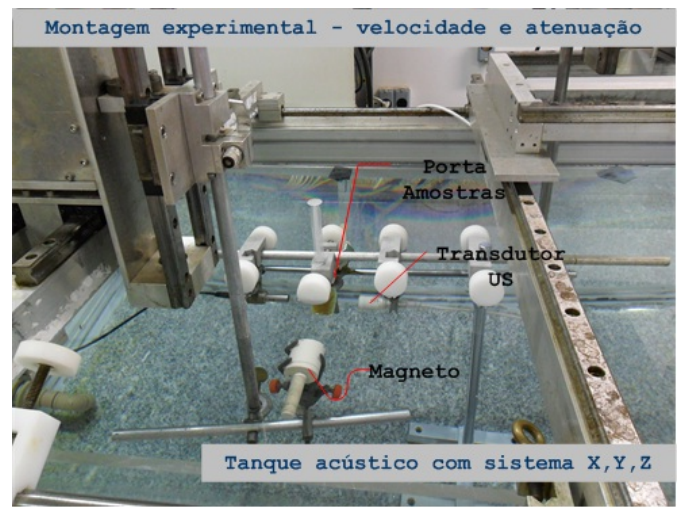

(b) Experimento Tanque

Figura 3.7: Montagem experimental para análise da velocidade e atenuação.

Um par de magnetos foi fixado a um sistema robótico móvel (3D), de modo a deslocá-los perpendicularmente ao porta amostra e os transdutores. Este conjunto foi imerso num tanque contendo água [figura 3.7 (b)], a fim de proporcionar acoplamento acústico.

A configuração do sistema robótico (3D), mostrada na figura 3.8, possibilitou aproximar e afastar os magnetos, com propósito de verificar a dependência da velocidade e atenuação ultrassônica nas amostras com a presença do campo magnético.

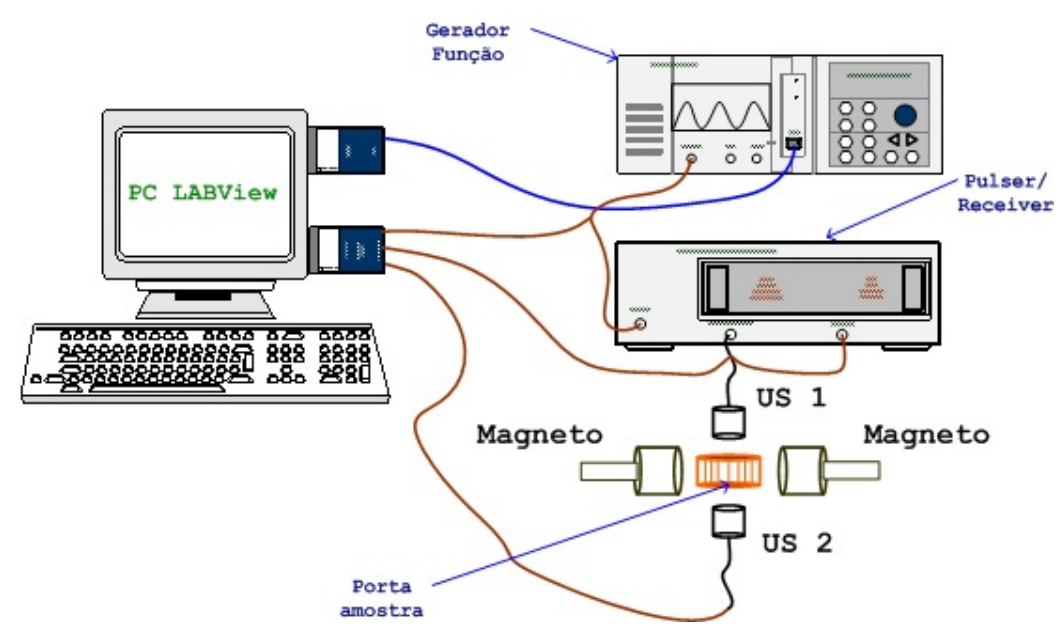

Figura 3.8: Esquema de medição da velocidade e atenuação sonora no tanque acústico.

O gerador de função sincronizado ao "pulser/receiver" e a placa osciloscópica do Computador, na função de "trigger" possibilitaram disparar o "pulser/receiver" e habilitar a aquisição do sinal através de um software 
desenvolvido em LABVIEW $^{\mathrm{TM}}$, ao mesmo tempo em que o controle do sistema robótico, também em $\mathrm{LABVIEW}^{\mathrm{TM}}$, movimentava os magnetos e disparava o sinal para efetuar as medições ultrassônicas.

Esta montagem experimental permitiu verificar a velocidade e atenuação da onda sonora através de dois métodos: reflexão e transmissão, com o objetivo de verificar qual método proporciona menor incerteza. Deste modo, após análise das medições com seus respectivos desvios, adotou-se a técnica de reflexão para avaliar a velocidade relativa do meio, em relação a água filtrada e desgaseificada do tanque acústico, e a técnica de transmissão para avaliar a atenuação relativa do meio, também em relação a água filtrada e desgaseificada do tanque acústico.

\subsection{Aparato Instrumental - "Protótipos"}

\subsubsection{Oscilador multifrequência a mão livre}

Num primeiro momento construiu-se um protótipo de um sistema oscilatório multifrequência, acoplado a um transdutor linear de ultrassom, configurado em modo Doppler colorido, a fim de observar o mapa de velocidade das estruturas internas de simuladores de tecidos biológicos em função da frequência de oscilação. A figura 3.9 apresenta uma foto do protótipo com o esquema de funcionamento.

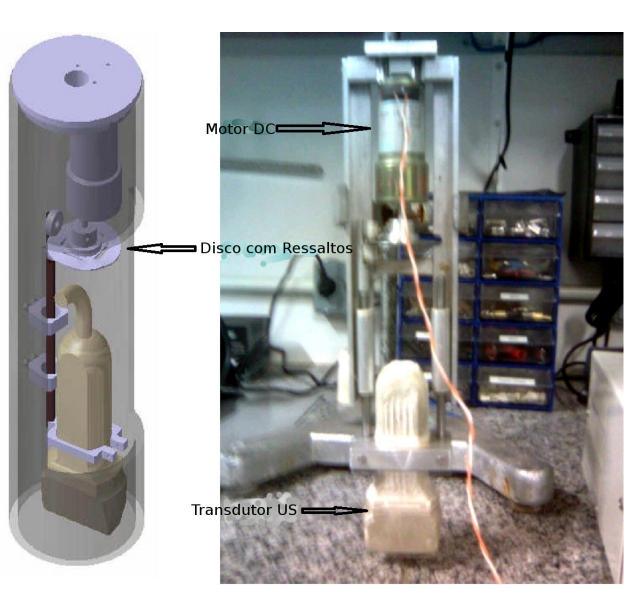

(a) Oscilador multifrequência

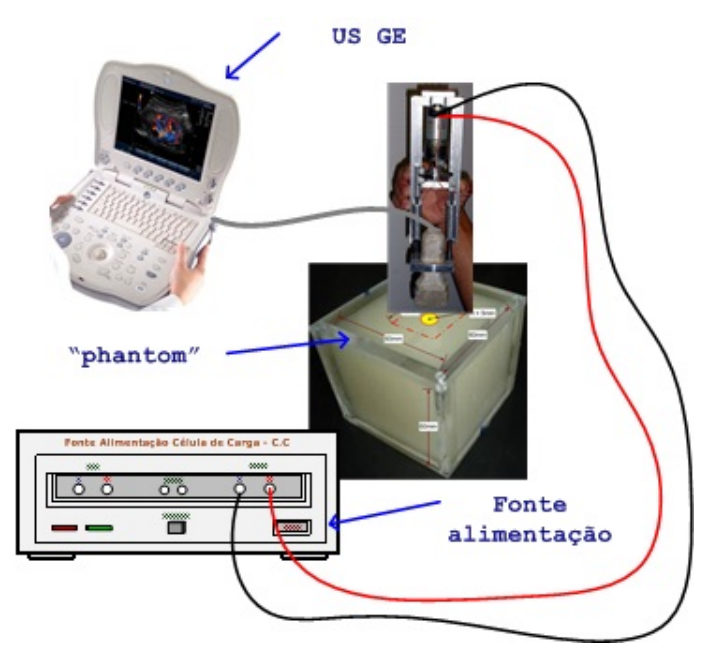

(b) Configuração medição

Figura 3.9: Diagrama e foto do Oscilador multifrequência.

A ideia foi utilizar um transdutor linear de ultrassom que pudesse 
vibrar, em uma faixa de frequências pré-definidas, e construir imagens que mostrassem as diferenças de rigidez em função da frequência, no modo Doppler. Corroborando assim, com trabalhos anteriores do grupo. [86].

A estrutura do protótipo, confecionada na oficina do departamento de Física - USP/FFCLRP, foi construida em alumínio e aço inoxidável. Seu mecanismo de funcionamento é composto por: (a) um sistema de disco com ressaltos que estabelece a oscilação ao ser rotacionado através do eixo do redutor acoplado a um motor DC, da PITTMAN, modelo GM8712D6622 24 VDC - 6.3:1 'ratio' e (b) uma fonte de alimentação regulável digital, modelo FTDR-1510, 1.2 - 15 volts - 10 A, da Hayonik, que foi usada para ajustar a velocidade de rotação (frequência).

O transdutor linear de ultrassom foi fixado a duas hastes inox, que estão ligadas ao disco acoplado ao motor. O movimento de rotação do disco transfere movimento oscilatório ao transdutor. A medida que se altera a rotação, ocorre mudança na frequência de oscilação do transdutor. Pela relação entre rotação e números de ressaltos foi possível obter a frequência de oscilação do transdutor.

As imagens, em modo-B e modo Doppler, foram adquiridas num ultrassom comercial da GE medical system, modelo logic-book XP.

Num segundo estágio, acrescentaríamos à estrutura, um sensor de carga ("straingauge") para determinar a força aplicada sobre o meio e tentar levantar a curva tensão ("stress") versus deformação ("strain"). Entretanto, alguns ajustes mecânicos no projeto seriam necessários para eliminar falhas na fabricação e montagem dos componentes. Isto permitiria minimizar efeitos devido ao atrito nas partes móveis que interferem na qualidade dos dados coletados.

O protótipo permite de forma qualitativa verificar mudanças na rigidez do meio analisado, conforme apresentado no capítulo de resultados. Contudo, para obter valores quantitativos com acurácia é necessário um projeto de engenharia mais elaborado, a fim de dimensionar e calcular os esforços transferidos para a estrutura e estabelecer os parâmetros de medição das forças e deslocamentos aplicados.

Devido as limitações técnicas na confecção de um protótipo com precisão para avaliar as microdeformações nos tecidos, decidimos avançar e buscar um outro modelo apresentado na próxima seção. 


\subsubsection{Analisador de deslocamento por ultrassom - Estático}

Neste segundo aparato, montado numa estrutura de acrílico foram acoplados uma célula de carga da MK - controle e instrumentos Ltda, Modelo CSA/ZL-05, carga $5 \mathrm{kgf}$, tensão de excitação variando de $5 \mathrm{Vcc}-10 \mathrm{Vcc}$, sensibilidade de $2 \mathrm{mV} / \mathrm{V} / \mathrm{g}$; um transdutor de ultrassom monocanal, modelo ROHE 5630 de $3,5 \mathrm{MHz} / 13 \mathrm{~mm}$, LIF 4911OH, um micrômetro da ZAAS precision, $(0-25) \times 0,01 \mathrm{~mm}$, acoplado a um motor de passo da Kalatec automação, modelo KTC-HT23-401-D, 1, $8^{\circ}-1,9$ ๆm/ 3,0 V-3,0 A, e dois magnetos de Neodímio ("NdFeB") da superimãs, no formato cilíndrico com dimensões $\phi=2,9 \mathrm{~cm}$ e $\mathrm{h}=1,4 \mathrm{~cm}$, cuja função foi magnetizar as inclusões contendo material ferromagnético $\left(\mathrm{Fe}_{3} \mathrm{O}_{4}\right)$, a fim de alterar a sua rigidez. A figura 3.10 mostra detalhes deste aparato com seus respectivos componentes.

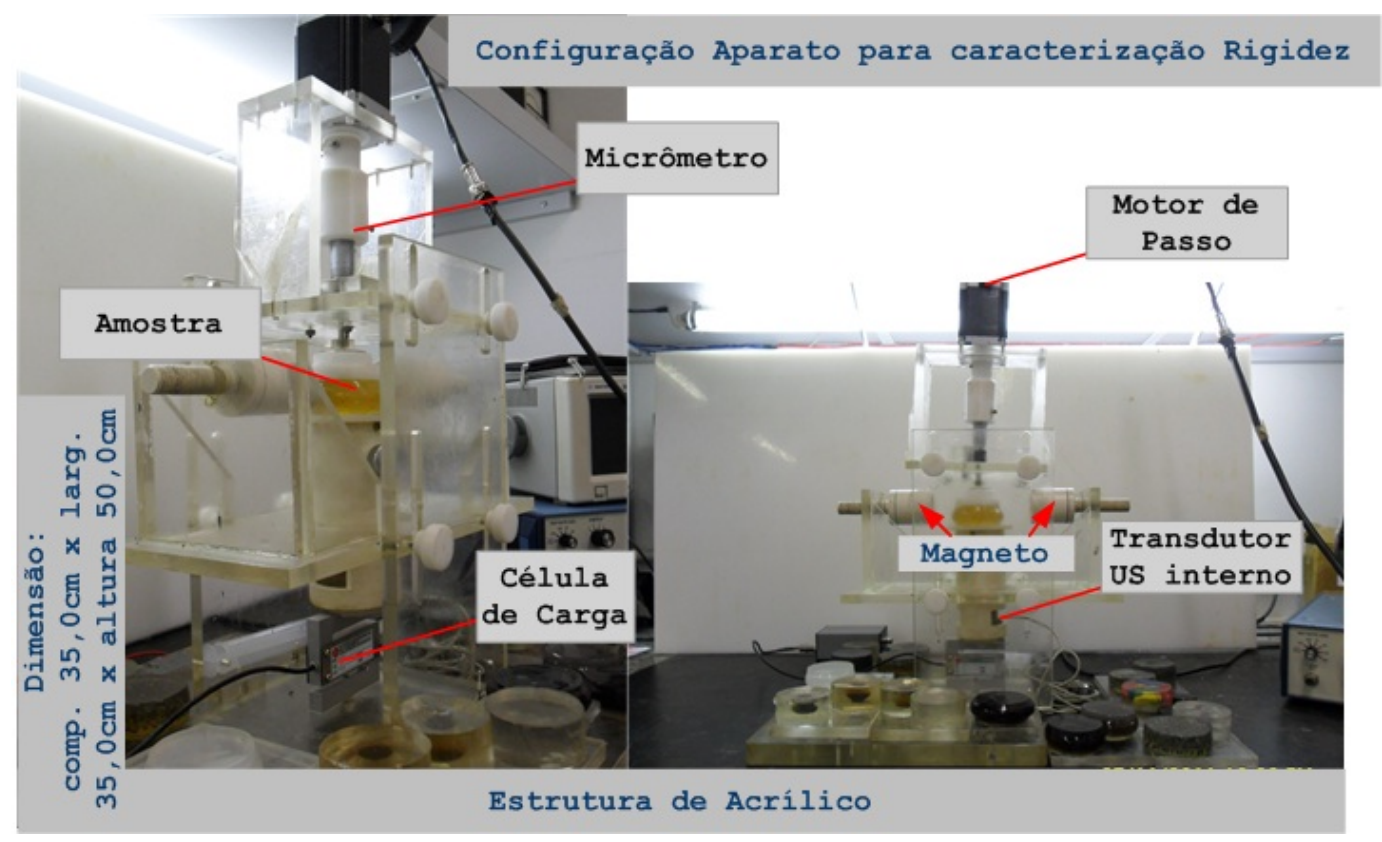

Figura 3.10: Montagem experimental para medições de rigidez.

A célula de carga tem sua estrutura em alumínio e acoplada com sensores resistivos ("strainguage") ligados em uma configuração de "ponte de Wheastone". A saída da célula de carga foi conectada a um Filtro passa-baixas da Stanford Research Systems, INC; modelo SR650, numa frequência de corte de 2,7 Hz, com ganho de $30 \mathrm{~dB}$ na entrada ("in") e $20 \mathrm{~dB}$ na saída ("out"), totalizando uma amplificação de $50 \mathrm{~dB}$.

Esta célula de carga foi calibrada por um conjunto de massas aferidas 
numa balança de precisão da "BEL engineering" equipamentos Ltda, modelo UMark 250A, com precisão de $\pm 0,001 \mathrm{~g}$, capacidade variando de $\pm 0,01 \mathrm{~g}$ a $250,00 \mathrm{~g}$.

Foram obtidas duas curvas de calibração: Uma variando de $0,0 \mathrm{~g}$ a $50,0 \mathrm{~g}$, com incrementos de 5,0 g e, uma segunda, variando de $0,0 \mathrm{~g}$ a $300,0 \mathrm{~g}$, com incrementos de 50,0 g. O limite superior foi estabelecido por limitações técnicas na colocação das massas sobre o suporte da célula, visto que sua capacidade máxima está acima da utilizada nesta calibração, conforme especificação do fabricante descrita anteriormente.

Os apêndices B.3, B.4 mostram essas curvas de calibração, cuja sensibilidade média da célula de carga ficou em torno de $0,61 \mathrm{mV} / \mathrm{gf}$ com desvio médio percentual de $0,7 \%$ entre os valores experimentais e o ajuste linear.

A calibração do campo magnético dos imãs permanentes foi obtida utilizando um gaussímetro digital da Globalmag, modelo TMAG-1T, saída 1Volt/1Tesla, acoplado a um oscilóscopio da Agilent Technologies, modelo MSO6012A, $100 \mathrm{MHz}-2 \mathrm{GSa} / \mathrm{s}$. O apêndice C.5 mostra a curva de calibração obtida do campo magnético em função da distância.

Para produzir o pulso de excitação na cerâmica do transdutor de ultrassom utilizamos um transmiter/receiver em modo de excitação e recepção do eco ultrassônico da empresa Olympus - panametrics/NDT, modelo 5800, na configuração: mode $=$ Pulso $/$ Eco, PRF $=$ Ext.-BNC $(1 \mathrm{kHz})$, Energia $=100 \mu \mathrm{J}$, amortecimento $=50 \Omega$, filtro passa-altas $=100 \mathrm{kHz}$, filtro passa-baixas $=5 \mathrm{MHz}$, atenuação de entrada $=20 \mathrm{~dB}$, atenuação de saída $=3 \mathrm{~dB}$ e ganho de $60 \mathrm{~dB}$.

Um par de geradores de função da Agilent Technologies, model LXI $33220 \mathrm{~A}$ - $200 \mathrm{MHz}$ foi usado para sincronizar o sistema de movimento do motor de passo com a célula de carga e uma placa oscilóscopio da National Instruments, NI - modelo PCI 5122 - $100 \mathrm{MSa} / \mathrm{s}$. Todo o sistema foi automatizado em ambiente LABVIEW ${ }^{\mathrm{TM}}$, da National Instruments (NI).

O sistema permite através do micrômetro, aplicar deslocamento na estrutura do "phantom" da ordem de 1 micrômetro. A depender da espessura da amostra utilizada, foram aplicados deslocamentos que variaram de $5 \mu \mathrm{m}$ a $50 \mu \mathrm{m}$, com incrementos de $5 \mu \mathrm{m}$ até atingir o limite de $250 \mu \mathrm{m}$, de modo manual ou por meio do motor de passo.

O motor de passo foi acoplado ao sistema de controle do braço robótico da empresa Figlabs, modelo TA-125u, resolução por eixo de 12,5 $\mu \mathrm{m}$, com 
motores de passo, fuso de esfera com folga zero e software de controle desenvolvido em LABVIEW ${ }^{\mathrm{TM}}$.

O limite de $250 \mu \mathrm{m}$ foi estabelecido em função da altura da amostra, a fim de evitar que os deslocamentos incrementassem deformações que ultrapassassem 1\% de deformação e assim, permanecer dentro de limites nos quais os efeitos elásticos fossem predominantes em relação aos viscosos.

A figura 3.11 mostra detalhes deste arranjo experimental construído para avaliar rigidez de estruturas internas de amostras que simulem tecidos biológicos.

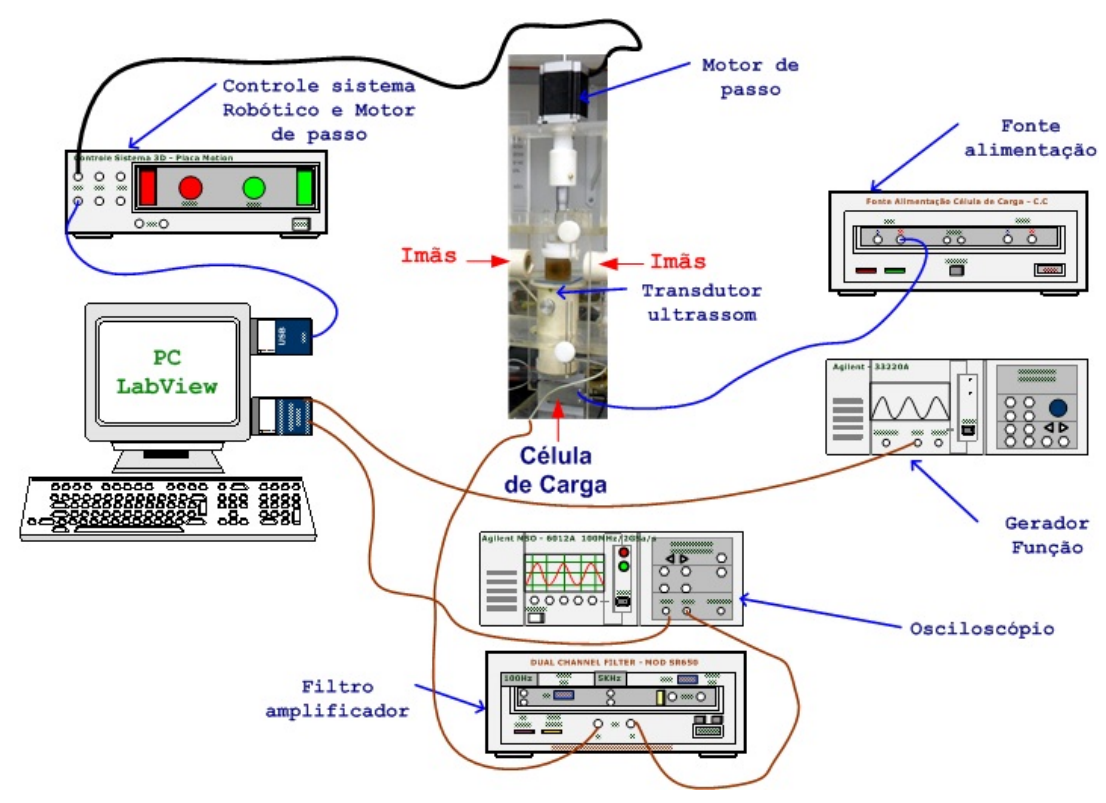

Figura 3.11: Configuração para medições de rigidez, em modo quase estático.

Nesta configuração o gerador de frequência sincroniza o disparo do sinal do movimento do motor de passo e, a aquisição do eco do ultrassom e a resposta da célula de carga são adquiridos com o osciloscópio.

O deslocamento das estruturas internas do meio foi obtido a partir da medida de fase entre os ecos, usando processamento de correlação cruzada entre pares de segmentos dos ecos ultrassônicos programados em ambiente MatLab. Assim, é possível obter, para um mesmo intervalo de tempo, a força média aplicada e o deslocamento das estruturas internas da amostra. 


\subsubsection{Analisador de deslocamento por ultrassom - Dinâmico}

A princípio, por estar implementando simuladores de tecidos biológicos, que contém partículas ferromagnéticas, idealizou-se um sistema que pudesse vibrar estas estruturas internas através de um campo magnético externo variável. Deste modo, para produzir a excitação dinâmica do sistema, através da variação de frequência, foi construida uma bobina com fios de cobre, de calibre AWG 21, cuja resistividade nominal é de $1,7 \times 10^{-8} \Omega . \mathrm{m}$.

Esta bobina contém 8 camadas sobrepostas de fios, cada camada com 50 espiras, totalizando 400 espiras, conforme mostra a figura 3.12 (b).

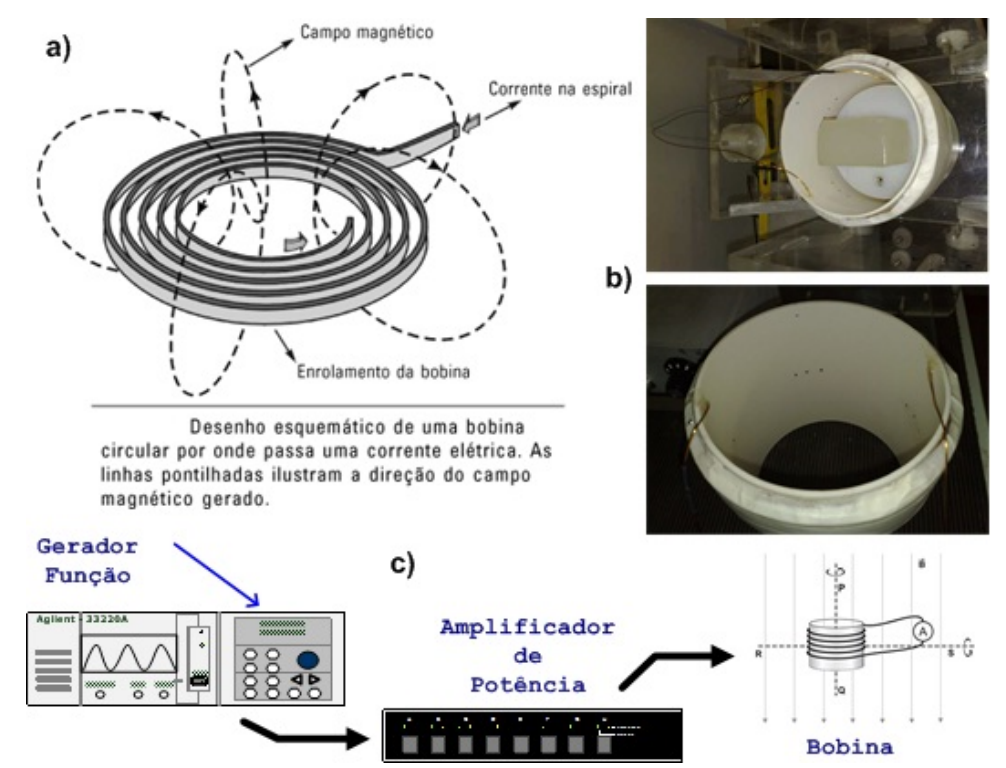

Figura 3.12: (a) Esquema das linhas de campo numa bobina, (b) foto da bobina excitadora e (c) esquema com fluxo de amplificação.

Os parâmetros indutivos, reativos e capacitivos foram levantados em um medidor RCL, FLUKE ${ }^{6}$, modelo PM 6304 - DC $100 \mathrm{kHz}$ com acurácia de $0,1 \%$. O módulo resistivo médio na faixa de $100 \mathrm{kHz}-1 \mathrm{kHz}$ foi de $\approx 5,76 \Omega$, a $10 \mathrm{kHz}(\approx 16,0 \Omega)$ e a $100 \mathrm{kHz}(\approx 1,37 \mathrm{k} \Omega)$. O campo indutivo teve seu módulo variando entre $16 \mathrm{mH}-18,4 \mathrm{mH}$, com valor médio de $(17,50 \pm 0,02) \mathrm{mH}$, na faixa de $10 \mathrm{~Hz}-500 \mathrm{~Hz}$. O módulo capacitivo apresentou valor aproximado de $(236,66 \pm 0,24) \mu \mathrm{F}$ a partir de uma frequência acima de $100 \mathrm{kHz}$.

Com estes dados foi possível estabelecer a frequência de ressonância da

\footnotetext{
${ }^{6}$ http://www.fluke.com/fluke/usen/bench-instruments/rcl-meters/pm6306-\&-pm6304.htm?PID=56500.
} 
bobina em aproximadamente $(78,21 \pm 0,08) \mathrm{Hz}$, através da equação 3.1 .

$$
f_{\text {res }}=\frac{1}{2 \cdot \pi \cdot \sqrt{\text { L.C }}}
$$

A bobina foi acoplada ao gerador de funções da Agilent Technologies, model LXI 33220A - $200 \mathrm{MHz}$ e pré-amplificado por amplificador da Ciclotron, modelo Dynamic $4000 \Omega 2$ class AB, 2000 watts RMS ('Root Mean Square').

As curvas características do amplificador e da bobina com uma carga de $50 \Omega$ são apresentadas nos apêndices D.6, D.7, E.8, E.9 e E.10, respectivamente.

Os dados foram adquiridos com um oscilóscopio da Agilent e/ou numa placa oscilóscopio da NI, através de uma interface desenvolvida em LABVIEW $^{\mathrm{TM}}$ e processados no MATLAB e no ORIGIN ${ }^{\mathrm{TM}}{ }^{7}$.

A caracterização de cada componente do sistema permite identificar a faixa de medições e suas incertezas (sistemáticas - incertezas tipo B). Como nosso objetivo é caracterizar os simuladores de tecidos para medições elastográficas, é importante verificar o modo pelo qual as incertezas estão se propagando em todo o sistema, e quais as contribuições nas medições finais.

A deformação dinâmica das estruturas internas das amostras também foi aplicada. Para tal, usamos o movimento oscilatório do motor de passo. Este, acoplado a um platô cilíndrico comprime a amostra, em toda a sua superfície superior.

Os parâmetros de controle são configurados em ambiente LABVIEW ${ }^{\mathrm{TM}}$ : número de passos, velocidade e aceleração do motor, através do sistema de rastreio automatizado da empresa Figlabs, modelo TA-125u, resolução por eixo de 12,5 $\mu \mathrm{m}$, com motores de passo, fuso de esfera com folga zero.

Entretanto, o processo de automação do sistema, com o motor de passo, trouxe outras dificuldades, pois o motor de passo, ao acelerar e desacelerar, perde passos na mesma ordem de grandeza, $\pm 5 \mu \mathrm{m}$. Assim, para um deslocamento de $250 \mu \mathrm{m}$ temos um erro em torno de $2 \%$, enquanto para um deslocamento de $50 \mu \mathrm{m}$ este erro já representa algo em torno de $10 \%$.

Apesar disto, as medidas executadas tanto aplicando deslocamento manual quanto através do motor de passo, apresentaram resultados semelhantes, com pequenas discrepâncias devido ao movimento de aceleração e desaceleração do motor de passo.

\footnotetext{
${ }^{7}$ http://www.originlab.com.
} 
Ao se efetuar as medições estáticas (ou quase-estáticas), aplica-se o deslocamento no micrômetro que comprime a amostra sobre a célula de carga, a qual acoplada ao osciloscópio possibilita leitura direta do sinal, em $\mathrm{mV}$, de modo pontual. Em seguida, através da curva de calibração da célula de carga, transforma-se o sinal de tensão (em milivolts "mV"), em "grama-força"("gf"), depois em Newton $(\mathrm{N})$ e, pela razão entre a área da superfície, obtém-se o valor em "Pascal" [Pa].

Para atingir o deslocamento de $250 \mu \mathrm{m}$, estimado, o motor de passo repete uma sequência de rampas de idas e voltas (adotei 6 vezes). Na sequência, os dados são salvos e processados posteriormente no MATLAB, na tentativa de obter a declividade (derivada) das curvas e seus respectivos valores médios.

Os magnetos (imãs) foram acoplados ao sistema com objetivo de alterar o campo magnético nas proximidade dos simuladores de tecidos, a fim de verificar de que modo a intensidade do campo magnético modifica a relação de rigidez nas inclusões contendo as partículas ferromagnéticas. Ou seja, ao impor um campo magnético externo aos simuladores contendo marcadores magnéticos, estes se polarizam na direção do campo e criam estruturas que modificam a rigidez mecânica do meio. Assim, ao aplicarmos uma deformação, a força sentida na célula de carga seria maior. Confirmando deste modo a mudança das propriedades mecânicas da amostra.

Os valores da intensidade do campo magnético externo aplicado através dos magnetos foram obtidos pela a curva de calibração dos imãs, que estão no apêndice C.5. Através desta curva é possível inferir o valor da intensidade do campo em função da posição do magneto em relação ao centro da inclusão que contém as partículas ferromagnéticas.

A bobina, todavia, foi confecionada para produzir oscilações nas inclusões que contém partículas ferromagnéticas $\left(\mathrm{Fe}_{3} \mathrm{O}_{4}\right)$, para diferentes frequências. E, através do transdutor de ultrassom, verificarmos o deslocamento das estruturas internas dos simuladores de tecidos.

Além disso, ao ligar as bobinas num gerador de função pré-amplificado, pode-se variar a frequência de oscilação do campo magnético na região em torno do "phantom". Este campo induziu vibrações nas partículas das inclusões ferromagnéticas no interior da amostra, perceptíveis tatilmente. Entretanto, por limitações técnicas, não foi possível detectar os deslocamentos das estruturas internas, nem obter uma resposta da intensidade da força através da célula de 
carga, provavelmente pela sensibilidade do oscilóscopio utilizado na medição e também pelo fato da célula de carga não responder a frequências acima de $10 \mathrm{~Hz}$.

Além do mais, ao amplificar a corrente na bobina para intensificar a força magnética, o calor produzido aqueceu as amostras de parafina até seu ponto de fusão, danificando-as. Contudo, estas medidas dinâmicas, conforme descrito na seção 2.1.2.1, permitem levantar as propriedades viscoelásticas destes meios.

Assim, visando suplantar as dificuldades técnicas do processo descrito anteriormente e, buscar levantar medições dinâmicas mais acuradas e que propiciasse uma análise das propriedades viscosas do meio, substituiu-se o motor de passo por um atuador mecânico (mini-vibrador) da Brüel \& Kjær, modelo mini-shaker 4810, cujas especificações são: limite de frequência DC até $18 \mathrm{kHz}$; classificação de força (no pico) de $10 \mathrm{~N}$ para $65 \mathrm{~Hz}$ a $4 \mathrm{kHz}, 7 \mathrm{~N}$ para 65 $\mathrm{Hz}$ a $18 \mathrm{kHz}$; com aceleração máxima sem carga de $550 \mathrm{~m} . \mathrm{s}^{-1}$ (na faixa de 65 $\mathrm{Hz}$ a $4 \mathrm{kHz}$ ) e $383 \mathrm{~m} \cdot \mathrm{s}^{-1}$ (na faixa de $6,5 \mathrm{kHz}$ a $18 \mathrm{kHz}$ ); máximo deslocamento de $6 \mathrm{~mm}$ (pico-a-pico) e corrente máxima na entrada de 1,8 A (RMS), montado sobre uma estrutura de alumínio.

A fim de gerar um mapa de deslocamento das estruturas internas das amostras, também foi utilizado um transdutor linear (128 elementos) acoplado a um aparelho de ultrassom diagnóstico por imagem, da ultrasonix ${ }^{\mathrm{R}}$, modelo RP ("research platform"), que dá acesso aos mapas de " $R F "$ ".

$\mathrm{Na}$ base desta estrutura, fixada em uma mesa antivibratória, foi construído, em acrílico e borracha de silicone, um suporte que possibilita fixação do transdutor linear de ultrassom. Na parte superior desta estrutura, se acoplou o mini vibrador, shaker 4810, ao sistema estático descrito na seção 3.2.2.

Para garantir uma força constante no mini-vibrador, segundo especificações técnicas, é necessário controle da corrente na bobina que produz o deslocamento na membrana do mini-vibrador. Como o método experimental previa uma varredura em diferentes frequências foi levantada a curva de corrente versus frequência para três valores de corrente: 0,25 A, 0,50 A e $0,75 \mathrm{~A}$, a fim de verificar o comportamento do mini-vibrador com a variação de frequência. 
A curva de calibração é apresentada no apêndice F.11. Enquanto a figura 3.13 mostra detalhes da montagem.
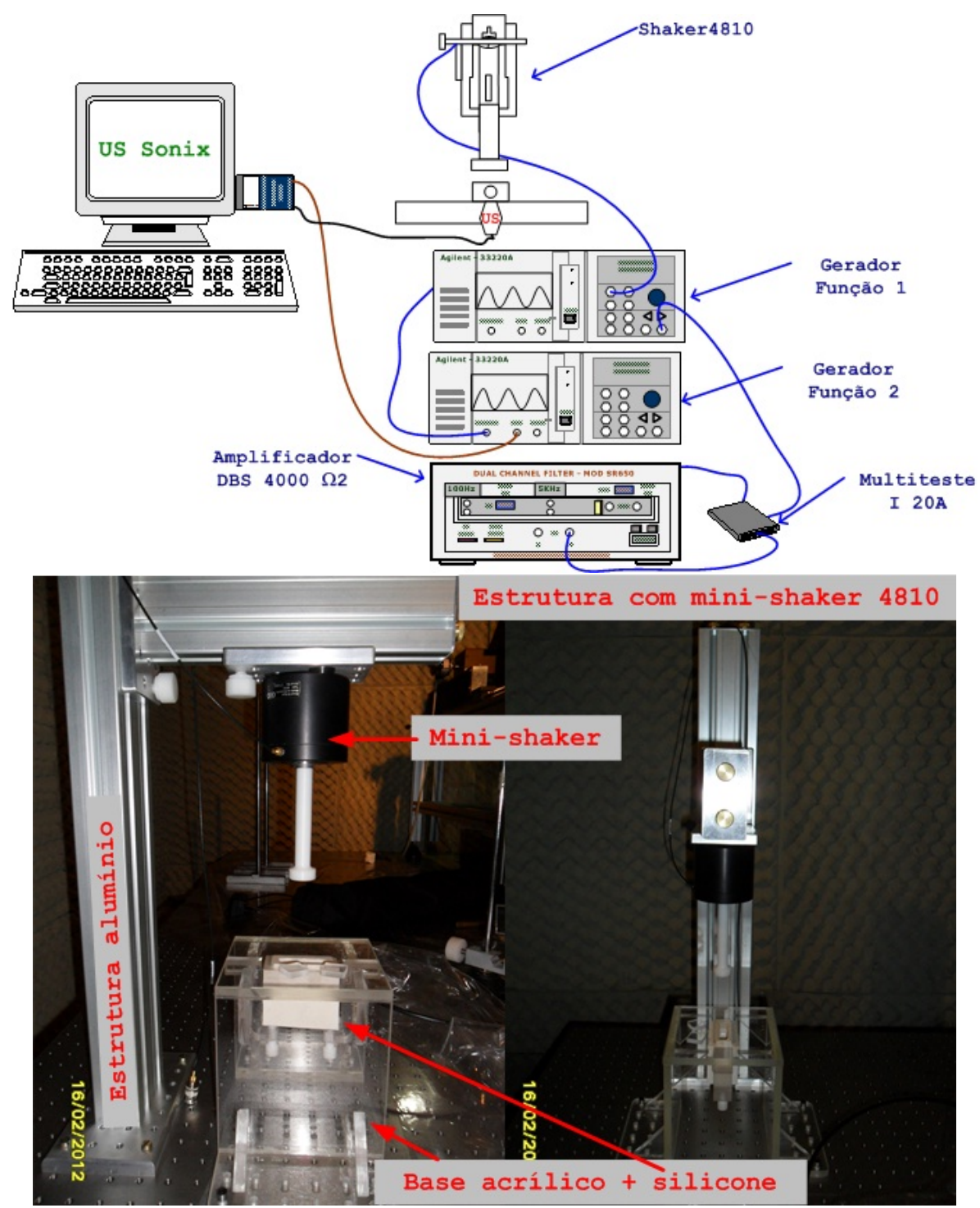

Figura 3.13: Esquema e imagem da estrutura para medições dinâmicas com vibrador, mini-shaker 4810 e Ultrasonix ${ }^{\mathrm{R}}$, modelo "RP".

$\mathrm{O}$ acoplamento e funcionamento integrado destes componentes permitem caracterizar, de modo quase-estático e dinâmico, simuladores de tecidos ("phantoms"), que possuem características mecânicas similares aos dos tecidos biológicos com prováveis alterações e potencial para aplicações "in-vivo". Esta caracterização foi feita para alguns "phantoms" de parafina contendo inclusões com partículas magnéticas, em diferentes concentrações, sem e com aplicação de um campo magnético externo, como apresentado no capítulo de resultados. 
A figura 3.14 mostra um esquema com imagem desta configuração, montado para obter dados dinâmicos dos deslocamentos das estruturas internas dos simuladores de tecidos biológicos, utilizando um oscilóscopio da Agilent Technologies de alta taxa de amostragem (20Gsa/s).

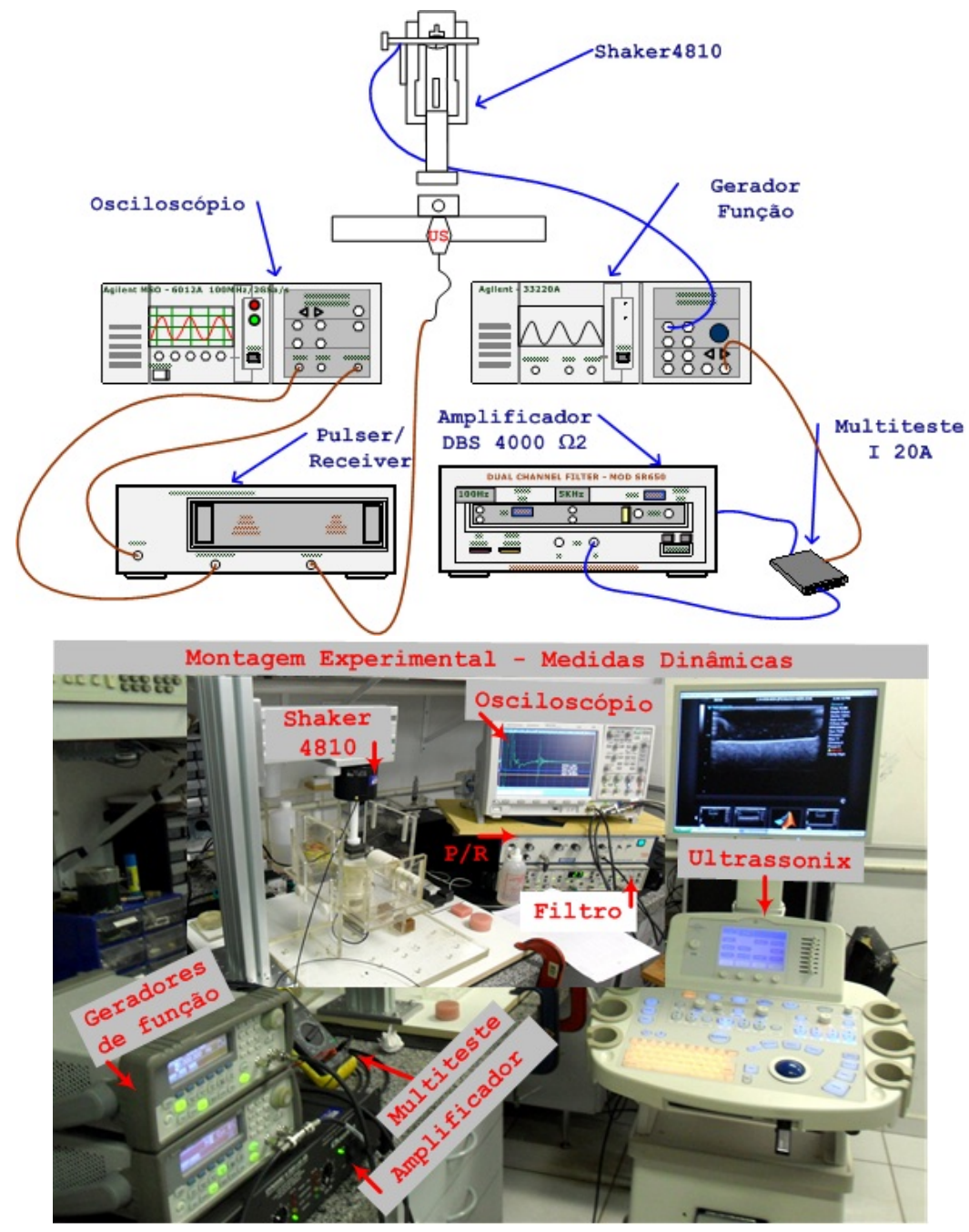

Figura 3.14: Esquema para medições dinâmicas com mini-shaker 4810 acoplado ao Oscilóscopio de alta taxa de amostragem e ao Ultrasonix ${ }^{\mathrm{R}}$.

\subsubsection{Imagens elastográficas - Ultrasonix ${ }^{\mathrm{R}}$}

Com objetivo de verificar mudanças de rigidez, em amostras contendo partículas magnéticas e, sob ação de um campo magnético externo, imagens elastográficas também foram exploradas. Para isto, foi utilizado um equipamento de US da Ultrasonix, modelo RP ("Research Platforms"), com 
transdutor linear, modelo L14 - 5/38, largura de banda de $5 \mathrm{MHz}$ a $14 \mathrm{MHz}$, comprimento "array" de $38 \mathrm{~mm}$.

Este sistema possui módulo elastográfico acoplado, o que possibilita aquisição de imagens elastográficas relativas, isto é, o sistema permite comparar regiões distintas na imagem e fornece um fator de rigidez entre elas, indicando se as áreas selecionadas possuem rigidez mecânica diferentes e em qual proporção. Assim, foi possível obter imagens elastográficas de "phantoms“ com inclusões magnéticas com e sem a presença de um campo magnético externo.

As imagens foram adquiridas numa frequência de $10 \mathrm{MHz}$, numa taxa de 30 FPS ('frames per second'), a uma profundidade de $40 \mathrm{~mm}$, opacidade de $20 \%$ e ganho de $50 \%$. 


\section{Capítulo}

\section{Resultados e Discussões}

\subsection{Oscilador Multifrequência a mão livre}

Usando o sistema oscilatório de multifrequência e detecção de imagem em modo Doppler, foi possível discriminar, qualitativamente, regiões com rigidezes diferentes através do deslocamento das estruturas internas dos meios, conforme pode ser visto nas imagens da figura 4.1, obtidas num sistema de Ultrassom (modelo Logig Book, GE) com transdutor linear, utilizando modo Doppler colorido.
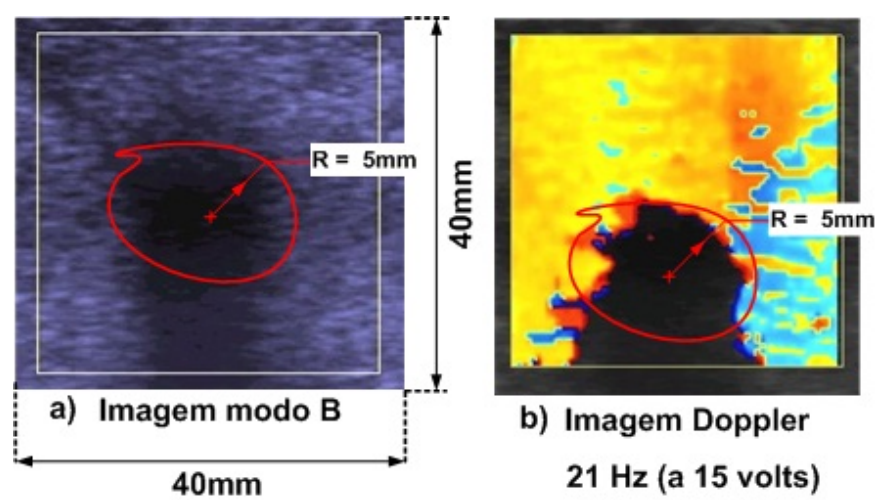

b) Imagem Doppler $21 \mathrm{~Hz}$ (a 15 volts)

Figura 4.1: (a) Imagem modo-B na inclusão, (b) Imagem Doppler na inclusão numa frequência aproximada de $21 \mathrm{~Hz}-15 \mathrm{~V}$, no motor $D C$, seção 3.2.1.

Contudo, o protótipo como foi construído (conforme apresentado na seção 3.2.1), apresenta falhas no sistema de deslocamento, ou seja, há folgas na faixa de $\pm 1 \mathrm{~mm}$. Se tomarmos a região, endurecida pela radiação, no "phantom", um disco de diâmetro igual a $10 \mathrm{~mm}$ e uma profundidade de 10 $\mathrm{mm}$, teremos um erro relativo, no deslocamento, da ordem de 10\%. Além disso, buscávamos impor um deslocamento máximo da ordem de 1,0 mm. Estas limitações técnicas não permitiria detectar regiões micro-calcificadas, nem inferir a força aplicada para produzir tal deslocamento. 
Outro fator limitante do sistema é a faixa de frequência máxima alcançável, visto que o motor utilizado, conforme descrição na seção 3.2.1, tinha um patamar de tensão de no máximo 24 VDC, que corresponde a uma frequência máxima de aproximadamente $37 \mathrm{~Hz}$. É evidente que poderíamos substituir a fonte e o motor por outros que permitissem maior frequência de rotação, todavia, os ajustes mecânicos necessitariam de um projeto de engenharia mais elaborado.

Além disto, buscávamos um sistema que permitisse obter resultados de deformação em baixas frequências (entre $5 \mathrm{~Hz}$ e $50 \mathrm{~Hz}$ ), parâmetro almejado inclusive para utilização em outras técnicas elastográficas, como a de transiente elastográfico, método utilizado por Bercoff et al., 2003 [87]. Assim, o aparato forneceu oscilações estáveis na faixa de $5 \mathrm{~Hz}$ a $25 \mathrm{~Hz}$, contudo, os deslocamentos aplicados deveriam ter ótima precisão (na faixa micrométrica), isto não foi possível com o modelo atual.

Mesmo assim, foi possível visualizar um bom contraste entre os meios com diferença de rigidez de aproximadamente duas vezes, usando imagem de ultrassom Doppler colorido. A mudança na rigidez destes "phantoms" já foi apresentada na literatura por diversos autores, como Baldock et al., 1999 [85]; Lepage et al., 2001 [88] e Crescenti et al., 2009 [89].

Estes resultados também corroboram com os encontrados por Marini et al., 2008 [86], realizados no GIIMUS sob coordenação do prof. Dr. Adilton Carneiro, que excitaram um "phantom" com regiões rígidas diferenciada, aplicando uma força eletromagnética com frequência variando de $(20-400) \mathrm{Hz}$, durante a aquisição da imagem em modo Doppler. As imagens elastográficas obtidas durante a vibração são mostradas na figura 4.2.

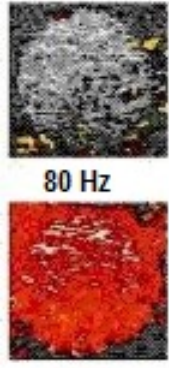

$190 \mathrm{~Hz}$

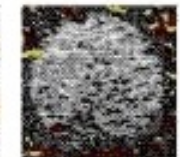

$130 \mathrm{~Hz}$

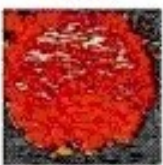

$210 \mathrm{~Hz}$

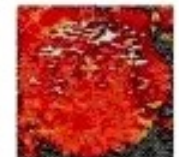

$160 \mathrm{~Hz}$

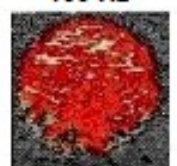

$240 \mathrm{~Hz}$

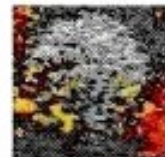

$170 \mathrm{~Hz}$

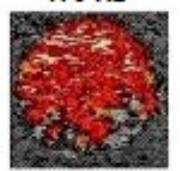

$250 \mathrm{~Hz}$

Figura 4.2: (a) Imagens obtidas em ultrassom modo-B e Doppler colorido durante vibração do "phantom" com inclusão rigida (Marini et al, 2008) [86]. 
Na configuração montada por Marini e colaboradores, a vibração foi transmitida à amostra através de um ímã permanente fixado em sua superfície, o qual atuou como pistão mecânico quando excitado por um campo magnético gerado por uma bobina circular, posicionada próxima e desacoplada do imã.

\subsection{Analisador de velocidade e atenuação}

A fim de estudar as características mecânicas das amostras, com propriedades mecânicas equivalentes as dos tecidos moles, confecionados a partir de parafinas com misturas e inclusões de fluidos magnetoreológicos, foi feita uma análise da relação entre a velocidade, atenuação e concentração de partículas magnéticas, sem e com aplicação de um campo magnético externo.

Para cada uma das amostras foi feita uma sequência de três varreduras (idas e voltas) em oito pontos de campo magnético distinto, obtendo valores através de dois modos simultâneos, transmissão e reflexão ("Pulser/receiver"), com seis pares de transdutores de ultrassom na faixa de $1 \mathrm{MHz}-10 \mathrm{MHz}$.

Contudo, priorizamos a análise da velocidade pelo método da reflexão e a atenuação pelo método da transmissão, a fim de minimizar as incertezas decorrentes de cada método.

Para avaliar a precisão e capacidade de medidas do sistema, efetuou-se uma série de medições da velocidade da água mili-Q (pura) e da água filtrada e desgaseificada contida no tanque acústico, para diferentes frequências de transdutores (entre $1 \mathrm{MHz}-10 \mathrm{MHz}$ ).

As medições da velocidade da água mili-Q permitiram que comparássemos com valores apresentados na literatura por krautkramer, 1983 [90] e Cobbold, 2007 [56]; como apresentado no anexo A, tabela A.1.

Este valor obtido da velocidade da água mili-Q para a temperatura de nossas medições foi calculado estabelecendo um regressão linear e interpolando os valores na curva. Assim, para temperaturas variando entre $23{ }^{\circ} \mathrm{C}-24{ }^{\circ} \mathrm{C}$, a velocidade média foi de $(1491,72 \pm 1,34) \mathrm{m} / \mathrm{s}$.

Por outro lado, neste trabalho, as medições da velocidade e atenuação, como ditas anteriormente, foram adquiridas em relação à água do tanque acústico. Assim, procurou-se estabelecer um valor de referência para as medições de velocidade e atenuação das amostras que foram inseridas dentro do tanque acústico. Os resultados da média das velocidades do som na água 
do tanque acústico, comparado com o valor médio da interpolação supracitado, apresenta um desvio de apenas 0,01\%.

$\mathrm{Na}$ tabela 4.1 apresentamos os valores médios da velocidade da água filtrada e desgaseificada do tanque acústico para diferentes transdutores de US, através do método da reflexão.

Tabela 4.1: Velocidade média da $\mathrm{H}_{2} \mathrm{O}$ (tanque acústico) a $(24 \pm 1){ }^{\circ} \mathrm{C}[T / R]$ - Diferentes frequências US.

\begin{tabular}{c|c}
\hline \hline Frequência $[\mathrm{MHz}]$ & $\mathrm{V}_{\text {média }}[\mathrm{m} / \mathrm{s}]$ (Reflexão) \\
\hline 1,0 & $(1491,36 \pm 1,71)$ \\
2,25 & $(1488,71 \pm 2,45)$ \\
3,5 & $(1494,43 \pm 1,93)$ \\
5,0 & $(1489,31 \pm 1,99)$ \\
7,5 & $(1494,33 \pm 1,79)$ \\
10,0 & $(1493,21 \pm 1,37)$ \\
\hline Média & $(1491,89 \pm 2,50)$ \\
\hline \hline T/R = transmiter/receiver (ou Reflexão).
\end{tabular}

O valor da velocidade média para a água mili-Q $(1492,03 \pm 1,94) \mathrm{m} / \mathrm{s}$, obtido em nossas medições, em diferentes frequências, comparado com o estimado na literatura por Cobbold, 2007 [56], teve um desvio relativo de aproximadamente $0,004 \%$.

Ao compararmos o valor da velocidade média para a água do tanque acústico $(1489,31 \pm 1,99) \mathrm{m} / \mathrm{s}$, na mesma frequência de $5 \mathrm{MHz}$, apresentada por Cobbold, 2007 [56]; utilizando o método da reflexão, verificamos um desvio relativo percentual de apenas $0,16 \%$.

Logo, pode-se perceber um ótimo grau de precisão no processo de medições da velocidade através da configuração montada.

Quando utilizamos o método de transmissão, para medições de velocidade, verificamos que este método propiciou desvios maiores comparados com o método da reflexão, visto que, além de tomarmos o sinal após a onda atravessar o meio em estudo, o processo de medição utiliza dois transdutores de US, que provavelmente possuem pequenas diferenças de construção e caracterização, além dos erros inerentes ao processo de alinhamento entre eles. 
A tabela 4.2 mostra os dados obtidos para velocidade dos diferentes meios analisados, utilizando o método de medição através do pulser/receiver.

Tabela 4.2: Velocidade do Som pelo método da Reflexão (T/R) - Diferentes meios.

\begin{tabular}{c|c}
\hline \hline Material & Velocidade $[\mathrm{m} / \mathrm{s}]$ \\
\cline { 2 - 2 } $\mathrm{H}_{2} \mathrm{O}$ mili-Q & $(1492,03 \pm 1,94)$ \\
$\mathrm{H}_{2}$ O tanque acústico & $(1491,89 \pm 1,87)$ \\
Parafina Cristal pura & $(1472,03 \pm 2,14)$ \\
Parafina Cristal 50\% PM sc & $(1476,99 \pm 2,41)$ \\
Parafina Cristal 50\% PM cc & $(1484,56 \pm 2,72)$ \\
Óleo STP sc & $(1471,77 \pm 2,13)$ \\
Óleo STP cc & $(1471,77 \pm 2,13)$ \\
Óleo 20\% PM sc & $(1479,03 \pm 2,34)$ \\
Óleo 20\% PM cc & $(1479,81 \pm 2,33)$ \\
Óleo 50\% PM sc & $(1481,28 \pm 2,35)$ \\
Óleo 50\% PM cc & $(1486,86 \pm 2,37)$ \\
\hline \hline
\end{tabular}

velocidade média do som a $\overline{\overline{\bar{m}(24 \pm 1)^{\circ} \mathrm{C} \text { medidos com diferentes transdutores numa faixa de }}} 1 \mathrm{MHz}$ a $10 \mathrm{MHz} ; \mathrm{PM}=$ partículas magnéticas, $\mathrm{sc}=\mathrm{sem}$ campo e $\mathrm{cc}=$ com campo.

Ao efetuarmos uma série de 12 medições para cada meio e frequência, nota-se que a repetibilidade individual das medições da velocidade, numa mesma faixa de frequência, teve uma variação média menor do que $1 \%$. Entretanto, as variações nas medições, da atenuação, entre as diferentes faixas de frequência, aumentam, em média, em torno de $2 \%$, a medida que aumentamos a concentração de partículas ferromagnéticas e a frequência dos transdutores. Provavelmente devido a alta atenuação e consequente perda de sinal.

Na figura 4.3 é mostrado o comportamento da velocidade média em função do campo magnético externo, para o óleo STP com concentrações de $20 \%$ e $50 \%$ de partículas magnéticas, para a faixa de frequências ultrassônicas entre $1 \mathrm{MHz}$ a $10 \mathrm{MHz}$. Constata-se uma mudança na velocidade devido a concentração de partículas ferromagnéticas e um leve incremento devido a alteração na intensidade do campo magnético externo aplicado através da aproximação dos magnetos. 


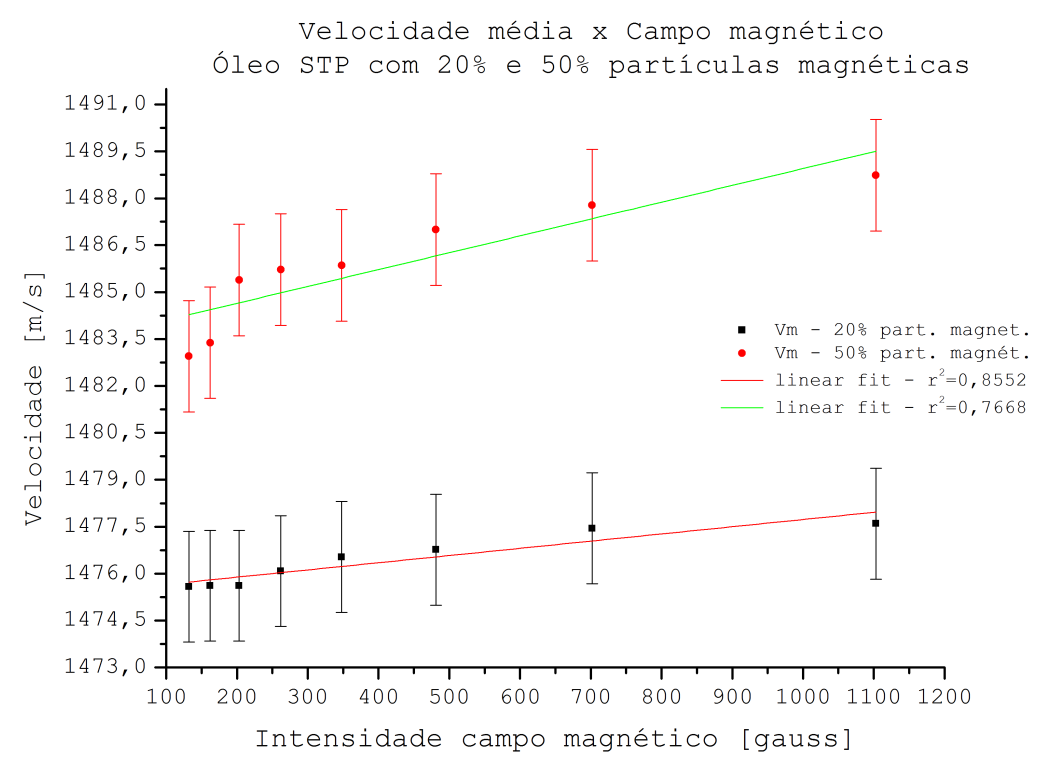

Figura 4.3: Velocidade em função do campo magnético para Óleo STP com 20\% e 50\% de concentração de partículas magnéticas - Medições com transdutor de $1 \mathrm{MHz}$.

Além disso, o gráfico da figura 4.4 mostra que a velocidade média nos

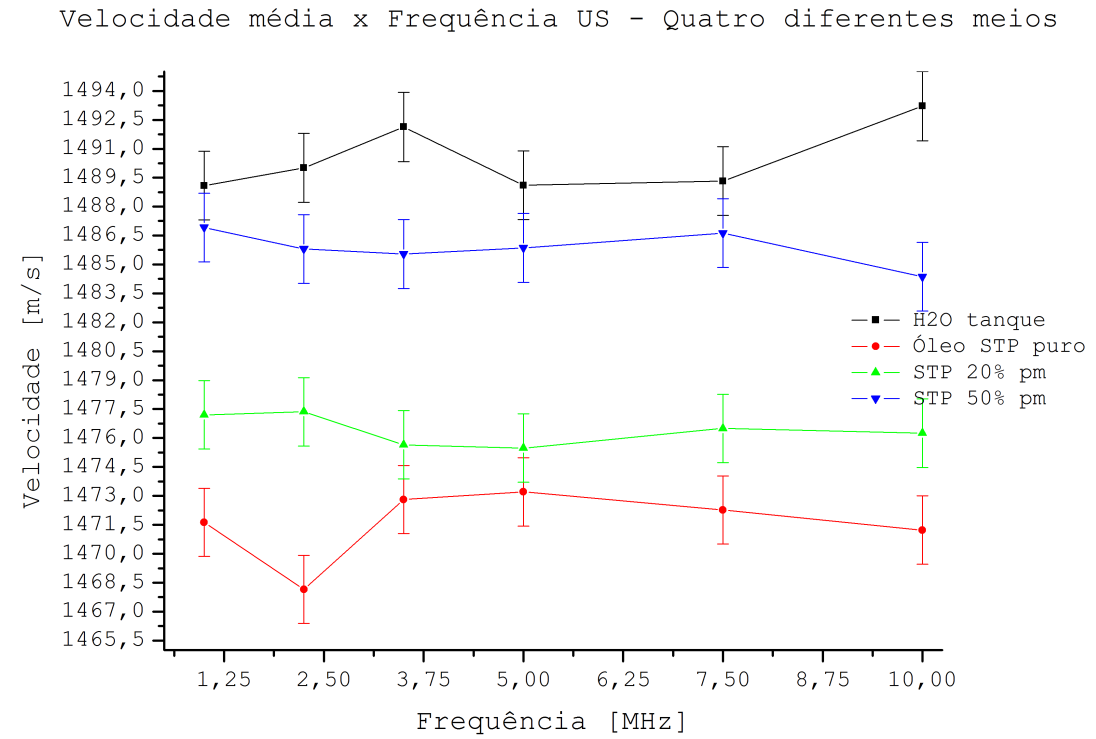

Figura 4.4: Velocidade em função da frequência dos transdutores para quatro meios: $\mathrm{H}_{2} \mathrm{O}$, Óleo STP puro e com duas concentrações de partículas magnéticas (20\% e $50 \%$ ).

respectivos meios destacados não depende da frequência central dos transdutores, apenas do meio de propagação da onda, como previsto na teoria 
linear.

Também é possível verificar que o óleo STP utilizado diminui a velocidade de propagação da onda ultrassônica, comparado com a água. Contudo, ao se acrescentar diferentes concentrações de partículas ferromagnéticas observa-se um incremento na velocidade de propagação da onda ultrassônica.

O mesmo comportamento foi observado com óleo de oliva puro e óleo de girassol/soja, cuja velocidade média, obtida a $24^{\circ} \mathrm{C}$, foi de aproximadamente $(1446,65 \pm 1,49) \mathrm{m} / \mathrm{s}$. A viscosidade dos óleos, utilizados neste estudo, contribuí na redução da velocidade de propagação da onda, enquanto que, ao incrementar a densidade do meio, com partículas ferromagnéticas, a velocidade tendeu a crescer.

Para estudar a resposta dos meios quanto a atenuação sonora, utilizou-se o mesmo procedimento e configuração das medidas de velocidade. Contudo, a atenuação é mensurada a partir da amplitude dos ecos, medidos aqui em milivolts, e, comparados com a do meio de referência que em nosso estudo é a água filtrada e desgaseificada do tanque acústico.

Entretanto, como não estabelecemos um protocolo para medições experimentais da atenuação absoluta da água do tanque acústico, esta atenuação da água filtrada e desgaseificada do tanque foi calculada a partir da equação 4.1, que segundo Krautkramer, 1983 [90], pode ser expressa por:

$$
\alpha_{\mathrm{H}_{2} \mathrm{O}}=2,17 \times 10^{-15} \cdot \mathrm{f}^{2}
$$

Tomando este valor como referência foi possível determinar a atenuação dos demais meios em relação a água, ou em relação ao porta amostra. Para tanto, foi utilizado a equação 4.2, apresentada por Vieira, 2005 [91], Crescenti, 2007 [81], em que " $d$ " é o caminho percorrido pela onda ultrassônica no meio analisado e $A_{o}$ é a amplitude do sinal de referência $\left(\mathrm{H}_{2} \mathrm{O}\right)$.

$$
\left(\frac{A}{A_{0}}\right)=e^{-\alpha \cdot x} \Rightarrow \alpha=-\left(\frac{20}{d}\right) \cdot \log _{10}\left(\frac{A}{A_{0}}\right) ;
$$

Na tabela 4.3 apresentam-se os valores da atenuação e impedância acústica para elementos que serviram de base na confecção de alguns dos simuladores de tecidos moles caracterizados neste trabalho. As medições foram feitas usando um par de transdutores de $1 \mathrm{MHz}$ que estavam fixados numa pequena cuba de dimensões $(11,0 \times 11,0 \times 13,0) \mathrm{cm}$, contendo água filtrada e 
Tabela 4.3: Atenuação e impedância Acústica nos diferentes meios utilizados como base das inclusões, comparados com a $\mathrm{H}_{2} \mathrm{O}$.

\begin{tabular}{c|cc}
\hline \hline Material & $\begin{array}{c}\text { Atenuação } \\
{[\mathrm{dB} / \mathrm{cm} / \mathrm{MHz}]}\end{array}$ & $\begin{array}{c}\text { Impedância Acústica } \\
\mathrm{Z}=\rho \cdot v_{\mathrm{s}}\left[\mathrm{Kg} / \mathrm{m}^{2} . \mathrm{s}\right] \times 10^{6}\end{array}$ \\
\hline $\mathrm{H}_{2} \mathrm{O}$ mili-Q & $0,00217 *$ & $(1,48 \pm 0,01)$ \\
$\mathrm{H}_{2} \mathrm{O}$ filtrada e desgaseificada & $(0,29 \pm 0,01) \star$ & $(1,48 \pm 0,01)$ \\
Óleo STP puro & $(0,58 \pm 0,03)$ & $(1,26 \pm 0,02)$ \\
Óleo soja/girassol & $(0,42 \pm 0,03)$ & $(1,29 \pm 0,02)$ \\
Parafina Cristal pura & $(0,83 \pm 0,01)$ & $(1,36 \pm 0,10)$ \\
Parafina Gel pura & $(1,22 \pm 0,02)$ & $(1,26 \pm 0,31)$ \\
Gelatina (250Bloom) 5\% sem pm & $(0,98 \pm 0,05)$ & $(1,54 \pm 0,14)$ \\
Parafina Cristal 10\% óleo vegetal sem pm & $(0,94 \pm 0,01)$ & $(1,31 \pm 0,02)$ \\
Parafina Cristal 5\% pm & $(4,40 \pm 0,11)$ & $(1,39 \pm 0,02)$ \\
Gelatina (250Bloom) 5\% com 10\% pm & $(6,85 \pm 0,24)$ & $(1,71 \pm 0,12)$ \\
\hline \hline
\end{tabular}

* valor calculado; $\mathrm{pm}=$ partículas magnéticas; $\star$ estimado em relação a $\mathrm{H}_{2} \mathrm{O}$ mili-Q; $\rho$ é a densidade do meio e $v_{\mathrm{s}}$ é a velocidade do som a $24{ }^{\circ} \mathrm{C}$, em cada meio. Para soja: $\rho_{\text {soja }}=0,891$, Para água filtrada a $24{ }^{\circ} \mathrm{C}: \rho_{\mathrm{H}_{2} \mathrm{O}}=0,99297$.

desgaseificada do tanque acústico a uma temperatura de $(24 \pm 1)^{\circ} \mathrm{C}$.

A densidade de cada composto foi obtida através da relação entre a massa, medida numa balança de precisão (descrita na seção 3.2.2) e o volume ocupado quando o mesmo encontrava-se em estado líquido dentro de um becker graduado.

Estas medições estão sujeitas a um erro médio de 2,5\%, com prováveis fontes decorrentes das variações dos componentes da água, paralelismo das amostras frente ao transdutor, leitura dos dados, por parte do operador, direto na tela de um oscilóscopio e reverberações da onda nas paredes do recipiente.

As medições efetuadas no tanque acústico, por ter dimensões maiores, sofre menos influência das reverberações em suas paredes e da acuidade do operador em ler os valores, pois, o sinal é adquirido numa placa osciloscópica, de maior taxa de amostragem, fixada num computador e processado através do MATLAB.

A figura 4.5 mostra um exemplo dos sinais adquiridos, na água com o porta amostra (PA), com um par de transdutores de $1 \mathrm{MHz}$, pelo método de reflexão e transmissão, o qual foi mostrado em MATLAB. 

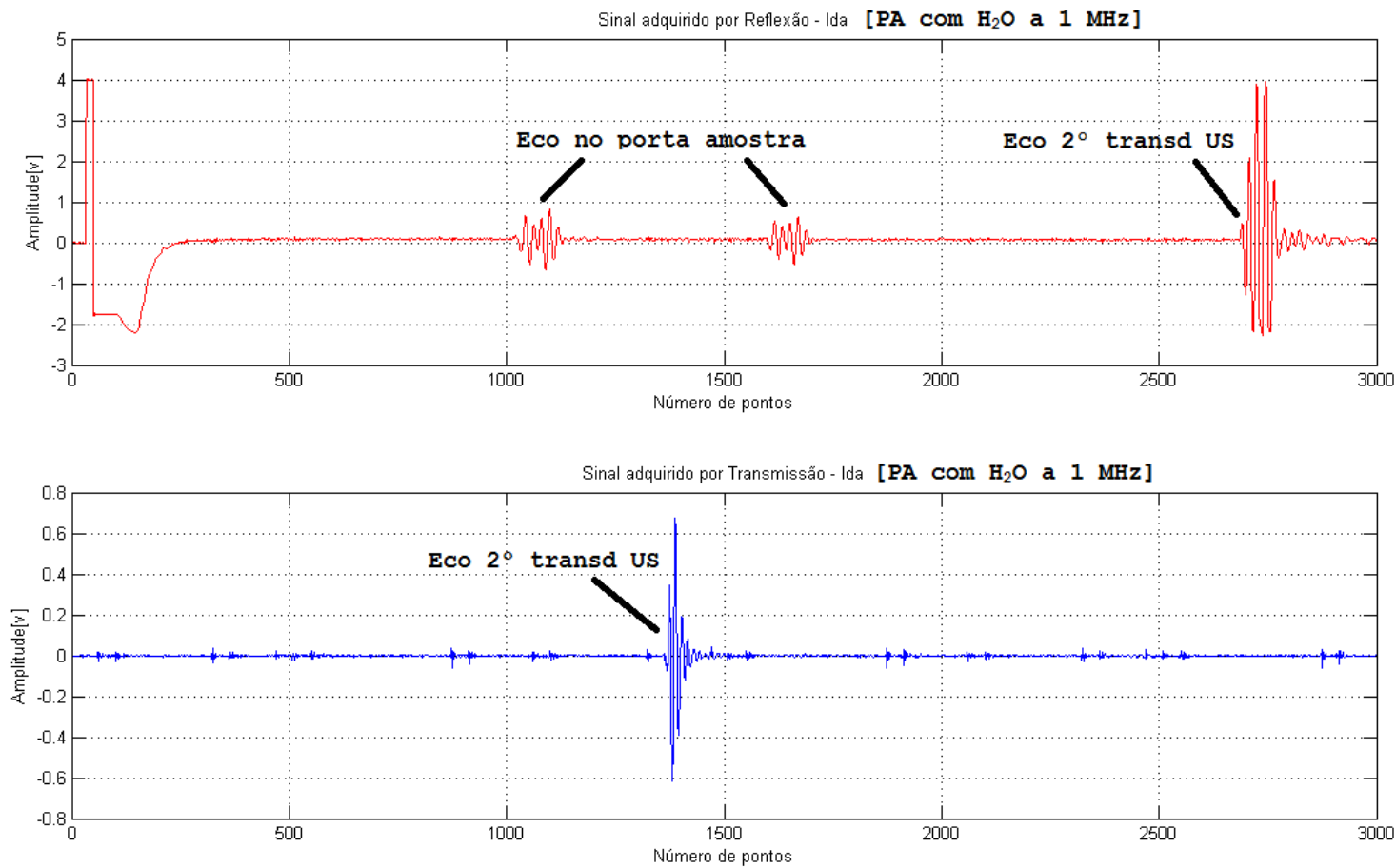

Figura 4.5: Sinal ultrassônico adquirido através do porta-amostra contendo água, com um par de transdutores de $1 \mathrm{MHz}$, através do método "pulser/receiver" (reflexão) e Transmissão.

Conforme ilustrado no gráfico 4.5 anterior, no método de transmissão o tempo do eco é metade do tempo transcorrido pelo método de reflexão, no qual a onda tem que percorrer o dobro do caminho. A partir do sinal mostrado utiliza-se uma função do Matlab ("PEAKDET - Detect peaks in a vector") para detectar os picos nos pontos referentes ao ecos. Assim, é possível saber o tempo que possibilita determinar a velocidade, e a amplitude do sinal, a qual permitirá estabelecer a atenuação do sinal.

Ao analisar o comportamento da propagação da onda nas amostras estudadas, é perceptível a dependência do coeficiente de atenuação com a frequência central do transdutor de ultrassom, e esta relação não é linear para a maioria das amostras analisadas, exceto para o porta-amostra contendo a água filtrada e desgaseificada, que mostrou-se bem linear. 
A tabela 4.4 apresenta os valores médios de um conjunto de dados adquiridos no tanque acústico, para o coeficiente de atenuação em função da frequência dos transdutores utilizados (1 MHz a $10 \mathrm{MHz})$.

Tabela 4.4: Atenuação Sonora obtida através do método de Transmissão - Para diferentes meios e concentração de partículas magnéticas, tendo como referência a água filtrada e desgaseificada do tanque acústico.

\begin{tabular}{|c|c|c|c|c|}
\hline & Referências & & $10 \% \mathrm{pm}$ & $20 \% \mathrm{pm}$ \\
\hline Frequência & $\mathrm{PA}\left(\mathrm{H}_{2} \mathrm{O}\right)$ & Óleo $\left(\mathrm{H}_{2} \mathrm{O}\right)$ & Relação $\left(\mathrm{H}_{2} \mathrm{O}\right)$ & Relação $\left(\mathrm{H}_{2} \mathrm{O}\right)$ \\
\hline $\mathrm{MHz}$ & {$[\mathrm{dB} / \mathrm{cm}]$} & {$[\mathrm{dB} / \mathrm{cm}]$} & {$[\mathrm{dB} / \mathrm{cm}]$} & {$[\mathrm{dB} / \mathrm{cm}]$} \\
\hline 1 & $(0,39 \pm 0,01)$ & $(0,58 \pm 0,03)$ & $(2,72 \pm 0,07)$ & $(3,09 \pm 0,08)$ \\
\hline 2,25 & $(0,60 \pm 0,02)$ & $(2,93 \pm 0,07)$ & $(4,48 \pm 0,11)$ & $(6,03 \pm 0,15)$ \\
\hline 3,5 & $(0,91 \pm 0,02)$ & $(3,59 \pm 0,09)$ & $(4,59 \pm 0,12)$ & $(7,49 \pm 0,19)$ \\
\hline 5 & $(1,32 \pm 0,03)$ & $(7,03 \pm 0,18)$ & $(8,02 \pm 0,20)$ & $(9,97 \pm 0,25)$ \\
\hline 7,5 & $(1,38 \pm 0,03)$ & $(8,87 \pm 0,22)$ & $(10,58 \pm 0,26)$ & $(10,60 \pm 0,26)$ \\
\hline 10 & $(2,48 \pm 0,06)$ & $(9,00 \pm 0,26)$ & $(15,56 \pm 0,39)$ & $(18,14 \pm 0,45)$ \\
\hline & $30 \% \mathrm{pm}$ & $40 \% \mathrm{pm}$ & $50 \% \mathrm{pm}$ & \\
\hline Frequência & Relação $\left(\mathrm{H}_{2} \mathrm{O}\right)$ & Relação $\left(\mathrm{H}_{2} \mathrm{O}\right)$ & Relação $\left(\mathrm{H}_{2} \mathrm{O}\right)$ & \\
\hline $\mathrm{MHz}$ & {$[\mathrm{dB} / \mathrm{cm}]$} & {$[\mathrm{dB} / \mathrm{cm}]$} & {$[\mathrm{dB} / \mathrm{cm}]$} & \\
\hline 1 & $(6,44 \pm 0,32)$ & $(8,91 \pm 0,45)$ & $(9,45 \pm 0,47)$ & \\
\hline 2,25 & $(7,83 \pm 0,39)$ & $(9,19 \pm 0,46)$ & $(10,34 \pm 0,52)$ & \\
\hline 3,5 & $(10,88 \pm 0,54)$ & $(12,27 \pm 0,61)$ & $(14,82 \pm 0,74)$ & \\
\hline 5 & $(14,82 \pm 0,74)$ & $(15,04 \pm 0,75)$ & $(19,11 \pm 0,96)$ & \\
\hline 7,5 & $(20,84 \pm 1,04)$ & $(21,66 \pm 1,08)$ & $(25,93 \pm 1,30)$ & \\
\hline 10 & $(24,42 \pm 1,22)$ & $(27,15 \pm 1,36)$ & $(28,77 \pm 1,44)$ & \\
\hline
\end{tabular}

Atenuação do som a $(24 \pm 1){ }^{\circ} \mathrm{C}, \mathrm{PA}=$ porta-amostras, pm = partículas magnéticas. O desvio percentual médio foi de $2,5 \%$ para até $20 \%$ de pm, acima de $20 \%$ o desvio percentual médio cresce para até $5 \%$. O óleo utilizado na solução foi o STP, descrito na seção 3.1 .

A figura 4.6 mostra a atenuação do porta-amostra, em relação a água, para a faixa de transdutores utilizados. A curva continua representa um ajuste linear, cujo coeficiente de determinação está em torno de 94,4\%.

Todavia, ao analisar o comportamento da atenuação para o óleo STP puro e com diferentes concentrações de partículas magnéticas (10\% a 50\%), obtidos com os transdutores de $1 \mathrm{MHz}$ a $10 \mathrm{MHz}$, temos um crescimento não 


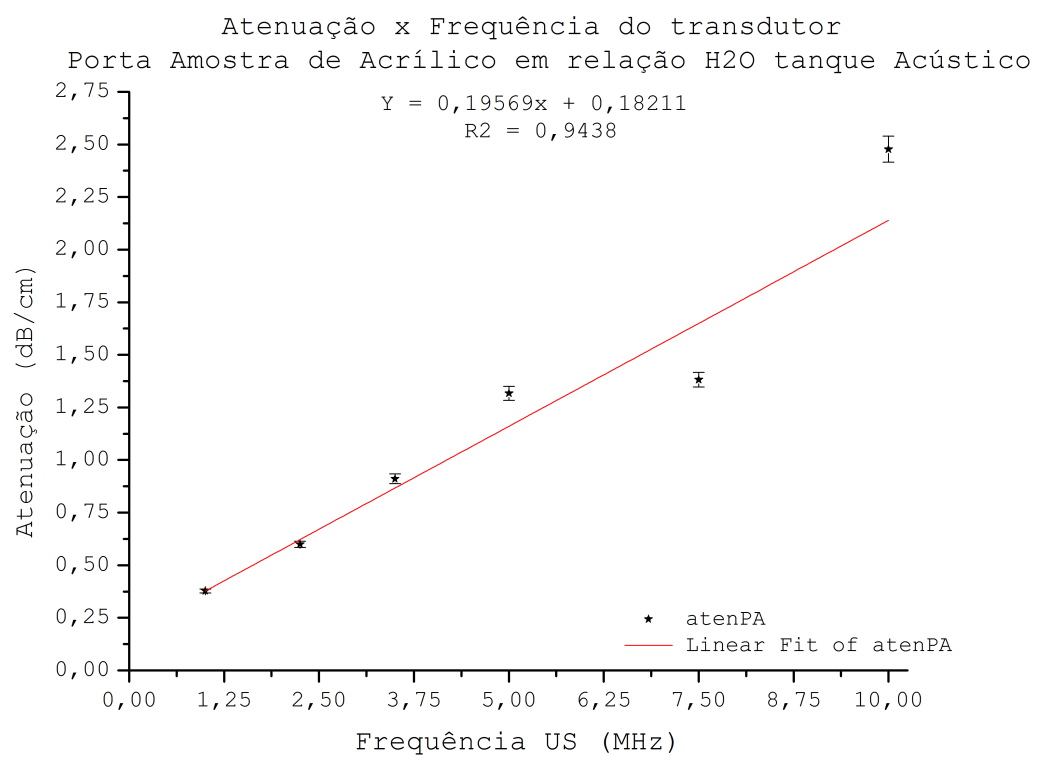

Figura 4.6: Atenuação do porta amostra em função da frequência do transdutor US, em relação a água filtrada e desgaseificada do tanque acústico.

linear e proporcional a frequência do transdutor, conforme mostra o gráfico 4.7.

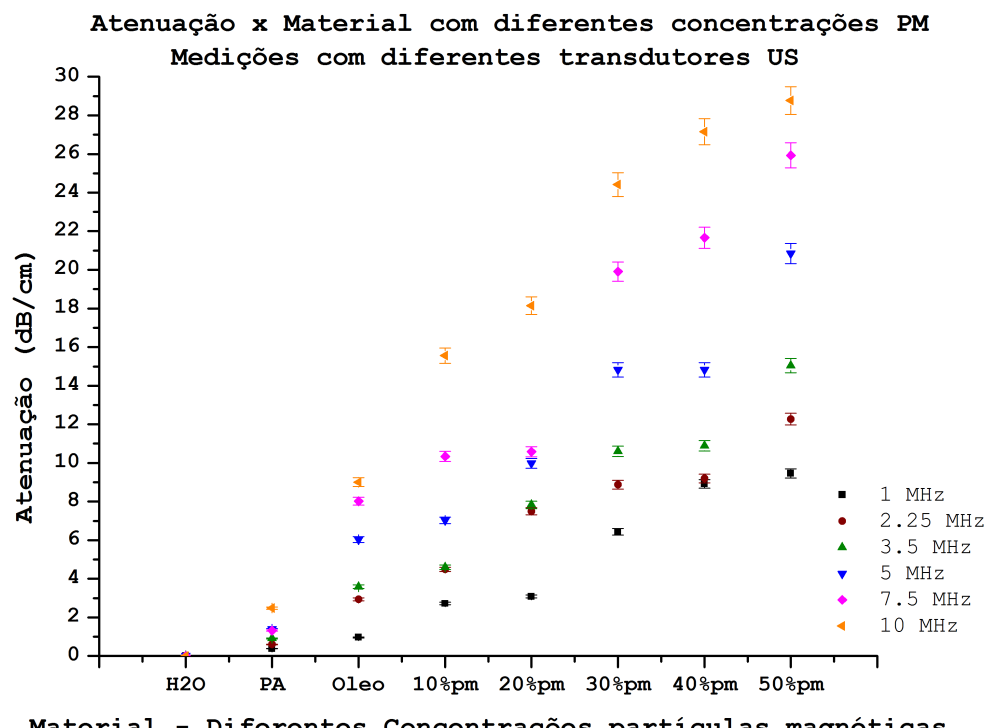

Figura 4.7: Atenuação em função do material com diferentes concentrações de partículas magnéticas obtidas pelo conjunto de transdutores de US.

Ao destacarmos a primeira curva, transdutor de $1 \mathrm{MHz}$, é possível observar que a linha de tendência apresenta um crescimento do tipo polinomial 
quadrático, com coeficiente de determinação de aproximadamente 95,6\%. O mesmo comportamento pode ser visto para as demais frequências de transdutores.

O gráfico da figura 4.8 mostra esta relação entre o coeficiente de atenuação e a concentração de partículas magnéticas quando se utiliza um transdutor cuja frequência central é de $1 \mathrm{MHz}$.

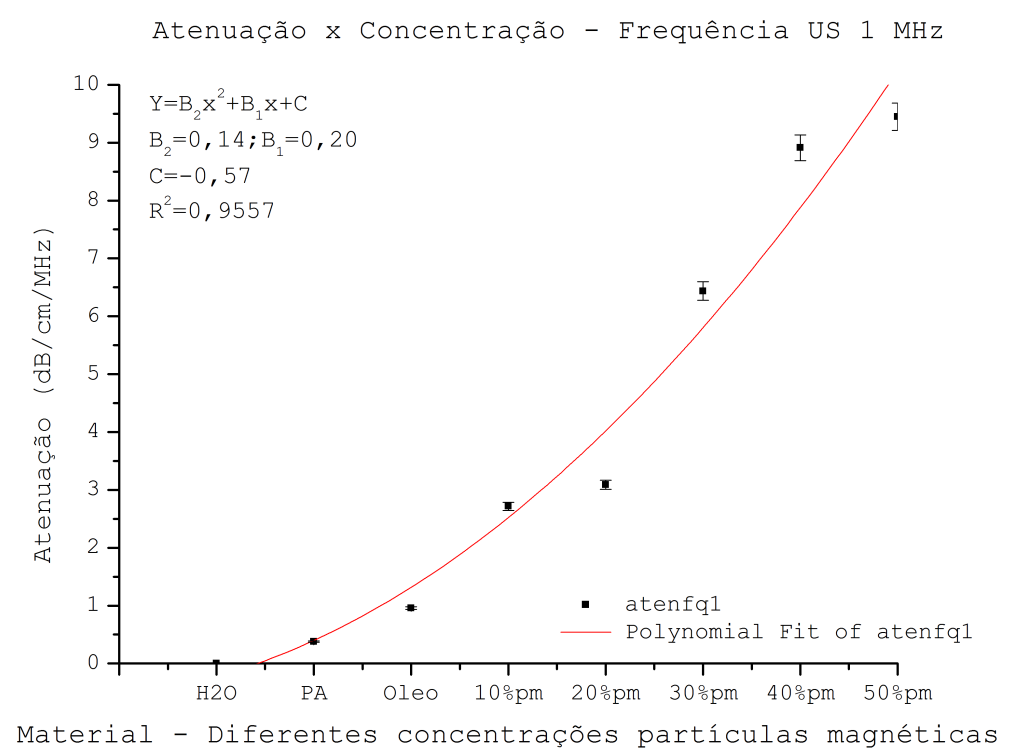

Figura 4.8: Atenuação em função do meio com e sem concentração de partículas magnéticas, para um transdutor de $1 \mathrm{MHz}$, sem aplicação do campo magnético.

Vale ressaltar que o processo de leitura do sinal de amplitude, que permite calcular o coeficiente de atenuação, é mais crítico a medida que ocorre o incremento das concentrações de partículas magnéticas e da frequência do transdutor de US, visto que o sinal sofre degradação e muitas vezes se mistura ao nível do ruído. Daí, o desvio relativo percentual ser maior.

Outro aspecto observado e que dificulta as medições do coeficiente de atenuação é a viscosidade do meio em que estão as partículas magnéticas. Esta mesma viscosidade que retarda a decantação das partículas no meio, também produz um tempo maior para que as partículas se desalinhem do campo externo, mesmo após a sua retirada.

O gráfico da figura 4.9 apresenta os valores do coeficiente de atenuação em função do campo externo, para uma amostra de óleo STP contendo 20\% de partículas magnéticas, adquiridos com um transdutor de $1 \mathrm{MHz}$. Assim, o 
resultado da atenuação pode ser expresso em $\mathrm{dB} / \mathrm{cm} / \mathrm{MHz}$.

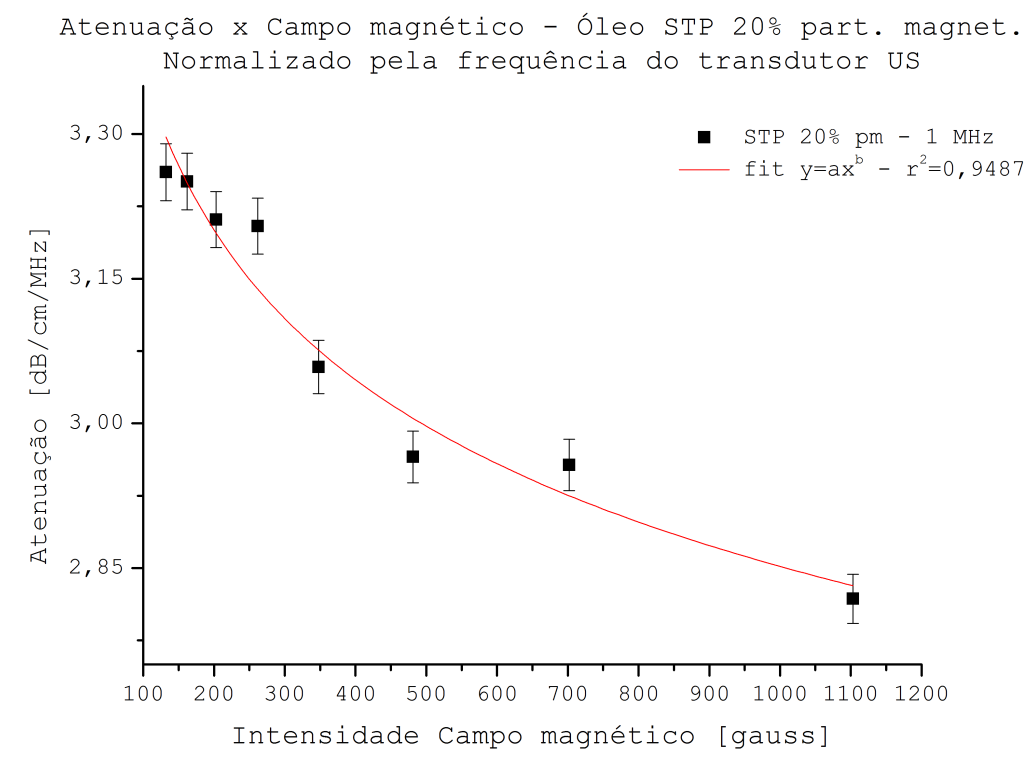

Figura 4.9: Atenuação em função do campo magnético - Óleo STP com $20 \%$ de partículas magnéticas.

$\mathrm{Na}$ seção seguinte procurou-se analisar o comportamento entre a viscosidade do meio contendo partículas ferromagnéticas e o campo magnético externo.

\subsection{Viscosidade e efeitos do campo magnético}

Num primeiro momento buscou-se analisar o comportamento viscoso de inclusões com diferentes concentrações de partículas ferromagnéticas, num gel ultrassônico, cuja composição básica, a depender do fabricante, pode conter: polímero carboxivinilico (carbopol), imidazolidil ureia, glicerina, metil parabeno, Nipagim, Nipazol, 2-amino, 1-propanol (AMP), ISN-524, propileno glicol, água desmineralizada ou deionizada.

O gráfico da figura 4.10 mostra a taxa de cisalhamento versus a tensão de cisalhamento do gel de ultrassom com inclusão de $10 \%$ de partículas ferromagnéticas, sem aplicação de um campo externo e com aplicação do campo externo. Pode-se verificar que o gel ultrassônico possui um comportamento pseudoplástico, conforme descrição apresentada na seção 2.1.2.

Também verificou-se que não ocorre adesão das partículas à estrutura do 


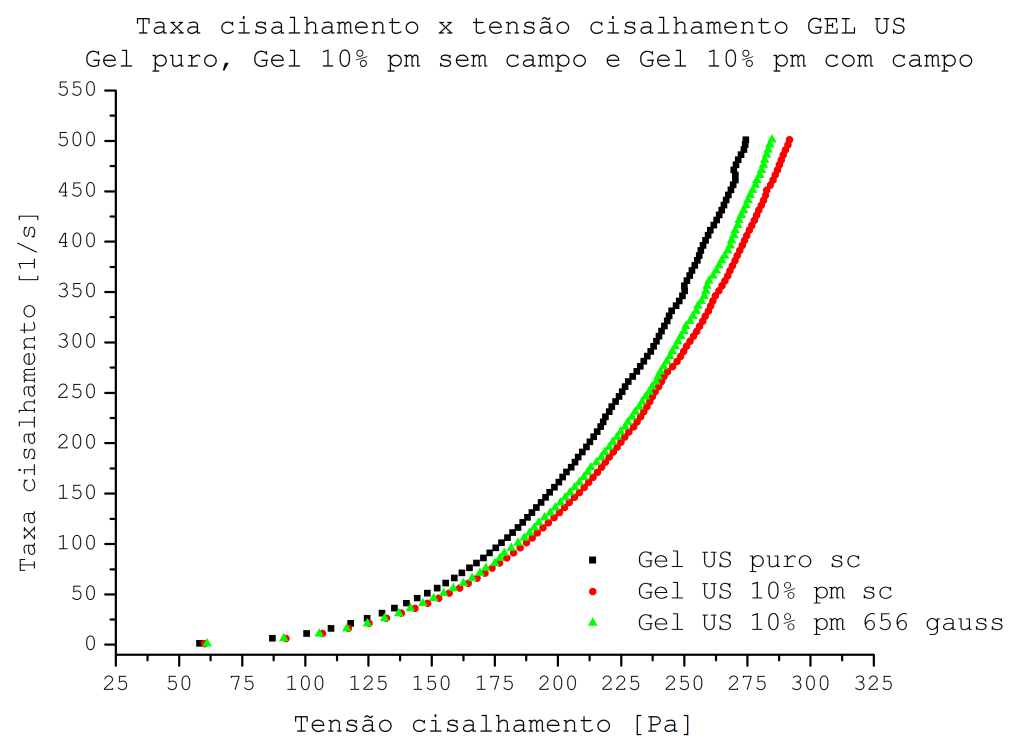

Figura 4.10: Taxa de cisalhamento [1/s] em função da tensão de cisalhamento [Pa] para o gel de ultrassom com $10 \%$ de partículas ferromagnéticas.

gel, apenas uma dispersão coloidal, pois, ao aplicar o campo magnético externo há uma difusão das partículas na direção do campo separando gel e partículas magnéticas.

A figura 4.11 mostra a curva de viscosidade do gel de US para três condi-

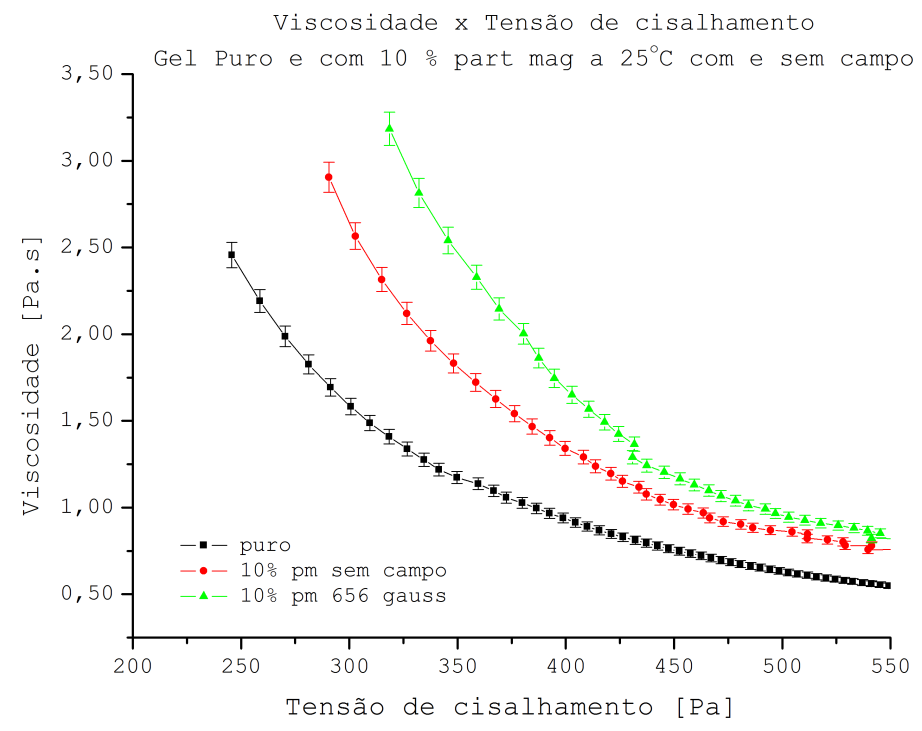

Figura 4.11: Viscosidade em função da tensão de cisalhamento para o gel de US, a $25{ }^{\circ} \mathrm{C}$, sem partículas magnéticas, com e sem campo externo. 
ções, com e sem aplicação de um campo magnético externo. Apesar de uma boa discriminação de viscosidade quando aplicado um campo externo, há problemas quanto a variação da temperatura, pois, ao elevarmos a temperatura do gel até aproximá-la da temperatura do corpo humano, ocorre a fusão daquele. Isto dificulta a aplicação do gel nas inclusões dos simuladores de tecidos moles.

Assim, buscou-se analisar meios à base de óleos, vegetal e mineral, que não apresentam mudanças de estado na faixa de temperatura entre $25{ }^{\circ} \mathrm{C}$ e $37{ }^{\circ} \mathrm{C}$, e que pudessem ser misturados com materiais ferromagnéticos.

O fluido magnetoreológico adquirido (da "Lord Corporation") tem por base um óleo mineral (hidrocarbonetos), conforme descrito na seção 3.1. Entretanto, se observou que, mesmo dentro do recipiente no qual foi armazenado ocorria uma decantação das partículas magnéticas. Então, aproveitou-se esta "pasta" de partículas decantadas, obtida através da separação do óleo por escoamento num becker, para diluí-la em diferentes concentrações em outros meios, como a parafina, gelatina 250 Bloom, gel US e outros óleos.

Além disso, um pó de nanopartículas de $\mathrm{Fe}_{3} \mathrm{O}_{4}$, adquirido comercialmente, foi usado em algumas misturas de óleo de oliva e gel US para verificar se a granulação destas partículas, por serem menores, produzia efeitos magnéticos mais intensos do que a mistura com a "pasta" decantada do FMR supracitado.

Foi feito um ensaio de viscosidade nestas misturas contendo nanopartículas de $\mathrm{Fe}_{3} \mathrm{O}_{4}$, nos diferentes meios, com e sem aplicação do campo magnético externo produzido pelos imãs e não se constataram mudanças significativas.

Assim, tomou-se primeiramente o azeite de oliva e analisou-se o comportamento da viscosidade sem inclusão de partículas e com inclusão de partículas, tanto de dimensões micrométricas, quanto nanométricas. Em ambos os casos, o comportamento foi idêntico: linear e newtoniano. O gráfico da figura 4.12 apresenta o resultado experimental deste comportamento linear, newtoniano, do azeite de oliva puro, sob ação do campo externo em diferentes pontos. 


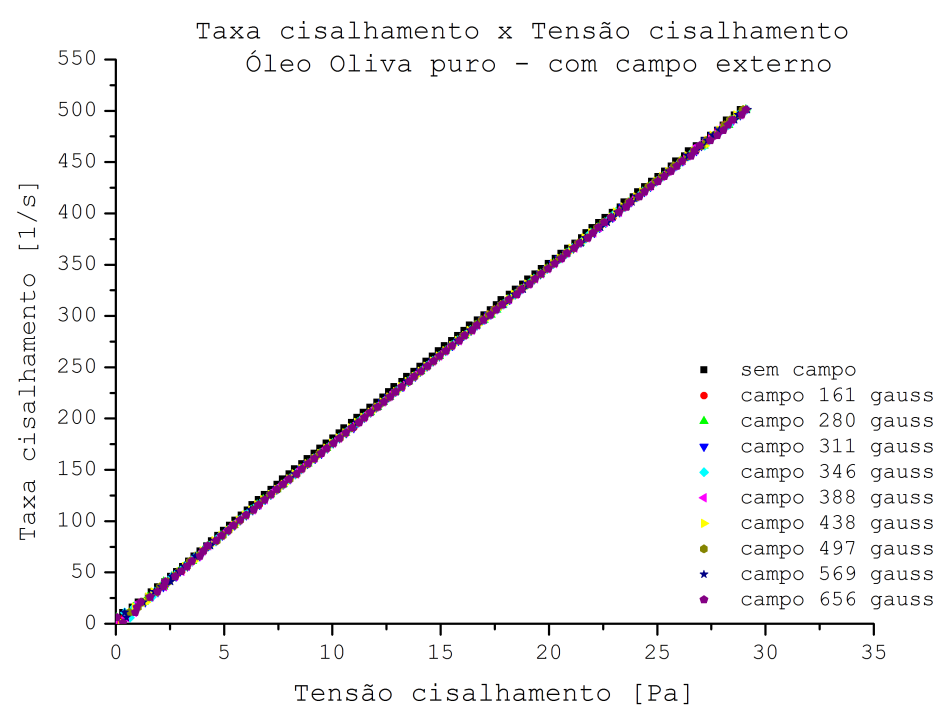

Figura 4.12: Taxa de cisalhamento em função da tensão de cisalhamento para óleo vegetal (Oliva) sob ação de um campo externo variável.

A figura 4.13 mostra o exemplo deste mesmo fluido com $10 \%$ de partículas magnéticas, também sob ação de um campo magnético externo variável. E, mesmo com acréscimo de partículas magnéticas, o meio mantém a linearidade.

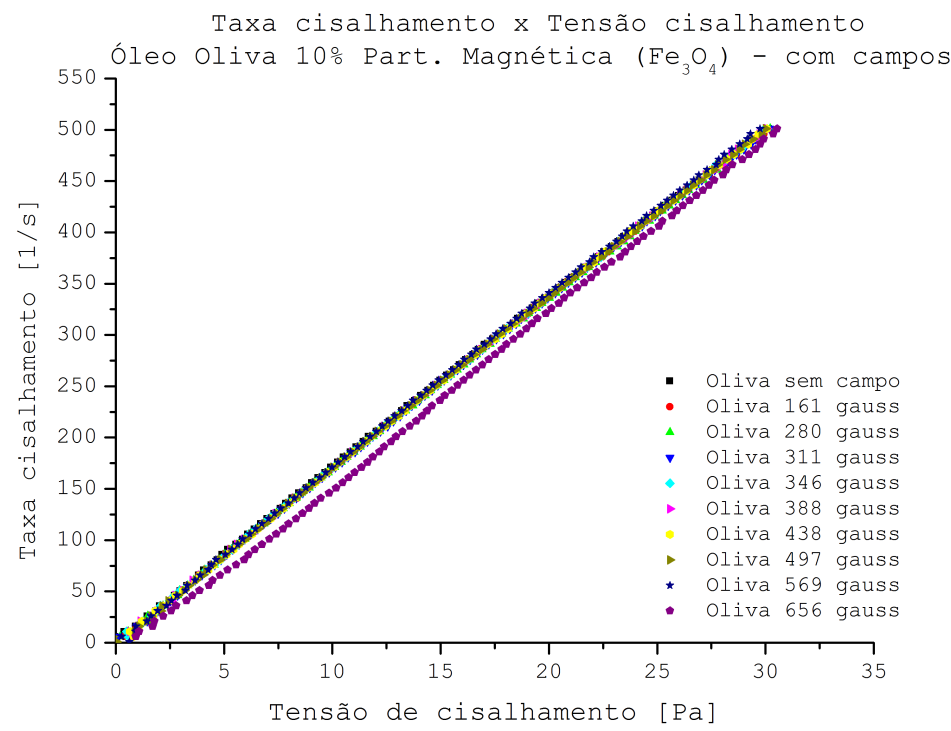

Figura 4.13: Taxa de cisalhamento em função da tensão de cisalhamento para óleo de oliva com $10 \%$ de partículas magnéticas sob ação de um campo externo variável.

Isto também foi observado quando substituímos a "pasta" do fluido 
ferromagnético pelo pó de nanopartículas ferromagnéticas, pois, buscávamos verificar se, usando uma granulação menor de partículas, o comportamento da viscosidade em função do campo magnético externo seria maior ou menor, e, se o comportamento do meio (óleo + nanopartículas) deixaria de ser newtoniano.

Pode-se perceber uma leve distorção (afastamento) da curva quando da aplicação do campo de maior intensidade (656 gauss), que é o máximo ponto de aproximação dos magnetos, mais acentuada numa tensão de cisalhamento entre $5 \mathrm{~Pa}$ a $20 \mathrm{~Pa}$. Todavia, apesar do óleo de oliva apresentar um comportamento newtoniano, a baixa viscosidade possibilita uma decantação das partículas num tempo muito curto. Assim, experimentou-se um óleo com maior viscosidade. Um óleo aditivo para motores de combustão, de uso comercial da marca STP, conforme descrito na seção 3.1 .

O comportamento viscoso deste óleo, em seis diferentes concentrações é mostrado no gráfico da figura 4.14, em que se percebe um relação não linear e pseudoplástica, conforme apresentado na seção 2.1.2, visto que, existe uma pequena tensão de cisalhamento inicial diferente de zero.

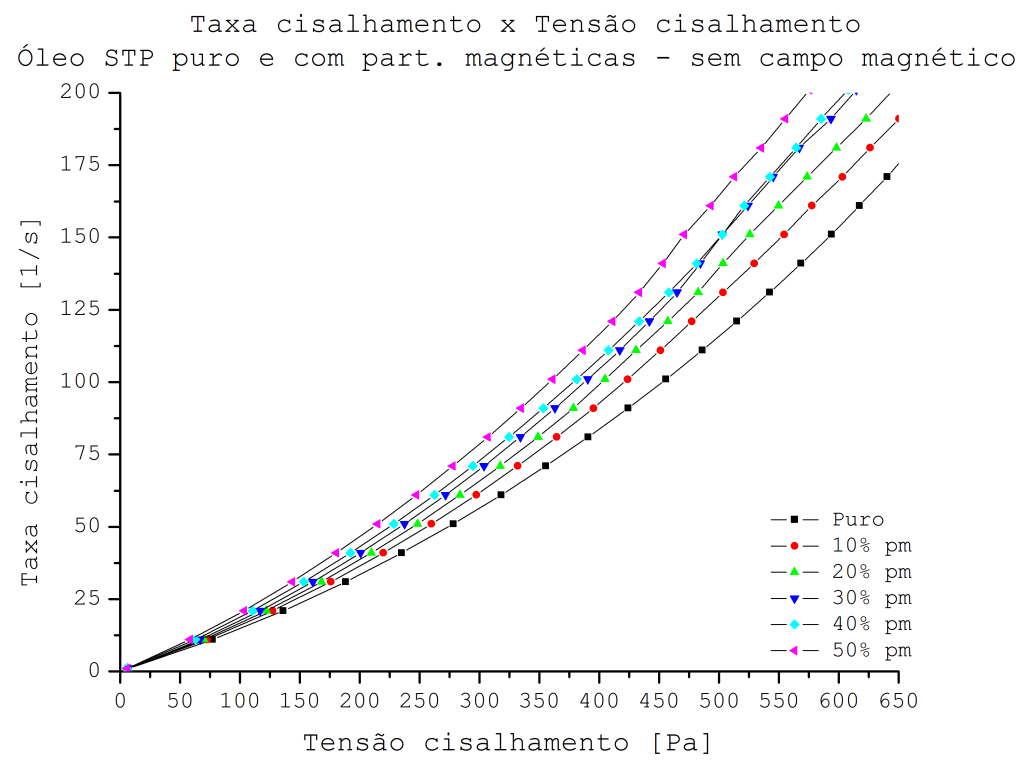

Figura 4.14: Taxa de cisalhamento versus tensão de cisalhamento do óleo STP para diferentes concentrações partículas magnéticas, sem campo externo.

Como não existe um valor único para viscosidade de um fluido não-newtoniano, é necessário escolher, a partir dos dados, um valor de taxa cisalhante e qual a tensão associada para estabelecer a viscosidade [Pa.s], que é 
expressa pela razão entre a tensão de cisalhamento [Pa] e a taxa de cisalhamento $[1 / \mathrm{s}]$.

Entre as concentrações de $30 \%$ e $40 \%$ ocorre uma sobreposição das curvas. O que não permite uma boa diferenciação para taxas de cisalhamento maiores do que $130 \mathrm{~s}^{-1}$. Todavia, se escolhermos uma taxa de cisalhamento entre $75 \mathrm{~s}^{-1}$ e $125 \mathrm{~s}^{-1}$, é possível obter um valor de viscosidade bem definido para cada meio analisado.

Quando se aplica um campo magnético externo ao óleo, com diferentes concentrações de partículas ferromagnéticas, observa-se um afastamento entre as curvas, consequentemente melhor discriminação dos meios. Além disso, verificou-se um deslocamento da curva da amostra pura, provavelmente por picos de tensão na rede elétrica que alteraram a velocidade de rotação da haste do viscosímetro. No gráfico da figura 4.15 , pode-se perceber a influência do campo externo aplicado.

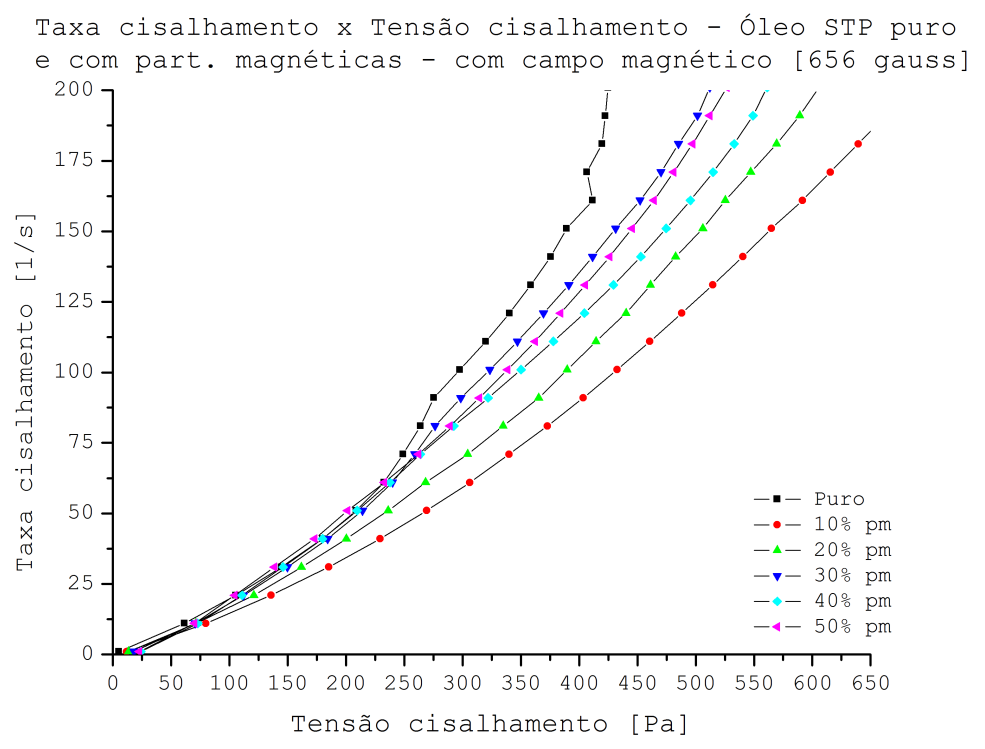

Figura 4.15: Taxa de cisalhamento versus tensão de cisalhamento do óleo STP para diferentes concentrações partículas magnéticas, com campo externo.

Para valores de taxa cisalhante acima de $75 \mathrm{~s}^{-1}$ observa-se uma maior variação da viscosidade para as diferentes concentrações de partículas ferromagnéticas. Comparando a figura $4.14 \mathrm{com}$ a figura 4.15 observa-se uma mudança na viscosidade dos meios analisados devido a presença do campo magnético externo aplicado. Contudo, para que se perceba com mais destaque as alterações da viscosidade devido a aplicação de um campo magnético externo 
faz-se necessário aplicar campos com intensidade acima de 500 gauss. O gráfico 4.16 mostra um exemplo no qual foi aplicado um campo magnético externo variável, ao óleo STP com 50\% de partículas ferromagnéticas.

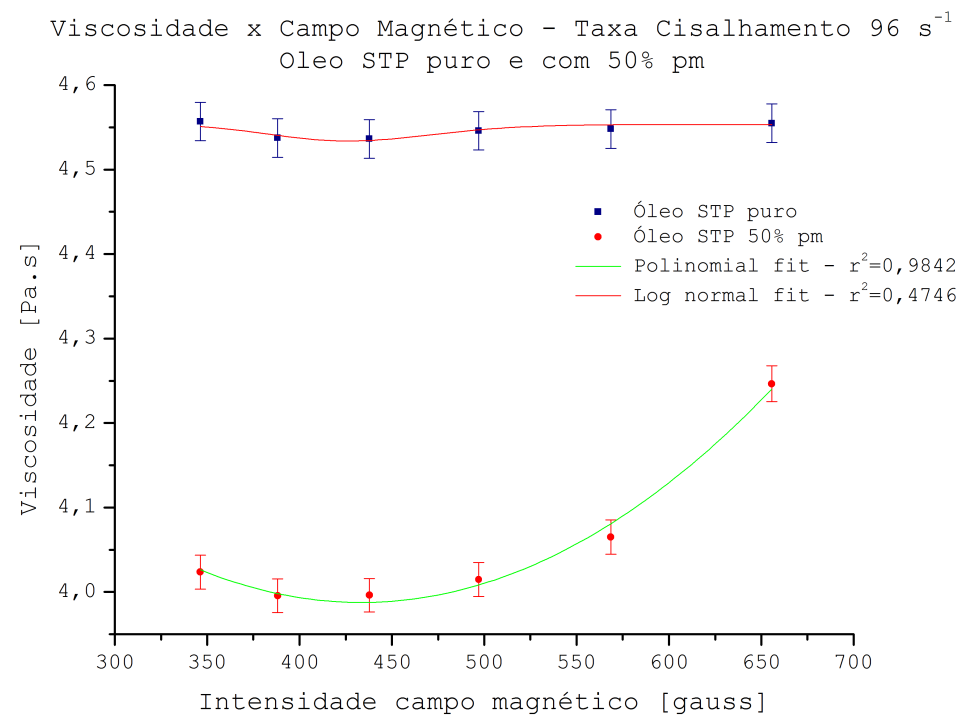

Figura 4.16: Taxa de cisalhamento versus Tensão de cisalhamento para óleo STP puro e com $50 \%$ de partículas magnéticas, sob ação de um campo magnético externo variável.

A viscosidade incrementou seu valor quando a intensidade do campo magnético ultrapassou o limite de 400 gauss. A linha contínua representa a linha de tendência para o óleo puro e com $50 \%$ de partículas magnéticas.

A princípio, acreditávamos que esta diminuição na viscosidade inicial, quando da aplicação do campo, poderia está relacionada a interferência dos recipientes do viscosímetro. Todavia, após uma análise do comportamento do campo magnético dentro dos copos do viscosímetro, através de um gaussímetro, vimos que a intensidade do campo, nas proximidades daqueles, provoca um pequeno deslocamento no valor da viscosidade devido a campos induzidos pela haste giratória do viscosímetro, que é diamagnética. Contudo, como o valor do campo manteve-se fixo, observamos que o comportamento da viscosidade em função da concentração de partículas mudava com a presença do campo magnético externo produzido pelos magnetos. Isto pode ser verificado ao se aplicar um campo da ordem de 656 gauss (valor máximo devido a limitações técnicas), pois a viscosidade sofreu incrementos proporcionais a concentração de partículas magnéticas.

O comportamento deste fluido ao se incrementar a concentração de 
partículas ferromagnéticas, sem aplicação de um campo magnético externo, mostrou-se decrescente, todavia, ao aplicar o campo magnético verificou-se um aumento da viscosidade. Um comportamento "curioso", que necessita de um estudo mais aprofundado para tentar compreender e explicar o que ocorre no nível micro-estrutural, e que não foi foco deste trabalho.

O gráfico da figura 4.17 apresenta o comportamento deste óleo (STP) com diferentes concentrações de partículas magnéticas, sem e com aplicação de um campo magnético externo. A curva de tendência representa um ajuste exponencial sem aplicação do campo magnético, e um ajuste polinomial quadrático com aplicação do campo magnético, cujo coeficiente de determinação ficou em torno de $96 \%$.

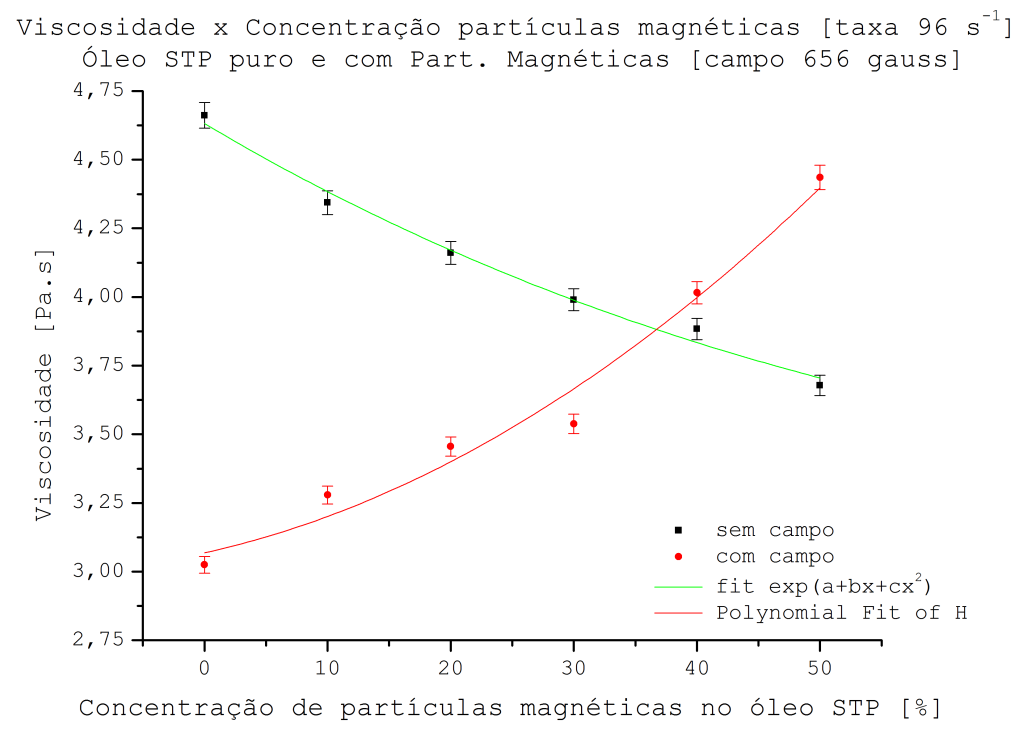

Figura 4.17: Viscosidade do Óleo STP para diferentes concentrações de Partículas magnéticas sem campo e com campo magnético.

Na tabela 4.5 apresenta-se os resultados da viscosidade para os diferentes meios analisados, numa taxa de cisalhamento de $96 \mathrm{~s}^{-1}$, para uma intensidade magnética de 656 gauss, que foi mais significativa. Contudo, a análise da viscosidade, para os diferentes meios citados, tenha sido realizada para uma faixa de campo magnético variando de 0 gauss a 656 gauss. 
Tabela 4.5: Viscosidade para os diferentes meios analisado, numa taxa de cisalhamento de $96 \mathrm{~s}^{-1}$.

\begin{tabular}{c|cc}
\hline \hline Material & Viscosidade & [Pa.s] \\
sem campo & com campo \\
\hline Gel US puro & $(1,83 \pm 0,01)$ & $(1,83 \pm 0,01)$ \\
Gel US 10\% PM & $(1,90 \pm 0,01)$ & $(1,93 \pm 0,01)$ \\
Óleo oliva & $(0,05 \pm 0,01)$ & $(0,05 \pm 0,01)$ \\
Óleo oliva 10\% PM & $(0,06 \pm 0,01)$ & $(0,07 \pm 0,01)$ \\
Óleo oliva 10\% nPM & $(0,06 \pm 0,01)$ & $(0,07 \pm 0,01)$ \\
Óleo STP puro & $(4,06 \pm 0,10)$ & $(4,06 \pm 0,09)$ \\
Óleo STP 10\% PM & $(4,08 \pm 0,05)$ & $(4,18 \pm 0,06)$ \\
Óleo STP 20\% PM & $(4,25 \pm 0,03)$ & $(4,26 \pm 0,03)$ \\
Óleo STP 30\% PM & $(4,26 \pm 0,02)$ & $(4,42 \pm 0,06)$ \\
Óleo STP 40\% PM & $(4,32 \pm 0,03)$ & $(4,45 \pm 0,06)$ \\
Óleo STP 50\% PM & $(4,55 \pm 0,01)$ & $(4,78 \pm 0,09)$ \\
\hline \hline
\end{tabular}

Medições feitas a temperatura de $(25 \pm 0,5)^{\circ} \mathrm{C}$ no viscosímetro da Anton Paar - Rheolab QC; PM = partículas magnéticas; $\mathrm{nPM}=$ nanopartículas magnéticas.

\subsection{Atuador de carga estática}

Nesta seção os resultados preliminares concernentes ao atuador estático, calibrado e configurado conforme apresentado na seção 3.2.2, superaram as limitações de precisão do atuador multifrequência.

Inicialmente montou-se um recipiente cilíndrico com um fundo em filme de PVC transparente, sobre a plataforma da célula de carga que continha o transdutor de US acoplado internamente. No interior do cilindro colocamos água e uma mola helicoidal de aço, que foi submetido ao deslocamento do micrômetro e leitura através de um transdutor de ultrassom. O recipiente cilíndrico tinha a superfície superior aberta e com espaço para extravasar a água, caso necessário.

Este modelo considera uma mola helicoidal, de constante elástica " $\mathrm{K}$ ", como a representada na figura 4.18. Em que, " $d$ " é o diâmetro do fio de aço, no qual foi construída a mola, " $\mathrm{D}$ " é o diâmetro dos elos da espiral, " $h$ " é o comprimento (altura) da mola, " $i$ " é o número de espiras. Os valores das dimensões desta mola foram medidos com um paquímetro digital, cuja precisão é de $\pm 0,001 \mathrm{~mm}$. 


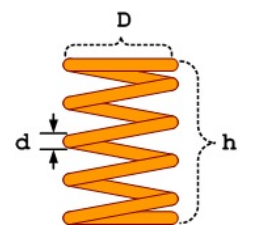

Figura 4.18: Modelo de uma mola helicoidal.

Para a mola utilizada em nosso experimento, $\mathrm{D}=12,04 \mathrm{~mm}, \mathrm{~h}=$ $23,23 \mathrm{~mm}, \mathrm{~d}=0,80 \mathrm{~mm}, \mathrm{i}=8 \mathrm{e}$, a razão de poisson considerada para $\mathrm{o}$ aço foi $v=0,346$. Através das equações 4.3 e $4.4^{1}$, encontramos os valores apresentados na tabela 4.6 .

$$
\begin{aligned}
& K=\frac{G \cdot d^{4}}{8 \cdot i \cdot D^{3}} \\
& G=\frac{Y}{2(1+v)}
\end{aligned}
$$

Esta montagem possibilitou aferir o deslocamento do micrômetro com a leitura do transdutor de US. Assim, foi possível estabelecer o desvio entre os dois instrumentos de medidas. Além disso, foi possível determinar o módulo de elasticidade transversal da mola $(\mathrm{G})$ e o módulo de Young do aço (Y), com desvio percentual de $0,5 \%$ entre micrômetro e ultrassom, e 9,1\% entre o valor calculado.

A tabela 4.6 apresenta os resultados que também são comparados com valores fornecidos por um fabricante de molas.

Tabela 4.6: Comparação das medições da Constante elástica da mola com US e micrômetro.

\begin{tabular}{c|ccc}
\hline \hline Mola de aço & Constante elástica $[\mathrm{N} / \mathrm{mm}]$ & $\mathrm{G}\left[\mathrm{N} / \mathrm{mm}^{2}\right]$ & $\mathrm{Y}[\mathrm{kPa}]$ \\
\hline Calculado & $(280,15 \pm 1,40)$ & 76.400 & $(205,69 \pm 1,87)$ \\
Medida Micrômetro & $(304,20 \pm 2,13)$ & $(82.958,08 \pm 0,57)$ & $(223,32 \pm 1,53)$ \\
Medida ultrassom & $(307,15 \pm 2,15)$ & $(83.762,57 \pm 0,57)$ & $(225,49 \pm 1,53)$ \\
\hline Média & $(305,67 \pm 2,09)$ & $(83.360,33 \pm 0,57)$ & $(224,41 \pm 1,53)$ \\
\hline Desvio médio [\%] ( $\mu$ m e US) & $0,5 \%$ & $0,5 \%$ & $0,5 \%$ \\
Desvio médio [\%] (calculado) & $9,1 \%$ & $9,1 \%$ & $9,1 \%$ \\
\hline \hline
\end{tabular}

Utilizado módulo de elasticidade transversal para aços $\mathrm{G}=76400 \mathrm{~N} / \mathrm{mm}^{2}$, conforme

http://www.hoesch.com.br/index.php/tecnologia-constante/br/constante-elastica. Acesso: 24/02/2012.

\footnotetext{
${ }^{1}$ Fonte: file:///media/Dados/Downloads/Cylindrical\%20Coil\%20Spring.htm; último acesso: 18/08/2012.
} 
Os valores de " $K$ ", " $G$ " $e$ " $Y$ " obtidos por meio do US são a partir do tempo de deslocamento do sinal e da velocidade de propagação da onda no meio, que no nosso caso, é a água filtrada e desgaseificada. Foram feitas duas séries de três medições de tempo e determinado o valor médio. A partir daí, calcularam-se os deslocamentos medidos no US que são comparados com os mostrados no micrômetro, conforme apresentado na tabela 4.7.

Tabela 4.7: Valores das medições do deslocamento da mola de aço no micrômetro e US.

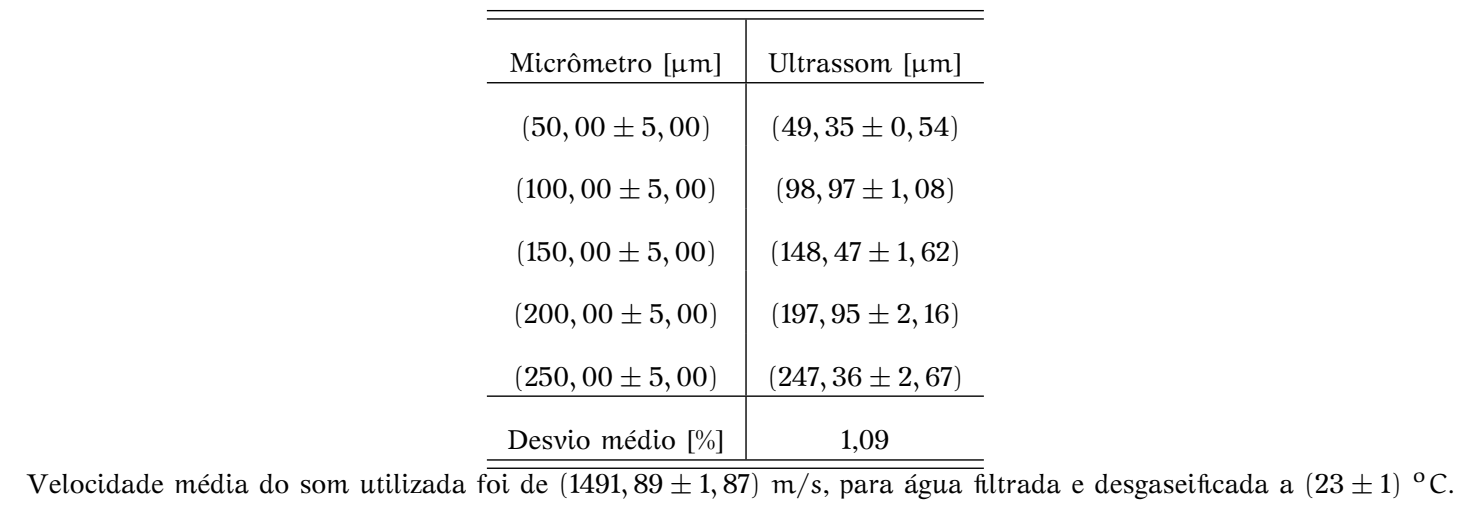

Este método possibilita a calibração do sistema, visto que medições com ultrassom são mais precisas. Além do mais, ao analisar os valores destas medições observa-se um incremento sistemático nos deslocamentos obtidos. Este fato pode ser atribuído a diferença entre o valor da velocidade do som na água, calculado, e o valor verdadeiro.

Assim, estabelecendo a diferença entre os deslocamentos, com os respectivos intervalos de tempo, pode-se obter a velocidade real do som na água, pela declividade da curva distância versus tempo. O valor obtido para velocidade do som na água filtrada e desgaseificada à temperatura de $(23 \pm 1){ }^{\circ} \mathrm{C}$ foi de $(1494,2 \pm 1,0) \mathrm{m} / \mathrm{s}$. Se comparado com o valor da velocidade utilizado no cálculo do deslocamento $(1491,89 \pm 1,87) \mathrm{m} / \mathrm{s}$ têm-se um desvio percentual de $0,15 \%$.

No gráfico da figura 4.19, mostra-se este comportamento para as medições realizadas neste experimento, cujo coeficiente de correlação foi de $98,2 \%$.

Com propósito de verificar se as medições na célula de carga estavam confiáveis, foi feita uma série de cinco medições de força, num balança digital da "BEL Engineering", descrita na seção 3.2.2, com um "phantom" de parafina cristal, sem misturas, e comparadas com as medições obtidas na célula de carga. 


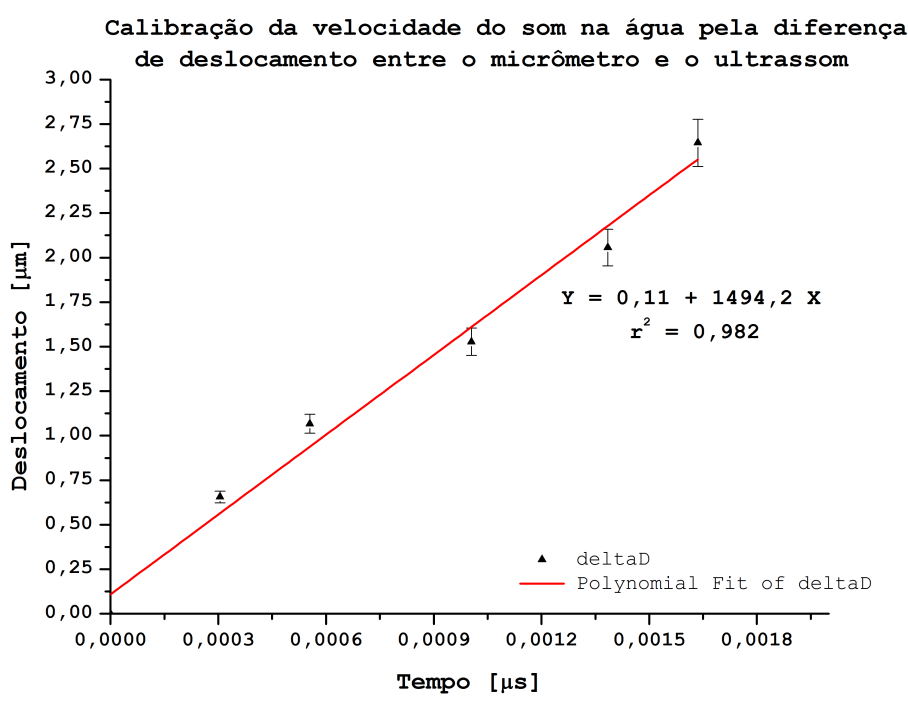

Figura 4.19: Velocidade do som na água a partir da diferença de deslocamento entre as medições: ultrassom versus micrômetro.

A partir destes valores, se calculou o módulo de elasticidade da parafina cristal pura, que também estão coerentes com os apresentados na tabela 4.9, cujo desvio percentual médio foi de apenas $0,7 \%$. Sendo $0,5 \%$ em relação ao valor medido na balança e 1,3\% em relação à célula de carga. Estes resultados médios entre os dois processos de medição foram mostrados no gráfico da figura 4.20.

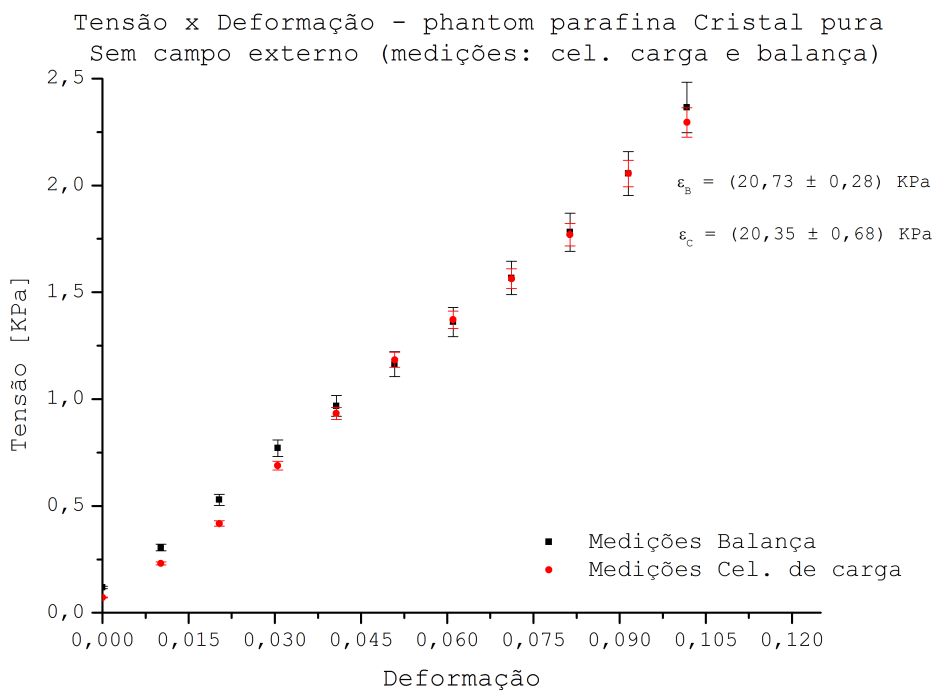

Figura 4.20: Tensão versus deformação para um "phantom" de parafina cristal, sem partículas magnéticas, medidas numa balança de precisão. 
Após validado o sistema de medição, foram feitas diversas medições em diferentes "phantoms" com mistura de óleos, partículas ferromagnéticas e espalhadores de ultrassom.

Nosso objetivo neste procedimento foi verificar se o sistema estava propício à caracterização das propriedades mecânicas dos simuladores de tecidos moles. Para tal, necessitávamos de medições precisas da força e do deslocamento sofridos pela estrutura do "phantom".

Para analisar a influência do campo magnético externo sobre uma inclusão contendo partículas magnéticas, confecionou-se um "phantom" com uma inclusão esférica com mesma base da região externa, mas acrescida de $10 \%$ de fluido ferromagnético. A base de parafina continha $2 \%$ de espalhador ultrassônico, que nesse caso foi o pó de madeira. A tabela 4.8 apresenta os resultados com e sem aplicação do campo magnético externo.

Tabela 4.8: Valores do módulo de Young para um "phantom" contendo 10\% de FMR, com $2 \%$ de espalhador.

\begin{tabular}{c|cccc}
\hline \hline $\begin{array}{c}\text { Parafina gel 10\% PM } \\
2 \% \text { de espalhador }\end{array}$ & $\begin{array}{c}\text { Deslocamento } \mu \mathrm{m} \\
\text { Módulo Young }[\mathrm{kPa}]\end{array}$ & $\begin{array}{c}\text { Coeficiente } \\
\text { Pearson }\end{array}$ & $\begin{array}{c}\text { Deslocamento US } \\
\text { Módulo Young [kPa] }\end{array}$ & $\begin{array}{c}\text { Coeficiente } \\
\text { Pearson }\end{array}$ \\
\hline \multirow{2}{*}{ com campo } & $(7,23 \pm 0,86)$ & 0,9328 & $(7,30 \pm 0,87)$ & 0,9322 \\
\hline \hline \multicolumn{4}{r}{ PM = partículas magnéticas. Espalhador utilizado foi o pó de madeira. }
\end{tabular}

Na sequência, mostramos as curvas obtidas no ensaio com o "phantom" descrito anteriormente. A linha reta representa o ajuste linear, para os valores médios das medições e seus respectivos coeficientes de determinação.

O gráfico da figura 4.21 mostra o comportamento da parafina com inclusão, no qual os deslocamentos foram obtidos através do transdutor de ultrassom de 3,5 MHz, cuja velocidade média de propagação, neste "phantom", foi de aproximadamente $(1475,34 \pm 2,39) \mathrm{m} / \mathrm{s}$, com e sem aplicação do campo magnético externo.

Quando comparamos os módulos de elasticidade obtidos utilizando o ultrassom, com os aplicados através do micrômetro, sem campo magnético externo, temos um desvio relativo percentual de apenas 0,96\%.

Ao aplicarmos um campo magnético externo, da ordem de 1100 gauss, e medirmos os deslocamentos através do ultrassom, observamos que o módulo de Young sofre aumento de $(7,30 \pm 0,87) \mathrm{kPa}$ para $(9,88 \pm 0,30) \mathrm{kPa}$. Isto 


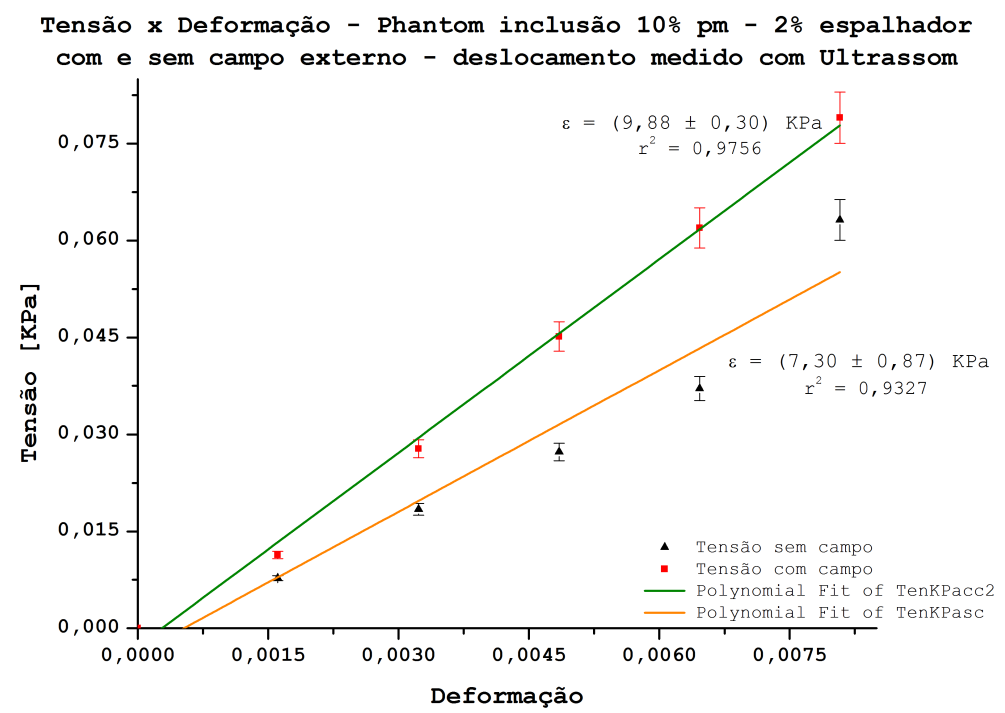

Figura 4.21: Tensão versus deformação para um "phantom" de parafina gel com $2 \%$ de espalhador e $10 \%$ de PM, com e sem campo externo, obtidos por US.

representa um aumento percentual de 35,3\%.

Pode-se perceber, ao analisar a curva de tendência que, ao aplicar o campo externo, o meio se comporta de modo mais linear e os desvios nas medições são menores, conforme registros apresentados, anteriormente, na tabela 4.8. Deste modo, pode-se dar prosseguimento as medições para caracterização dos demais simuladores de tecidos moles construídos em gelatina e parafinas.

A fim de ter parâmetros de comparação, uma quantidade de amostras dos simuladores foi enviada ao laboratório do departamento de Física médica, da Universidade de Wisconsin, Madison, EUA.

Os ensaios foram realizados de forma dinâmica com oscilação na faixa de 0,5 - 1,5\%, usando um sistema da Bose (Bose Corporation EletrectroForce Systems Group, Minnetonka, MN, USA), modelo EnduraTEC 3200 ELF, com uma célula de carga de $1 \mathrm{~kg}$ e uma placa plana de teflon ${ }^{\mathrm{R}}$ maior do que a superfície da amostra.

Nem todas as concentrações utilizadas nos "phantoms" tem valores correspondentes, visto que não foi possível encaminhar todas as amostras, inclusive concentrações maiores, construídas posteriormente. Como os parâmetros são dinâmicos e nossas medições são quase estáticas, adotamos por padrão de comparação os valores de menor frequência, ou seja, $1 \mathrm{~Hz}$. 
A tabela 4.9 mostra os resultados das medições, para a parafina Cristal e Gel, bem como a diferença percentual entre os valores, comparados com as medições na frequência de $1 \mathrm{~Hz}$.

Tabela 4.9: Comparação do Módulo de Young - Parafina Cristal e Gel diferentes concentrações $P M$.

\begin{tabular}{|c|c|c|c|}
\hline $\begin{array}{c}\text { Frequência } \\
\text { Material }\end{array}$ & $\begin{array}{c}\text { Quase-estático } \\
(1 \mathrm{~Hz})[\mathrm{kPa}]\end{array}$ & $\begin{array}{c}\text { Estático } \\
{[\mathrm{kPa}]}\end{array}$ & $\begin{array}{c}\text { Diferença com } 1 \mathrm{~Hz} \\
{[\%]}\end{array}$ \\
\hline Parafina Gel pura & $(14,70 \pm 0,07)$ & $(10,67 \pm 0,20)$ & 27,4 \\
\hline Parafina Cristal pura & $(30,50 \pm 0,15)$ & $(20,61 \pm 0,93)$ & 32,4 \\
\hline Parafina Gel $10 \%$ óleo & $(10,40 \pm 0,05)$ & $(9,51 \pm 0,23)$ & 8,6 \\
\hline Parafina Gel 1\% PM & $(13,50 \pm 0,07)$ & $(13,63 \pm 0,16)$ & 1,0 \\
\hline Parafina Gel 3\% PM & $(13,57 \pm 0,07)$ & $(12,58 \pm 1,01)$ & 7,3 \\
\hline Parafina Gel 5\% PM & $(14,10 \pm 0,07)$ & $(10,19 \pm 0,24)$ & 27,7 \\
\hline Parafina Gel 7\% PM & $(13,90 \pm 0,07)$ & $(9,73 \pm 0,28)$ & 30,0 \\
\hline Parafina Gel 9\% PM & $(12,50 \pm 0,06)$ & $(5,88 \pm 0,20)$ & 53,0 \\
\hline
\end{tabular}

Um dos fatores que mais contribuiu para uma margem de erro acima do esperado, foi o tamanho padrão das amostras confecionadas. As amostras para os ensaios nos laboratórios da Universidade de Wisconsin - Madison, tinham tamanho reduzido, $10 \mathrm{~mm}$ de espessura e diâmetro de $254 \mathrm{~mm}$ (padrão utilizado nos ensaios do laboratório de departamento de Física médica de Wisconsin, Madison).

Assim, ao aplicar um deslocamento da ordem de $1 \mathrm{~mm}$ já estávamos produzindo uma deformação da ordem de 10\% na amostra, além da pré-carga necessária a acomodação da amostra para iniciar as medições.

Este fato contribuiu para que os valores ultrapassassem os limites elásticos recomendados, menores do que 1\%, conforme relatado na literatura por diversos autores, tais como Wellmann et al., 1999 [76]; Ophir et al., 2002 [14]; Sinkus et al., 2006 [24]. Deste modo, os efeitos não-lineares predominaram sob os lineares em algumas amostras ensaiadas.

O gráfico tensão versus deformação na figura 4.22 mostra um exemplo da curva média para um conjunto de medições da parafina Cristal, sem qualquer tipo de mistura. As deformações sofridas pela amostra foram menores do que 
$1 \%$, portanto, dentro do patamar de linearidade. A linha contínua representa a linha de tendência, com um ajuste linear, cujo coeficiente de determinação aproximado de $99,2 \%$.

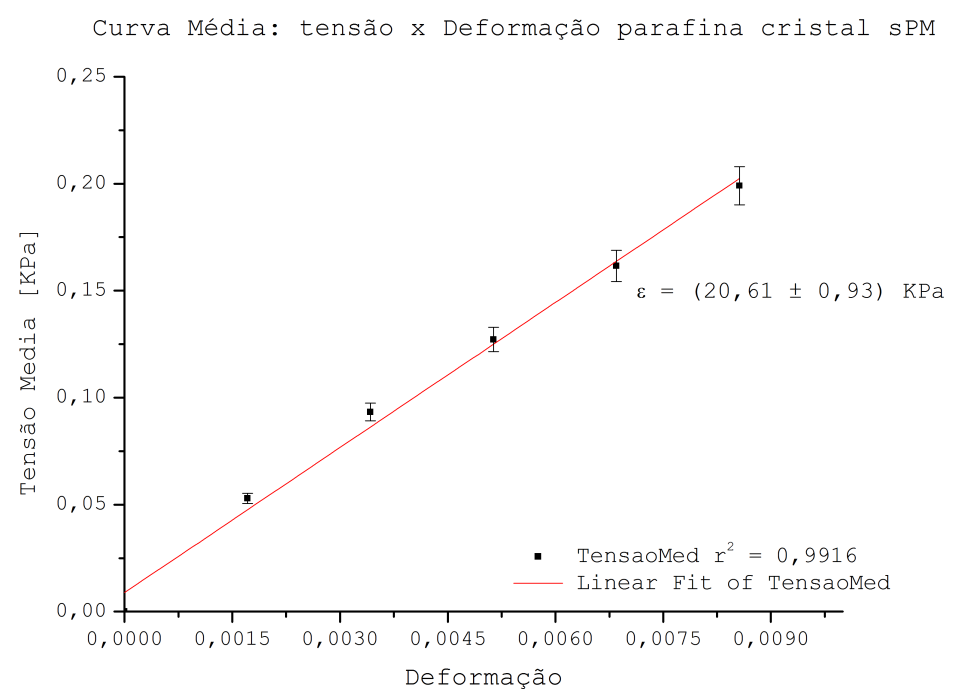

Figura 4.22: Tensão versus deformação para a parafina cristal sem partículas magnéticas.

No gráfico da figura 4.23, mostramos a curva média de Tensão versus deformação da parafina gel, onde a reta representa um ajuste linear. Deste mo-

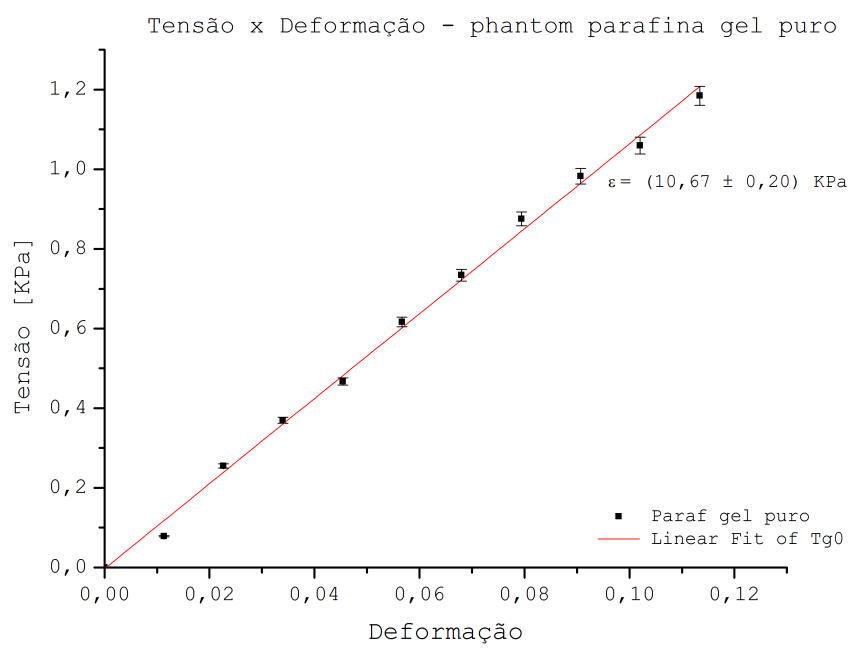

Figura 4.23: Tensão versus deformação para a parafina gel sem partículas magnéticas.

do, a declividade da curva determina o módulo de elasticidade médio (módulo 
de "Young") do meio. Que, para este caso foi igual a $(10,67 \pm 0,20) \mathrm{kPa}$.

Após obtermos tais resultados, modificamos o tamanho das amostras para que tivessem uma espessura (altura) maior, para outros ensaios. A fim de permitir que deslocamentos até $250 \mu \mathrm{m}$ não alcançasse deformações superiores a $1 \%$, que foi o limite de deslocamento que adotamos.

O processo de mistura do óleo a água, na confecção da gelatina é crítico. Devido a limitações técnicas de um produto 'surfactante' que possibilitasse a emulsão da mistura e um sistema que mantivesse a mistura em agitação até sua completa solidificação, sem que houvesse decantação das partículas de $\mathrm{Fe}_{3} \mathrm{O}_{4}$. Além disso, os "phantoms" de gelatina, após endurecidos, precisam de um alto controle da temperatura. É preciso mantê-los resfriados e isolados com filmes de PVC para diminuir o tempo de exposição ao ar atmosférico, pois estes fatores alteram sua estrutura e consequentemente a precisão das medições [89].

Em decorrência destes fatores, não avançamos na confecção de novos "phantoms" feitos à base de gelatina, visando inclusões das partículas ferromagnéticas. Deste modo, somente apresentamos resultados em "phantoms" de gelatina sem inclusões de partículas ferromagnéticas.

A tabela 4.10 traz os valores das medições, para a gelatina sem inclusões de partículas ferromagnéticas.

Tabela 4.10: Comparação do Módulo de Young - Gelatina 250 blomm diferentes concentrações.

\begin{tabular}{c|ccc}
\hline \hline $\begin{array}{c}\text { Frequência } \\
\text { Material }\end{array}$ & $\begin{array}{c}\text { Quase-estático } \\
(1 \mathrm{~Hz})[\mathrm{kPa}]\end{array}$ & $\begin{array}{c}\text { Estático } \\
{[\mathrm{kPa}]}\end{array}$ & $\begin{array}{c}\text { Diferença com 1 Hz } \\
{[\%]}\end{array}$ \\
\hline Gelatina 3\% & $(4,50 \pm 0,02)$ & - & - \\
Gelatina 4\% & $(7,20 \pm 0,04)$ & $(8,69 \pm 0,12)$ & 20,7 \\
Gelatina 5\% & $(9,14 \pm 0,05)$ & $(11,23 \pm 0,15)$ & 22,9 \\
Gelatina 6\% & $(17,81 \pm 0,09)$ & $(11,39 \pm 0,06)$ & 36,0 \\
Gelatina 8\% & $(32,00 \pm 0,16)$ & $(20,66 \pm 0,22)$ & 35,4 \\
Gelatina 10\% & - & $(25,41 \pm 1,01)$ & - \\
\hline \hline
\end{tabular}

O gráfico da Tensão versus deformação na figura 4.24 apresenta o comportamento de um simulador de tecido feito de gelatina 250 Bloom a 8\%.

A linha contínua representa um ajuste linear, cujo coeficiente de 


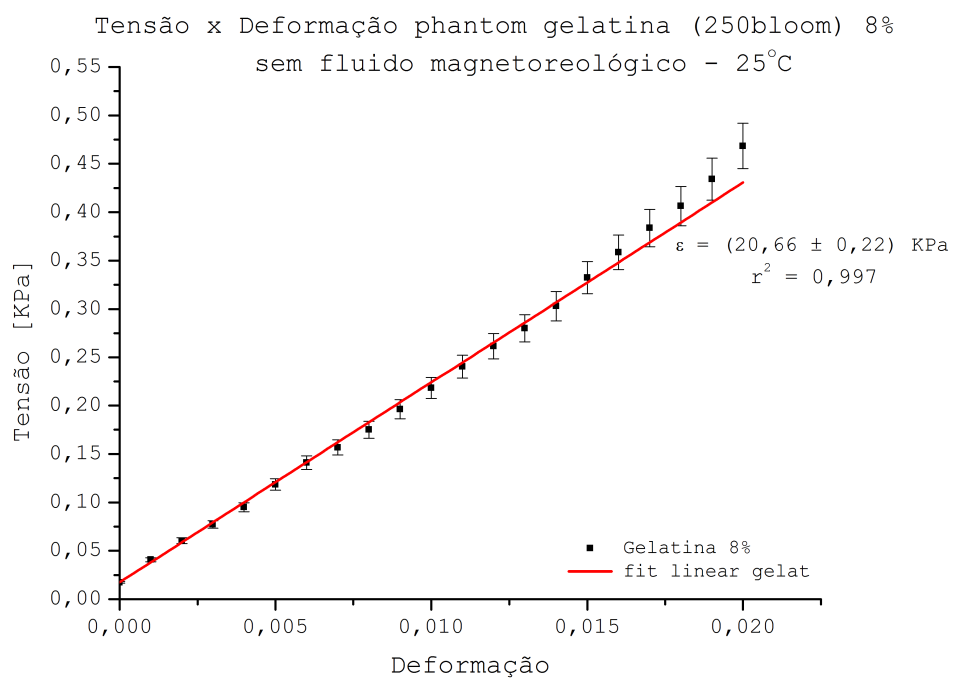

Figura 4.24: Tensão versus deformação para a gelatina (250Blomm) a $8 \%$ sem partículas magnéticas.

determinação foi de 99,7\%. E, cuja declividade determina o módulo de elasticidade desta amostra, no valor de $(20,66 \pm 0,22) \mathrm{kPa}$.

A figura 4.25 mostra as curvas médias de Tensão versus Deformação pa-

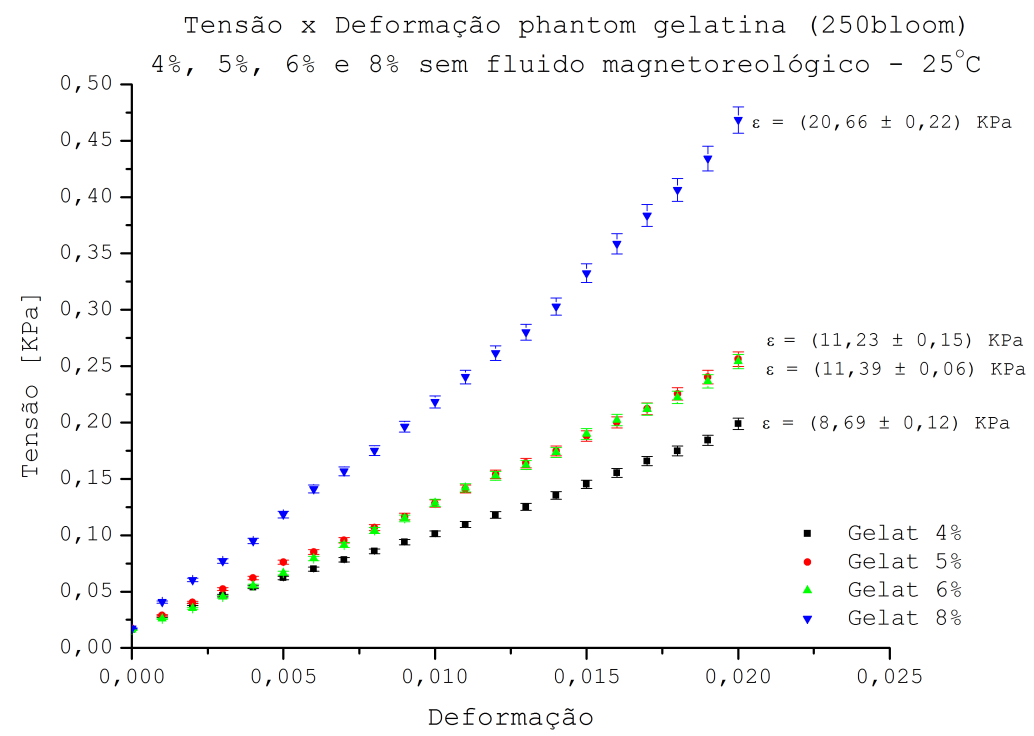

Figura 4.25: Tensão versus deformação para a gelatina 250 blomm em 4 concentrações, sem partículas magnéticas.

ra os "phantoms" de gelatina com quatro concentrações, tomadas a uma temperatura de $(25 \pm 1){ }^{\circ} \mathrm{C}$. Pode-se observar no gráfico que, para concentrações 
entre 5\% e 6\%, não foi possível diferenciar o módulo de Young. Entretanto, há uma excelente discriminação entre uma amostra de gelatina 250 Bloom com $4 \%$ e $8 \%$ de concentração. O módulo de elasticidade sofreu incremento de aproximadamente 2,4 vezes.

Com propósito de verificar o comportamento das estruturas internas, ao se aplicar uma tensão ("stress") sobre a superfície do "phantom", utilizamos o transdutor ultrassônico fixado a estrutura da célula de carga (seção 3.2.2) para "enxergar" os deslocamentos e deformações em função da profundidade.

Como esperado, ao analisar o simulador de parafina cristal com $2 \%$ de espalhador, sem partículas magnéticas, tomado como referência, observa-se que o deslocamento aumenta com a profundidade. Este efeito é mostrado, de modo similar, nos três gráficos que se seguem.

O gráfico 4.26 mostra que os deslocamento, aplicados dentro dos limites elásticos, é incrementado de forma bastante linear à medida que adentramos na estrutura do "phantom".

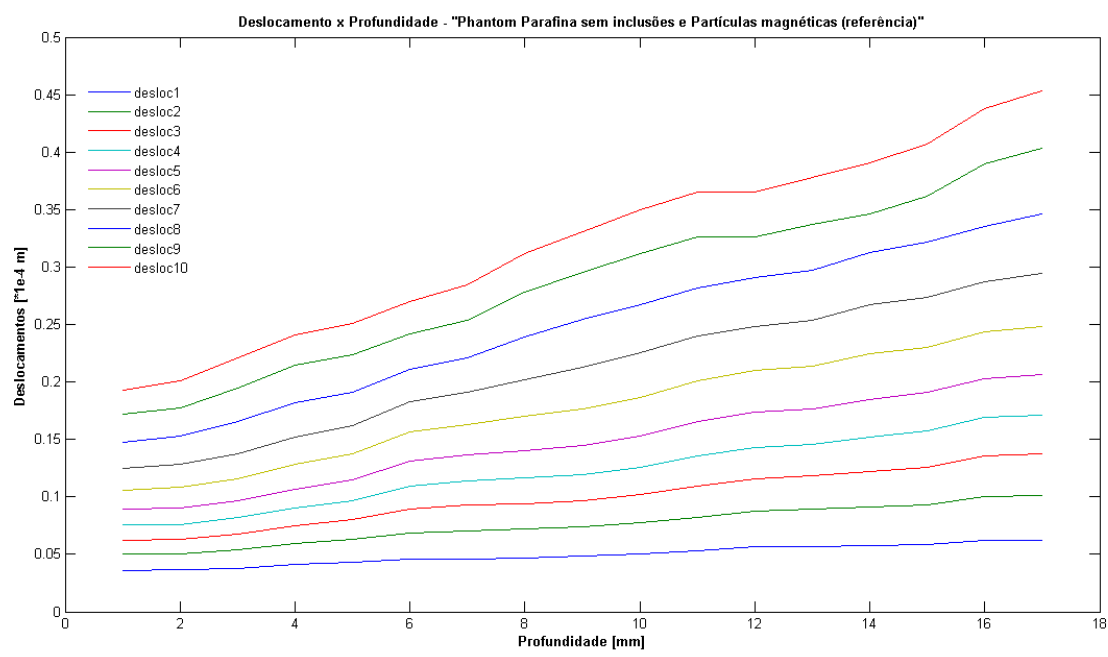

Figura 4.26: Deslocamento versus profundidade - "Phantom" de parafina com espalhador sem partículas magnéticas [referência].

Neste exemplo, temos um meio homogêneo que está submetido a deformações menores do que $1 \%$, assim, é esperado que as mesmas obedeçam uma relação linear. Ao derivarmos espacialmente as curvas de deslocamento, mostrada na figura 4.26, foi possível traçar um mapa de deformações em função da profundidade. É possível observar que estas deformações também obedecem uma relação bastante linear, conforme apresentado no mapa de cor 
da figura 4.27 .

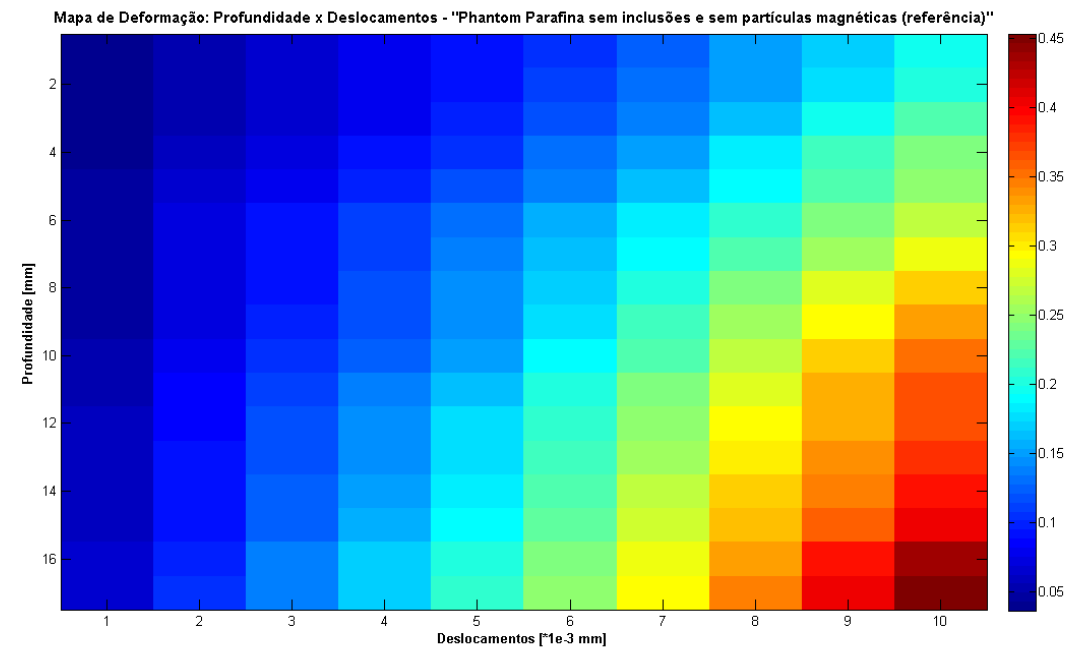

Figura 4.27: Mapa de Deformação em função da profundidade - "Phantom" de parafina com espalhador sem partículas magnéticas [referência].

De modo conjunto, pode-se ver os dois efeitos, deslocamento e deformação em função da profundidade através do gráfico 4.28.

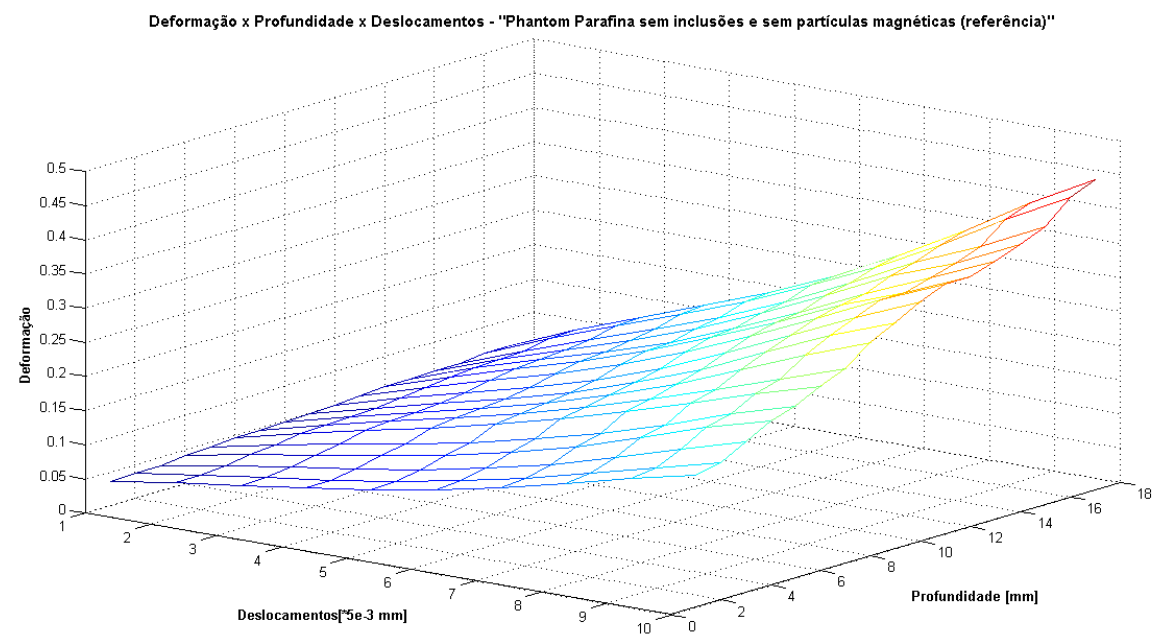

Figura 4.28: Deformação em função da profundidade e deslocamentos - "Phantom" de parafina com espalhador sem partículas magnéticas [referência].

O mesmo procedimento foi feito para um "phantom" de parafina cristal com $2 \%$ de espalhador e com uma inclusão esférica de mesma base, acrescido de $10 \%$ de partículas ferromagnéticas, conforme mostra a figura 4.29 . 


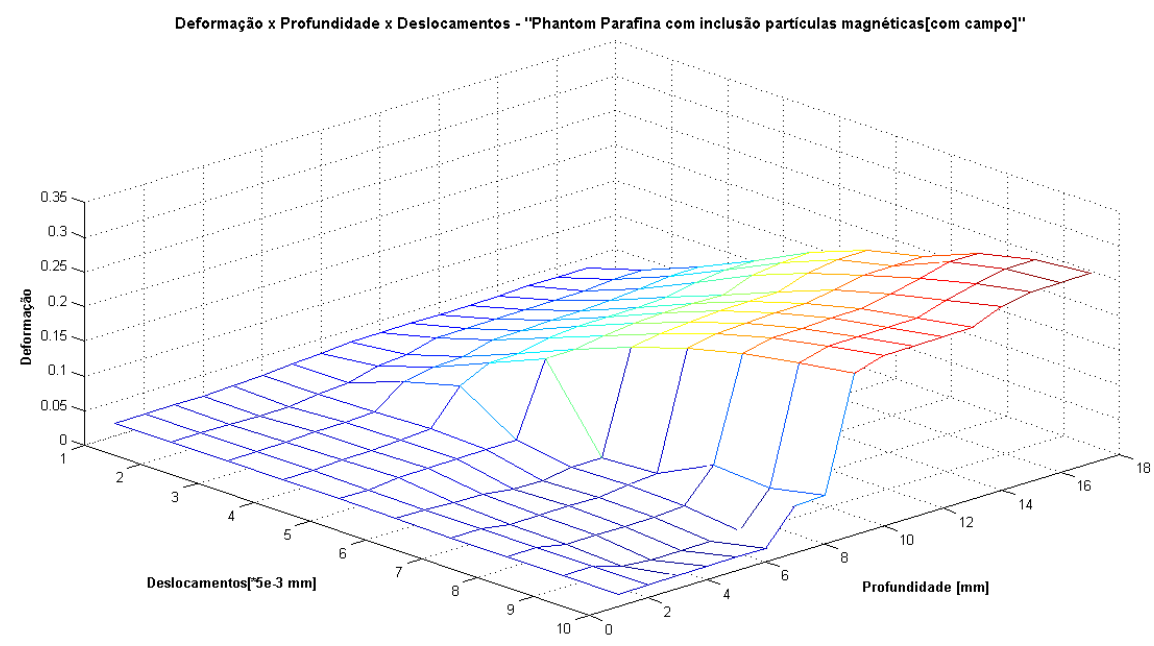

Figura 4.29: Deformação em função da profundidade e deslocamentos - "Phantom" de parafina com espalhador com inclusão de $10 \%$ de partículas magnéticas.

É possível perceber que ocorreram mudanças, se comparadas com o "phantom" de referência, na região da inclusão.

Ao compararmos as medições de deslocamento e deformação entre o "phantom" de referência, com o "phantom" contendo inclusão de partículas ferromagnéticas, com e sem aplicação do campo magnético externo, pode-se verificar, através da figura 4.30, uma relação aproximadamente linear entre de-

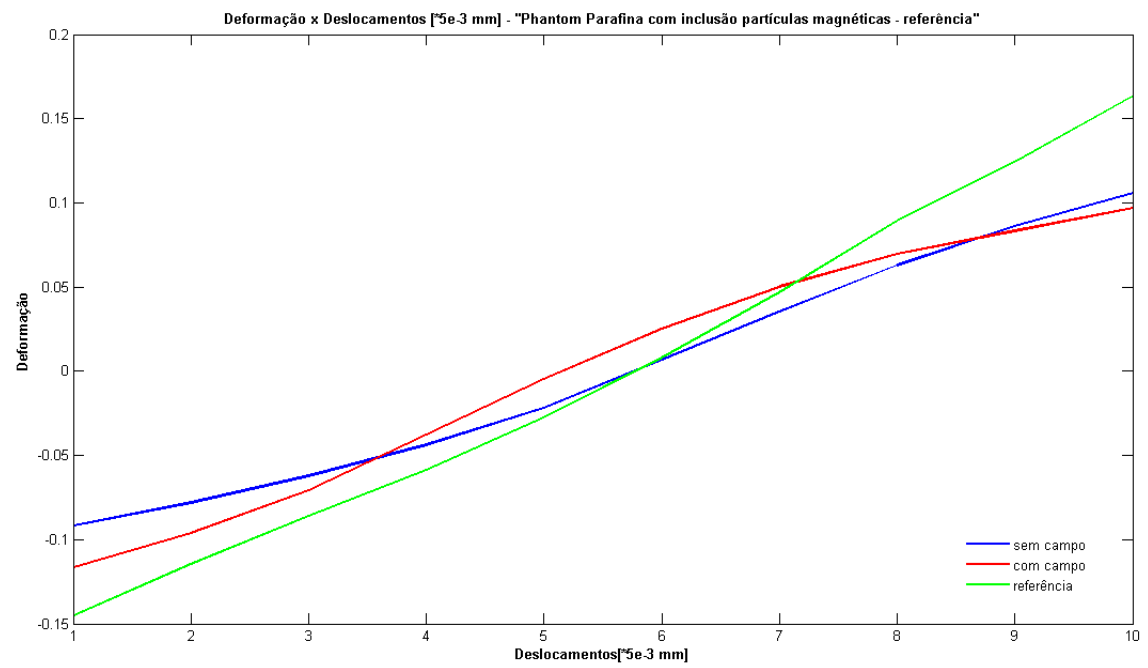

Figura 4.30: Deformação versus deslocamentos - "Phantom" de parafina com espalhador com e sem partículas magnéticas, com e sem campo externo. 
formação e deslocamento, com uma pequena variação no centro da inclusão com partículas magnéticas.

A linha verde continua representa a relação deformação versus deslocamento para o "phantom" de parafina sem inclusão, enquanto as linhas continuas, em azul e vermelho, representam, respectivamente, a relação deformação versus deslocamento para o "phantom" com inclusão de partículas ferromagnéticas sem e com aplicação de um campo magnético externo aproximado de 1100 gauss.

Este efeito nos permite inferir que a estrutura sofre modificações com aplicação de um campo magnético externo e, provavelmente com campos de maior intensidade seja possível ampliar este fenômeno.

Como as partículas estão misturadas em óleo, conforme descrito na seção 3.1, ao aplicar o campo externo ocorre a alinhamento desta partículas na direção do campo produzindo novamente o enrijecimento da estrutura na região da inclusão.

\subsection{Atuador de carga dinâmica}

Os resultados preliminares da excitação dinâmica através de uma bobina construída no laboratório não foram satisfatórios, pelos fatores já apontados na seção 3.2.3, deste modo, substituímos a bobina por um sistema de excitação mecânica com um mini-vibrador, conforme, descrito na mesma seção 3.2.3.

Assim, foi possível acoplar o sistema vibratório tanto para medições dinâmicas com um ultrassom monocanal quanto pelo sistema comercial de multi-canal. Em ambas foram aplicadas vibrações na faixa de $40 \mathrm{~Hz}$ a 140 $\mathrm{Hz}$, com incrementos de $20 \mathrm{~Hz}$.

As medições foram feitas em um "phantom" de parafina cristal, de $(3,00 \pm$ $0,01) \mathrm{cm}$ de altura, contendo uma inclusão central, misturada com $20 \%$ de partículas ferromagnéticas, de $(1,00 \pm 0,01) \mathrm{cm}$.

Entretanto, os sinais de " $R F$ " adquiridos em ambos os equipamentos são processados posteriormente a aquisição, a fim de fornecer as informações referentes aos deslocamentos e deformações. Quando ocorrem mudanças na posição da estrutura interna do meio em estudo, o sinal do eco pode sofrer defasagem maior do que o janelamento (ROI) escolhido para estabelecer a correlação, e, quando processados, produzem efeitos de perda de coerência de 
fase, conforme mostra a figura 4.31 .

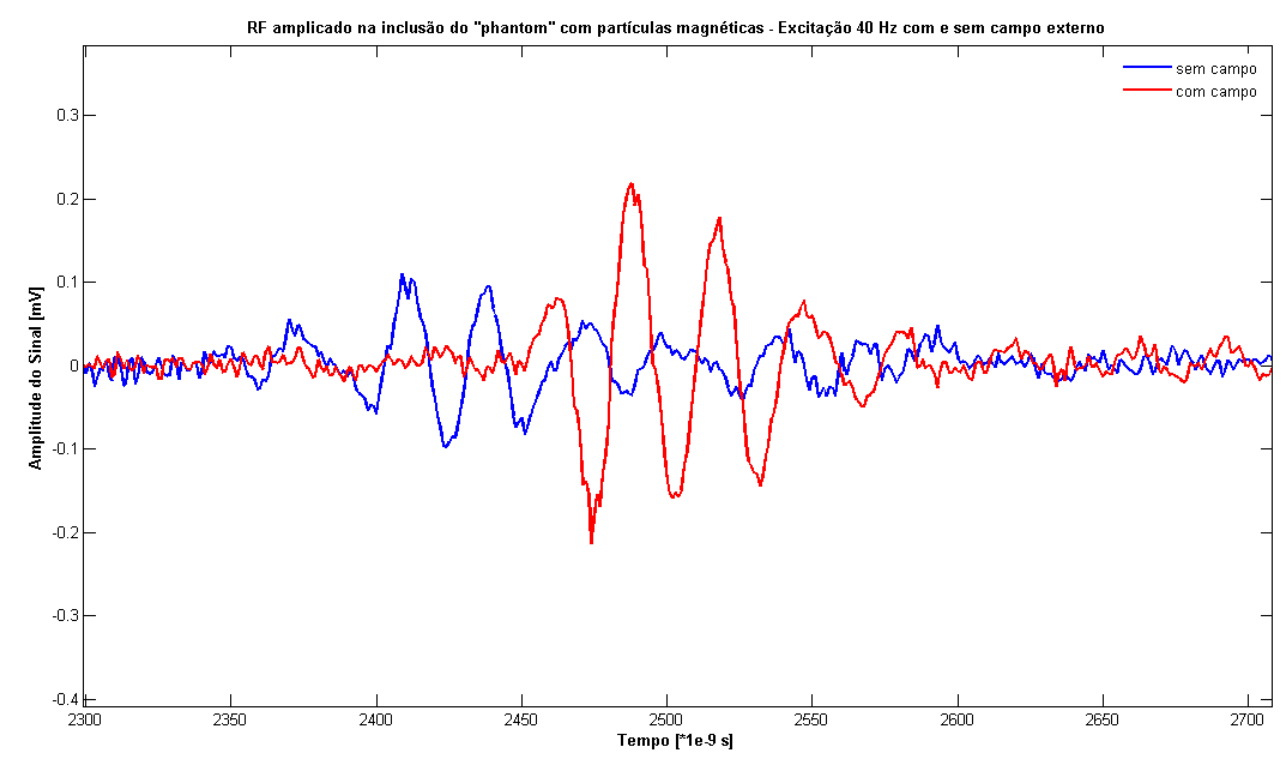

Figura 4.31: Sinal Amplificado de "RF", numa região da amostra contendo partículas magnéticas, com e sem ação do campo magnético externo.

Estes dois segmentos de " $R F$ " (Azul e vermelho) foram adquiridos na mesma janela temporal. Assim, se considerarmos o primeiro pico de " $R F$ " azul, no intervalo de 2350 a $2400 \eta \mathrm{s}$, com o primeiro pico de " $R F$ " vermelho, no intervalo de 2450 a 2500 ๆs, têm-se um intervalo muito maior do que

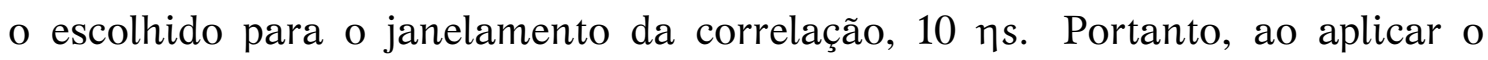
algoritmo de correlação cruzada, o mesmo não encontrará equivalência entre os picos correspondentes a mesma região espacial ocasionando perdas de pontos na curva de deslocamento.

É nítida a diferença de fase e amplitude entre os dois ecos, na região da inclusão, devido a presença do campo magnético externo, quando o "phantom" é deformado com o atuador mecânico, numa frequência de $40 \mathrm{~Hz}$. Na análise das medições, feitas neste trabalho, verificou-se que a introdução do campo magnético externo, nas amostras contendo partículas magnéticas, induzem ao fenômeno da perda de coerência de fase.

Este fato pode explicar o porquê do sinal de deslocamento e deformação perder coerência à medida que se incrementa a frequência de excitação dos "phantoms". O campo magnético externo aplicado muda a posição das partículas fazendo com que o sinal de eco registre as mesmas estruturas deslocadas em 
tempos distintos. Quando o algoritmo de correlação é aplicado, temos uma defasagem em relação ao eco inicial de referência. Isto produz perda de pontos que distorcem as curvas de deslocamento e deformação.

A seguir mostram-se alguns resultados obtidos nos dois processos. Um através do oscilóscopio da Agilent Technologies MSO9404A ${ }^{2}$, o outro no equipamento comercial da ultrasonix ${ }^{\mathrm{R}}$, modelo $R P$. A diferença principal entre eles, além da aquisição ser através de um ou múltiplos elementos, é a taxa de aquisição do sinal.

\subsubsection{Ultrassom Monocanal}

O transdutor ultrassônico utilizado nestas medições tem uma frequência central de 3,5 MHz, cujas características já foram descritas na seção 3.2.2. Ele estava acoplado a estrutura da célula de carga e posicionado de forma que a parte inferior do "phantom" esteja em contato com sua superfície, e, acoplados por meio do gel "US" para permitir o ajuste de impedância acústica.

O gráfico 4.32 mostra um mapa de deslocamento no tempo de um "phantom" com inclusões de partículas ferromagnéticas, cuja excitação foi na

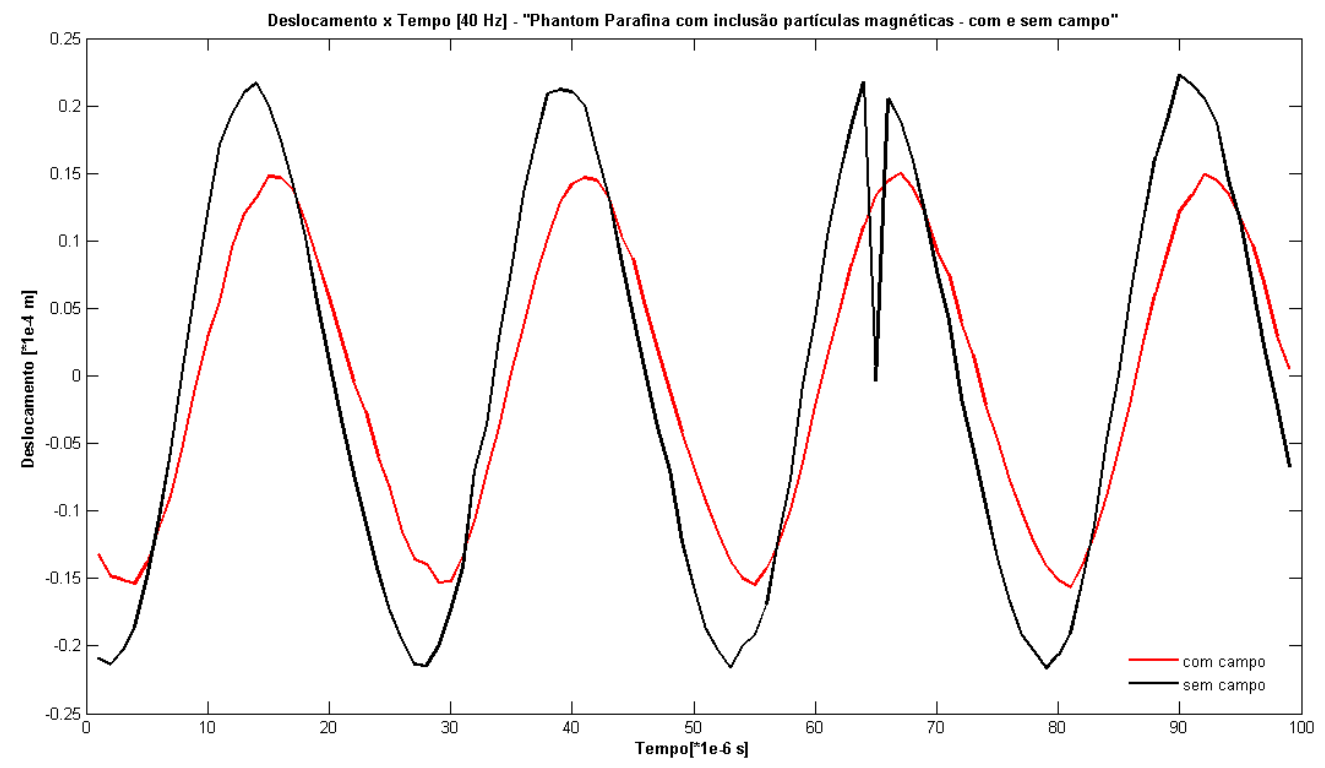

Figura 4.32: Mapa de deslocamento no tempo para frequência de $40 \mathrm{~Hz}$ - "Phantom" de parafina com partículas magnéticas, com e sem campo magnético externo.

\footnotetext{
${ }^{2}$ Osciloscópio da Agilent Technologies, modelo Infiniium 9000 - MSO9404A, 4 GHz, 20 GSa/s. Disponível em: http://www.home.agilent.com/agilent/product.jspx; último acesso: 17/08/2012.
} 
frequência de $40 \mathrm{~Hz}$. É possível observar que a aplicação de um campo magnético externo da ordem de 1100 gauss, nesta frequência, diminui a amplitude de deslocamento.

Isto nos leva a inferir que a região contendo partículas ferromagnéticas muda sua dureza e se desloca menos, se comparado ao deslocamento sem aplicação do campo magnético externo. Esta diferença na amplitude de deslocamento, para $40 \mathrm{~Hz}$, é de 7,7\% em torno do valor médio das medidas.

$\mathrm{O}$ gráfico 4.33 mostra que à medida que se incrementou a frequência ocorreu um aumento do deslocamento, na faixa de $60 \mathrm{~Hz}$ a $80 \mathrm{~Hz}$, seguido de uma redução.

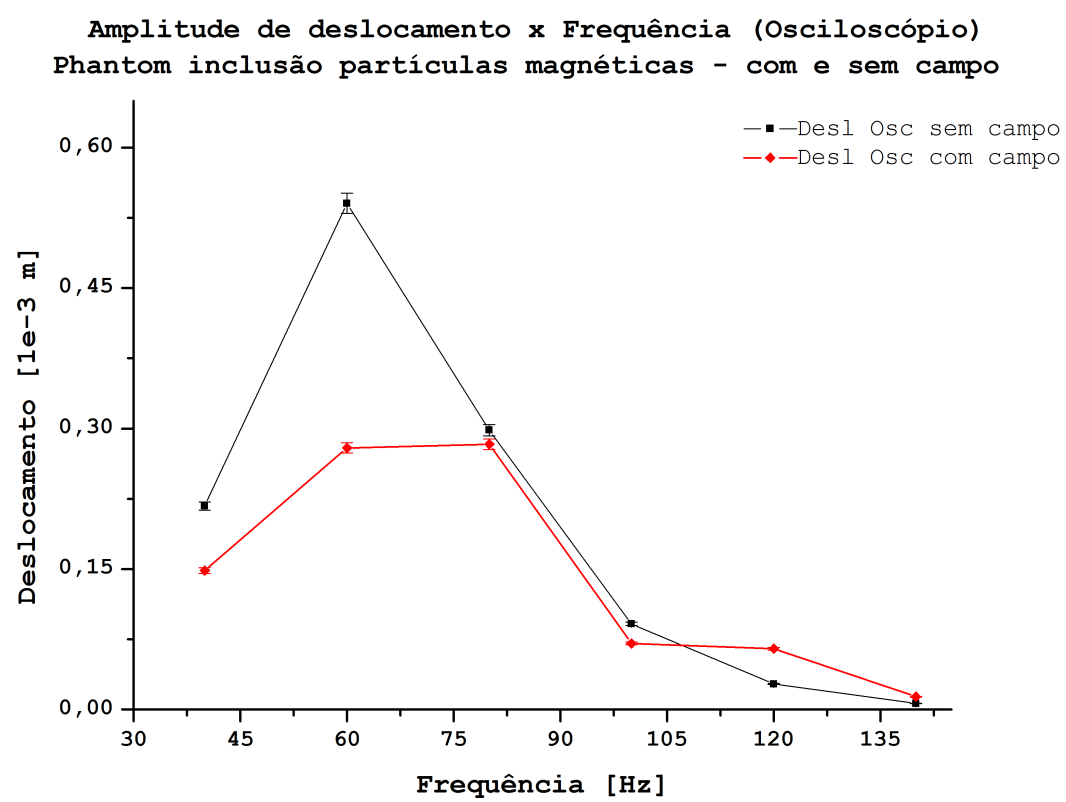

Figura 4.33: Amplitude de deslocamento versus frequência de excitação - "Phantom" de parafina com espalhador e partículas magnéticas - Medições no Osciloscópio.

Ao analisar a faixa de ressonância do mini-vibrador, apresentado no apêndice F.11, verifica-se que este aumento na amplitude de deslocamento do "phantom", na faixa de frequência entre $(60 \mathrm{~Hz}-80 \mathrm{~Hz})$, é decorrente do efeito ressonante do mini-vibrador.

Quando a frequência de excitação do mini-vibrador atinge e ultrapassa a frequência de $120 \mathrm{~Hz}$, ocorre o processo de defasagem do sinal e o efeito de perda de coerência de sinal é bastante acentuado, produzindo o serrilhado na ligação dos pontos que distorce a curva de deslocamento no tempo, como pode ser observado no gráfico da figura 4.34 . 


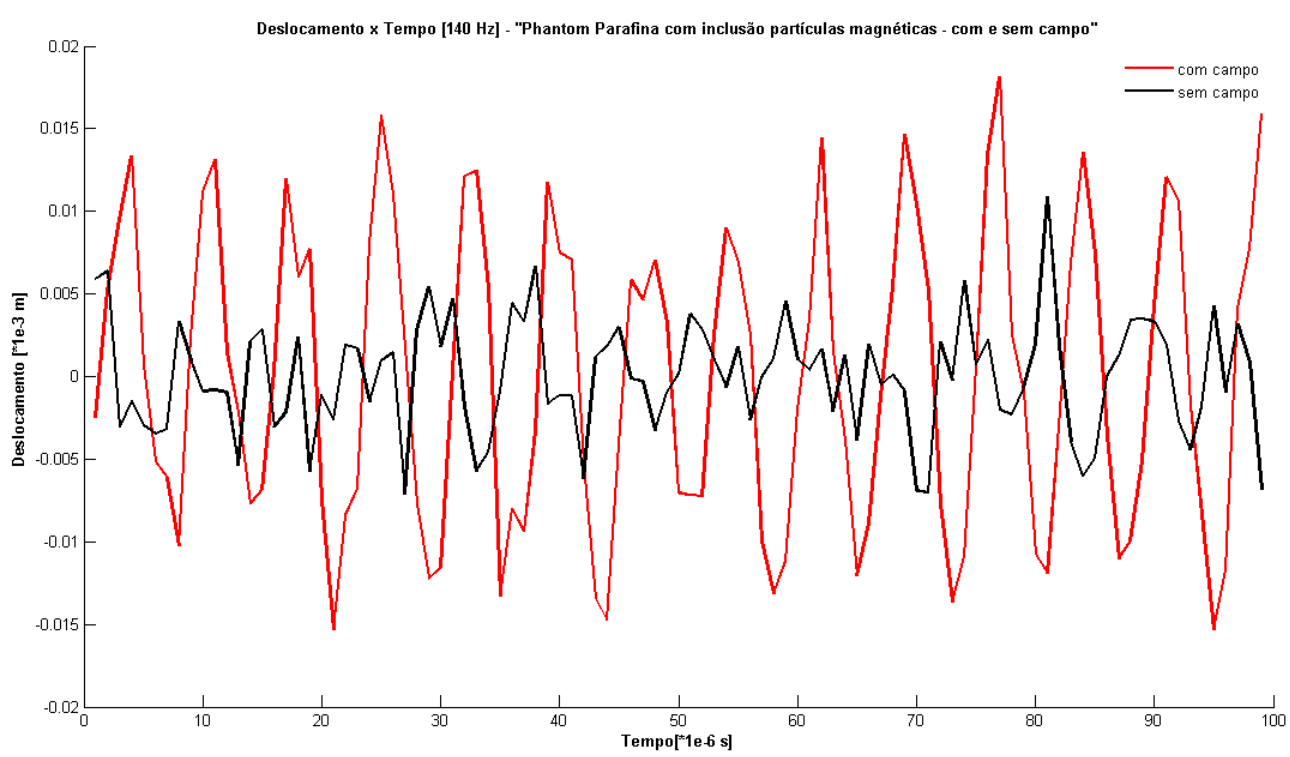

Figura 4.34: Mapa de deslocamento no tempo para frequência de $140 \mathrm{~Hz}$ - "Phantom" de parafina com partículas magnéticas, com e sem campo magnético externo.

Para valores acima de $100 \mathrm{~Hz}$ as medições do sistema ficam comprometidas, devido a atenuação no deslocamento das estruturas internas do "phantom", e, consequentemente, perda de coerência de fase nos sinais de " $R F$ ", pois, o sinal fica na mesma ordem de grandeza do ruído, não sendo possível discriminar bem entre o sinal e o ruído, visto que, os valores de deslocamento atingem os limites de resolução, devido as características físicas do transdutor e taxa de aquisição do equipamento.

Na tabela 4.11 é possível verificar os valores da amplitude de deslocamenTabela 4.11: Amplitude de deslocamento versus frequência - Medições com Osciloscópio.

\begin{tabular}{c|cc}
\hline \hline & Deslocamento & {$\left[\times 10^{-3} \mathrm{~m}\right]$} \\
Frequência [Hz] & sem campo & com campo \\
\hline 40 & $(0,217 \pm 0,002)$ & $(0,148 \pm 0,001)$ \\
60 & $(0,541 \pm 0,005)$ & $(0,279 \pm 0,005)$ \\
80 & $(0,298 \pm 0,003)$ & $(0,283 \pm 0,005)$ \\
100 & $(0,091 \pm 0,003)$ & $(0,071 \pm 0,004)$ \\
120 & $(0,027 \pm 0,003)$ & $(0,065 \pm 0,004)$ \\
140 & $(0,006 \pm 0,003)$ & $(0,014 \pm 0,003)$ \\
\hline \hline
\end{tabular}

Frequência transdutor $=3,5 \overline{\overline{\mathrm{MHz} \text {, Velocidade do som no meio }=(1473,56 \pm 2,67) \mathrm{m} \cdot \mathrm{s}}}$ - , Taxa aquisição de $1 \mathrm{KHz}$. 
to em função da frequência de excitação, para as medições obtidas com um osciloscópio. Sendo assim, a menor amplitude detectada, para a frequência de $100 \mathrm{~Hz}$, conforme apresentada na tabela 4.11, seria da ordem de $3 \mu \mathrm{m}$, correspondente ao desvio-padrão das medições.

O padrão de deslocamento das estruturas internas pode ser acompanhado no decorrer do tempo. A figura 4.35 mostra um mapa de deslocamento com a
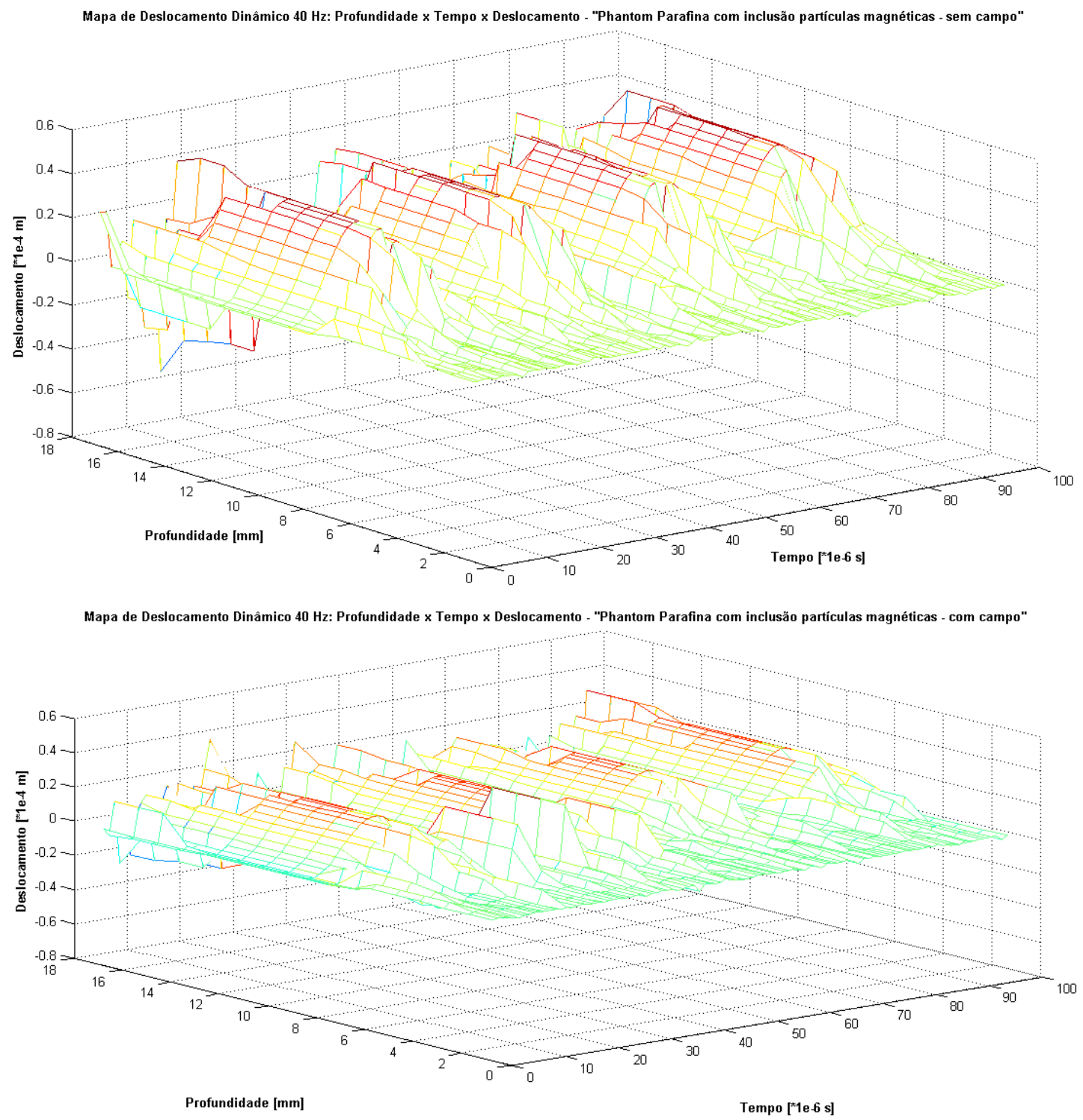

Figura 4.35: Mapa de deslocamento no tempo para frequência de $40 \mathrm{~Hz}$ - "Phantom" de parafina com partículas magnéticas, sem e com campo magnético externo.

profundidade em função do tempo para o sistema oscilando a $40 \mathrm{~Hz}$, sem e com aplicação do campo magnético externo. 
Neste gráfico 4.35, na origem do sistema $(0,0)$ encontra-se o mini-vibrador e na parte frontal oposta (eixo profundidade) temos o transdutor de ultrassom. No eixo de profundidade, entre $10 \mathrm{~mm}$ e $16 \mathrm{~mm}$, temos a inclusão com partículas ferromagnéticas. Apesar do "phantom" ter $30 \mathrm{~mm}$ de espessura, estamos mostrando apenas uma faixa, na qual cortamos alguns pontos no início e no final, visto que, não há espalhadores ultrassônico nestas regiões.

Deste modo, a partir do gráfico 4.35, é possível verificar que os deslocamentos aumentam com a profundidade, à medida que se aproxima do transdutor de US, e também que a aplicação do campo magnético externo diminui a amplitude de deslocamento. Confirmando assim, o endurecimento desta região devido a atuação do campo magnético externo.

Fora da região da inclusão não se observam oscilações devido ao fato de o material utilizado (parafina) como base, na composição deste "phantom", não possuir estruturas espalhadoras do sinal ultrassônico.

\subsubsection{Ultrassom Multicanal}

No equipamento comercial da Ultrasonix ${ }^{\mathrm{R}}$ foi utilizado um transdutor linear de 128 canais, modelo L14-5/38, conforme descrito na seção 3.2.4. Como fizemos uso do módulo pesquisador ("Research platform"), foi possível alterar algumas configurações do sistema. Assim, com ajuda do colega Diego Thomaz (aluno de iniciação científica do GIIMUS) e do prof ${ }^{\circ}$.Dr. Theo Pavan, foi possível reprogramar o sistema, com o objetivo de adquirir mapas de " $R F$ " em alta taxa de amostragem, visto que, por características físicas, do próprio ultrassom, a taxa de amostragem é limitada pelo número de elementos cerâmicos ativos, assim como pela profundidade da região de interesse na amostra.

Diante disso, visando analisar o sistema e obter os mapas de " $R F$ " com os sinais de deslocamento das estruturas internas das amostras, que possibilitasse um processamento em menor tempo computacional; foram feitas aquisições com apenas os 10 elementos cerâmicos centrais, dentre os 128 elementos disponíveis.

Embora a aquisição e processamento tenha sido feita para os dez elementos ativos do transdutor, os gráficos apresentados aqui, salvo quando expresso em contrário, mostram o sinal de apenas um dos dez elementos. A figura 4.36 mostra um exemplo da curva de deslocamento em função do tempo para frequência de oscilação de $80 \mathrm{~Hz}$, obtido com o quinto elemento cerâmico do transdutor, numa taxa de amostragem de 500 ciclos/s. 


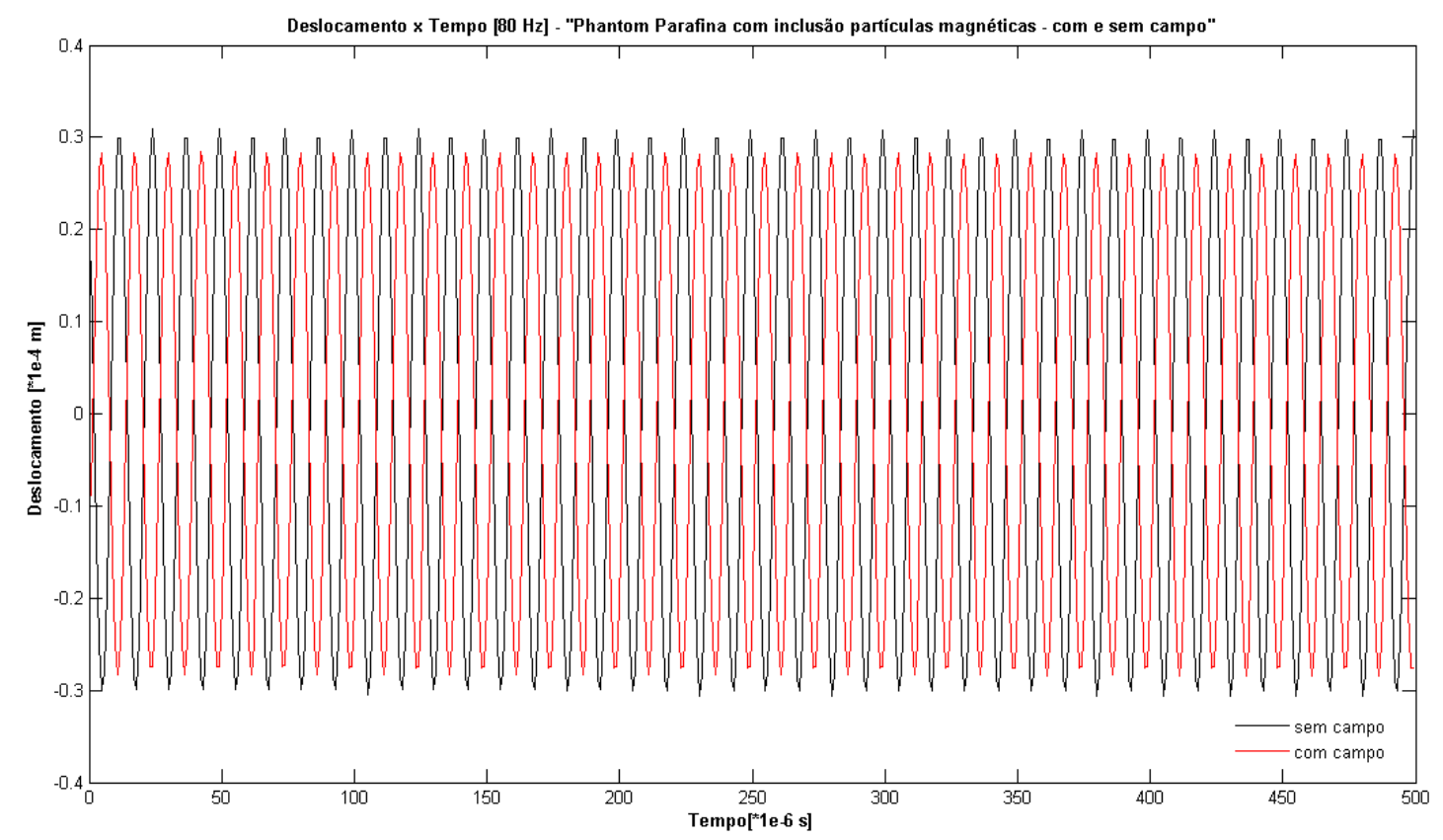

Figura 4.36: Deslocamento no tempo para frequência de $80 \mathrm{~Hz}$ - "Phan tom" de parafina com partículas magnéticas, com e sem campo magnético externo.

É perceptível, através do gráfico 4.36, que o sinal adquirido com mais elementos apresentou melhor coerência de fase, visto que foram adquiridos mais linhas de " $R F$ " para correlacionar. Isto implica pontos bem definidos e curva mais suavizada. Entretanto, o sistema mono-canal adquiriu uma amostragem de pontos muito maior (taxa de amostragem $(1 \mathrm{kHz})$ e frequência de aquisição (100 MHz - num canal de $2 \mathrm{GSa}$ ) superiores), portanto com maior resolução, isto é, menor distância entre os pontos. Contudo, o janelamento estipulado para correlação no sistema mono-canal não foi o mais adequado. É necessário fazer outras tentativas a fim de estipular valores que permitam um melhor processamento. Deste modo, o sinal adquirido com o oscilóscopio e o "pulser/receiver" apresentou uma coerência de fase pior, em relação ao de multi-canais.

O comportamento da amplitude de deslocamento em função da frequência para as medições no Ultrasonix ${ }^{\mathrm{R}}$ é similar ao realizado com o transdutor monocanal, apenas com menor desvio-padrão. Provavelmente por ter sido adquirido com mais elementos, logo, mais linhas de "RF" para correlacionar e atenuar distorções.

O gráfico 4.37 mostra a relação entre a amplitude de deslocamento e a 
frequência de oscilação do sistema.

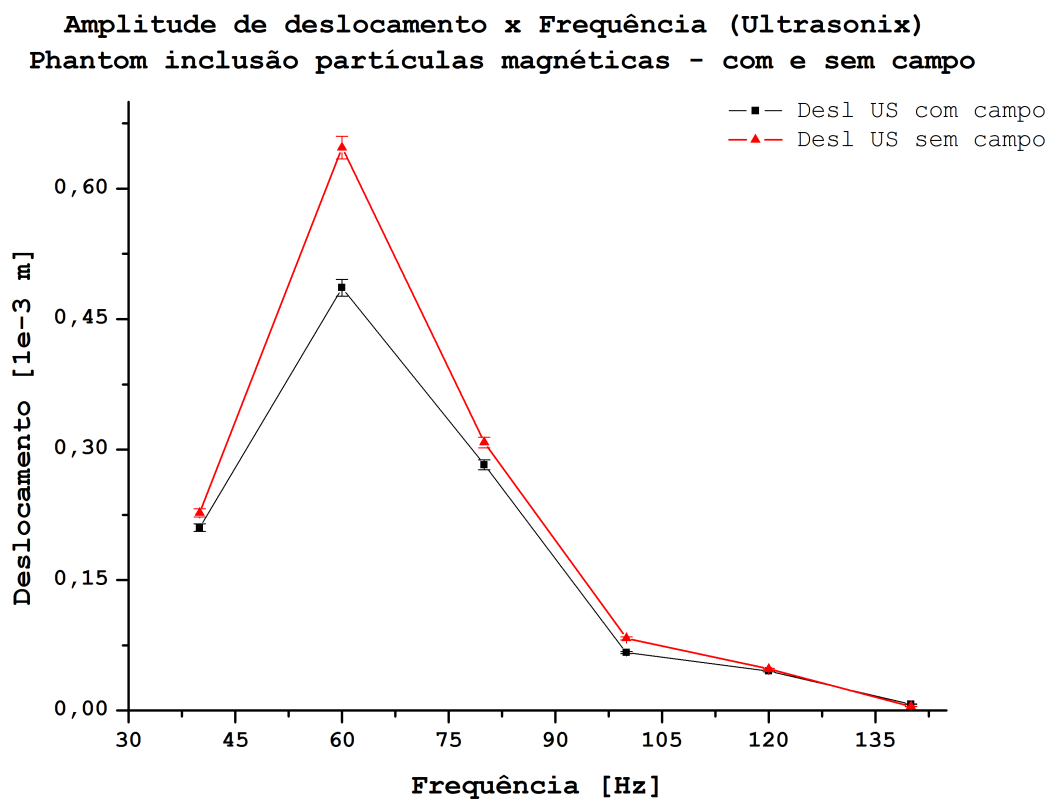

Figura 4.37: Amplitude de deslocamento em função da frequência - "Phantom" de parafina com espalhador e partículas magnéticas - Medições no Ultrasonix ${ }^{\mathrm{R}}$.

A tabela 4.12 apresenta os valores da amplitude de deslocamento em função da frequência de excitação, para as medições obtidas com o equipamento comercial da Ultrasonix ${ }^{\mathrm{R}}$.

Tabela 4.12: Amplitude de deslocamento versus frequência - Medições com Ultrasonix.

\begin{tabular}{c|cc}
\hline \hline & Deslocamento & {$\left[\times 10^{-3} \mathrm{~m}\right]$} \\
Frequência [Hz] & sem campo & com campo \\
\hline 40 & $(0,227 \pm 0,001)$ & $(0,210 \pm 0,001)$ \\
60 & $(0,647 \pm 0,004)$ & $(0,486 \pm 0,003)$ \\
80 & $(0,308 \pm 0,001)$ & $(0,282 \pm 0,001)$ \\
100 & $(0,083 \pm 0,001)$ & $(0,067 \pm 0,002)$ \\
120 & $(0,048 \pm 0,001)$ & $(0,045 \pm 0,002)$ \\
140 & $(0,005 \pm 0,003)$ & $(0,007 \pm 0,001)$ \\
\hline \hline
\end{tabular}

Frequência transdutor $=10 \overline{\overline{\mathrm{MHz}} \text {, Velocidade do som no meio }=(1473,56 \pm 2,67){\mathrm{m} . \mathrm{s}^{-1}}^{1}}$, Taxa aquisição de $0,5 \mathrm{kHz}$.

Se tomarmos a mesma frequência de $100 \mathrm{~Hz}$, como parâmetro de comparação, pode-se verificar que a menor amplitude detectada, conforme visto 
na tabela 4.12 seria de aproximadamente $1 \mu \mathrm{m}$, considerando o desvio-padrão das medições.

A medida que se aumentou a frequência de oscilação em limites superiores a $120 \mathrm{~Hz}$, não foi possível verificar mudanças significativas nos gráficos da amplitude de deslocamentos, visto que, a vibração do sistema também contribui na oscilação das amostras, mesmo mantendo o controle do deslocamento, consequentemente o módulo da força aplicada. Ou seja, a amplitude de deslocamento aparentemente manteve-se a mesma.

Este efeito (provavelmente passa baixas da viscosidade), a princípio, nos pareceu ser decorrente da predominância dos aspectos viscosos (não-lineares) sobre os elásticos (lineares), isto é, a medida que ocorre o incremento da frequência, o meio não reage na mesma velocidade que a frequência de oscilação. Assim, há retardo na resposta da estrutura defasando o sinal no tempo, amortecendo e diminuindo a resposta de amplitude de deslocamento. Todavia, nos parece que ocorre interferência de vibrações em todo conjunto estrutural, não sendo possível confirmar tais suposições.

Outra possibilidade de apresentar os efeitos dos deslocamentos, em um "phantom" com inclusões de partículas magnéticas, quando o mesmo está excitado de forma dinâmica é através de imagens como os mapas de deslocamento com código de cores.

A figura 4.38 traz exemplo de um mapa de deslocamento em função da profundidade, de um "phantom" com inclusão de partículas ferromagnéticas, na região central, sem e com aplicação de um campo magnético externo, oscilando a $40 \mathrm{~Hz}$.

Nestas imagens 4.38, o transdutor de US encontra-se na região mais profunda (parte inferior) enquanto o sistema de excitação do mini-vibrador está na parte superior. A inclusão de partículas ferromagnéticas está na região central, onde se apresentam os padrões de oscilação (pela mudança de cores). Conforme já mencionado anteriormente, a não oscilação na parte inferior e superior da amostra é devido ao fato de não ter espalhadores nestas regiões do "phantom", apenas parafina pura.

A barra lateral mostra os valores correspondentes ao deslocamento baseado no código de cores. Regiões mais "quentes" (em vermelho) representam deslocamentos positivos, enquanto regiões mais "frias" (azul escuro) representam deslocamentos negativos. A alternância das faixas representam os vales e picos 

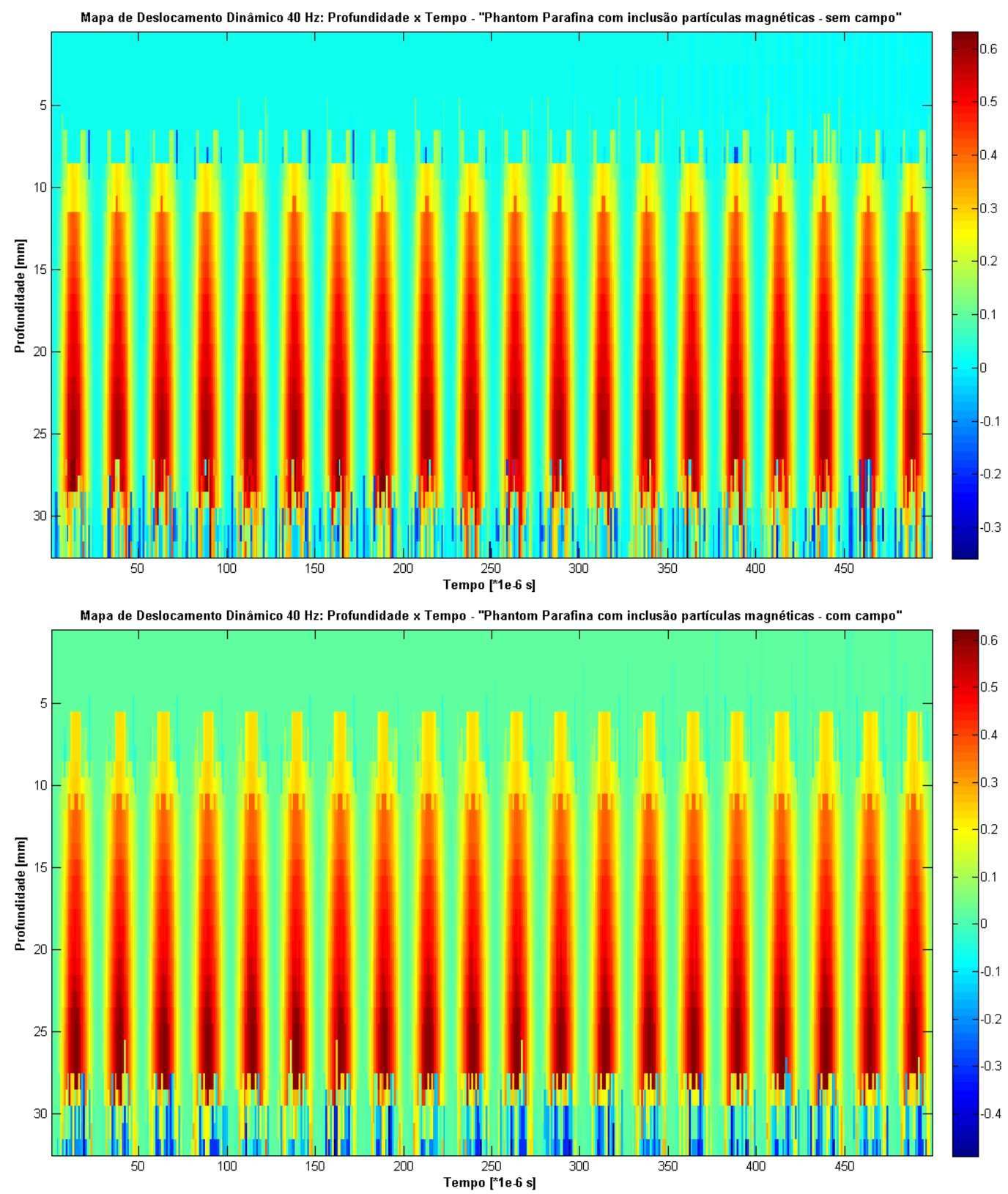

Figura 4.38: Mapa de deslocamento no tempo para frequência de $40 \mathrm{~Hz}$ - "Phantom" de parafina com partículas magnéticas, sem e com campo magnético externo.

das oscilações da estrutura, de acordo com a frequência de excitação.

A figura 4.39 mostra um mapa de deslocamento para excitação de $80 \mathrm{~Hz}$, sem aplicação do campo magnético externo. Assim, é possível verificar as mudanças relativas entre os deslocamentos quando do incremento da frequência. Com incremento da frequência ocorre diminuição na amplitude de deslocamento e, consequentemente, menor relação sinal-ruído. 


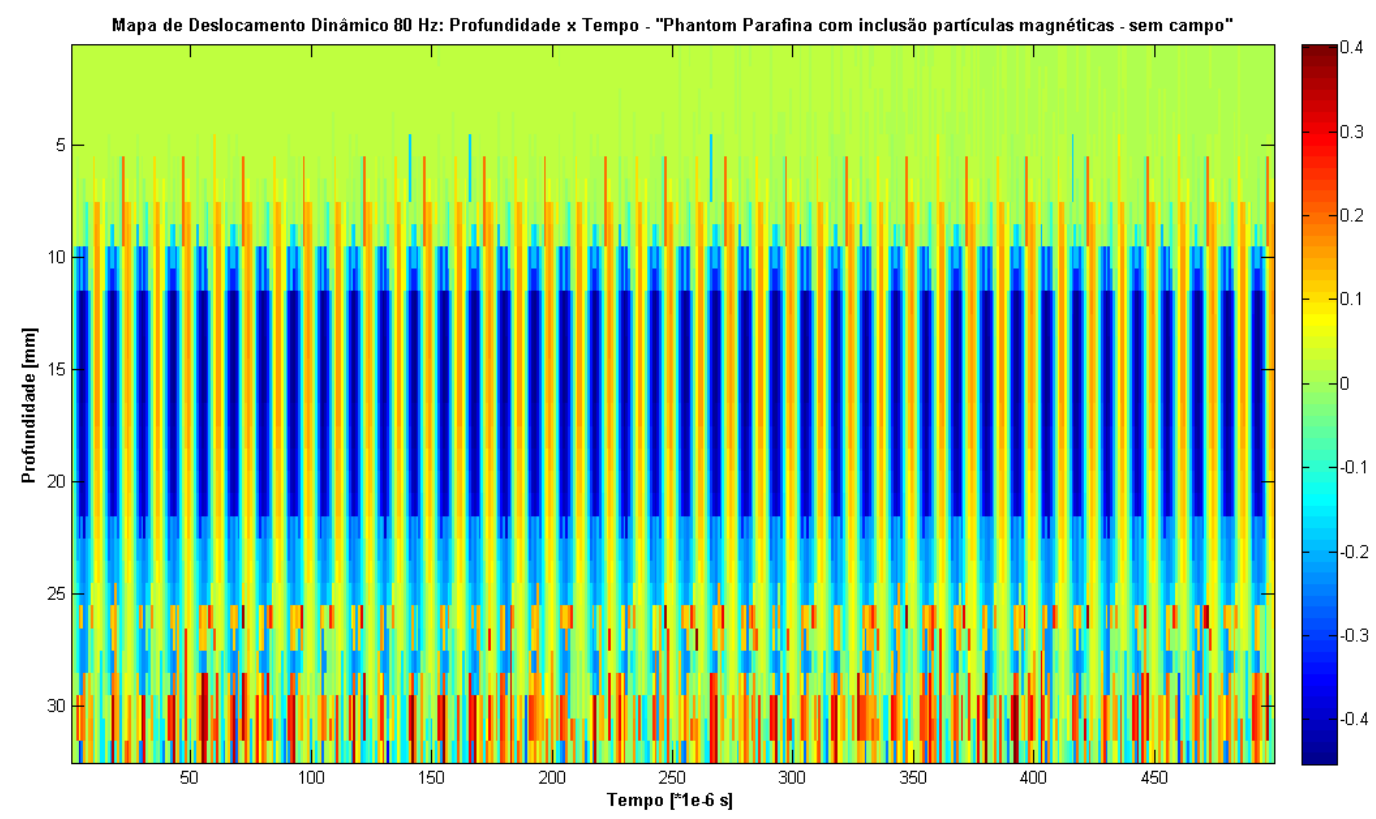

Figura 4.39: Mapa de deslocamento no tempo para frequência de $80 \mathrm{~Hz}$ - "Phantom" de parafina com partículas magnéticas, sem campo magnético externo.

\subsection{Imagem elastográfica - Ultrasonix}

Nesta seção pode-se verificar através do módulo elastográfico de um equipamento comercial $\left(\right.$ Sonix $^{\mathrm{R}}$ ) que os "phantoms" (simuladores de tecidos moles) contendo material ferromagnético podem ser utilizados para inferir diferentes rigidezes no meio, de modo a permitir treinamentos e classificação de anomalias nos tecidos moles, supondo que se supere as limitações técnicas da aplicação de campos externos variáveis de maior intensidade e mais direcionados.

O transdutor utilizado na obtenção das imagens elastográficas tem frequência central ajustada para $10 \mathrm{MHz}$, configurado para ganho de $50 \%$, profundidade de $40,0 \mathrm{~mm}$, opacidade em $20 \%$ e produziu imagens numa taxa de $30 \mathrm{fps}$.

O campo externo aplicado foi fornecido por dois magnetos (com características descritas na seção 3.2.2), cuja intensidade do campo é fixa, assim, a variação do campo foi feita pela aproximação e afastamento dos magnetos. Levando-se em conta que o campo diminui com o quadrado da distância, ficamos limitado em algumas situações, a aplicar o campo o mais próximo da amostra e a retirá-lo, a fim de perceber os efeitos das mudanças 
nas propriedades mecânicas das inclusões dos "phantoms".

Dentre as caracterizações levantadas, fica evidente a necessidade de se estabelecer qual a melhor relação entre a concentração de partículas ferromagnéticas, campos aplicados, espalhadores e atenuação sonora. Pois, constatamos que ao aumentar a concentração de partículas ferromagnéticas para incrementar o efeito de agrupamento magnético das partículas, perdemos o sinal ultrassônico que nos permite mensurar os deslocamentos destes aglomerados.

Deste modo, concentrações de fluidos magnetoreológicos acima de $10 \%$ produzem uma atenuação ultrassônica que dificulta o retorno do sinal ultrassônico, consequentemente a visualização das imagens em modo-B e elastográfico. Entretanto, para maximizar os efeitos de polarização magnética das inclusões é necessário impor um campo magnético de maior intensidade.

Outro aspecto que considerado como limitante no módulo comercial utilizado é que, o mesmo não fornece uma medida absoluta da rigidez do meio analisado, apenas valores relativos, expressos através da comparação entre duas regiões pré-selecionadas após a execução do processo de compressão e descompressão da região de interesse. Contudo, isto não impossibilita o estabelecimento de uma relação de rigidez entre os simuladores de tecidos moles com inclusões ferromagnéticas, com diferentes campos aplicados e os diferentes tipos de tecidos biológicos sadios e doentes. Aspectos que poderão ser abordados em trabalhos futuros.

$\mathrm{Na}$ tabela 4.13 apresenta-se os valores de rigidez para cinco diferentes

Tabela 4.13: Relação de rigidez nas imagens elastográficas obtidas com um equipamento de US da Sonix ${ }^{\mathrm{R}}$ - Diferentes meios e concentração.

\begin{tabular}{c|ccc}
\hline \hline & \multicolumn{3}{|c}{ Taxa de deformação relativa ("strain ratio") } \\
Material & Sem campo externo & Com campo externo & Percentual acréscimo [\%] \\
\hline $10 \%$ PM líquido & 0,51 & 0,75 & 32,0 \\
$15 \%$ PM líquido & 0,95 & 1,03 & 7,8 \\
$15 \%$ PM sólido & 0,45 & 0,60 & 25,0 \\
$20 \%$ PM sólido & 0,51 & 0,67 & 23,9 \\
$25 \%$ PM sólido & 0,94 & 0,97 & 3,1 \\
\hline \hline
\end{tabular}


inclusões com três concentrações de partículas ferromagnéticas, em meio fluido (FMR) e semi-fluido (parafina), referente a região vizinha sem partículas magnéticas.

Em cada sequência de imagens sem campo e com campo magnético, tem-se duas imagens: uma imagem elastográfica à esquerda (em cores) e uma imagem à direita em modo-B (tons de cinza).

Como mostrado na primeira linha da tabela 4.13, os valores da taxa de deformação relativa ao meio sem partículas e sem campo foi de 0,51, e, com campo magnético aplicado foi de 0,75 , representando um aumento relativo percentual na rigidez de $32,0 \%$. Esta mudança de rigidez num determinado tipo de tecido sadio provavelmente pode ser caracterizado como um tipo de lesão.

Na figura 4.40 [(a) e (b)] tem-se uma inclusão líquida com 10\% de FMR, no interior de uma parafina gel com $2 \%$ de espalhador acústico (pó de serra). Cada quadro contendo duas imagens, uma elastográfica à esquerda e outra em modo-B à direita.

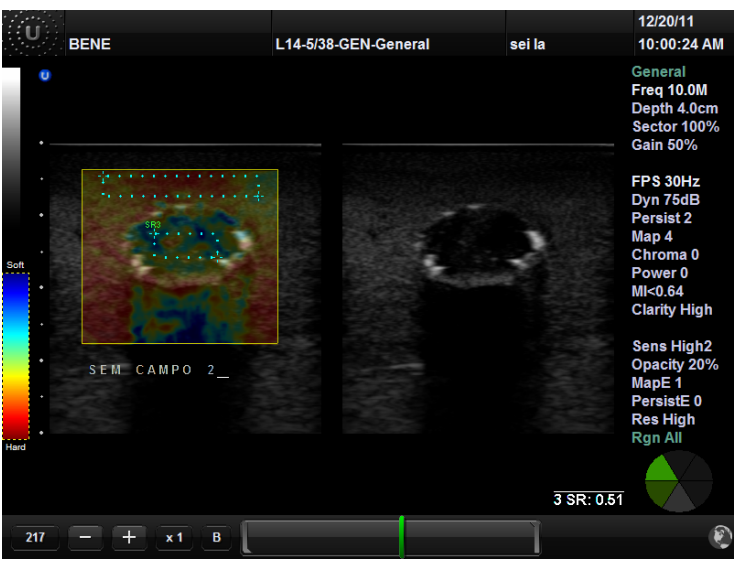

(a) Imagem elastográfica $10 \%$ pm sc - Líquido.

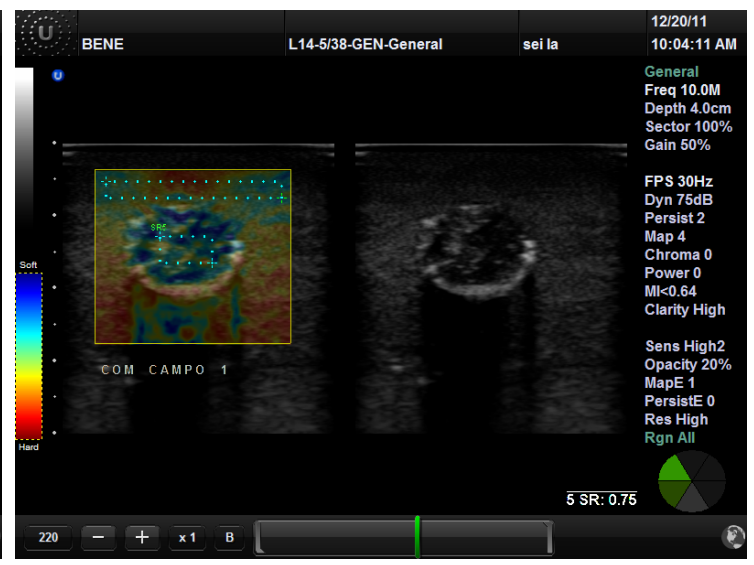

(b) Imagem elastográfica $10 \%$ pm cc - Líquido.

Figura 4.40: Imagem ultrasonix de "phantom "com inclusão líquida contendo $10 \%$ de partículas magnéticas. Em cada quadro [(a) e (b)] há uma imagem elastográfica (direita) e uma imagem em modo-B (esquerda). (a) Sem campo externo, (b) com campo externo.

A figura 4.41 mostra uma inclusão líquida com 15\% de FMR. A grande mancha escura, na parte inferior da região contendo o fluido ferromagnético, representa atenuação completa da onda ultrassônica, não permitindo definir com clareza os contornos da inclusão. Apesar disto, foi possível inferir um aumento relativo na rigidez do meio, porém em percentual menor, expressando assim maiores incertezas. 


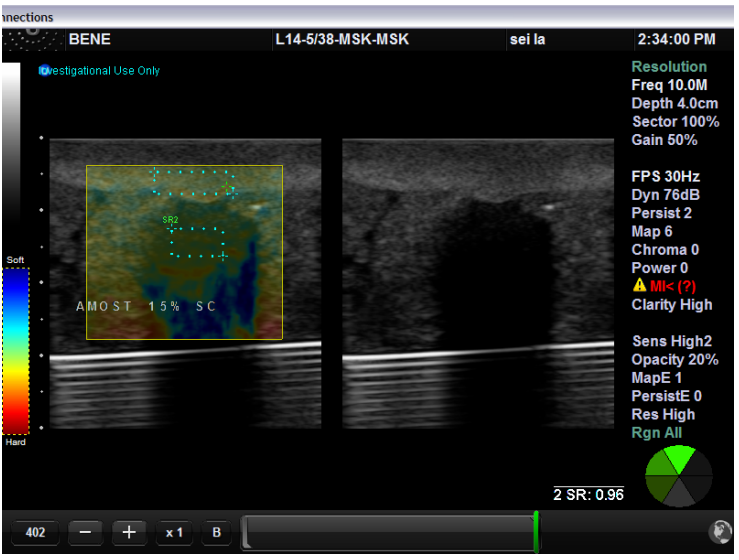

(a) Imagem elastográfica $15 \%$ pm sc - Líquido.

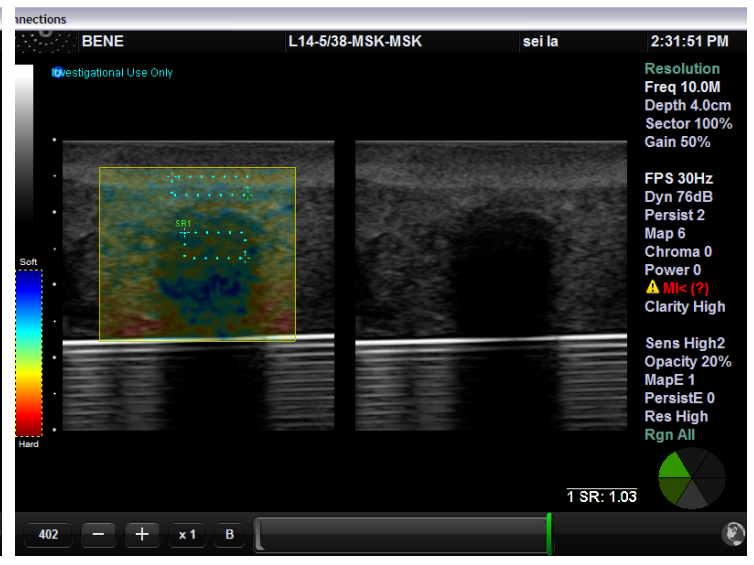

(b) Imagem elastográfica 15\% pm cc - Líquido.

Figura 4.41: Imagem ultrasonix de "phantom"com inclusão líquida contendo 15\% de partículas magnéticas. Em cada quadro [(a) e (b)] há uma imagem elastográfica (direita) e uma imagem em modo-B (esquerda). (a) Sem campo externo, (b) com campo externo.

A figura 4.42 mostra a imagem de uma inclusão sólida com mesma base

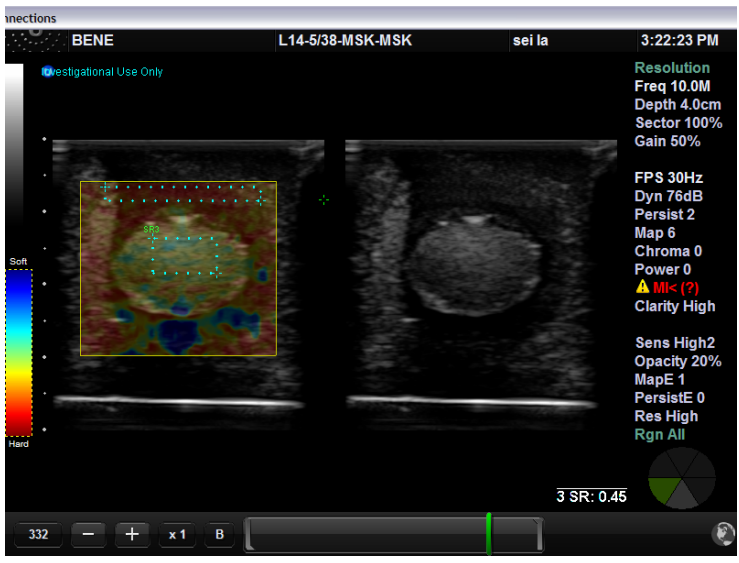

(a) Imagem elastográfica 15\% pm sc - Sólido.

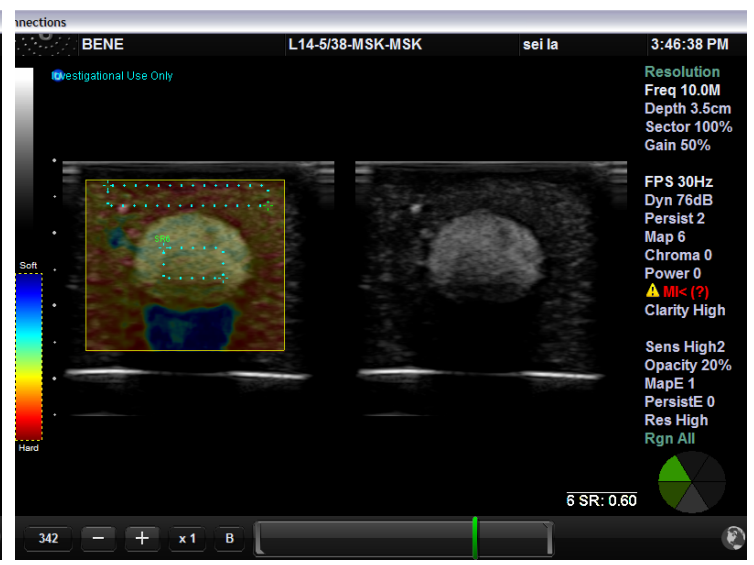

(b) Imagem elastográfica $15 \%$ pm cc - Sólido.

Figura 4.42: Imagem ultrasonix de "phantom "com inclusão sólida contendo $15 \%$ de partículas magnéticas. Em cada quadro [(a) e (b)] há uma imagem elastográfica (direita) e uma imagem em modo-B (esquerda). (a) Sem campo externo, (b) com campo externo.

de parafina gel da região externa, todavia, contendo $15 \%$ de FMR. O efeito de atenuação é minimizado, mas, ainda há indícios de absorção sonora na parte inferior da amostra.

É possível verificar pelos valores apresentados na tabela 4.13, que a mudança de estado da inclusão, líquido $\Longrightarrow$ semi-líquido (parafina gel), melhorou a relação de rigidez de 0,45 sem campo, para 0,60 com campo. Um 
incremento percentual de $25 \%$ quando da aplicação do campo externo.

$\mathrm{Na}$ imagem da figura 4.43 aumentamos a concentração de partículas magnéticas para 20\% e também de espalhador ultrassônico (pó de serra), em mais $2 \%$. Isto tornou a amostra um pouco mais visível ao ultrassom.

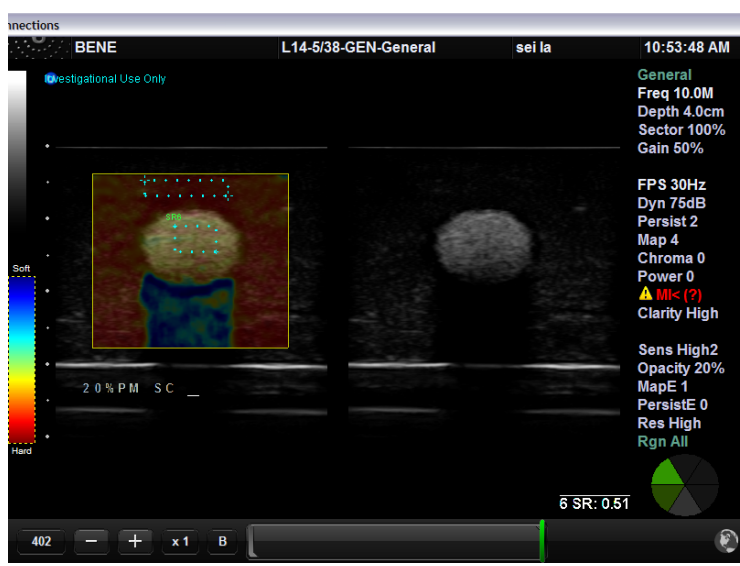

(a) Imagem elastográfica 20\% pm sc - Sólido.

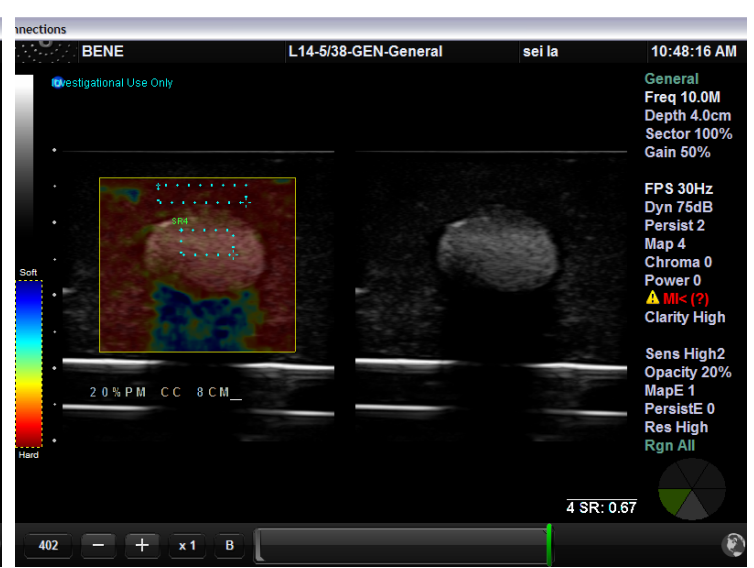

(b) Imagem elastográfica $20 \%$ pm cc - Sólido.

Figura 4.43: Imagem ultrasonix de "phantom "com inclusão sólida contendo $20 \%$ de partículas magnéticas. Em cada quadro [(a) e (b)] há uma imagem elastográfica (direita) e uma imagem em modo-B (esquerda). (a) Sem campo externo, (b) com campo externo.

Entretanto, a amostra ficou um pouco mais dura, em relação à de $15 \%$. Assim, os valores de rigidez aumentaram, contudo, quando submetido ao mesmo campo externo anterior, o percentual de incremento relativo na rigidez foi menor.

Por fim, foi construído um "phantom" com a mesma base de espalhador da amostra anterior (4\%) e aumentou-se a concentração de FMR para $25 \%$. A ideia foi verificar se, com mais espalhador e concentração de partículas magnéticas, o efeito de visibilidade do ultrassom e mudanças nas propriedades mecânicas aumentaria.

Contudo, o módulo elastográfico do equipamento mostrou uma leve mudança na rigidez entre as duas regiões comparadas, mas com um incremento bem inferior as amostras com menor concentração de partículas magnéticas. Apenas 3,1\%, conforme apresentado na tabela 4.13 .

Esta abordagem pressupõe que seja possível estabelecer uma melhor relação entre a variação de rigidez na estrutura interna do "phantom" em função do campo magnético externo aplicado. Assim, em estudos posteriores delinear uma escala de dureza do "phantom" em função da intensidade do campo magnético, que possa ser associada a rigidez de tecidos biológicos moles. 
As imagens em modo-B e elastográficas, registradas na figura 4.44, mostram que ocorre uma saturação, baixa relação sinal-ruído, de modo que não é possível discriminar muito bem as regiões de interesse, o que dificultaria estabelecer um bom diagnóstico, por parte dos especialistas.

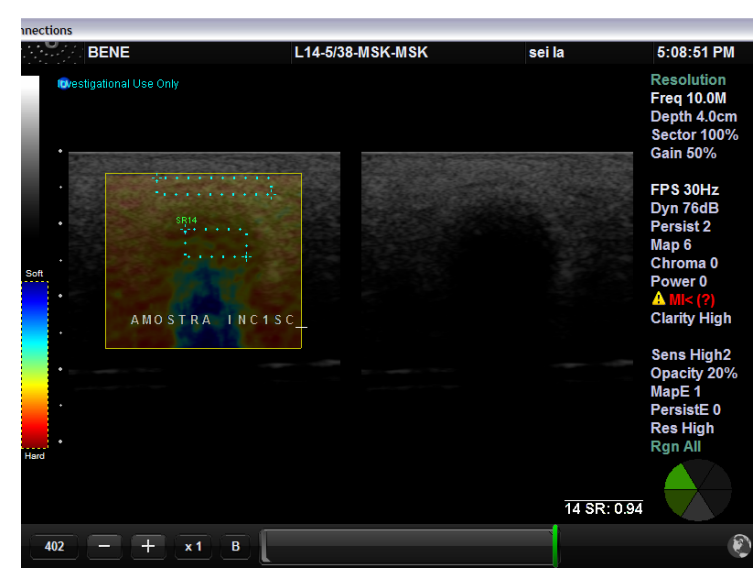

(a) Imagem elastográfica 25\% pm sc - Sólido.

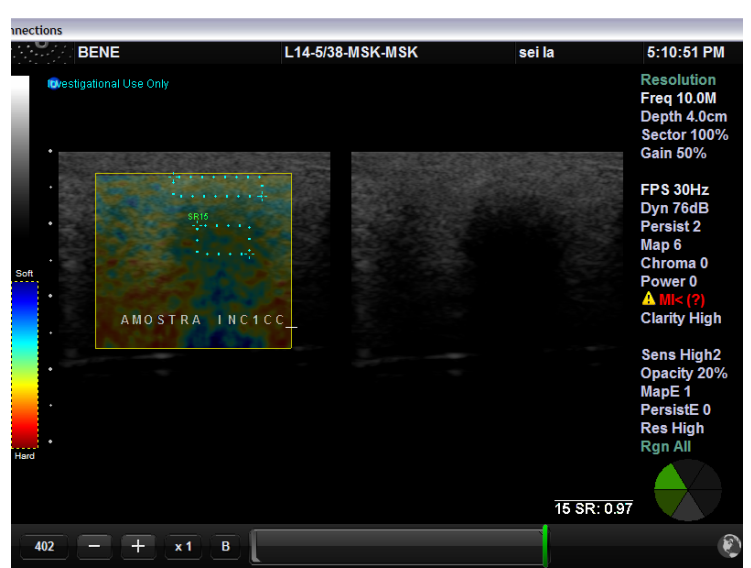

(b) Imagem elastográfica 25\% pm cc - Sólido.

Figura 4.44: Imagem ultrasonix de "phantom "com inclusão sólida contendo $25 \%$ de partículas magnéticas. Em cada quadro [(a) e (b)] há uma imagem elastográfica (direita) e uma imagem em modo-B (esquerda). (a) Sem campo externo, (b) com campo externo.

Daí, pode-se inferir que os limites de concentração de partícula magnéticas, nos simuladores de tecidos, confeccionados a partir de parafinas, não devam exceder a $20 \%$. 


\section{Capítulo}

\section{Conclusões e Perspectivas Futuras}

\subsection{Conclusões}

Nesta tese, foi apresentada, de forma cronológica, uma revisão da teoria da elasticidade para meios lineares através do estudo de uma nova proposta de produzir simuladores de tecidos biológicos com propriedades mecânicas dependentes de um campo magnético externo. Para tal, houve a confecção e caracterização de um sistema para avaliar as propriedades elásticas de simuladores de tecidos biológicos de forma estática e dinâmica por ultrassom.

Os estudos com simuladores marcados com material magnéticos reológico mostraram que é possível produzir materiais moles com propriedades mecânicas equivalentes aos dos tecidos biológicos e dependentes do campo magnético externo. Estes simuladores apresentam potencial para uso na confecção de "phantoms", que podem ser utilizados no treinamento de radiologista e na avaliação de equipamentos de ultrassom dedicados ao diagnóstico clínico que faça uso de medidas elastográficas por ultrassom. Neste caso, a mudança da rigidez do "phantom" e/ou inclusões seria por meio de um campo magnético externo, que poderá ser controlado através da corrente aplicada a uma bobina.

Os protótipos dos sistemas reológicos desenvolvidos neste trabalho, usando perturbação mecânica e detecção da deformação interna da amostra por ultrassom, também representam uma contribuição inovadora e de grande interesse para apoio no desenvolvimento de materiais com propriedades mecânicas equivalentes aos tecidos biológicos, permitindo obter a medida da constante elástica de objetos imersos em meios semi-fluidos (parafinas).

O primeiro protótipo desenvolvido, fazendo uso de um sistema mecânico motorizado (seção 3.2.1) para promover perturbações mecânicas oscilatórias 
na amostra e detecção Doppler por ultrassom, permitiu uma avaliação da viabilidade de gerar imagens Doppler em meios estáticos com potencial aplicação para o diagnóstico de lesões em tecidos moles.

Embora, este estudo tenha sido interrompido por limitações técnicas na confecção de um sistema motorizado para medidas dinâmicas com frequências maiores do que $20 \mathrm{~Hz}$, os testes preliminares com o protótipo confeccionado (figura 3.9) indicaram a viabilidade de uso de um transdutor ultrassônico vibracional para gerar mapas de ecos em tempo-real e gerar imagens viscoelásticas em tempo-real.

Em estudos paralelos, desenvolvidos pela aluna de iniciação científica Gislaine Marine, também orientanda do prof ${ }^{\circ}$.Dr. Antonio Adilton O. Carneiro, se verificou que os melhores contrastes das imagens Doppler eram obtidos para frequências acima de $50 \mathrm{~Hz}$. Foi com base nesses resultados e conclusões preliminares, que se optou por explorar o desenvolvimento de um sistema reológico que permitisse aplicar uma maior frequência de deformação dinâmica das estruturas internas das amostras, e, através do ultrassom pulso-eco, verificar o comportamento de tais deformações.

O primeiro sistema mecânico montado com este propósito, fazendo uso de um motor de passo, acoplado a um sistema robótico com deslocamentos micrométricos, permitiu aplicar deformação estática e dinâmica com precisão da ordem de um micrômetro e frequências de até $20 \mathrm{~Hz}$. Entretanto, ao substituir o motor de passo pelo oscilador mecânico da Brüel \& Kjær, modelo mini-shaker 4810, ampliou-se a faixa de frequência de deformação das amostras de $40 \mathrm{~Hz}$ até $4 \mathrm{kHz}$, apesar de se trabalhar na faixa de $40 \mathrm{~Hz}$ a $140 \mathrm{~Hz}$. Dentro dessa faixa este oscilador permitiu deslocamentos lineares e proporcionais a corrente aplicada, conforme especificações técnicas do fabricante.

O modelo desenhado para este protótipo permitiu o uso de transdutores mono-elementos e matriciais, para medição das deformações das estruturas internas das amostras, sincronizados com os deslocamentos aplicados. O módulo de aquisição com o transdutor mono-elemento permitiu uma melhor relação sinal ruído na medida do deslocamento das estruturas internas, devido ao fato da aquisição do eco ter sido realizada fazendo uso de um osciloscópio de alto desempenho, que possibilitou uma aquisição em altas taxas (até 200 $\mathrm{MHz}$ ), permitindo a configuração de médias. Além disso, este osciloscópio permite a configuração de casamento de impedância elétrica com o transdutor, 
diminuindo perdas de energia devido ao acoplamento.

O modulo de aquisição com o transdutor matricial gerou imagens do mapa de deslocamento dinâmico, sincronizado com a excitação mecânica e, a partir desse, pode-se construir os mapas de deformação e de velocidade. Desde que se conheça a força aplicada, pode-se gerar também o mapa do módulo de "Young".

O software de aquisição dos dados de " $R F$ ", adquiridos em altas taxas usando a plataforma do próprio ultrassom, foi desenvolvido paralelamente pelo aluno de iniciação científica Diego Thomaz em colaboração com o prof ${ }^{\circ}$.Dr. Theo Pavan, o qual disponibiliza ao usuário escolher a região de interesse, configurar a taxa de amostragem combinada com o número de linhas de " $R F$ " e a profundidade da região de interesse.

Através de medições em "phantoms", visando a caracterização do sistema, foi possível observar que as medidas do módulo de elasticidade dos "phantoms" de gelatina 250 Bloom são estáveis, desde que se mantenha controle da temperatura, entretanto, por serem difíceis de confeccioná-los com misturas de partículas ferromagnéticas, devido a limitações técnicas, não foi possível verificar seu comportamento com a aplicação de campos magnéticos.

Durante a caracterização dos diversos módulos do sistema, célula de carga, excitação e medidas ultrassônicas, ficou evidente a complexidade e a necessidade de sincronia entre os processos de aplicação das cargas, calibração dos instrumentos, leitura do sinal e processamento dos dados. A célula de carga usada nos protótipos, por exemplo, não possui uma resposta linear com a frequência de excitação mecânica, o que restringiu seu uso às medidas estáticas ou quase estáticas $(<20 \mathrm{~Hz})$.

Entretanto, o uso do mini-vibrador superou várias dificuldades encontradas na confecção de um sistema de excitação de alta frequência com estabilidade. Pois, se a frequência e a corrente de alimentação deste módulo forem mantidas constantes a partir de $40 \mathrm{~Hz}$, a força exercida por este vibrador mantém-se uniforme, segundo especificações técnicas do fabricante.

Além disso, observou-se que os aspectos viscosos dos meios estudados começam a predominar sobre os elásticos em duas situações: na medição estática, quando se aplicam cargas ("tensões") que produzem deformações acima de $1 \%$ em relação ao comprimento, na direção axial a aplicação da carga; e, na medição dinâmica, quando a frequência de excitação ultrapassa o limite de 100 
$\mathrm{Hz}$.

Uma das características importantes dos simuladores analisados foi a inclusão de partículas ferromagnéticas $\left(\mathrm{Fe}_{3} \mathrm{O}_{4}\right)$ propiciando às parafinas propriedades magnéticas. As quais, sob ação de um campo magnético externo alteram sua dureza e possibilitaram determinar valores para o módulo de elasticidade do meio em estudo.

Todavia, um dos aspectos negativos na confecção de simuladores de tecidos moles marcados com o material reológico usado neste trabalho foi a alta atenuação que essas partículas proporcionaram na propagação da onda ultrassônica. Estudos de novos materiais magnéticos misturados em diferentes bases semi-fluidas deverão ser exploradas em trabalhos futuros, com o objetivo de minimizar essa limitação. Outro aspecto a ser explorado em trabalhos futuros será a produção de campos magnéticos mais intensos para a magnetização do "phantom" marcado com essas partículas magnetoreológicas ("MMR").

Por fim, os resultados deste trabalho mostraram a viabilidade do desenvolvimento de um sistema, de baixo custo, para estudo das propriedades viscoelásticas de simuladores de tecidos moles, fazendo uso do ultrassom para medir a deformação das estruturas internas do meio, com precisão da ordem de um micrômetro. Também foi mostrada a viabilidade de alterar a rigidez de um meio através da inclusão de partículas ferromagnéticas, modificando o campo magnético externo em sua vizinhança.

\subsection{Perspectivas futuras}

Com o avanço tecnológico da qualidade e miniaturização dos sistemas ultrassônicos pulso-eco e, fazendo uso de osciladores mecânicos, do tipo aplicado neste trabalho, evidenciou-se aqui a possibilidade da confecção de sistemas de medição ultrassônica capaz de avaliar as propriedades elásticas e viscosas em materiais semi-fluidos marcados com partículas ferromagnéticas.

Uma adaptação deste sistema reológico através do ultrassom, prospectada para estudos em mama, consistirá no acoplamento de uma célula de força matricial para estimar a distribuição da deformação proporcionada nas estruturas internas das amostras. A partir desse mapa de força e do mapa da deformação das estruturas internas, estimada com a medida ultrassônica, poder-se-á gerar mapas das propriedades elásticas das estruturas internas da 
mama obtidas sobre diferentes frequências de deformação.

Também serão explorados novos materiais reológicos para confecção desses novos simuladores de tecidos biológicos, idealizados neste trabalho. Talvez elastômeros de silicone, nos quais as partículas ferromagnéticas possam sofrer o processo de polarização, quando da aplicação do campo, mas a energia armazenada na estrutura seja suficiente para retornar o sistema à posição inicial de forma mais rápida.

Também numa perspectiva futura, na continuação dessa pesquisa, é necessário compreender os processos microscópicos relacionados com as mudanças no comportamento visco-elástico dos materiais que compõem os "phantoms" marcados com estes materiais magnetoreológicos.

Com intuito de executar ensaios "in vivo" e "ex-vivo" de tecidos biológicos, em ambientes externo ao laboratório, é importante que todo o sistema seja compacto e móvel para facilitar o transporte e medições com precisão, sem interferência do ambiente externo. 


\section{Referências $^{1}$}

[1] GASKING, E. B. Biography - Lazzaro Spallanzani. [S.l.]: Britannica Academic edition, Ago. 2011. http://www.britannica.com/EBchecked/ topic/557970/Lazzaro-Spallanzani. 1

[2] WOO, J. A short History of the development of Ultrasound in Obstetrics and Gynecology. Jun. 2007. http: //www. ob-ultrasound.net/history1.html. 1, 3, 4

[3] CASTRO, A. C. de. Lord Rayleigh. [S.l.]: Centro de Divulgação Científica e Cultural da USP - CDCC, Out. 2007. http://fisica.cdcc.usp.br/ Cientistas/LordRayleigh.html. 1

[4] FISH, J. P. "The Sonar Primer". [S.l.]: By J. P. Fish, Apr. 2002. 3 p. http://www.instituteformarineacoustics.org/SonarPrimer/ SideScanSonar.htm. 2

[5] BELliS, M. "The History of Sonar". [S.l.]: By inventors.about, Apr. 1997. 1 p. http://inventors.about.com/od/sstartinventions/a/sonar_history . htm. 2

[6] GUARIGLIA, S. N. Breve história da ultra-sonografia. [S.l.]: Breves de saude - revista online, 2th ed., Nov. 2004. http://www.brevesdesaude.com.br/ ed02/ultrasonografia.htm. 2

[7] TUOTO, E. A. "Dussik, Gohr \& Wedekind: Pioneiros do Ultrassom em Medicina". in: História da Medicina. [S.l.]: By Dr. Elvio A. Tuoto (Internet) Brasil., Dez. 2006. 1 p. http://historyofmedicine.blogspot.com/2006/12/ os-pioneiros-do-diagnosticos-por-ultra.html. 2

[8] MARCONDES, S. R. et al. Caracterização de materiais utilizando a atenuação e velocidade de propagação de ondas Ultrassônicas. In: XXI

\footnotetext{
${ }^{1}$ De acordo com a Associação Brasileira de Normas Técnicas. NBR 6023.
} 
Congresso Brasileiro de Engenharia Biomédica. Salvador, BA: [s.n.], 2008. v. 34, p. 1123-1126. ISBN 978-85-60064-13-7. CBEB2008 - Salvador, Ba. 4

[9] ANTONIO, A. M. A Bioengenharia no Brasil, Século XX: Estado da Arte. 140 p. Dissertação (Mestrado) - Escola de Engenharia de São Carlos/Faculdade de Medicina de Ribeirão Preto/Instituto de Química de São Carlos, Universidade de São Paulo - São Carlos., 2004. 5

[10] SIMMONS, A. Medical Physics - Ultrasound (Página pessoal). Jun. 2007. http://www.genesis.net.au/ ajs/projects/medical_physics/ ultrasound/index.html. 8

[11] LASERS, L. 'Oxford. PZT Ultrasound Transducer oblique view. Ago. 2011. http://www.oxfordlasers.com/micromachining/applications/ pzt_micropillars. 8

[12] LERNER, R. M.; HUANG, S.; PARKER, K. J. Sonoelasticity images derived from ultrasound signals in mechanically vibrated tissues. Ultrasound in Medicine and Biology, v. 16, n. 3, p. 231-239, 1990. ISSN 0301-5629. Disponível em: <http://www.sciencedirect.com/science/article/pii/ 030156299090002T>. 9, 10

[13] PARKER, K.; DOYLEY, M.; RUBENS, D. Imaging the elastic properties of tissue: the 20 year perspective. Physics in Medicine and Biology, v. 56, n. 1, p. R1, 2011. Disponível em: <http://stacks.iop.org/0031-9155/56/i=1/a= R01>. 9, 12

[14] OPHIR, J. et al. Elastography: Imaging the elastic properties of soft tissues with ultrasound. Journal Med Ultrasonics, v. 29, n. 1, p. 155-171, 2002. Disponível em: <http://www.springerlink.com/content/ b6v78g3541651576/>. 9, 10, 33, 100

[15] FUNG, Y. C. Biomechanics: Mechanical Properties of Living Tissues. 2a. ed. New York, USA: Springer - Verlag, 1993. 235 p. ISBN 0-387-97947-6. xviii, 9, $20,24,28,33$

[16] PARKER, K. et al. Tissue response to mechanical vibrations for sonoelasticity imaging. Ultrasound in Medicine \& Biology, v. 16, n. 3, p. 241-246, 1990. ISSN 0301-5629. Disponível em: <http://www. sciencedirect.com/science/article/pii/030156299090003U>. 9 
[17] OPHIR, J. et al. Elastography: ultrasonic estimation and imaging of the elastic proprieties of tissues. Proc Instn Mech Engrs, v. 213, n. 3, p. 203-233, 1999. Disponível em: <http://www.mendeley.com/research/>. 9, 12

[18] MCKNIGHT, A. L. et al. Mr elastography of breast cancer: Preliminary results. Am. J. Roentgenol., v. 178, n. 6, p. 1411-1417, 2002. Disponível em: <http://www.ajronline.org/cgi/content/abstract/178/6/1411>. 9

[19] SAMANI, A. et al. Measuring the elastic modulus of ex vivo small tissue samples. Physics in Medicine and Biology, v. 48, n. 14, p. 2183, 2003. Disponível em: <http://stacks.iop.org/0031-9155/48/i=14/a=310>. 9

[20] MOFID, Y. et al. In-vivo human skin elastography: a preliminary study. In: WCU 2003. [S.l.: s.n.], 2003. v. 7, n. 10, p. 205-208. 9

[21] HALL, T. J.; ZHU, Y.; SPALDING, C. S. In vivo real-time freehand palpation imaging. Ultrasound in Medicine \& Biology, v. 29, n. 3, p. 427-435, 2003. ISSN 0301-5629. Disponível em: <http://www.sciencedirect.com/ science/article/pii/S0301562902007330>. 9, 12

[22] GENNISSON, J. L. et al. Assessment of elastic parameters of human skin using dynamic elastography. Ultrasonics, Ferroelectrics and Frequency Control, IEEE Transactions on, v. 51, n. 8, p. 980-989, aug. 2004. ISSN 0885-3010. 9

[23] MILLER, K. Method of testing very soft biological tissues in compression. Journal of Biomechanics, v. 38, n. 1, p. 153-158, 2005. ISSN 0021-9290. Disponível em: <http://www.sciencedirect.com/science/article/pii/ S0021929004001447>. 9

[24] SINKUS, R. et al. Nonlinear viscoelastic properties of tissue assessed by ultrasound. Ultrasonics, Ferroelectrics and Frequency Control, IEEE Transactions on, v. 53, n. 11, p. 2009-2018, november 2006. ISSN 0885-3010. 9,100

[25] SRIDHAR, M.; INSANA, M. F. Ultrasonic measurements of breast viscoelasticity. Medical Physics, AAPM, v. 34, n. 12, p. 4757-4767, 2007. Disponível em: <http://link.aip.org/link/?MPH/34/4757/1>. 9 
[26] BOYER, G. et al. In vivo characterization of viscoelastic properties of human skin using dynamic micro-indentation. In: Engineering in Medicine and Biology Society, 2007. EMBS 2007. 29th Annual International Conference of the IEEE. [S.l.: s.n.], 2007. p. 4584-4587. ISSN 1557-170X. 9

[27] ZHENG, Y.-P.; HUANG, Y.-P. More intrinsic parameters should be used in assessing degeneration of articular cartilage with quantitative ultrasound. Arthritis Research \& Therapy, v. 10, n. 6, p. 125, 2008. ISSN 1478-6354. See related research by Nakagawa et al.,http://arthritis-research.com/content/11/3/408. Disponível em: <http://arthritis-research.com/content/10/6/125>. 9

[28] VIEIRA, S. L. Imagens das Propriedades Viscoelásticas por ressonância Magnética e Ultrassom. 200 p. Tese (Doutorado) - Doutorado em Fisica Aplicada a Medicina e Biologia - Faculdade de Filosofia Ciências e Letras de Ribeirão Preto, Departamento de Física e Matemática, Universidade de São Paulo, 2009. xiii, 9, 12, 24, 57, 58

[29] PAVAN, T. Z. et al. Nonlinear elastic behavior of phantom materials for elastography. Physics in Medicine and Biology, v. 55, n. 9, p. 2679, 2010. Disponível em: <http://stacks.iop.org/0031-9155/55/i=9/a=017>. 9

[30] QUADROS, L. G. de A. Breast imaging reporting and data system: Bi-radsR. Revista Brasileira de Mastologia, American College of Radiology, v. 13, n. 4, p. 147, 2003. Copyright 1992, 1993, 1995, 1998, 2003 American College of Radiology. Disponível em: <http://portal.revistas.bvs.br/>. 9

[31] YAMAKOSHI, Y.; SATO, J.; SATO, T. Ultrasonic-imaging of internal vibration of soft-tissue under forced vibration. IEEE transactions on ultrasonics, ferroelectrics and frequency control, v. 37, n. 2, p. 45-53, mar. 1990. ISSN 0885-3010/90/0300-0045. 10

[32] SUGIMOTO, T.; YEDA, S.; ITOH, K. Tissue hardness measurement using the radiation force of focused ultrasound. In: . Honolulu, HI, USA: IEEE ultras., 1990. p. 1377-1380. ISSN 1051-0117/90/0000-1377. 11 
[33] FATEMI, M.; GREENLEAF, J. F. Ultrasound-stimulated vibro-acoustic spectrography. Science, Amer. Assoc. Advancement Science, Washington, 280, n. 5360, p. 82-85, apr. 1998. ISSN 0036-8075. 11

[34] NIGHTINGALE, $K$. et al. On the feasibility of remote palpation using acoustic radiation force. J. Acoust. Soc. Am., v. 110, p. 625-634, 2001. Disponível em: <http://www.bme.duke.edu/faculty/RogerNightingale/ publications $>$. 11

[35] CHEN, S.; FATEMI, M.; GREENLEAF, J. F. Remote measurement of material properties from radiation force induced vibration of an embedded sphere. The Journal of the Acoustical Society of America, ASA, v. 112, n. 3, p. 884-889, 2002. Disponível em: <http://link.aip.org/link/?JAS/112/884/ $1>.11$

[36] BAGGiO, A. L. Imagens acústicas geradas pela interação da radiação ultrassônica com o meio material. 143 p. Tese (Doutorado) - Doutorado em Fisica Aplicada a Medicina e Biologia - Faculdade de Filosofia Ciências e Letras de Ribeirão Preto, Departamento de Física, Universidade de São Paulo, 2011. 11

[37] ULRICH, W. D. Ultrasound dosage for nontherapeutic use on human beings - extrapolations from a literature survey. Biomedical Engineering, IEEE Transactions on, BME-21, n. 1, p. 48-51, jan. 1974. ISSN 0018-9294. Disponível em: <http://ieeexplore.ieee.org/xpls/abs_all. jsp?arnumber $=4120718 \&$ tag $=1>$. xvii, 11, 164, 165

[38] OPHIR, J. et al. Elastography: a quantitative method for imaging the elasticity of biological tissues. Ultrasonic Imaging, Elsevier, v. 13, n. 2, p. 111-134, 1991. 11, 13

[39] OPHIR, J. et al. Optical and acoustical imaging of biological media elastography. Biophysics-Applied physics, C. R. Acad. Sci. Paris, v. 2-IV, p. 1193-1212, Jul. 2001. 11

[40] OPHIR, J. e. a. Elastography: A systems approach. International Journal of Imaging Systems and Technology, v. 8, n. 1, p. 89-103, 1997. Disponível em: <www.uth.tmc.edu/.../Ophir>. 12 
[41] VARGHESE, T. et al. Tradeoffs in elastographic imaging. Ultrasonic Imaging, v. 23, n. 4, p. 216-248, 2001. Disponível em: <www.uth.tmc.edu/. . .$/ 0$ phir>. 12

[42] MANDUCA, A. et al. Image processing for magnetic resonance elastography. Medical Imaging 1996: Image Processing, v. 2710, n. 1042, p. 616-623, 1996. 12

[43] OLIPHANT, T. E. Direct methods for dynamic elastography reconstruction: Optimal inversion of the interior helmholtz problem. 210 p. Tese (Doutorado) - PhD Thesis - (Mayo Graduate School,Rochester, MN.), 2001. 12

[44] OLIPHANT, T. E.; EHMAN, R. L.; GREENLEAF, J. F. Estimation of complex valued stiffness using acoustic waves measured with magnetic resonance. In: . [S.l.: s.n.], 2002. v. 84, p. 277-294. 12

[45] HERO, A.; SCHWARTZ, S. C. A new generalized cross correlator. IEEE Transactions on Acoustics, Speech and signal Processing., ASSP-33, n. 1, p. 38-45, 1985. Disponível em: <http://ieeexplore.ieee.org/stamp/stamp. jsp?arnumber $=01164513>.15$

[46] NEVES, L. P. Otimização do algoritmo de 'block matching' aplicado a estudos elastográficos. 131 p. Dissertação (Mestrado) - Mestrado em Fisica Aplicada a Medicina e Biologia - Faculdade de Filosofia Ciências e Letras de Ribeirão Preto, Departamento de Física e Matemática, Universidade de São Paulo, 2007. 15

[47] COSSOLINO, L. C.; PEREIRA, A. H. A. Módulos elásticos: Visão geral e métodos de caracterização. [S.l.]: Informativo Técnico-Científico ITC-ME/ATCP Engenharia Física., Nov. 2010. 30 p. http://www.atcp.com.br/pt/produtos/caracterizacao-materiais/ propriedades-materiais/modulos-elasticos.html. 19

[48] VACALEBRI, P. et al. A robotic system for soft tissue characterization. In: The Eighth International Conference on Rehabilitation Robotics. [S.l.: s.n.], 2003. p. 001-004. 20

[49] GAO, L. et al. Imaging of the elastic properties of tissue - a review. Ultrasound in medicine \& biology, Elsevier, v. 22, n. 8, p. 959-977, 1996. xi, 20, 28 
[50] FATEMI, M. et al. Vibro-acoustic tissue mammography. IEEE Trans. Med. Imag., Iowa City, 21, n. 1, p. 1-8, jan. 2002. ISSN 0278-0062. 20

[51] JR, W. D. C. Materials Science and Engineering: An Introduction. 7th. ed. New York, USA: John Wiley and Sons, 2007. 720 p. Library of Congress catalog card number, TA403-C23 2007. ISBN 13-978-0-471-73696-7. Disponível em: <http://www.amazon.com/ Materials-Science-Engineering-William-Callister/dp/0471736961>. 21

[52] LAKES, R. S. Viscoelastic measurement techniques. Review of Scientific Instruments, AIP, v. 75, n. 4, p. 797-810, 2004. Disponível em: <http:// link.aip.org/link/?RSI/75/797/1>. 24

[53] DUCK, F. A. Physical properties of tissue - a comprehensive reference book. 6nd. ed. San Diego, London: Academic Press., 1990. 346 p. (Medical Science Series). ISBN 012222800 6. 24

[54] SARVAZYAN, A. et al. Novel Imaging Methods and System. 21. ed. New York: Plenum Press: Springer-Jones, J.P., 1995. 838 p. (Acoustical Imaging, vol. 21). ISBN 978-0-306-450009-9. 24

[55] FATEMI, M.; MANDUCA, A.; GREENLEAF, J. F. Imaging elastic properties of biological tissues by low-frequency harmonic vibration. Proceedings of the IEEE, v. 91, n. 10, p. 1503-1519, oct. 2003. ISSN 0018-9219. Disponível em: <http://ieeexplore.ieee.org/xpls/abs_all. jsp?arnumber $=1232190 \& \operatorname{tag}=1>.24$

[56] COBBOLD, R. S. C. Foundations of Biomedical ultrasound. 198 Madison Avenue, New York, USA: Oxford University press, 2007. 802 p. (Biomedical engineering series). ISBN 13-978-0-19-516831-0. xii, xix, 24, 50, 51, 52, 53, $76,77,155,159,161$

[57] VERONDA, D.; WESTMANN, R. Mechanical characterization of skin-finite deformations. Journal of Biomechanics, v. 3, n. 1, p. 111-124, 1970. ISSN 0021-9290. Disponível em: <http://www.sciencedirect.com/science/ article/pii/0021929070900552>. 25

[58] PAVAN, T. Z. Estudos de técnicas ultrassônicas para análise de propriedades mecânicas de meios viscoelásticos. 111 p. Tese (Doutorado) - 
Doutorado em Fisica Aplicada a Medicina e Biologia - Faculdade de Filosofia Ciências e Letras de Ribeirão Preto, Departamento de Física, Universidade de São Paulo, 2011. 25

[59] BIRD, R. B.; ARMSTRONG, R. C.; HASSAGER, O. Dynamics of Polymeric Liquids: Fluid Dynamics. 2a. ed. New York, USA: John Wiley \& Sons, 1987. 672 p. ISBN 978-0-471-80245-7. xi, 29

[60] VIEIRA, R. C. d. C. Atlas de mecânica dos fluidos: cinemática. Editôra E. Blúcher, 1971. 130 p. Disponível em: <http://books.google.com.br/books? id $=$ HntdAAAAMAA J $>$. 30

[61] TIMONSHENKO, S. P.; GOODIER, J. N. Theory of Elasticity. 3th. ed. Maple press company, NY, USA.: Mcgraw Hill Higher Education, 1970. 608 p. (World Students). ISBN 007858055. 31

[62] BUTKOV, E. I. Mathematical Physics. 1th. ed. Massachusetts Mento Park, California, USA.: Addison - Wesley Publishing Company, 1998. 740 p. (World Students). ISBN 8521611455. 32

[63] BARNES, H.; HUTTON, J.; WALTERS, K. An Introduction to Rheology. 3th. ed. Sara Burgerhartstraats, 25, 1000 AE, Amsterdam; The Netherlands: Elsevier, Science Publisher, 1993. 198 p. (Rheology series, vol. 3). ISBN 0-444-87469-0. 33

[64] DIEZ, P. F. Mecanica dos Fluidos. 1a. ed. Cantabria, España: Universidad de Cantabria. Departamento de ingenieria electrica y energética., 2003. 328 p. Último acesso em: 12/08/2011. Disponível em: <www.itescam.edu. $\mathrm{mx} / \mathrm{principal/sylabus/fpdb/recursos/r3984.PDF.} \mathrm{>.} \mathrm{xviii,} 33$

[65] COSSOlino, L. C.; PEREIRA, A. H. A. Amortecimento: classificação e métodos de determinação. [S.l.]: Informativo Técnico-Científico ITC-ME/ATCP Engenharia Física., Nov. 2010. 14 p. http://www.atcp.com. $\mathrm{br} / \mathrm{pt} / \mathrm{produtos} / \mathrm{caracterizacao-materiais/propriedades-materiais/}$ amortecimento.html. 36

[66] MEIROVITCH, L. Analytical Methods in Vibrations. 1a. ed. Canada, Toronto, Ontario USA: The Macmillan Company, 1967. 544 p. Library of Congress catalog card number, 67-15548. 38 
[67] RABINOW, J. The magnetic fluid clutch. AIEE Transactions, AIEE Transactions, v. 67, n. 1, p. 1308-1315, 1948. Disponível em: <http: //ieeexplore.ieee.org/xpls/>. 40

[68] JOLLY, M. R.; CARLSON, J. D.; MUNOZ, B. C. A model of the behaviour of magnetorheological materials. Smart Materials and Structures, v. 5, p. 607-614, 1996. ISSN 0964-1726/96. Disponível em: <http://iopscience. iop.org/0964-1726/5/009>. 40, 41, 42

[69] JOZEFCZAK, A. The time dependence of the changes of ultrasonic wave velocity in ferrofluid under parallel magnetic field. Journal of Magnetism and Magnetic Materials, v. 256, n. 1-3, p. 267 - 270, 2003. ISSN 0304-8853. Disponível em: <http://www.sciencedirect.com/science/article/pii/ s0304885302005723>. 41

[70] BRAMANTYA, M. et al. Ultrasonic investigation of the effect of volume fraction on the clustering structures of magneto-rheological fluids. Journal Materials Science Forum, Applied Electromagnetic Engineering, n. 670, p. 198-206, 2011. Disponível em: <http://www.scientific.net/MSF.670.198>. 41,59

[71] SAWADA, T.; NISHIYAMA, H.; TABATA, T. Influence of a magnetic field on ultrasound propagation in a magnetic fluid. Journal of Magnetism and Magnetic Materials, v. 252, n. 0, p. 186 - 188, 2002. ISSN 0304-8853. $<$ ce:title>Proceedings of the 9th International Conference on Magnetic Fluids $</$ ce:title $>$. Disponível em: <http://www.sciencedirect.com/science/ article/pii/S0304885302006777>. 41

[72] GOTOH, K.; CHUNG, D. Y. Ultrasonic attenuations in magnetic fluids. Journal of the Physical Society of Japan, The Physical Society of Japan, v. 53, n. 8, p. 2521-2528, 1984. Disponível em: <http://jpsj.ipap.jp/link? JPSJ/ $53 / 2521 />.41$

[73] SKUMIEL, A. et al. The influence of the concentration of ferroparticles in a ferrofluid on its magnetic and acoustic properties. Journal of Physics D: Applied Physics, v. 36, n. 24, p. 3120, 2003. Disponível em: <http: //stacks. iop.org/0022-3727/36/i=24/a=005>. 42 
[74] CHRISTENSEN, D. A. Ultrasonic Bioinstrumentation. New York, Chichester, USA: John Wiley and Sons, 1988. 235 p. ISBN 0-471-60496-8. xii, $43,48,49$

[75] SZABO, T. L. Diagnostic ultrasound Imaging: Inside Out. San Diego, California - USA: Elsevier Academic Press, 2004. 549 p. ISBN 0-12-680145-2. xii, xix, 43, 46, 47, 162, 163

[76] WELLMAN, P. S. et al. Breast tissue stiffness in compression is correlated to histological diagnosis. Harvard University Cambridge, MA 02143, Division of Engineering and Applied Science, p. 1-15, 1999. Último acesso em: 12/08/2011. Disponível em: <http://biorobotics.harvard.edu/ pubs/mechprops.pdf $>$. xii, 45, 100

[77] BAMBER, J. C. Physical principles of medical ultrasonics. 2nd. ed. Chichester, U.K: Wiley, 2004. 118-199 p. ISBN 978-0-471-97002-6. Disponível em: <http://www.wiley.com/WileyCDA/WileyTitle/ productCd-0471970026, descCd-google_preview.html>. xii, 52, 53

[78] BAMBER, J. C. Ultrasound in Medicine. 1nd. ed. Bristol, England: Inst. of Physics pub., 1998. 57-88 p. (Medical Science Series). ISBN 0750305932. xii, 52

[79] MAST, T. D. Empirical relationships between acoustic parameters in human soft tissues. Acoustics Research Letters Online, ASA, v. 1, n. 2, p. 37-42, 2000. Disponível em: <http://link.aip.org/link/?ARL/1/37/1>. 53, 161

[80] DORSET, D. L. Direct structure analysis of a paraffin solid solution. Proc. Natl. Acad. Sci., USA, Electron diffraction, Medical Foundation of Buffalo, 73, High street, Buffalo, NY, 14203, v. 87, p. 8541-8544, Nov. 1990. 54

[81] CRESCENTI, R. A. et al. Characterization of the ultrasonic attenuation coefficient and its frequency dependence in a polymer gel dosimeter. Physics in Medicine and Biology, v. 52, n. 22, p. 6747-6759, 2007. Disponível em: <http://www.ncbi.nlm.nih.gov/pubmed/17975295>. 55, 80

[82] YIN, Y.; LING, S.-F.; LIU, Y. A dynamic indentation method for characterizing soft incompressible viscoelastic materials. Materials Science and Engineering: A, v. 379, n. 1a-2, p. 334-340, 2004. ISSN 0921-5093. 
Disponível em: <http://www.sciencedirect.com/science/article/pii/ S0921509304002321>. 55

[83] ASTM-D4065-01. Standard Practice for Plastics: Dynamic Mechanical Properties: Determination and Report of Procedures. ASTM International, 100 Barr Harbor Drive, PO Box C700, West Conshohocken, PA, 19428-2959 USA, Dec. 1982. Last revision, 2006. Disponível em: <http://enterprise. astm.org/filtrexx40.cgi?HISTORICAL/D4065-01.htm>. 55

[84] FONG, P. M. et al. Polymer gels for magnetic resonance imaging of radiation dose distributions at normal room atmosphere. Physics in Medicine and Biology, v. 46, n. 12, p. 3105, 2001. Disponível em: <http://stacks.iop. org $/ 0031-9155 / 46 / i=12 / a=303>$. xviii, 56, 57

[85] BALDOCK, C. et al. Investigation of polymerization of radiation dosimetry polymer gels. In: . Canadian Organization of Medical Physicists, Edmonton, AB: J. L. Schriener, 1999. p. 99-105. 58, 75

[86] MARINI, G. et al. Doppler image of included gel phantom by multi-frequency vibration. In: . Lake Travis, Austin, Texas - USA.: [s.n.], 2008. p. 33. xiii, 63,75

[87] BERCOFF, J. et al. In vivo breast tumor detection using transient elastography. Ultrasound in Medicine and Biology, v. 29, n. 10, p. 1387-1396, 2003. ISSN 0301-5629. Disponível em: <http://www.sciencedirect.com/ science/article/pii/S0301562903009785>. 75

[88] LEPAGE, M. et al. Modelling of post-irradiation events in polymer gel dosimeters. Physics in Medicine and Biology, v. 46, n. 11, p. 2827, 2001. Disponível em: <http://stacks.iop.org/0031-9155/46/i=11/a=305>. 75

[89] CRESCENTI, R. A. et al. Characterization of dose-dependent youngs modulus for a radiation-sensitive polymer gel. Physics in Medicine and Biology, v. 54, n. 4, p. 843-857, 2009. Disponível em: <http://dx.doi. org/10.1088/0031-9155/54/4/002>. 75, 102

[90] KRAUTKRAMER, J.; KRAUTKRAMER, H. Ultrasonic testing of materials. Springer-Verlag, 1983. 667 p. ISBN 9783540117339. Disponível em: <http: //books.google.com.br/books?id=AvwrAAAAIAAJ>. xix, 76, 80, 157, 158 
[91] VIEIRA, S. L. Desenvolvimento de um "phantom"para treinamento de biópsia de mama guiada por Ultrassom. 110 p. Dissertação (Mestrado) Faculdade de Filosofia Ciências e Línguas de Ribeirão Preto - USP, área de concentração: Física Aplicada à Medicina e Biologia., 2005. 80

[92] ASTM-E2309-05M. Standard Practices for Verification of Displacement Measuring Systems and Devices Used in Material Testing Machines. ASTM International, 100 Barr Harbor Drive, PO Box C700, West Conshohocken, PA, 19428-2959 USA, jan. 2005. Last revision, 2011. Disponível em: <http://enterprise.astm.org/filtrexx40.cgi?+REDLINE_ PAGES/E2309E2309M.htm>. 100, 102 


\section{Apêndice}

\section{Protocolo para Medição de Viscosidade}

Neste apêndice apresentamos um procedimento para executar medições de viscosidade utilizando o viscosímetro da Anton Paar - Germany, modelo Rheolab QC acoplado a um aquecedor/refrigerador JULABO, modelo F25-MC, da Labortechnik GMbH, conforme mostra a figura A.1.

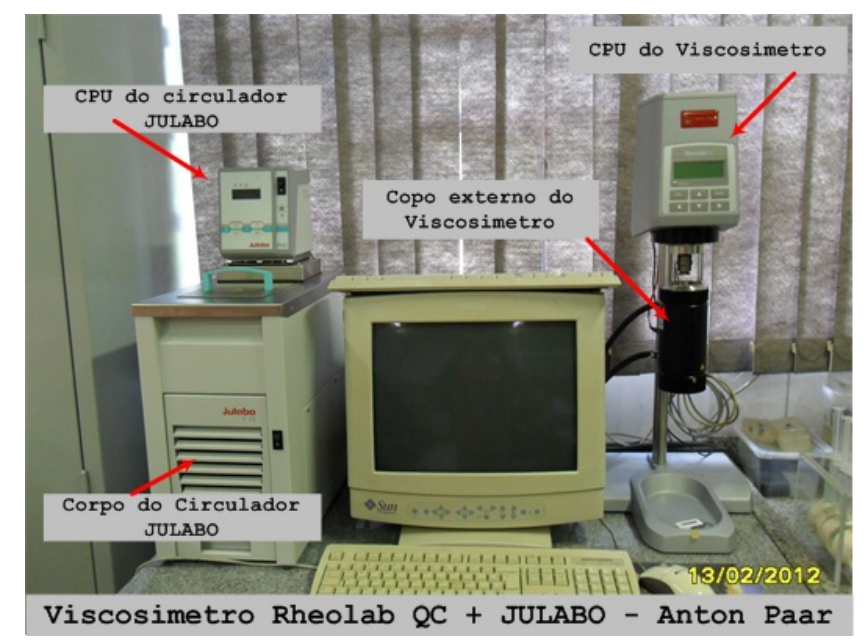

Figura A.1: Imagem do viscosímetro Rheolab QC com refrigerador - aquecedor JULABO.

O viscosímetro, modelo Rheolab QC, funciona acoplado a um sistema de aquecimento e refrigeração (JULABO). Ambos são sincronizados através de um software instalado num computador com sistema operacional da Microsoft $^{R}$ (Windows XP).

Este viscosímetro é do tipo primário, isto é, fornece medições direta da viscosidade. O modelo é híbrido, do tipo cone-cilíndrico, conforme mostra o esquema da figura A.2.

Para esta geometria os parâmetros de tensão de cisalhamento $(\tau-[\mathrm{Pa}])$, deformação $(\gamma-[\%])$ e taxa de cisalhamento $\left(\dot{\gamma}-\left[\mathrm{s}^{-1}\right]\right)$, baseados na norma ISO 


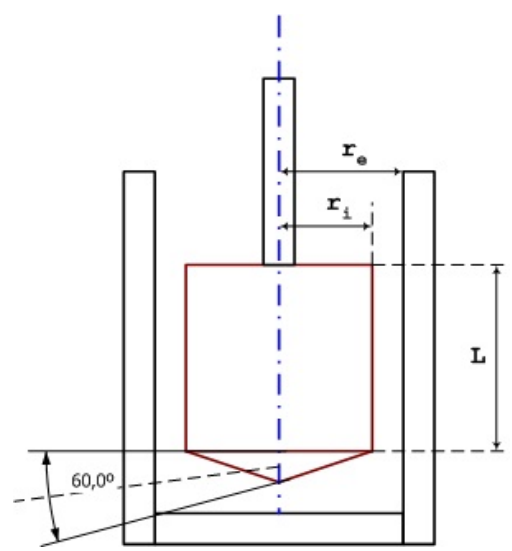

Figura A.2: Modelo da geometria do viscosímetro: Cone-cilíndrico.

$3219(\delta \leq 1,2)$, são dados pelas equações A.1, A.2 e A.3;

$$
\begin{gathered}
\gamma=\frac{1}{10} \cdot \frac{1+\delta^{2}}{\delta^{2}-1} \cdot \varphi ; \quad \delta=\frac{\mathrm{r}_{e}}{\mathrm{r}_{\mathrm{i}}} \\
\dot{\gamma}=\frac{\pi \cdot \mathrm{n}}{30} \cdot \frac{1+\delta^{2}}{\delta^{2}-1} ; \quad \omega=\frac{2 . \pi}{60} \cdot \mathrm{n} \\
\tau=\frac{1+\delta^{2}}{2000 \cdot \delta^{2}} \cdot \frac{\mathrm{M}}{2 \cdot \pi \cdot \text { L. } r_{\mathrm{i}}^{2} \cdot \mathrm{C}_{\mathrm{L}}}
\end{gathered}
$$

em que: $\mathrm{M}$ é o torque $[\mathrm{mN} . \mathrm{m}], \mathrm{n}$ é a velocidade $\left[\mathrm{min}^{-1}\right], \delta$ é a razão entre os raios [1], $\varphi$ é o ângulo de deflexão [mrad], $\omega$ é a velocidade angular $\left[\mathrm{s}^{-1}\right], \mathrm{L}$ é o comprimento do cilindro [m] e $C_{L}$ é fator de correção do efeito final [1]. Além disso, o ângulo da ponta de prova $\alpha_{\text {cil-cone }}=120^{\circ}$, a relação $\mathrm{L} / \mathrm{r}_{\mathrm{i}} \geq 3$ e a relação $r_{\text {eixo }} / r_{i} \geq 0,3$.

O sistema circulador de refrigeração e aquecimento (JULABO) vem com um manual de configuração bastante detalhado e possibilidade de programação em três modos de ajustes de temperatura alternadas. Além disso, há um software de controle no computador, para efetuar medições variando a temperatura continuamente numa faixa de $-20^{\circ} \mathrm{C}$ a $200^{\circ} \mathrm{C}$ com fator de estabilidade de $\pm 0,02^{\circ} \mathrm{C}$, com uso de fluido apropriado, conforme especificações.

Nas medições padrão usa-se a água, obedecendo os limites dos pontos de fusão - ebulição e pressão atmosférica. Assim, antes de ligar o equipamento, recomenda-se verificar o estado e o nível da água dentro do reservatório do circulador, levantando a tampa que se encontra na parte superior.

Feito estas considerações, podemos resumir o processo nos seguintes passos: 
1. Ligue o computador;

2. Ligue o botão do circulador que se encontra no corpo central (figura A.1);

3. Ligue a CPU do circulador que se encontra na parte superior (figura A.1);

4. Para configurar apenas um valor de temperatura, pressiona o botão $\langle\mathbf{T}\rangle$ e, com a setas $\triangle$ e $\nabla$ ajuste o valor da temperatura de trabalho. Pressione $\circlearrowleft$ para retornar ou pressione o botão "OK" para confirmar;

5. Para configurar outros valores para medir temperaturas em três estágios diferentes, após pressionar o botão $\langle\mathbf{T}\rangle$, pressione o botão 〈MENU > (mais detalhes consulte o manual);

6. Após estabelecer o valor de temperatura, o circulador irá acionar uma bomba que fará o fluido circular entre o reservatório central e o copo externo do viscosímetro. Um sensor de temperatura, tipo PT100, acoplado ao copo externo do viscosímetro faz a medição da temperatura e mostra no painel de controle tanto do circulador quanto do viscosímetro, quando este estiver ligado.

7. Antes de ligar o painel de controle do viscosímetro, através de um botão que se localiza na parte traseira superior direita, é necessário acoplar a ponta de prova do viscosímetro (um cilindro de aço inoxidável).

Para cada faixa de fluidos a serem medidos há uma ponta de prova apropriada. O modelo utilizado neste ensaio foi o CC27. Este é um modelo intermediário e não mede viscosidade de líquidos como a água, nem de líquidos tão espessos como o petróleo. Assim, é necessário verificar no manual a curva de viscosidade que pode ser medido com a ponta CC27.

8. O acoplamento da ponta de prova é simples. Primeiro retira-se o copo externo do viscosímetro (Cuidado! se estiver usando temperaturas elevadas, o copo estará aquecido). Segundo, basta encaixar a ponta no eixo central do viscosímetro e travá-la puxando o sistema de fixação para baixo. A seguir, coloca-se o copo externo na posição original.

9. Acoplada a ponta de prova, liga-se a CPU do viscosímetro. O sistema irá fazer uma varredura nos componentes instalados (Hardware: sensores, ponta de prova etc e Software: programas de usuários, sistema de controle etc) e, caso esteja tudo funcionando, mostrará no "display" um "Menu" de opções: editar um programa de medição, usar um programa já instalado ou fazer um teste rápido.

Para detalhes de programação do viscosímetro é melhor consultar o manual. Provavelmente o usuário terá que configurar os parâmetros de medição, assim, terá que entrar no modo "edit program". É possível escolher as grandezas que serão medidas, o tipo de ensaio: como em 
rampa ou constante, número de pontos a serem medidos, o tempo para cada sequência de medidas etc.

Deste modo, o usuário pode configurar um ensaio e salvar as configurações que poderão ser utilizadas em outras medições, sem necessidade de reprogramação, agilizando assim o processo. Terminado o processo de edição do programa, tecle "Esc" e retorne ao modo "start program".

10. Após configuração do ensaio, o sistema está apto a executar a programação. Agora, é necessário introduzir a amostra no copo de medição. Pressupõe-se que as amostras já estejam prontas. O volume das amostras a serem introduzidas no copo, de acordo com a ponta de prova escolhida (ver no manual), que para o nosso modelo (CC27), é de $19 \mathrm{~mL}$.

11. Após colocar a amostra dentro do copo de medição, este deve ser introduzido no interior do copo externo do viscosímetro pela parte inferior e ser travado com a tampa do copo externo, girando-a no sentido horário até que a mesma encontre a posição de travamento.

12. Após estes procedimentos o usuário deve escolher o programa ("display" deve está em "start program") que será executado no "display" do viscosímetro.

Com a setas $\triangle$ e $\nabla$ escolhe "start program". Com a setas $\triangle$ e $\nabla$ escolhe o nome do programa (salvo anteriormente pelo usuário), para cancelar pressiona a tecla "Esc". Ao pressionar a tecla "Enter", aparecerá uma linha para o usuário digitar um nome para aquela sequência de medições.

Esta digitação pode ser feita diretamente no "display" ou através do teclado que foi acoplado a CPU do viscosímetro. OBS: Há dois teclados: um ligado a CPU do computador e o outro a CPU do viscosímetro.

13. Após digitar o nome da sequência de medições, pressione a tecla "Enter" e o ensaio se iniciará.

14. Após executar o programa o sistema emitirá um sinal sonoro. Pressione a tecla "Enter" para confirmar a finalização. Caso tenha novas medições a fazer com a mesma amostra repetir os passos a partir do item 12.

15. Encerrado o processo de medição pressione a tecla "Enter", conforme indicado no passo anterior.

Agora o usuário deve abrir, no computador, o software (RheolabQC Data Export) que permite baixar as leituras dos dados do viscosímetro. $\mathrm{Na}$ interface deste software há alguns botões: "read data", "select data" "save data", "delete data" etc. Pressione a tecla "read data", marque a opção "select data" e a seguir a opção "save data" (atribua um nome ao arquivo). Se o processo foi concluído com sucesso, o sistema emitirá uma mensagem 
na janela do software. O resultado é apresentado numa tabela que pode ser aberto num software de planilha (.xls, .ods etc).

OBS: É recomendável, após salvar o arquivo com os dados no PC ("personal computer"), apagar os dados do viscosímetro. A capacidade de memória da CPU do viscosímetro é pequena, e várias vezes ocorreram perda de dados por falta de memória na CPU do viscosímetro.

16. Para iniciar medições com novas amostras é necessário desligar a CPU do viscosímetro (botão superior na parte traseira). Destravar a tampa do copo externo (girar no sentido anti-horário), retirar o copo interno com a amostra e retirar o copo externo, a fim de sacar a ponta de prova para efetuar a limpeza. OBS: O manuseio da ponta de prova e do copo de medição deve ser cuidadoso. Não deve sofrer impacto, nem usar material abrasivo, pois, a precisão nas medições depende do ajuste entre estas partes.

Para analisar as características do fluido em estudo e classificá-los segundo os parâmetros de viscosidade, recomendo uma leitura do capítulo 2, seção 2.1.2; deste trabalho, que aborda o tópico sobre viscosidade. 


\section{Apêndice}

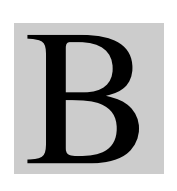

\section{Curva de calibração da Célula de carga}

Neste apêndice mostramos as curvas de calibração da Célula de carga usada na medição das força aplicadas sobre os simuladores de tecidos confecionados no laboratório GIIMUS - departamento de Física da USP/FFCLRP.

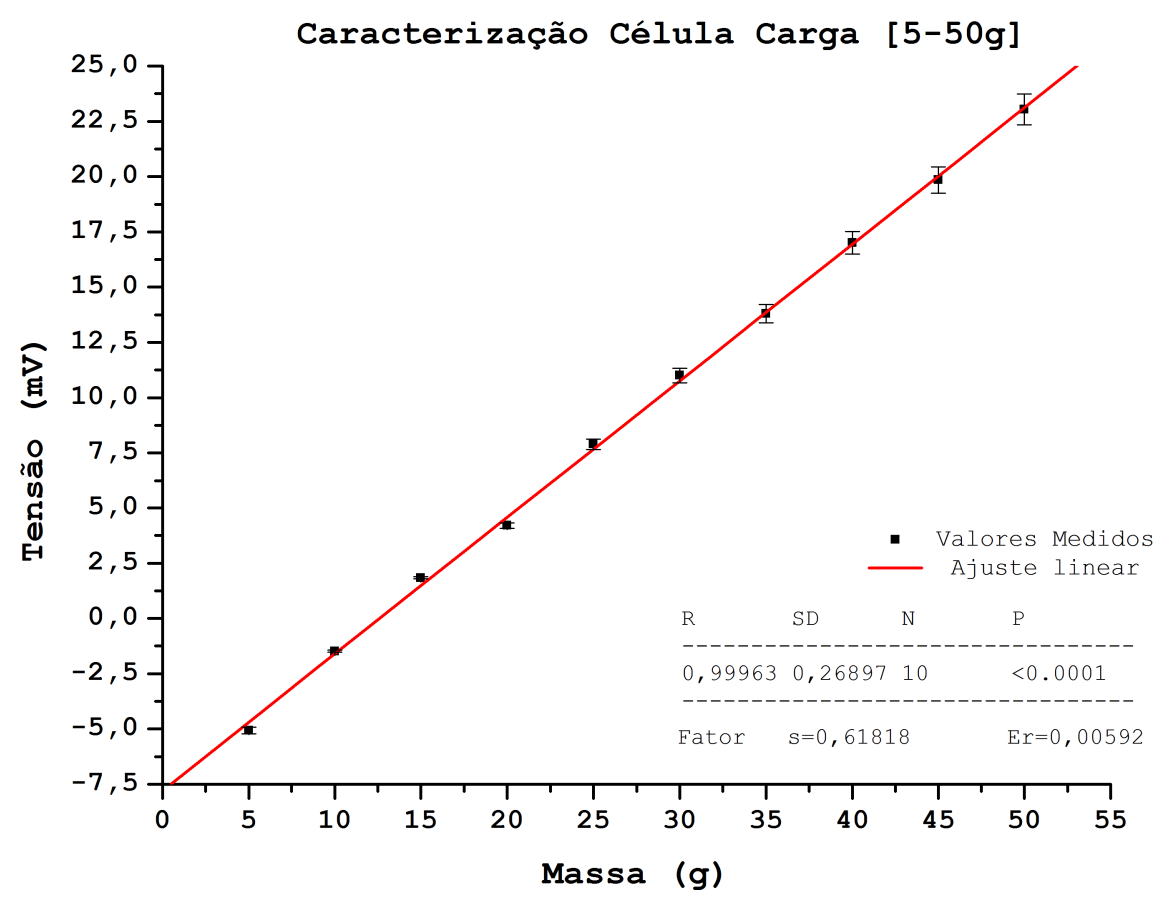

Figura B.3: Curva de caracterização da célula de carga [5, $0 \mathrm{~g}-50,0 \mathrm{~g}]$. 


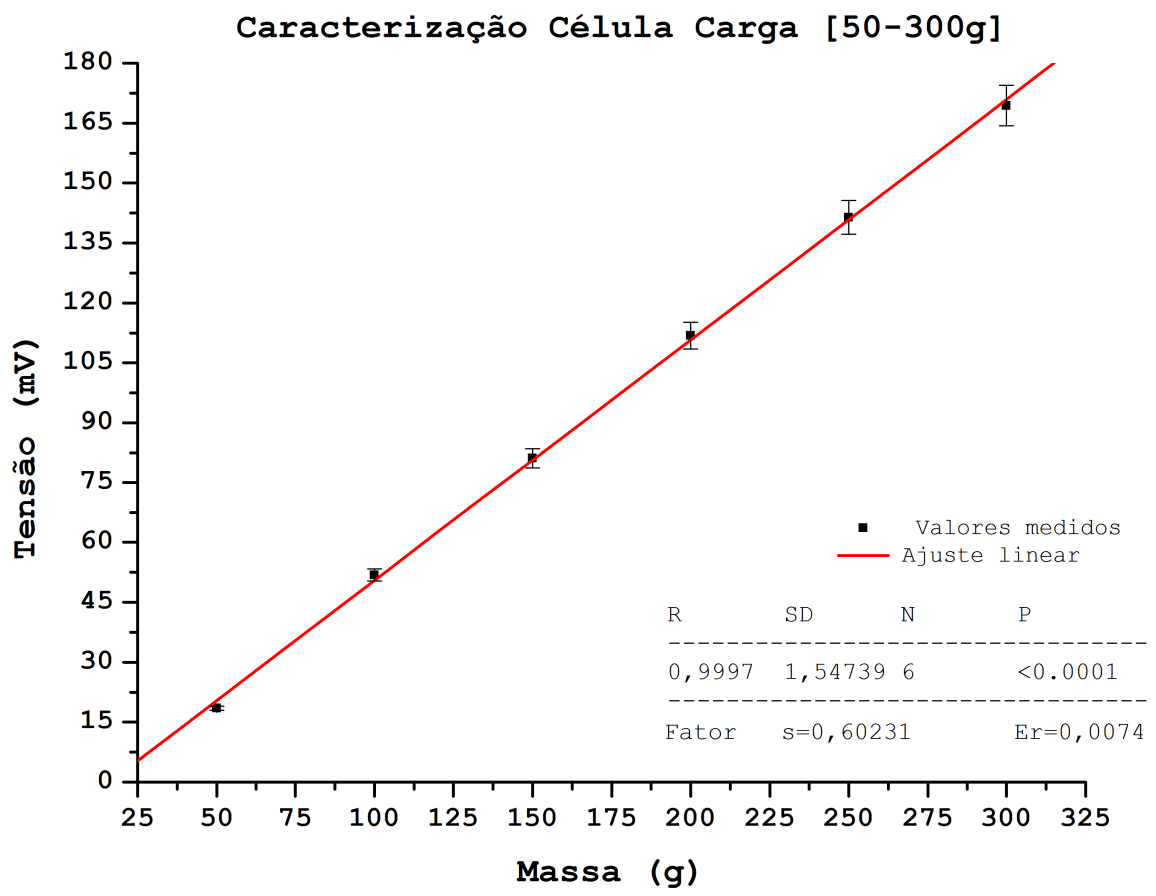

Figura B.4: Curva de caracterização da célula de carga [50,0 g-300,0 g]. 


\section{Apêndice}

\section{Curva de calibração do magneto}

Neste apêndice mostramos a curva de calibração dos magnetos usado na medição dos campos magnéticos aplicados sobre os simuladores de tecidos com inclusão magnética confecionados no laboratório GIIMUS - departamento de Física da USP/FFCLRP. 

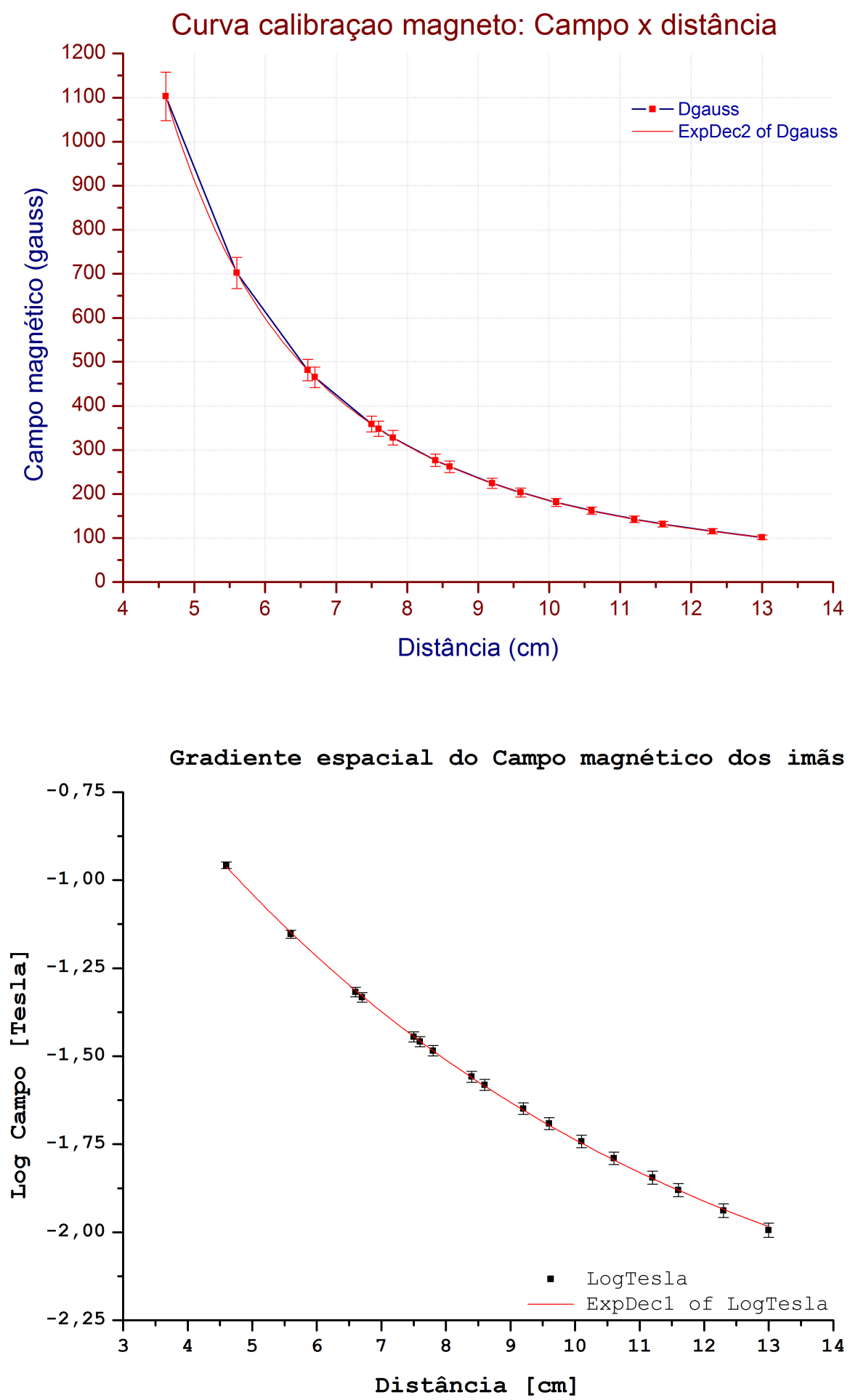

Figura C.5: Curvas de caracterização dos Imãs. 


\section{Apêndice}

\section{Curva de calibração do amplificador de potência}

Neste apêndice mostramos a curva de calibração do amplificador de potência usado na excitação das inclusões magnéticas através da bobina confecionada no laboratório GIIMUS - departamento de Física da USP/FFCLRP.

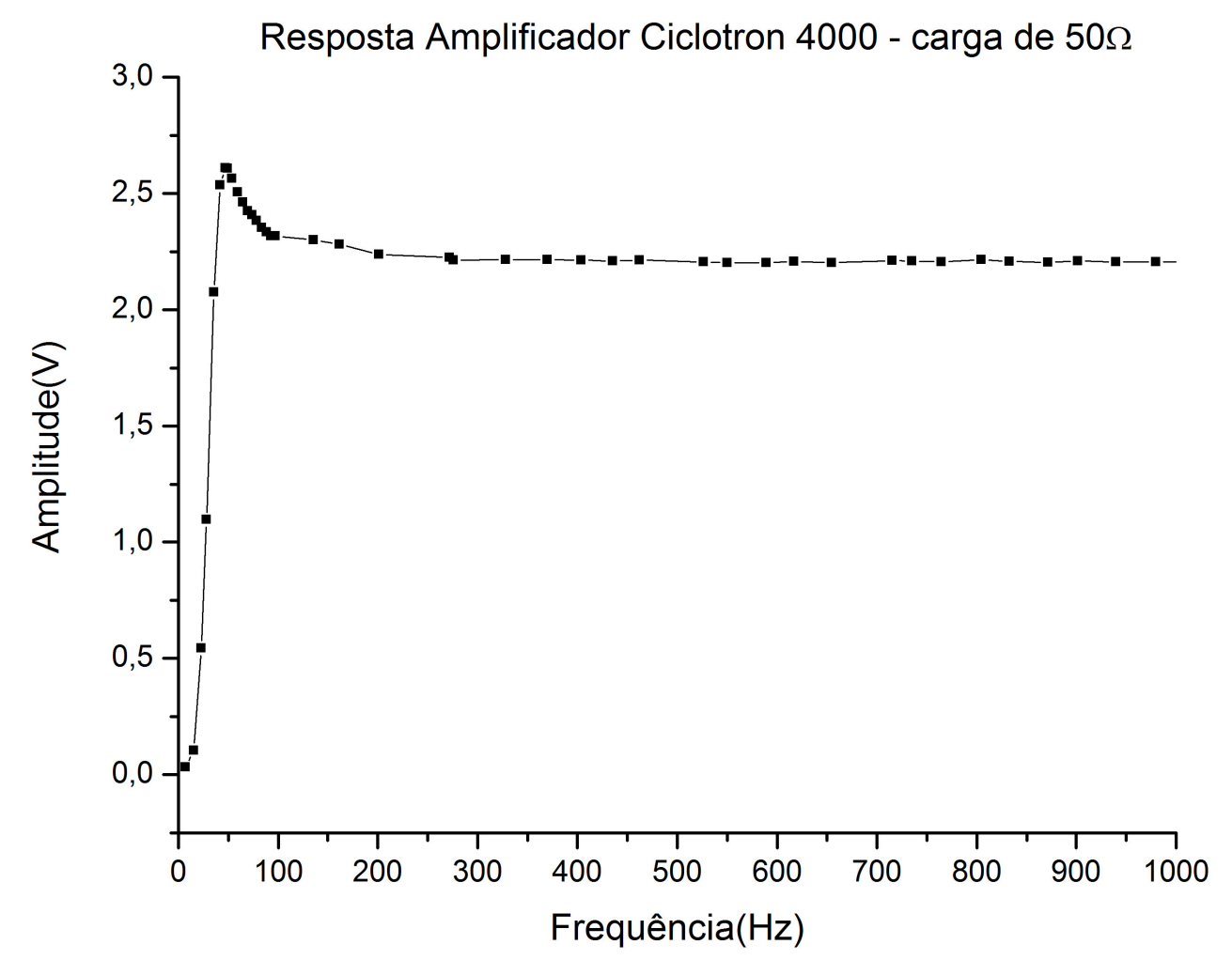

Figura D.6: Curva de caracterização do amplificador Ciclotron 4000-AB [Volts]. 


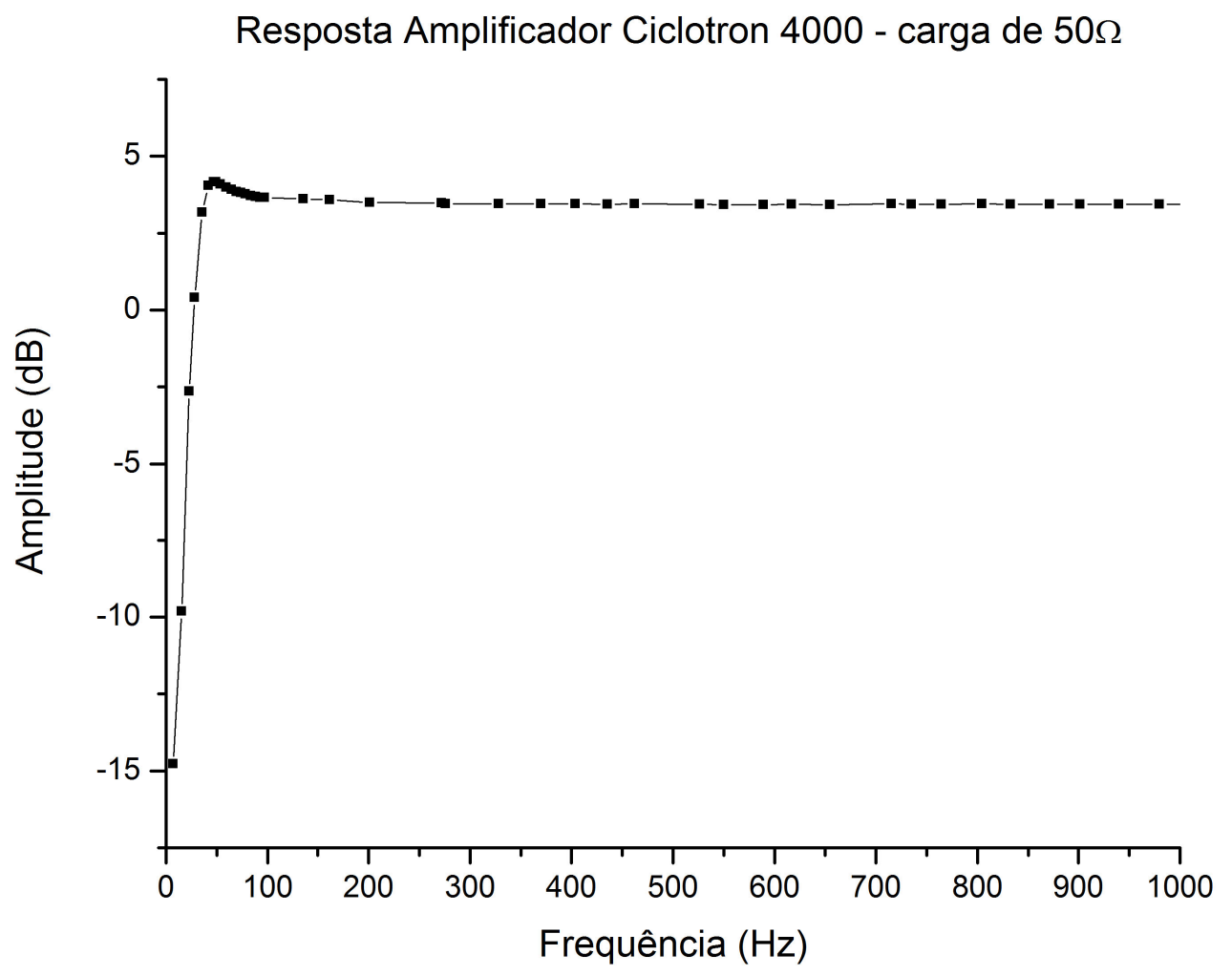

Figura D.7: Curva de caracterização do amplificador Ciclotron 4000-AB [dB]. 


\section{Apêndice}

\section{Curva de calibração da bobina excitadora para carga de 50 Ohms}

Neste apêndice mostramos as curva de calibração da bobina de excitação dos simuladores de tecidos para uma carga resistiva de $50 \Omega$ confecionada no laboratório GIIMUS - departamento de Física da USP/FFCLRP.

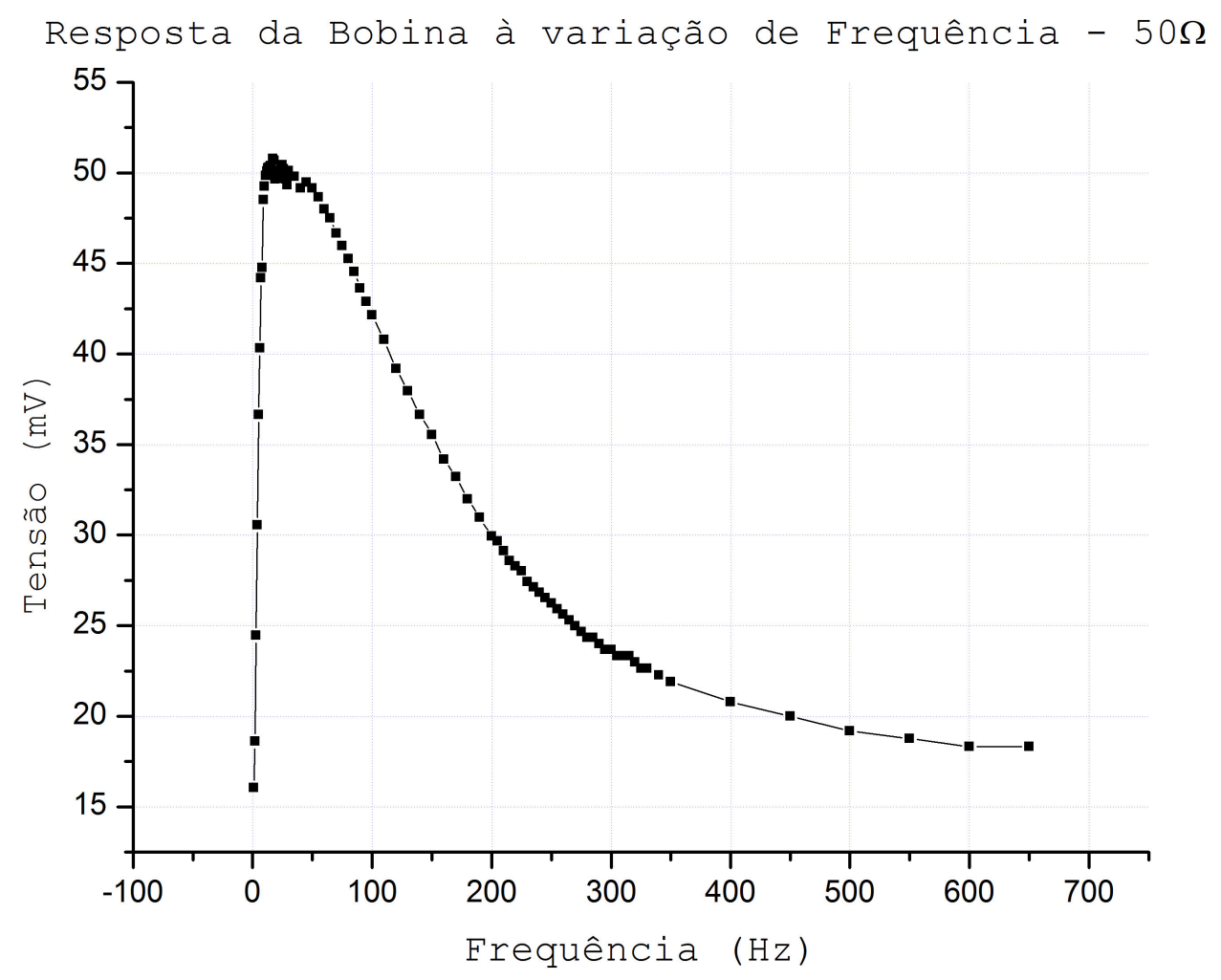

Figura E.8: Curva de caracterização da bobina de excitação [0 $\mathrm{Hz}-700 \mathrm{~Hz}]$. 


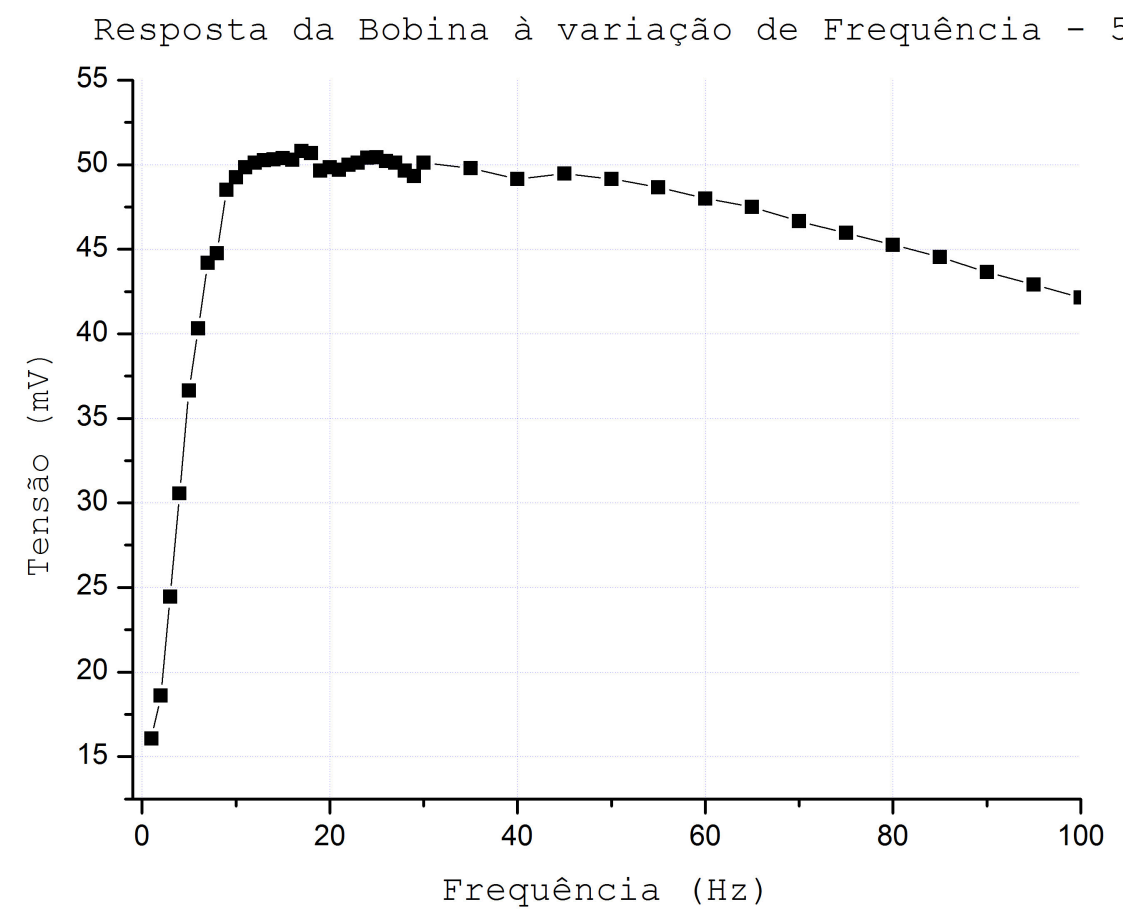

Figura E.9: Curva de caracterização da bobina de excitação [0 $\mathrm{Hz}-100 \mathrm{~Hz}$.

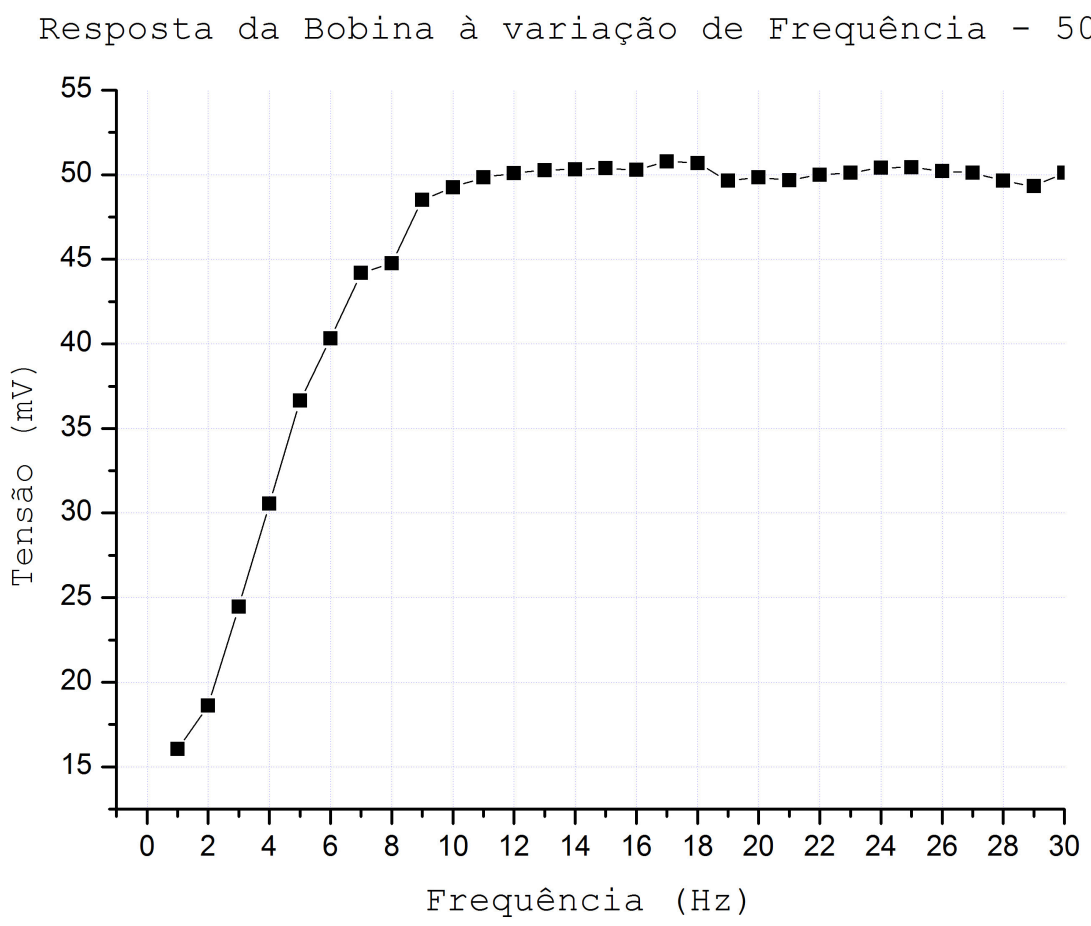

Figura E.10: Curva de caracterização da bobina de excitação [0 $\mathrm{Hz}-30 \mathrm{~Hz}]$. 


\section{Curva de calibração do mini-shaker 4810}

Neste apêndice mostramos a curva de calibração do mini vibrador (shaker 4810) usado na excitação dos simuladores de tecidos com inclusão magnética confecionados no laboratório GIIMUS - departamento de Física da USP/FFCLRP.

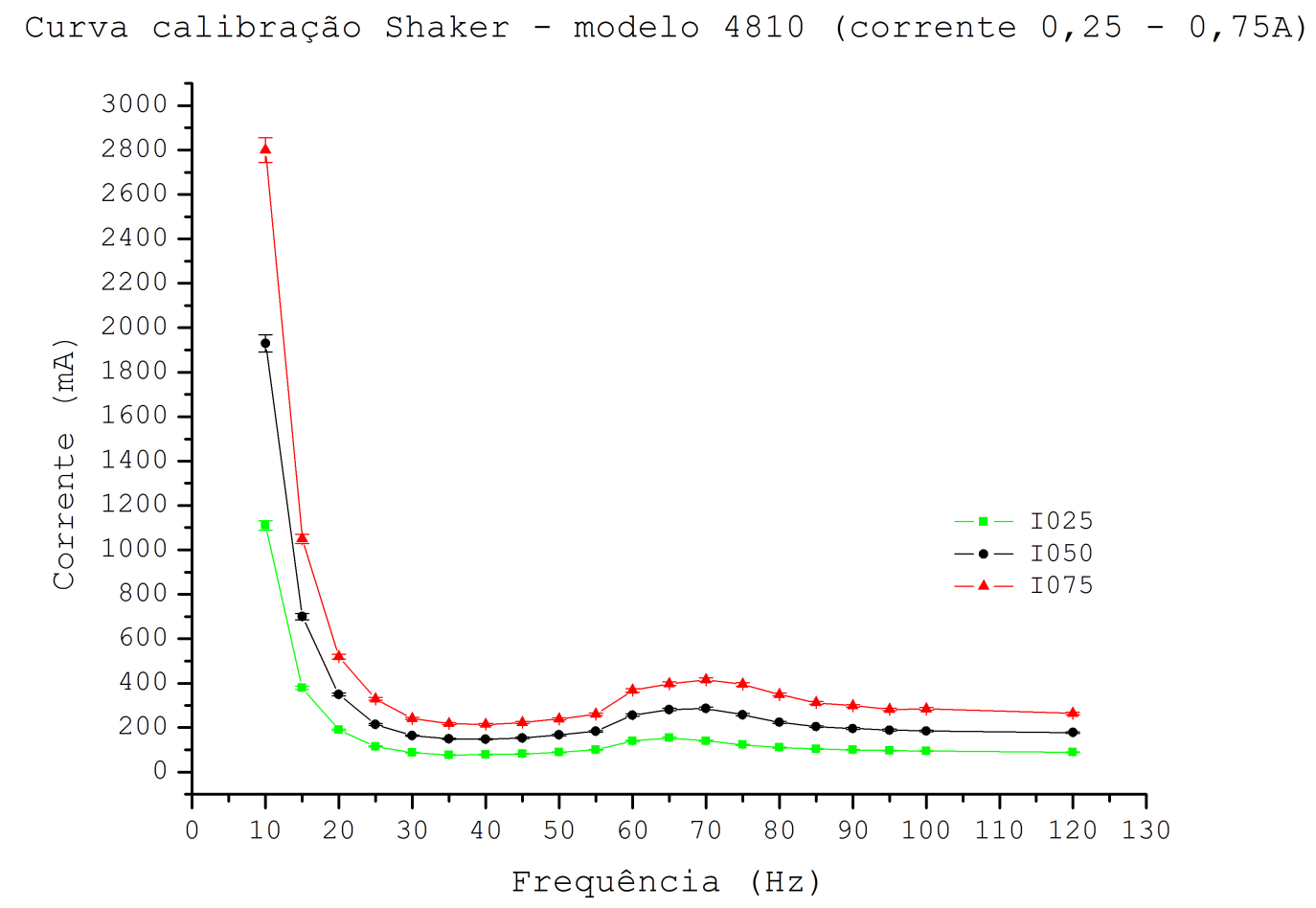

Figura F.11: Curva de caracterização do mini-shaker 4810. 
Anexo $A$

Algumas Propriedades da água pura 


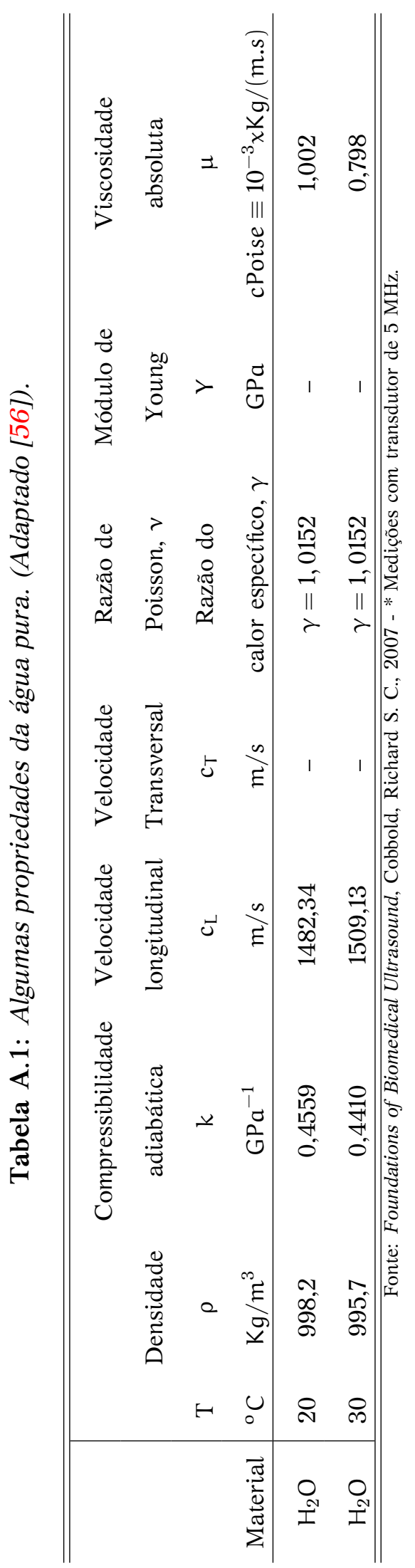


Anexo $\mathbf{D}$

Atenuação Sonora na Água em função da Frequência 
Tabela B.2: Atenuação na água em função da frequência [90].

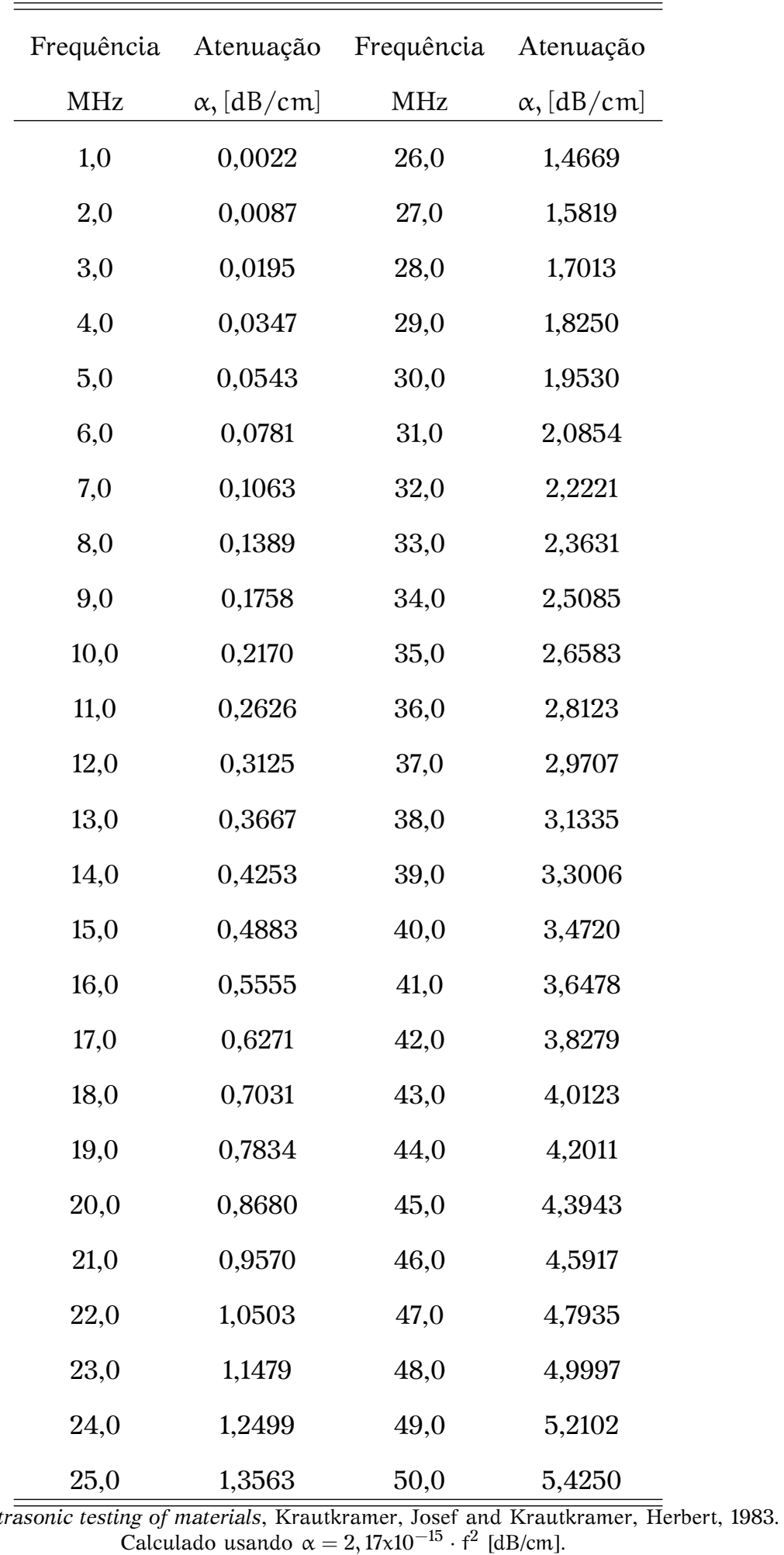
Fonte: Ultrasonic testing of materials, Krautkramer, Josef and Krautkramer, Herbert, 1983.
Calculado usando $\alpha=2,17 \times 10^{-15} \cdot \mathrm{f}^{2}[\mathrm{~dB} / \mathrm{cm}]$. 


\section{Anexo}

\section{Atenuação Ultrassônica para alguns materiais em função da Frequência}

Tabela C.3: Atenuação ultrassônica em alguns materiais em função da frequência [90].

\begin{tabular}{ccccc}
\hline \multicolumn{5}{c}{$\alpha,[\mathrm{dB} / \mathrm{cm}]$} \\
\hline Material & $1,0 \mathrm{MHz}$ & $2,5 \mathrm{MHz}$ & $5,0 \mathrm{MHz}$ & $10,0 \mathrm{MHz}$ \\
\hline Alumínio & $<0,01$ & 0,02 & 0,07 & 0,26 \\
Vidro & 0,02 & 0,06 & 0,12 & 0,24 \\
Acrílico & 1,5 & 3,5 & 7,0 & - \\
Quartzo fundido & - & $<0,007$ & 0,01 & 0,02 \\
Ar & 1,7 & 11,0 & 40,0 & 170,0 \\
\hline \hline
\end{tabular}




\section{Anexo}

\section{Contribuição do espalhamento no coeficiente de atenuação}

Tabela D.4: Contribuição do espalhamento no coeficiente de atenuação [56].

\begin{tabular}{c|cccc}
\hline \hline Meio & $2 \alpha_{\mathrm{s}}\left[\mathrm{cm}^{-1}\right]$ & $2 \alpha\left[\mathrm{cm}^{-1}\right]$ & $\alpha_{\mathrm{s}} / \alpha$ & Frequência \\
\hline Fígado humano fresco & 0,09 & 0,72 & $12 \%$ & $4 \mathrm{MHz}$ \\
Fígado humano fresco & 0,32 & 1,4 & $23 \%$ & $7 \mathrm{MHz}$ \\
Sangue Humano, Hct $=40 \%$ & $0,28 \times 10^{-3}$ & 0,17 & $0,1 \%$ & $4 \mathrm{MHz}$ \\
Sangue Humano, Hct $=40 \%$ & $1,8 \times 10^{-3}$ & 0,37 & $0,5 \%$ & $7 \mathrm{MHz}$ \\
Músculo esquelético fresc & 0,16 & 0,94 & $17 \%$ & $4 \mathrm{MHz}$ \\
Músculo esquelético fresc & 0,32 & 1,8 & $18 \%$ & $7 \mathrm{MHz}$ \\
\hline
\end{tabular}




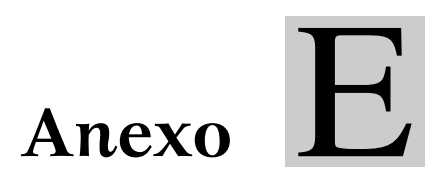

Propriedades determinadas de tecidos humanos moles à $37^{\circ} \mathrm{C}$ 
Tabela E.5: Algumas propriedades de tecidos humanos moles à $37^{\circ} \mathrm{C}$ [56].

\begin{tabular}{|c|c|c|c|c|}
\hline Tipo de Tecido Humano & $\begin{array}{c}\mathrm{C}_{0} \\
{[\mathrm{~m} / \mathrm{s}]}\end{array}$ & $\begin{array}{c}\rho_{0} \\
{\left[\mathrm{Kg} / \mathrm{m}^{3}\right]}\end{array}$ & $\begin{array}{c}\alpha_{\mathrm{dB}} \\
{[@ 1 \mathrm{MHz} \mathrm{dB} / \mathrm{cm}]}\end{array}$ & $\begin{array}{c}\text { B/A } \\
\text { Parâmetro de } \\
\text { Não-linearidade }\end{array}$ \\
\hline Conectivo & 1613 & 1120 & 1,57 & - \\
\hline Músculo & 1547 & 1050 & 1,09 & - \\
\hline Gordura & 1478 & 950 & 0,48 & - \\
\hline Adiposo & 1450 & 950 & 0,29 & 10,0 \\
\hline Sangue & 1584 & 1060 & 0,20 & 6,1 \\
\hline Cérebro & 1560 & 1040 & 0,60 & 7,1 \\
\hline Mama & 1510 & 1020 & 0,75 & - \\
\hline Lente do olho & 1645 & 1070 & 0,80 & - \\
\hline Humor vítreo & 1528 & 1010 & 0,1 & - \\
\hline Rim & 1560 & 1050 & 1,0 & 7,4 \\
\hline Fígado & 1595 & 1060 & 0,50 & 6,6 \\
\hline Músculo cardíaco & 1576 & 1060 & 0,52 & 7,1 \\
\hline Músculo esquelético & 1580 & 1050 & 0,74 & 6,6 \\
\hline Pele & 1615 & 1090 & 0,35 & 7,9 \\
\hline Gorduroso & 1465 & 985 & 0,40 & 8,5 \\
\hline Não gorduroso & 1575 & 1055 & 0,6 & 7,0 \\
\hline Células do sangue & 1627 & 1093 & 0,28 & - \\
\hline Plasma sanguíneo & 1543 & 1027 & 0,069 & - \\
\hline Córnea & 1586 & 1076 & - & - \\
\hline Cordão espinhal & 1542 & 1038 & - & - \\
\hline Baço & 1567 & 1054 & 0,40 & 7,8 \\
\hline Testículo & 1595 & 1044 & 0,17 & - \\
\hline
\end{tabular}




\section{Anexo}

\section{Comparação de modalidades de ultrassom médico para valores em água}

Tabela F.6: Comparação de modalidades de ultrassom médico para valores em água (entre parêntesis, valores médios) [75].

\begin{tabular}{ccccc}
\hline \hline Modalidade & $\begin{array}{c}\text { Frequência } \\
{[\mathrm{MHz}]}\end{array}$ & $\begin{array}{c}\text { Potência } \\
{[\mathrm{W}]}\end{array}$ & $\begin{array}{c}\text { Pressão } \\
{[\mathrm{MPa}]}\end{array}$ & $\begin{array}{c}\text { IntensidadesPTA } \\
{\left[\mathrm{W} / \mathrm{cm}^{2}\right]}\end{array}$ \\
\hline Modo B & $1-15$ & $0,0003-0,285(0,075)$ & $0,45-5,54(2,3)$ & $0,0003-0,991(0,34)$ \\
Doppler (PW) & $1-10$ & $0,01-0,44(0,1)$ & $0,67-5,3(2,04)$ & $0,173-9,08(1,18)$ \\
US Terapêutico & $0,75-3,4$ & $1-15$ & 0,3 & 3 \\
Hipertermia & $0,5-5,0$ & - & $0,6-6,0$ & $1-10$ \\
HIFU & $1-10$ & - & - & $1000-10.000$ (picos) \\
Litotripisia & $0,5-10$ & - & $5-15$ & - \\
\hline \hline
\end{tabular}

Fonte: (adaptado:Diagnostic Ultrasound Imaging: Inside out), Szabo, 2004 [75]. 'STPA' = Spatial peak temporal average intensity. 


\section{Anexo}

\section{Limites de Intensidade de saída acústica - FDA (secção 3)}

Tabela G.7: Limites de Intensidade de saída acústica - FDA [75].

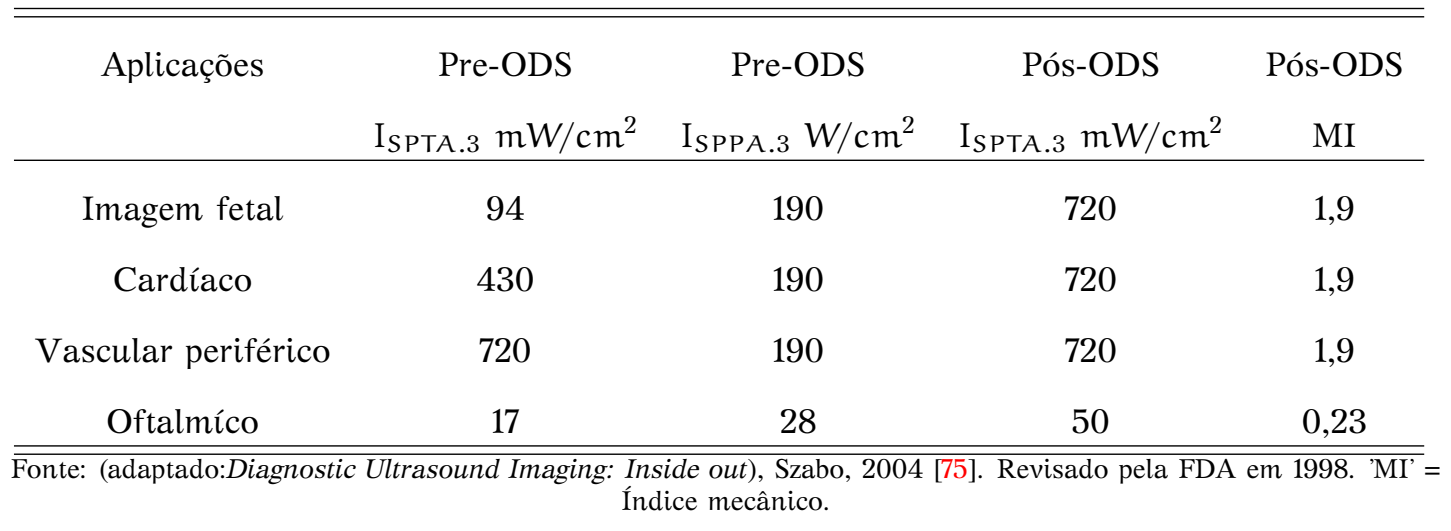


Anexo $\mathrm{H}$

\section{Limiar de danos no tecido biológico por US contínuo}

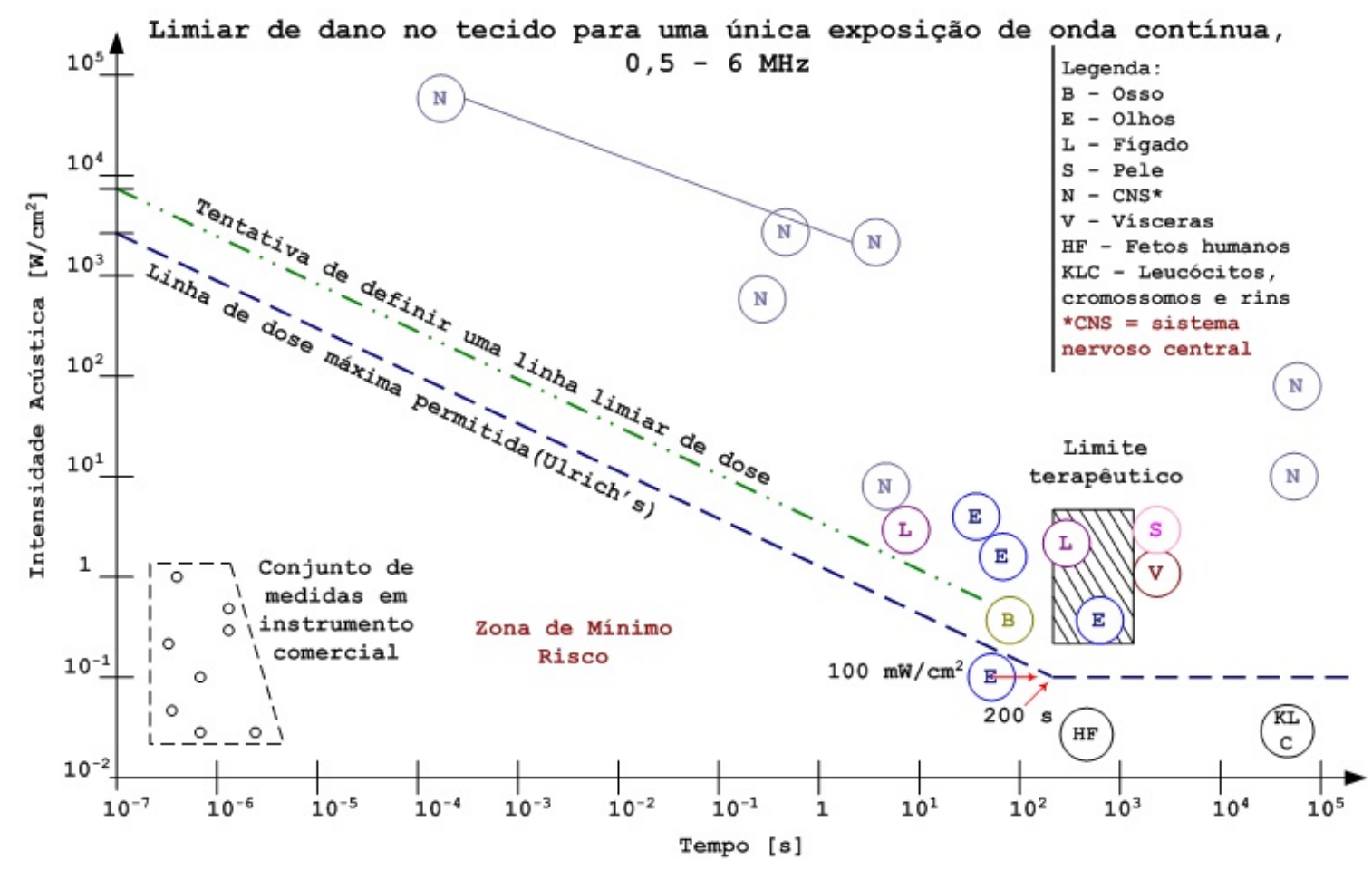

Figura H.12: Limiar de dano em tecidos biológicos por exposição a US contínuo. (adaptado: Ulrich, 1974 [37]). 


\section{Limiar de danos no tecido biológico por US pulsado}

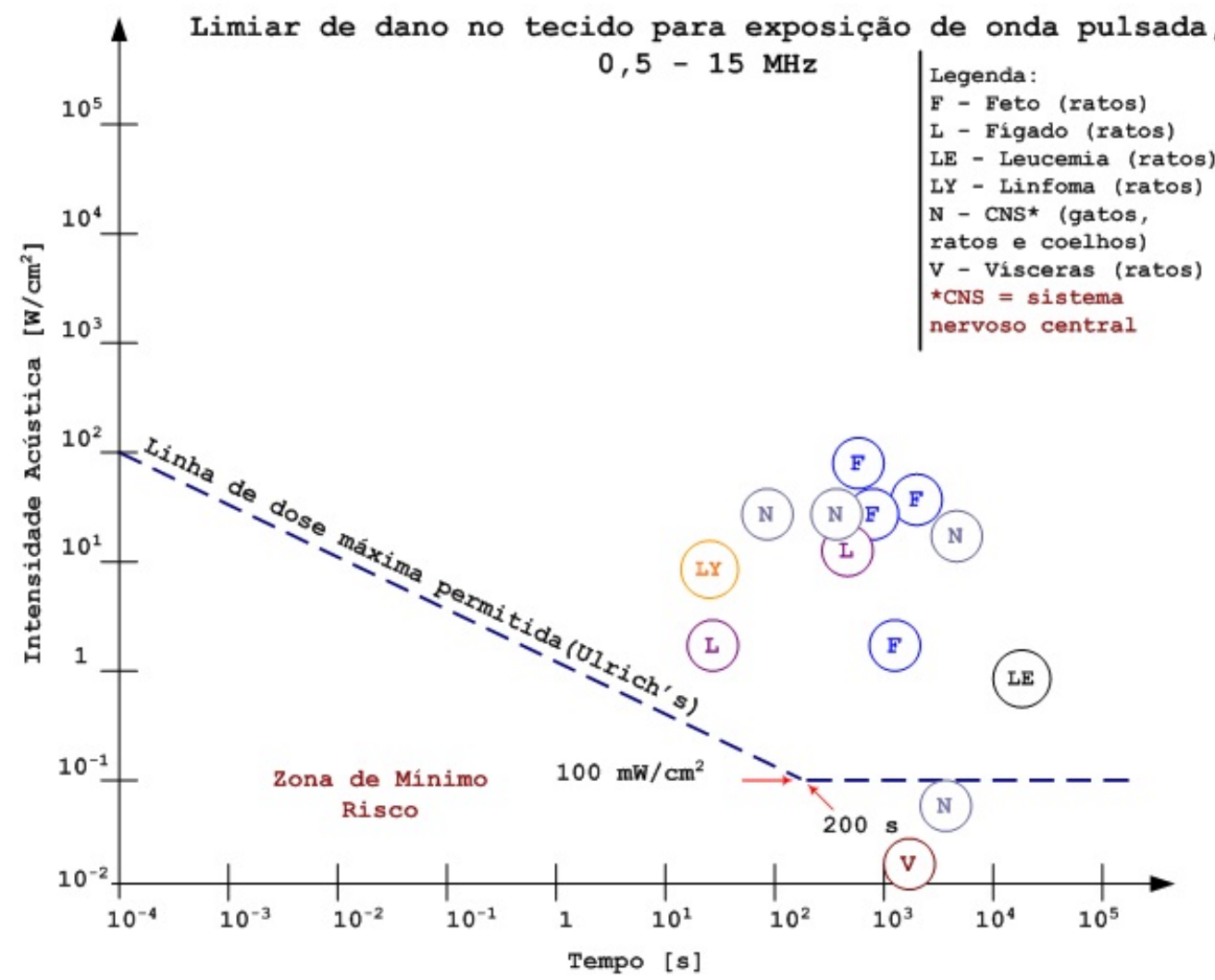

Figura I.13: Limiar de dano em tecidos biológicos por exposição a US pulsado. (adaptado: Ulrich, 1974 [37]). 